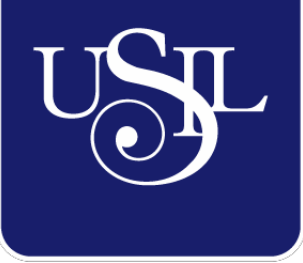

UNIVERSIDAD

SAN IGNACIO

DE LOYOLA

ESCUELA DE POSTGRADO

\title{
PLAN DE NEGOCIOS: LA INMOBILIARIA PROYECTO MULTIFAMILIAR AREQUIPA
}

Tesis para optar el grado de:

CINTHYA KARINA CERVANTES YÁBAR

Maestro en Ciencias Empresariales con Mención en Gestión Financiera

$$
\text { PEDRO ANTONIO GARCIA AYMAR }
$$

Maestro en Ciencias Empresariales con Mención en Gestión de Proyectos

Asesor:

Edmundo Rafael Casavilca Maldonado

Lima - Perú

2017 


\section{Dedicatoria}

Dedicamos el presente trabajo a nuestras familias, por todo el apoyo brindado para poder haber hecho posible el desarrollo en su totalidad del proyecto.

\section{Agradecimiento}

Agradecemos en primer lugar a nuestros asesores, por ser la guía principal para poder finalizar exitosamente el proyecto. En segundo lugar, a familiares y amigos que nos apoyaron brindando referencias y datos que fueron de mucha utilidad para concretar muchos de los capítulos presentados en el trabajo. 


\section{Resumen Ejecutivo}

El sector construcción es uno de los sectores más dinámicos de la economía del Perú con un crecimiento aproximado de $6 \%$ anual. Solo a nivel de vivienda, actualmente en el país existe una demanda insatisfecha de 400,000 unidades de las cuales, con la oferta actual, solo se logra cubrir el 7\%. En este sector se ha encontrado un mercado potencial que hoy está desatendido, se trata de 488,000 jóvenes adultos del segmento A y B, que hoy en día ya están demandando una vivienda con características específicas en función de su actual estilo de vida.

La Inmobiliaria, es una empresa que se constituirá con el fin de desarrollar y vender el proyecto de vivienda multifamiliar Arequipa, de naturaleza sostenible, aportando a la edificación ecológicamente responsable. Dentro de las últimas tendencias mundiales, ser eco amigable, no solo representa un beneficio al medio ambiente, sino también un beneficio a largo plazo para los consumidores que optan por este tipo de edificaciones. Esta característica llega a ser de peso si se evalúa la inversión inicial frente al beneficio futuro y el diseño sostenible.

Si bien el sector es altamente competitivo, existe aún una gran oportunidad de capturar esta creciente demanda y crear una ventaja diferencial de la cual obtener beneficios adicionales ya que, observamos que la mayoría de los competidores ofrecen productos muy similares, por lo que no existe un factor diferenciador para el cliente. En la actualidad se tienen pocos proyectos sostenibles en el Perú que estén debidamente certificados por el Ministerio de Vivienda y puedan gozar de ciertos beneficios que el Estado promueve para impulsarlos. 
Adicionalmente, el precio promedio propuesto para estos departamentos se encuentra dentro de los rangos que son elegibles para acceder al crédito hipotecario MiVivienda, el cual, entre otros beneficios de primera vivienda, se encuentran el Bono al Buen Pagador y el Bono MiVivienda Sostenible, que son un subsidio del Estado y representan un descuento sobre el precio de la vivienda, haciéndolo aún más atractivo.

Se eligió al segmento A y B, basados principalmente en la aceptación y preferencia de este segmento por las características del producto. Un cliente del segmento A y/o B, realiza una compra más racional, en la cual pueda evaluar las características al detalle de su inversión y, como puede convertirse a la larga en un beneficio. Además, este segmento valora las características del producto no solo lo sostenible, sino temas principales como su ubicación y tamaño. Por consiguiente, el poder adquisitivo que los potenciales clientes es alto, representando una gran oportunidad de rentabilidad para el proyecto. 


\section{ÍNDICE}

\section{Contenido}

DEDICATORIA

AGRADECIMIENTO

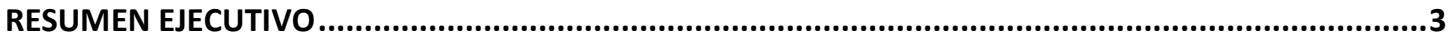

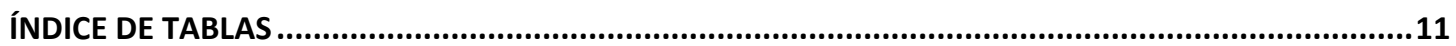

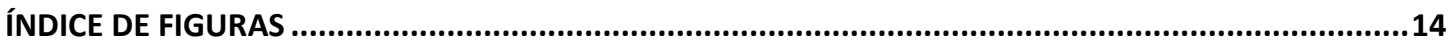

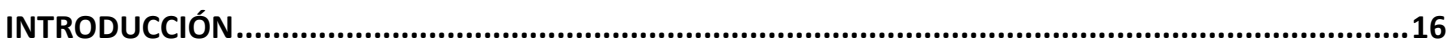

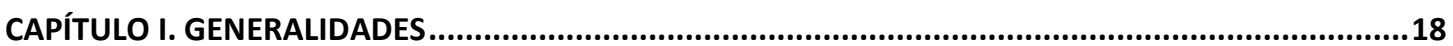

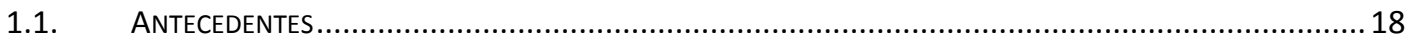

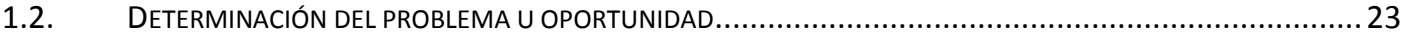

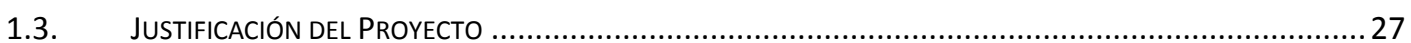

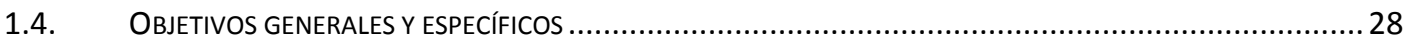

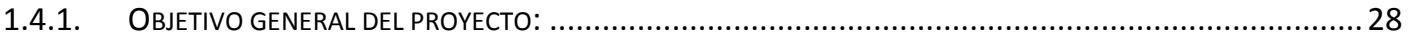

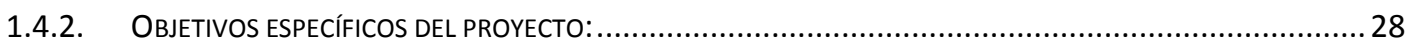

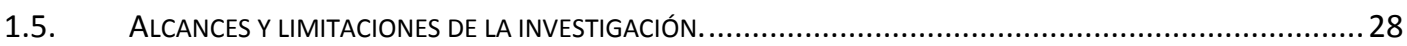

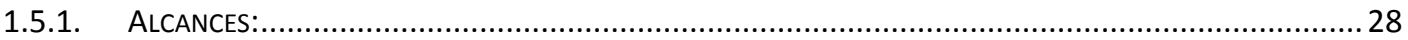

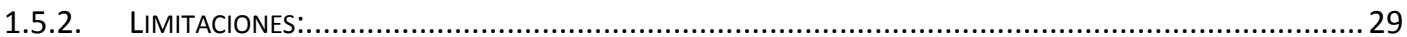

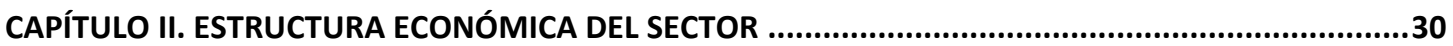

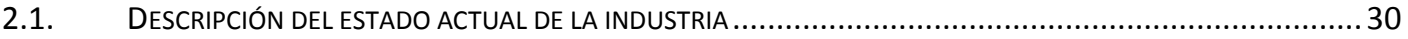

2.1.1. Segmentación de la industria ............................................................................... 35

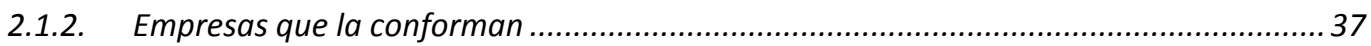

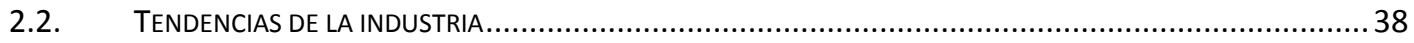




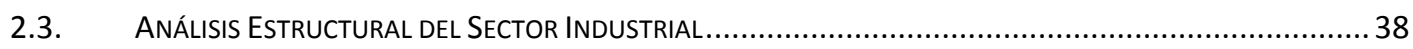

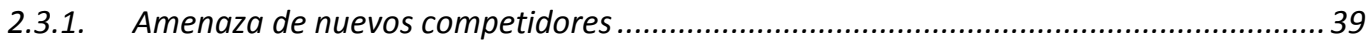

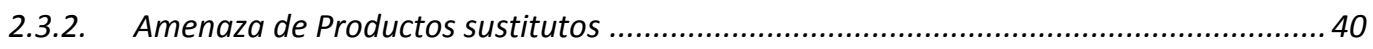

2.3.3. Poder de negociación de los consumidores ........................................................... 41

2.3.4. Poder de negociación de los Proveedores: ........................................................ 42

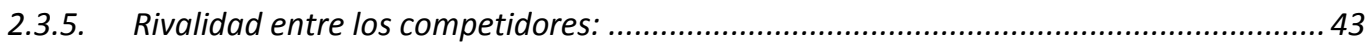

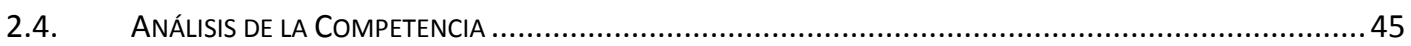

2.4.1. Empresas que ofrecen el mismo producto o servicio ........................................... 45

2.4.2. Participación de mercado de cada uno de ellos ...................................................... 47

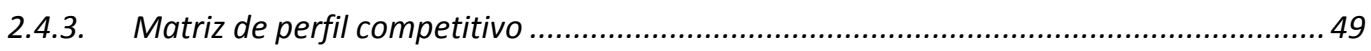

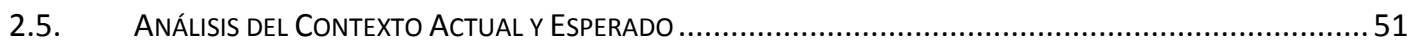

2.5.1. Análisis Político-Gubernamental .................................................................... 51

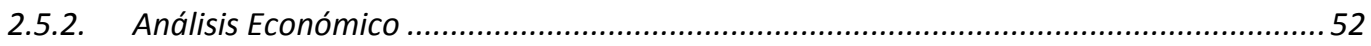

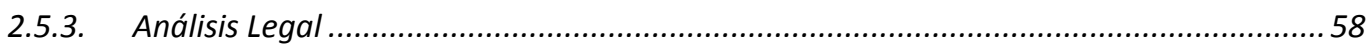

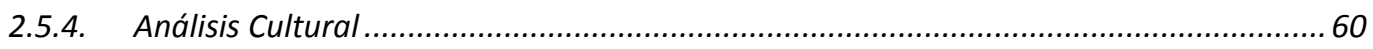

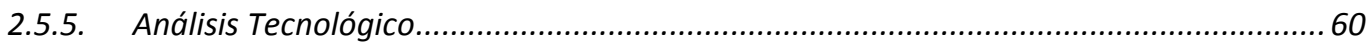

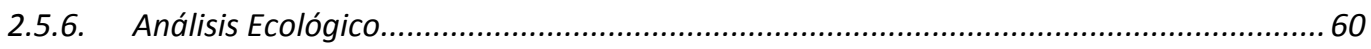

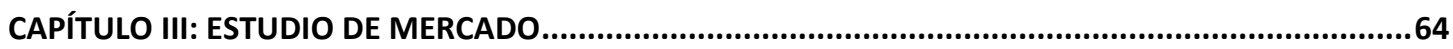

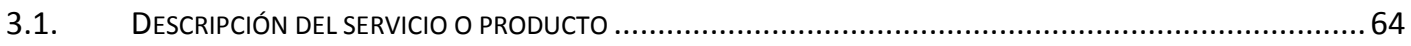

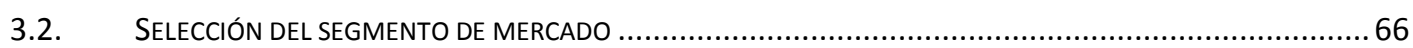

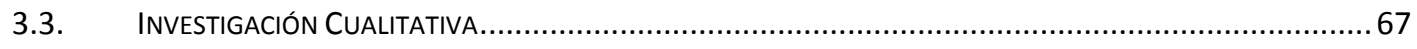

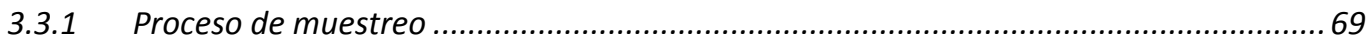

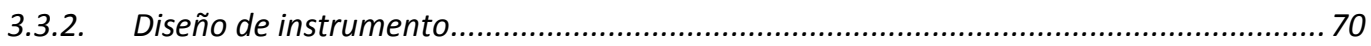

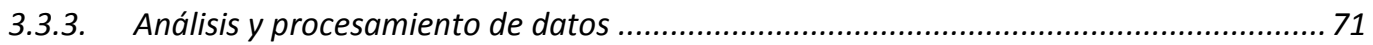

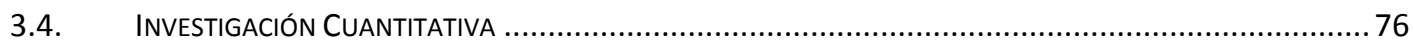

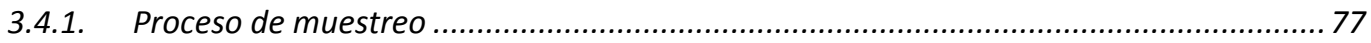

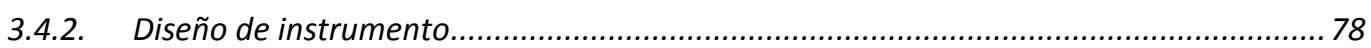




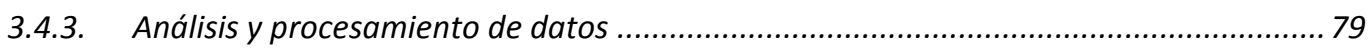

3.4. CONCLUSIONES Y RECOMENDACIONES DEL ESTUDIO CUALITATIVO Y CUANTITATIVO ..............................90

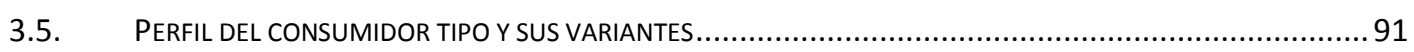

CAPÍTULO IV: PROYECCIÓN DEL MERCADO OBJETIVO .............................................................92

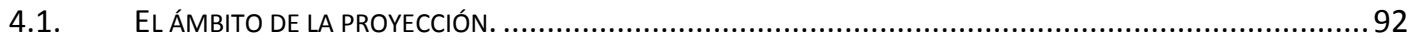

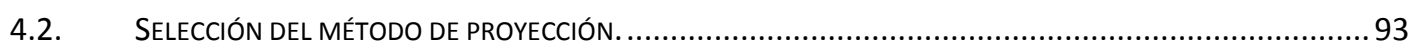

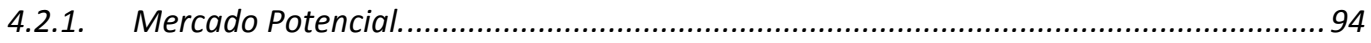

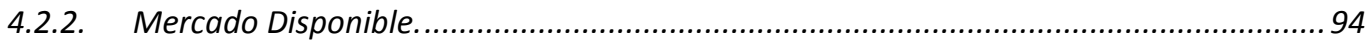

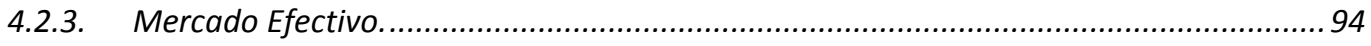

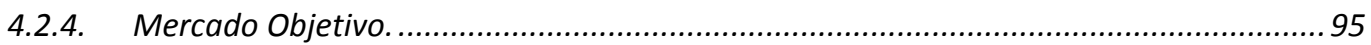

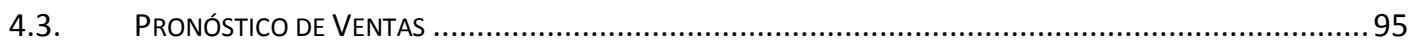

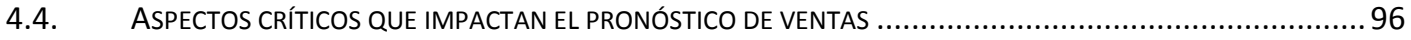

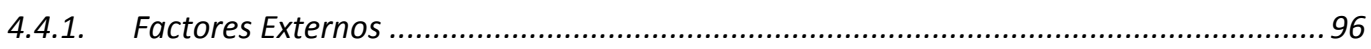

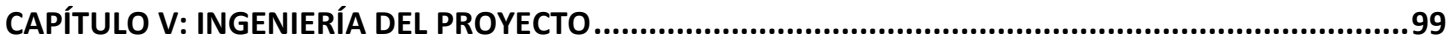

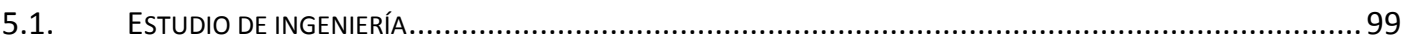

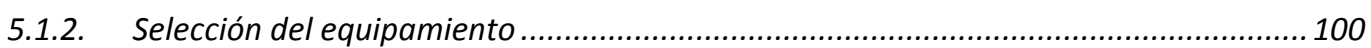

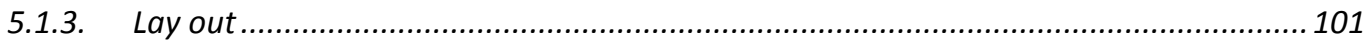

5.1.4. Distribución de equipos y maquinarias.......................................................... 102

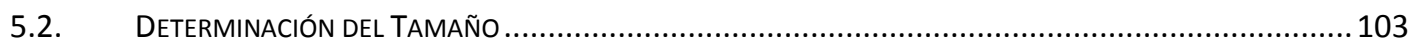

5.2.1. Proyección de crecimiento ................................................................................. 104

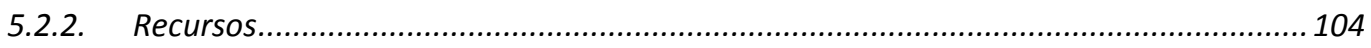

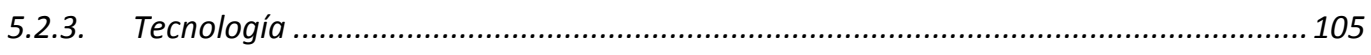

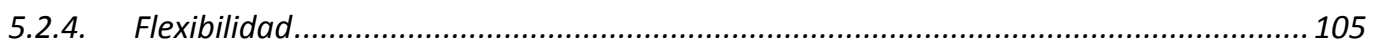

5.2.5. Selección del tamaño ideal ........................................................................... 105

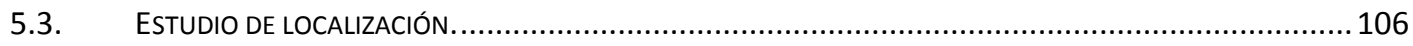

5.3.1. Definición de factores locacionales. ................................................................ 106

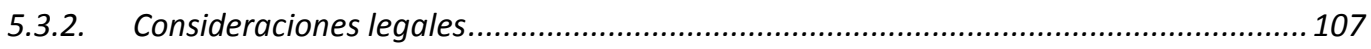


5.4. DETERMINACIÓN DE LA LOCALIZACIÓN ÓPTIMA 109

CAPÍTULO VI: ASPECTOS ORGANIZACIONALES

6.1. CARACTERIZACIÓN DE LA CULTURA ORGANIZACIONAL DESEADA................................................ 110

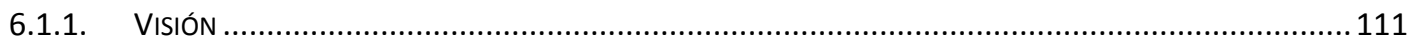

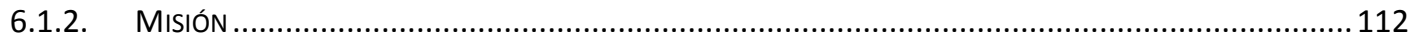

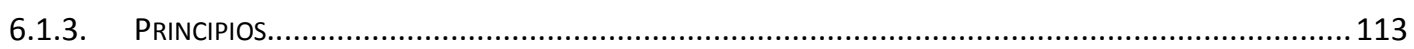

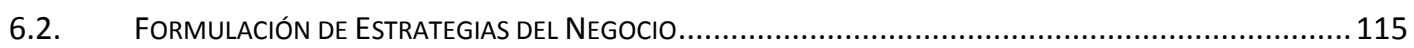

6.3. DETERMINACIÓN DE LAS VENTAJAS COMPETITIVAS CRÍTICAS ...................................................... 120

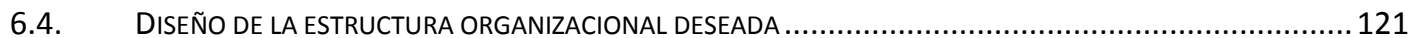

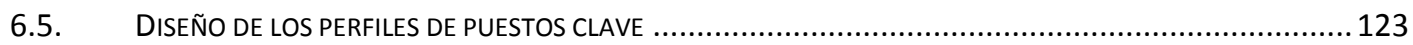

6.6. REMUNERACIONES, COMPENSACIONES E INCENTIVOS ..................................................... 126

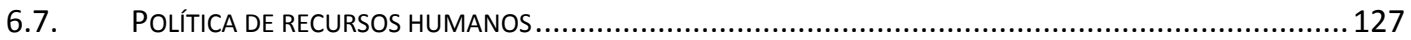

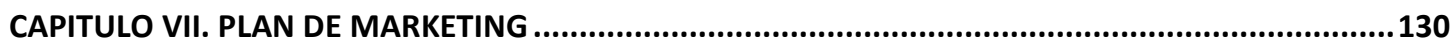

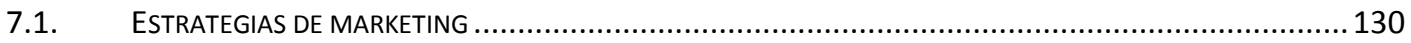

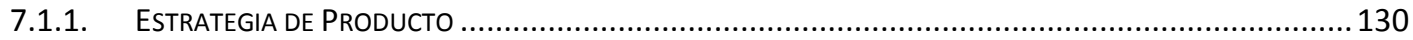

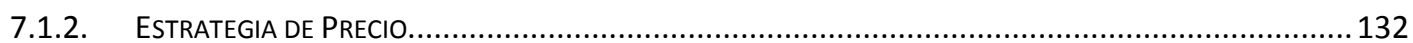

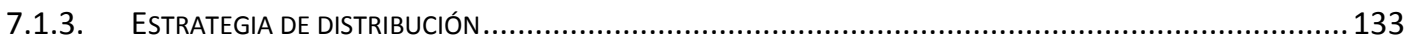

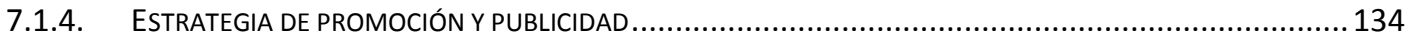

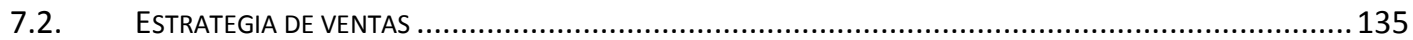

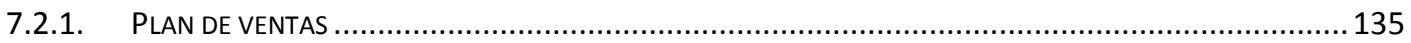

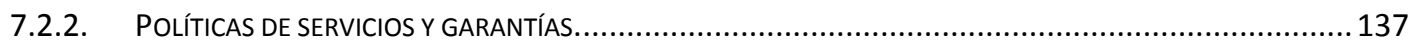

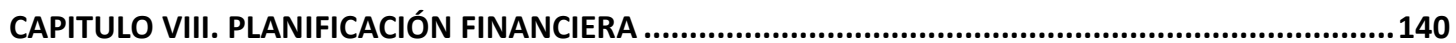

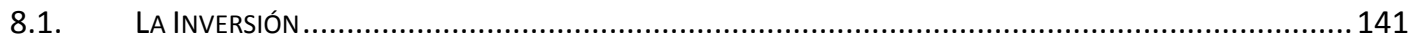

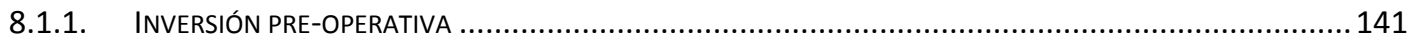

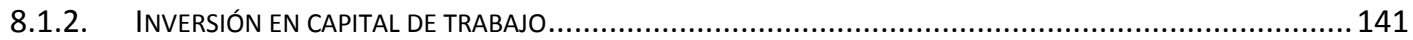

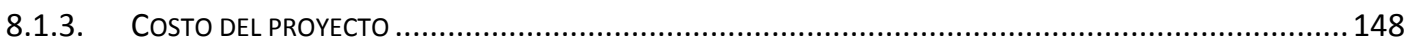




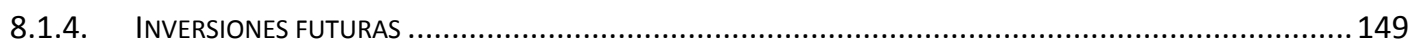

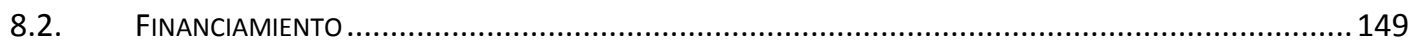

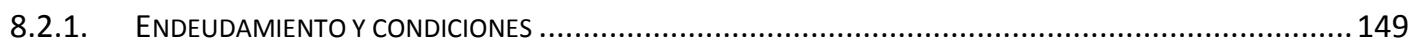

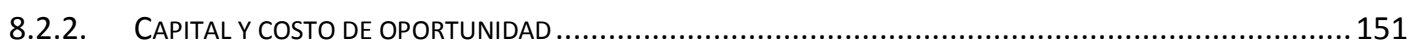

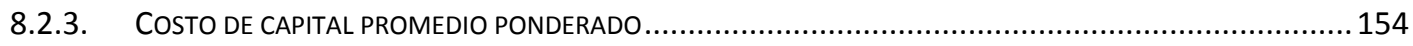

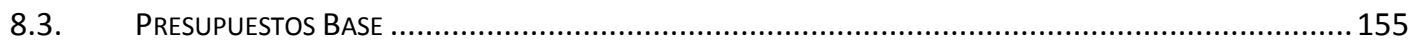

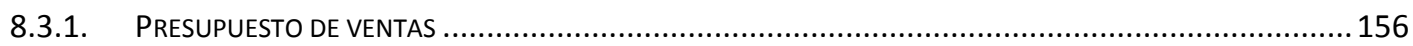

8.3.2. PRESUPUESTO DE COSTOS DE PRODUCCIÓN ................................................................ 157

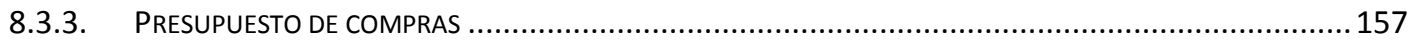

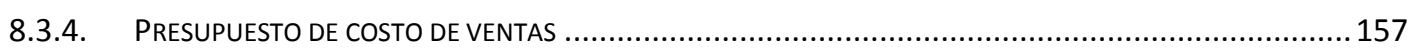

8.3.5. PRESUPUESTO DE GASTOS ADMINISTRATIVOS ................................................................... 158

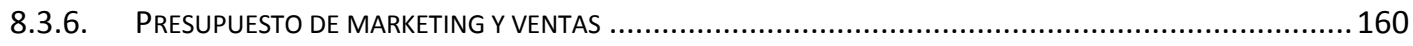

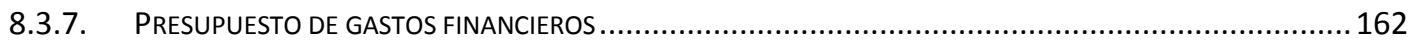

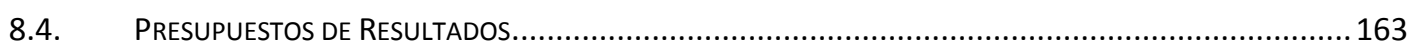

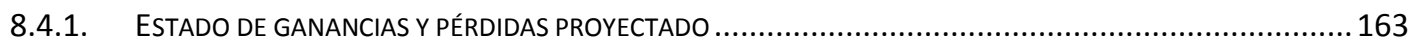

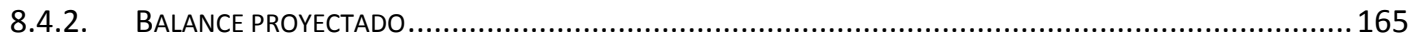

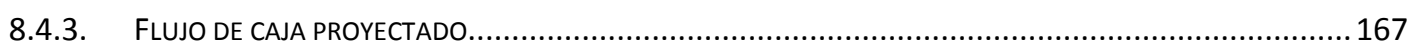

CAPÍTULO IX: EVALUACIÓN ECONÓMICO FINANCIERA ..........................................................171

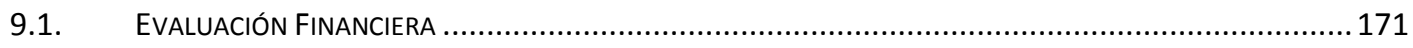

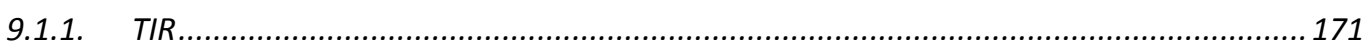

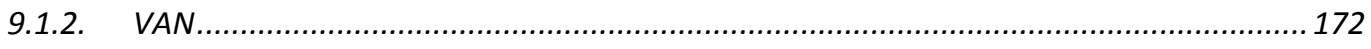

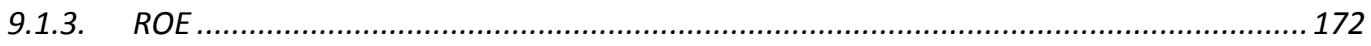

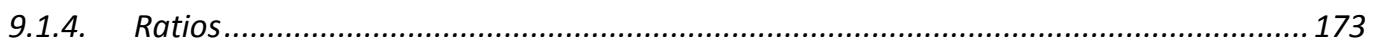

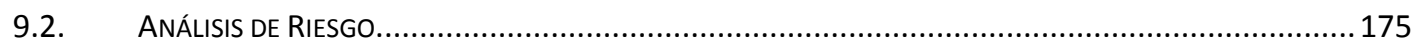

9.2.1. Análisis de punto de equilibrio.................................................................... 175

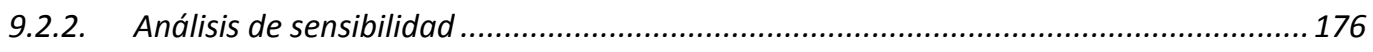

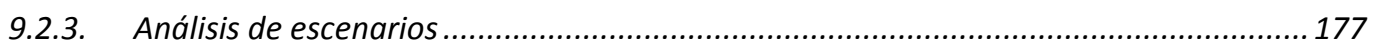




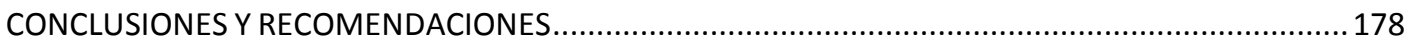

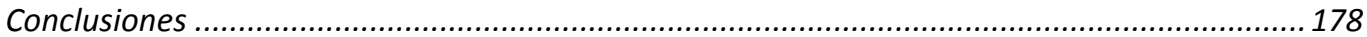

Recomendaciones ................................................................................................... 179

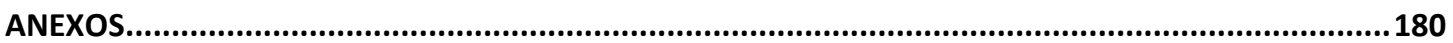

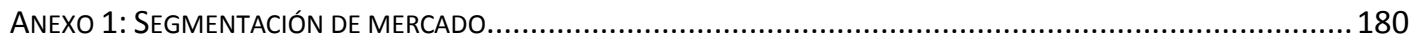

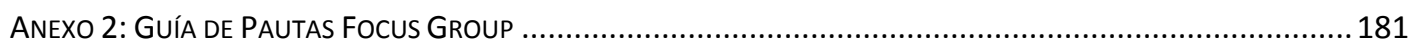

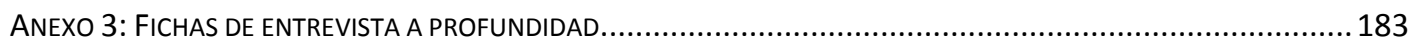

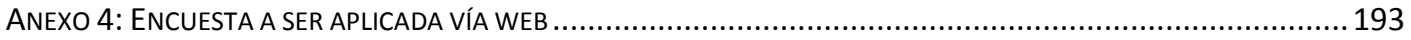

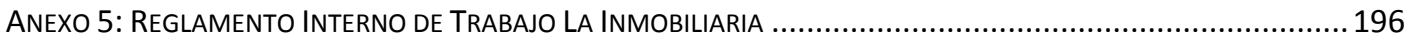

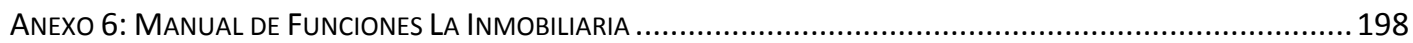

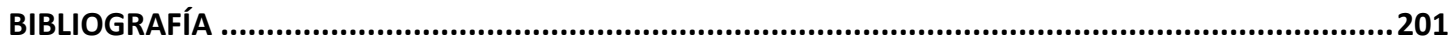

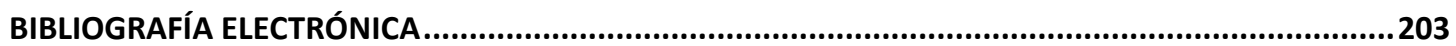




\section{Índice de tablas}

Tabla 1. Crecimiento del PBI...................................................................24

Tabla 2. Población Total por Tipo de Vivienda...........................................25

Tabla 3. Población total por tipo de vivienda - Magdalena ...........................27

Tabla 4 Actividad edificadora en Lima Metropolitana y el Callao ..............30

Tabla 5 Distribución de la Actividad edificadora según destinos ..................31

Tabla 6 Oferta total de edificaciones según destino 2015-2016 ...................31

Tabla 7 Oferta de vivienda en Lima ............................................................

Tabla 8 Estructura de la oferta total de departamentos .................................33

Tabla 9 Distribución de los hogares según estrato socioeconómico...............33

Tabla 10 Clasificación de las edificaciones según el RNE ............................36

Tabla 11 Principales Empresas Inmobiliarias a Nivel de Lima y Callao .......37

Tabla 12 Matriz de atractividad amenaza de nuevos competidores ..............40

Tabla 13 Matriz de atractividad amenaza de productos sustitutos ................41

Tabla 14 Matriz de atractividad Poder de negociación de los consumidores 42

Tabla 15 Matriz de atractividad Poder de negociación de los proveedores...43

Tabla 16 Matriz de atractividad Rivalidad entre competidores .....................44

Tabla 17 Empresas con proyectos en la zona de influencia...........................46

Tabla 18 Matriz de perfil competitivo entre las empresas con proyectos

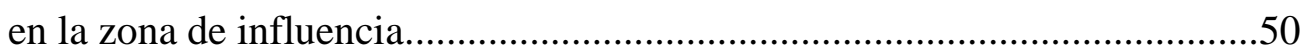

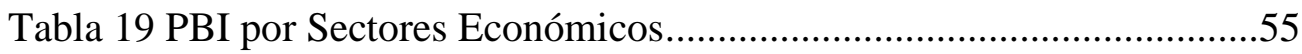

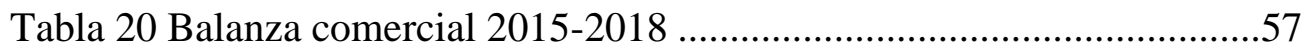

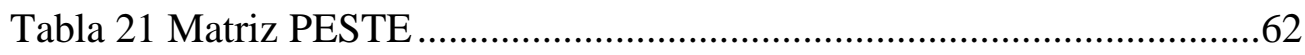

Tabla 22 Ficha de investigación cualitativa sesión de grupo........................70

Tabla 23 Ficha de investigación cualitativa entrevista en profundidad..........71

Tabla 24 Ficha de investigación cuantitativa encuesta .................................79

Tabla 25 Cantidad de encuestados según su edad .......................................79

Tabla 26 Cantidad de Encuestados Según su Género .....................................80

Tabla 27 Cantidad de encuestados según su Estado Civil .............................81 
Tabla 28 Cantidad de encuestados según su NSE ......................................82

Tabla 29 Cantidad de encuestados según su intención de compra ................82

Tabla 30 Cantidad de encuestados según su situación de vivienda ...............83

Tabla 31 Cantidad de encuestados según su nivel de satisfacción ................84

Tabla 32 Cantidad de encuestados según su pago por vivienda ....................85

Tabla 33 Cantidad de encuestados según su pago mensual vivienda ............85

Tabla 34 Cantidad de encuestados según preferencia de vecinos

Tabla 35 Cantidad de encuestados según su preferencia por vivienda

sostenible.

Tabla 36 Cantidad de encuestados según metraje de vivienda . .87

Tabla 37 Cantidad de encuestados según ubicación de vivienda .88

Tabla 38 Cantidad de encuestados según preferencia por estacionamiento ..89

Tabla 39 Requerimiento de equipos y mobiliario para la oficina .................101

Tabla 40 Matriz de evaluación de factores externos....................................115

Tabla 41 Matriz de evaluación de factores internos ....................................116

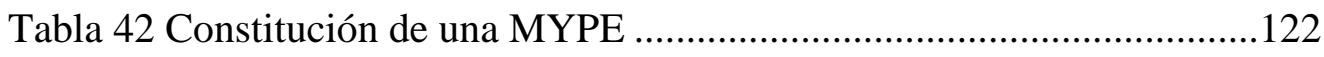

Tabla 43 Consideraciones para la remuneración de una PYME....................127

Tabla 44 Tipos de producto y sus características...........................................131

Tabla 45 Fijación de Precios por unidad de departamento ...........................132

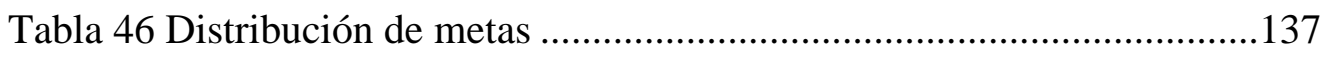

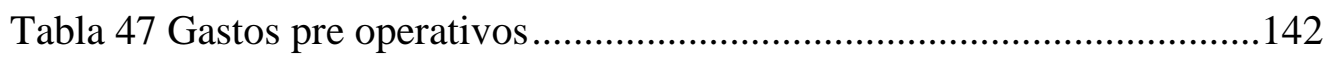

Tabla 48 Gastos de constitución de empresa ..............................................143

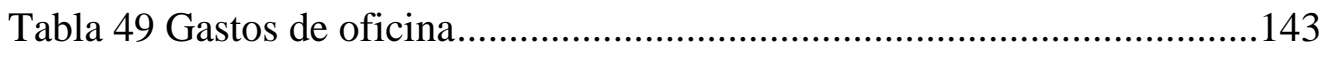

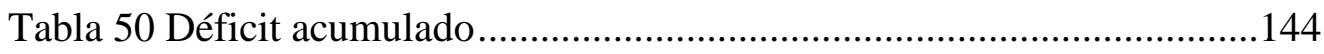

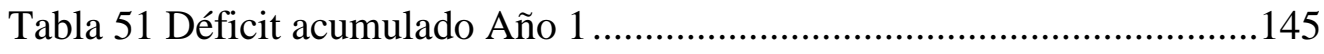

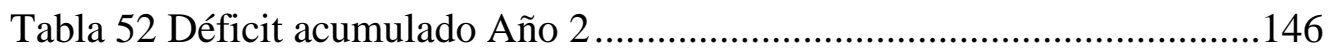

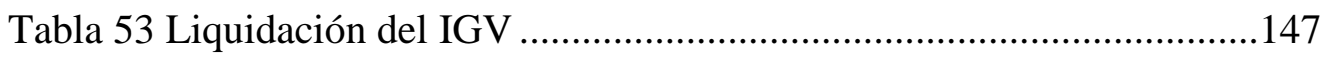

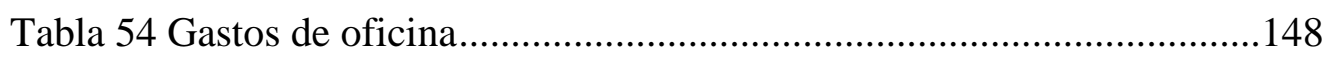

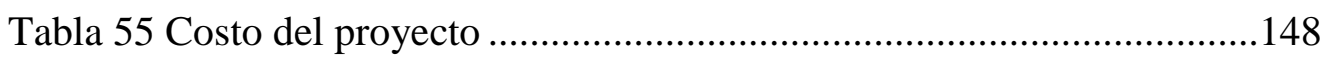

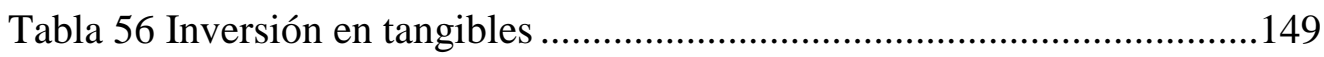

Tabla 57 Estructura Deuda-Capital...........................................................150

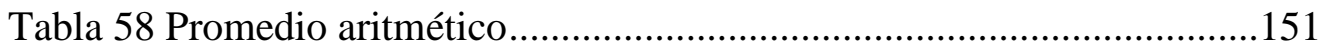




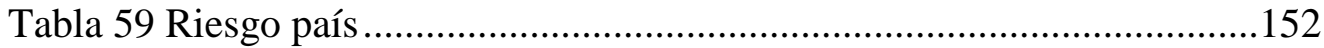

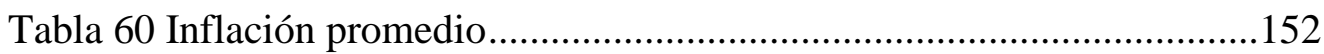

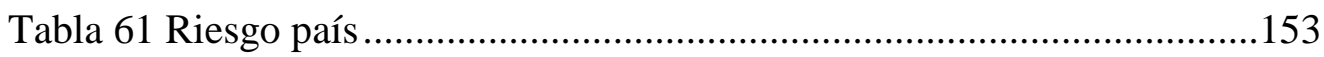

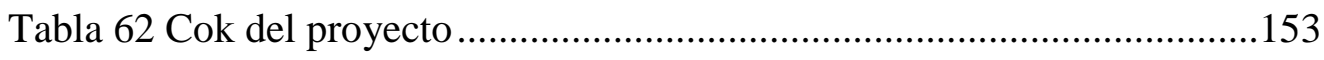

Tabla 63 Cok apalancado del proyecto ..................................................... 153

Tabla 64 Costo de capital promedio ponderado ............................................154

Tabla 65 Cálculo de áreas del proyecto ........................................................156

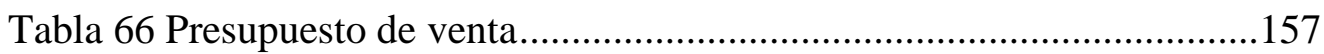

Tabla 67 Presupuesto de costo de venta ...................................................158

Tabla 68 Presupuesto de gastos administrativo ..........................................159

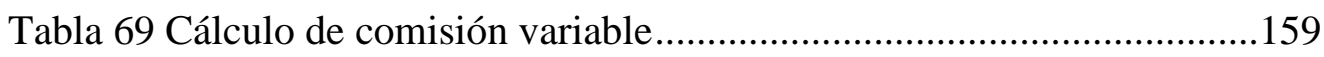

Tabla 70 Cálculo de costo laboral.............................................................160

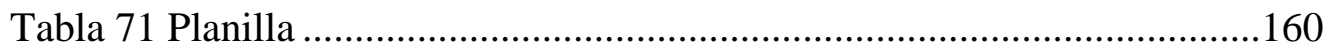

Tabla 72 Presupuesto de marketing ..........................................................161

Tabla 73 Distribución de gasto de marketing ............................................161

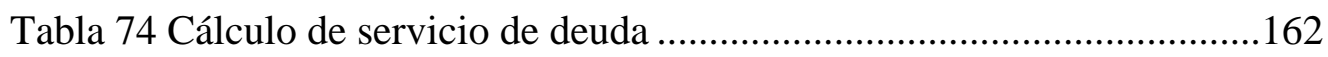

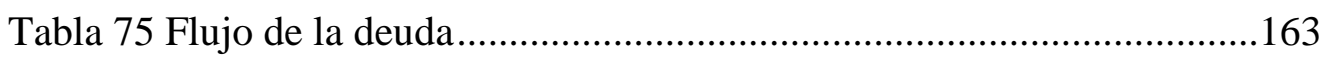

Tabla 76 Estado de Ganancias y Pérdidas Proyectado .................................164

Tabla 77 Balance General proyectado ......................................................166

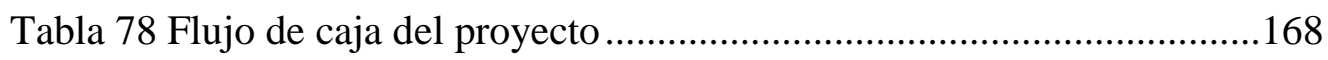

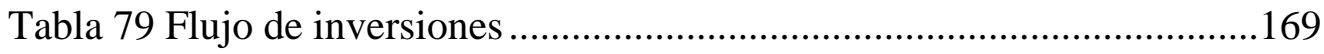

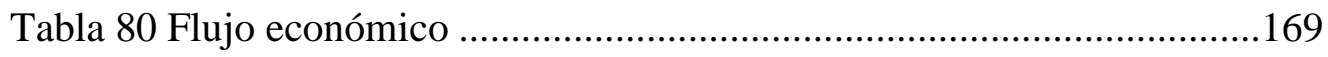

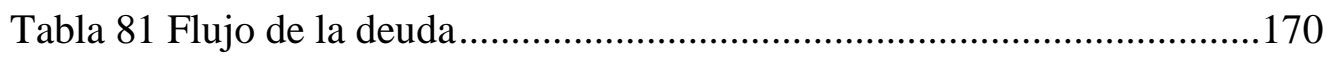

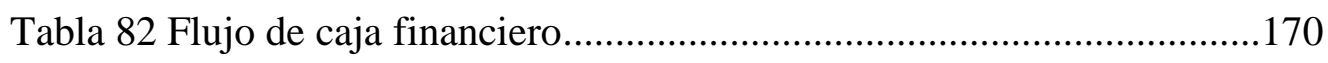

Tabla 83 Tasa Interna de Retorno Económica ...........................................171

Tabla 84 Tasa Interna de Retorno Financiera ..........................................171

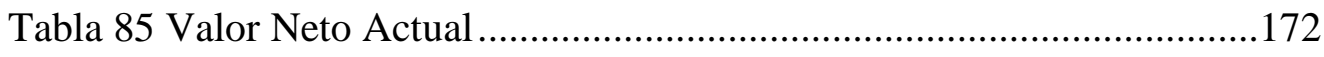

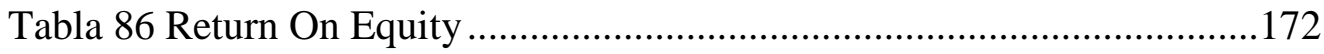

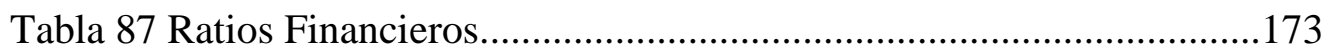

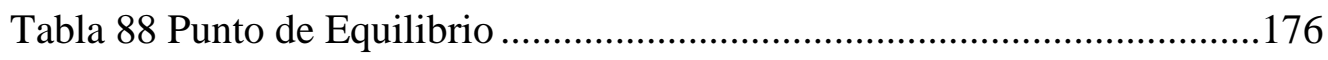

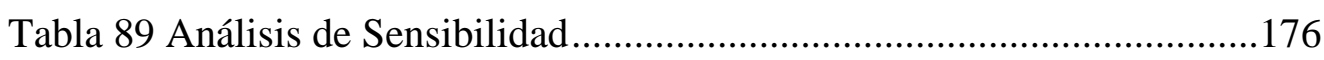




\section{Índice de figuras}

Figura 1. Línea de tiempo de la construcción. .............................................18

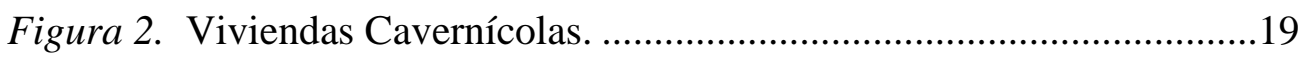

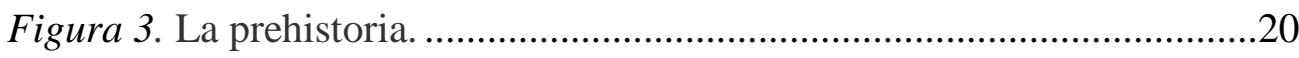

Figura 4. El misterio de cómo se construyeron las pirámides........................20

Figura 5: Construcción de vivienda romana. ..............................................21

Figura 6. Crecimiento anual del PBI mundial (\%)....................................23

Figura 7. Precio por metro cuadrado ciudad de Lima. .................................26

Figura 8. Distritos de preferencia para comprar vivienda...........................26

Figura 9. Oferta total de vivienda según sector urbano.................................32

Figura 10. Diagrama de las cinco fuerzas de Porter.....................................45

Figura 11. Participación en el mercado de las empresas inmobiliarias. .......48

Figura 12. Participación de proyectos multifamiliares en la zona ...............49

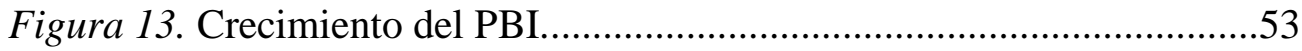

Figura 14. Consumo interno de Cemento 2013-2016. ................................53

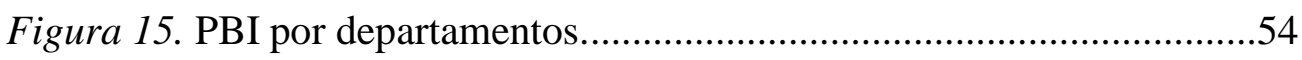

Figura 16. Crecimiento del PBI 2016-2017. ..........................................56

Figura 17. Tasa de interés de referencia nominal y real 2015-2016............57

Figura 18. Proyección de la inflación 2010-2018........................................58

Figura 19. Foto Panorámica Situación Actual Del Terreno ..........................65

Figura 20. Mapa de ubicación del terreno.....................................................66

Figura 21. Segmentación del mercado ....................................................66

Figura 22. Porcentaje de encuestados por Edad..........................................80

Figura 23. Porcentaje de encuestados por Género .....................................8 80

Figura 24. Porcentaje de encuestados por Estado Civil ................................81

Figura 25. Porcentaje de encuestados por NSE ..........................................82

Figura 26. Porcentaje de encuestados por Intención de compra...................83

Figura 27. Porcentaje de encuestados por situación de vivienda ..................84

Figura 28. Porcentaje de encuestados por nivel de satisfacción ...................84

Figura 29. Porcentainje de encuestados por pago por vivienda. ..................85

Figura 30. Porcentaje de encuestados por pago mensual vivienda. ..............86

Figura 31. Porcentaje de encuestados por número de vecinos ......................87 
Figura 32. Porcentaje de encuestados por preferencia vivienda sostenible ..87

Figura 33. Porcentaje de encuestados por metraje de vivienda.....................88

Figura 34. Porcentaje de encuestados por ubicación Magdalena..................89

Figura 35. Porcentaje de encuestados por estacionamiento ..........................89

Figura 36. Cadena de valor del negocio .................................................. 100

Figura 37. Distribución de espacios de la oficina .........................................102

Figura 38. Distribución equipo y maquinarias ...............................................103

Figura 39. Las cuatro dimensiones de Cameron Quinn. ..............................110

Figura 40. Estructura organizacional de la inmobiliaria. ............................123

Figura 41. Bloques de construcción de diferenciación organizacional.........124

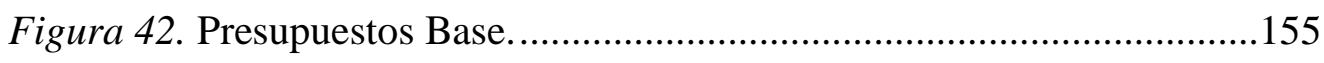

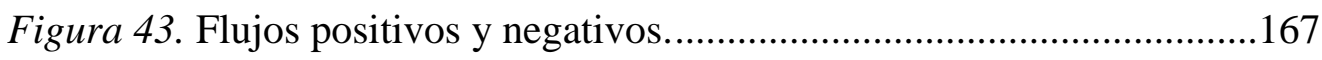




\section{Introducción}

En el capítulo uno, se detallan los antecedentes del negocio, además se hace la identificación de la oportunidad, se explica el por qué se desea realizar el plan de negocio, los objetivos que este buscará cumplir, sus alcances y limitaciones.

En el capítulo dos, se expone un estudio macroeconómico del sector, bajo el análisis de diversas variables exógenas que definieron las oportunidades sobre las cuales se apoya la viabilidad el proyecto.

En el capítulo tres, se presenta los resultados del estudio de mercado que son guía para poder delimitar el mercado objetivo y estudiar la posibilidad y percepción de los potenciales consumidores con respecto al proyecto final.

En el capítulo cuatro, se fija el mercado objetivo, y se realiza la cuantificación sobre la cual se realizó la proyección de ventas que permita obtener los resultados de rentabilidad deseados para el proyecto.

Para el capítulo cinco, se toca los temas técnicos del proyecto en cuanto al equipamiento, diseño, distribución, recursos, localización, revisión e identificación de la normatividad y leyes que aplican al proyecto, los cuales definen la realización del proyecto.

En el capítulo seis, se realiza la explicación de la cultura organizacional de la empresa que llevará a cabo el proyecto. También se explica la estructura organizacional, definición de misión, visión y valores, así como también la política remunerativa en función del alcance de la rentabilidad deseada.

En el capítulo siete, se plantean las estrategias de marketing a aplicar para el proyecto, por la cual se tangibiliza el precio, promoción y publicidad acorde con plan y proyección de ventas.

En el octavo capítulo, se cuantifica la inversión necesaria para la puesta en marcha del proyecto y su respectiva inversión futura. Se analiza el financiamiento requerido para 
realizarlo. Además, se calcula el presupuesto de producción y el presupuesto de resultados para analizar el costo de capital del proyecto.

En el capítulo nueve, se realiza la evaluación si el objetivo general se cumplió, mediante la evaluación financiera de indicadores como el TIR, VAN, ROE y principales ratios financieros. Adicionalmente se hace el análisis del punto de equilibrio, de sensibilidad y de escenarios. 


\section{Capítulo I. Generalidades}

\subsection{Antecedentes}

A lo largo de la historia, según Toca (2013), el hombre ha evolucionado en la industria de la construcción y este progreso se ha dado en función de la disponibilidad de materiales y su perfeccionamiento en las técnicas de trabajo, las cuales han determinado sus características, sofisticación y escalas de construcción.

Para conocer sus orígenes hay que tener en mente a las primeras civilizaciones del mundo, partiendo de las construcciones prehistóricas y pasando por la antigüedad de las primeras civilizaciones como los griegos, egipcios y romanos, referentes como pioneros en cuanto a sociedades constructoras modernas.

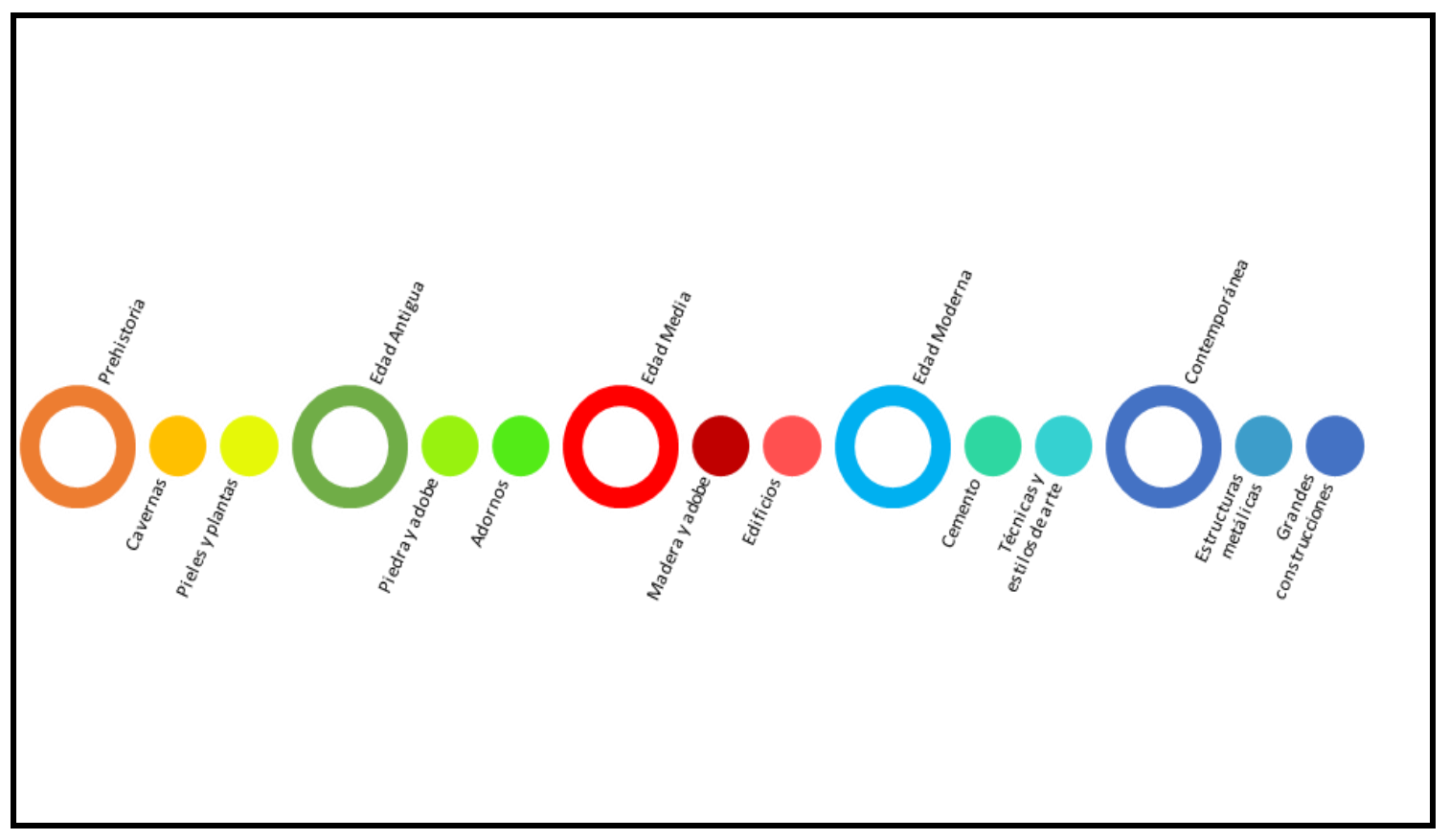

Figura 1. Línea de tiempo de la construcción. Tomado de:

https://www.timetoast.com/timelines/evolucion-de-la-vivienda

Hace más de dos millones de años, en el periodo Paleolítico, los humanos vivían en cuevas para guarecerse del frío, nieve y otros factores del clima que implicaron una amenaza 
para su bienestar. Pero, para determinadas épocas del año donde la temperatura era elevada, construían pequeñas casas con plantas o pieles para cubrirse de los rayos solares.

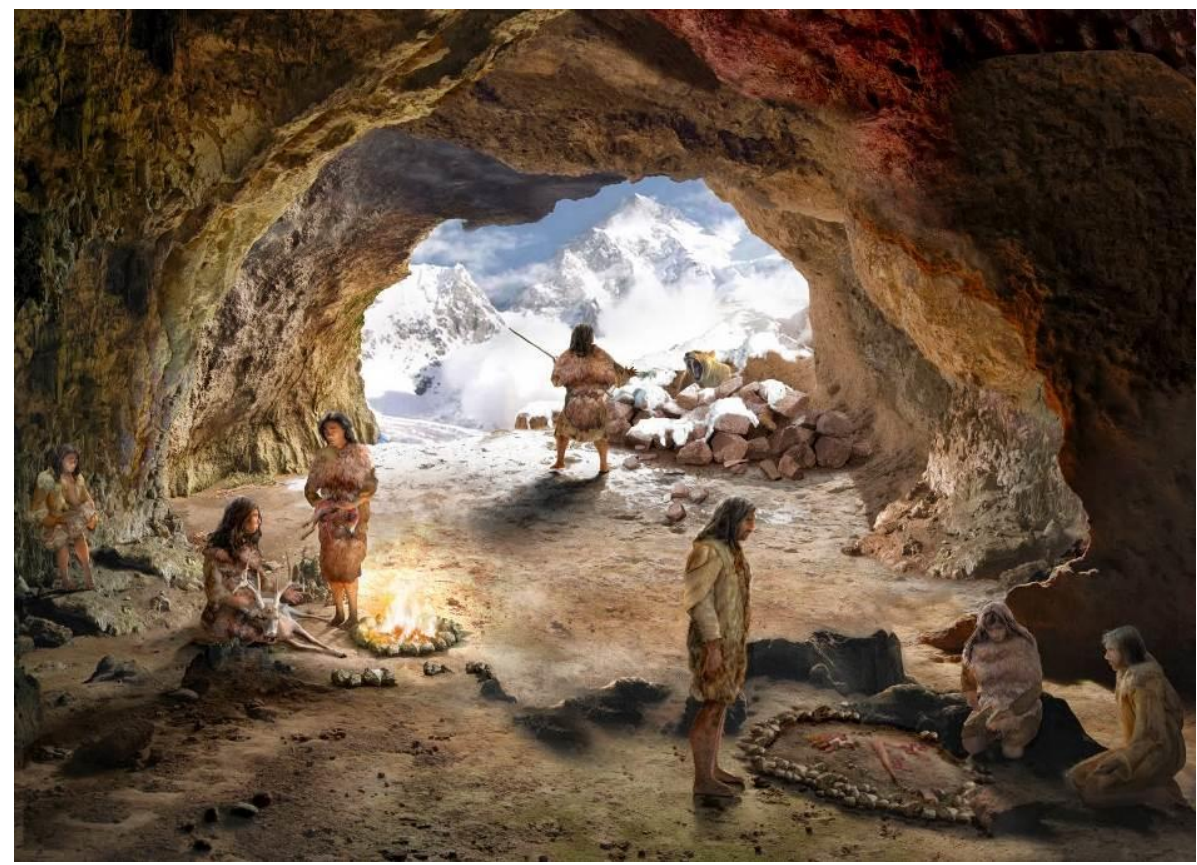

Figura 2. Viviendas Cavernícolas. Tomado de: http://www.trebolanimation.com/work

Las primeras técnicas de construcción se trabajaban con huesos de animales. Más adelante, en el periodo Mesolítico empezarían las primeras construcciones de chozas, las cuales estaban hechas de palos de madera y piel o plantas, un poco más sofisticadas que las construcciones para resguardarse del sol.

Luego, dentro de la Edad de Bronce y el desarrollo de la metalurgia para las herramientas principales, se producen viviendas más sólidas, hechas de adobe y piedra con una estructura horizontal con barro y caña como materia prima apoyadas en vigas de madera.

Con la llegada de la Edad de Hierro se produce un quiebre en la distinción entre las viviendas de los "pobres" y de los "ricos", que, fundamentalmente, se hacía en base al material de la construcción. Estas construcciones ya se hacían con herramientas de hierro, lo cual daba paso a construir edificaciones más fuertes o de mejor calidad. 


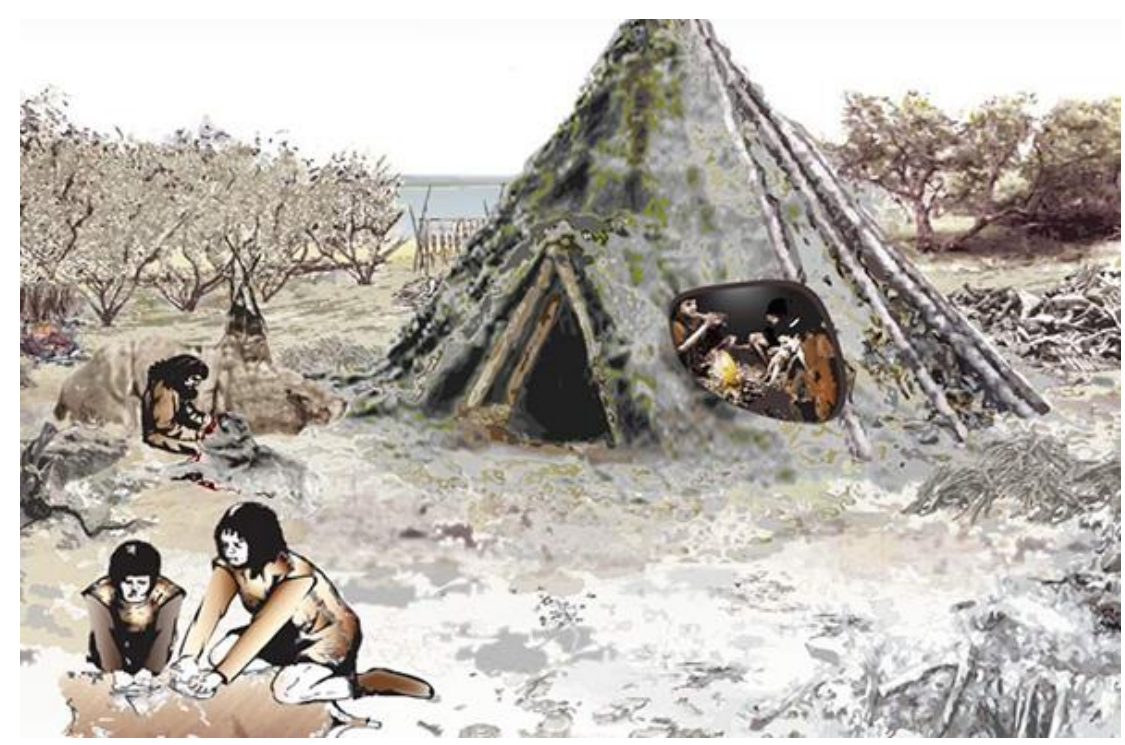

Figura 3. La prehistoria. Tomado de: Sophimania Hernandez Muro, Alexandra (2012)

En la Edad Antigua, en la Mesopotamia se descubrió el ladrillo, pieza clave para las principales edificaciones de la ciudad de Babilonia. La ciudad de Egipto marcó un hito en la historia de la construcción, creando las columnas como apoyos de sus construcciones.

Gracias a sus amplios conocimientos en geometría, los egipcios crearon grandes construcciones de piedra y madera, usando una técnica simplista, sus edificaciones siguen vigentes hoy en día.

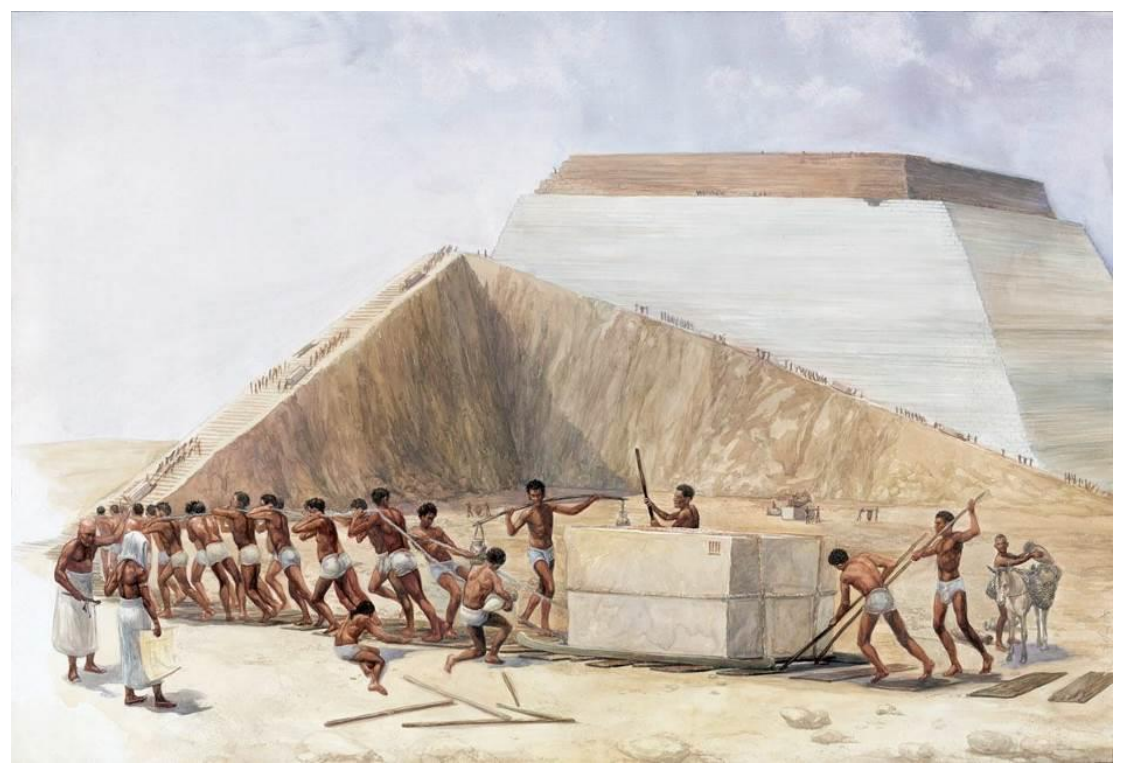

Figura 4. El misterio de cómo se construyeron las pirámides. Tomado de: http://www.sobrehistoria.com 
Para la llegada de los romanos en el siglo VIII a.C. ya se aprecian los primeros esnobismos en estas viviendas, que principalmente, estaban construidas en piedra y adobe y eran ya adornadas con mosaicos y frescos en los exteriores propios de la civilización Helenística. Toda la construcción de ésta era ya era bajo la idea de la monumentalidad, es decir, más allá del hombre, representaban la grandeza del imperio.

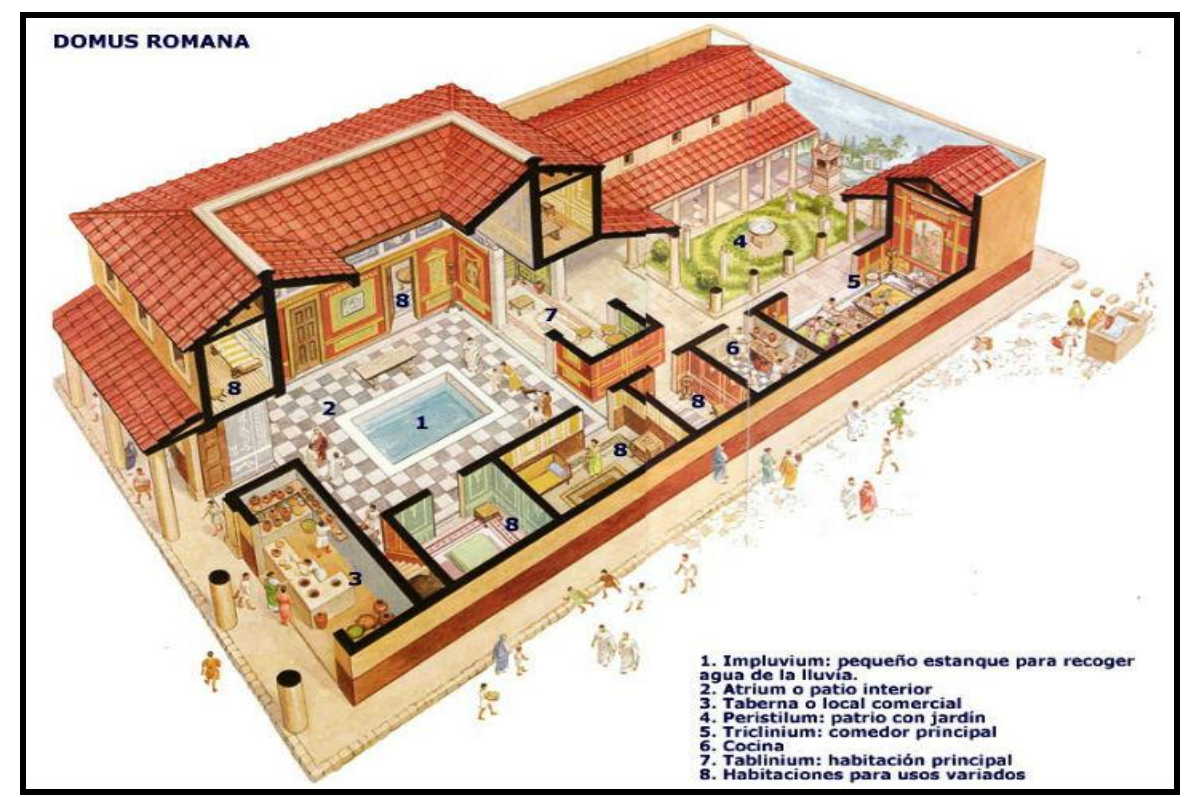

Figura 5: Construcción de vivienda romana. Tomado de: http://www.temporamagazine.com

Para la Edad Media, las construcciones eran de madera adobe y piedras, y en el techo se utilizaba paja. Luego estos espacios fueron transformándose para dar paso a los edificios que a su vez eran viviendas en las plantas superiores. En las grandes construcciones prevalecen los arcos, bóvedas y cúpulas. Se usa la caligrafía árabe como decoración y los colores brillantes.

Junto con el descubrimiento de América, surge la Edad Moderna teniendo como primeras escuelas al renacimiento, donde la escala humanística de la construcción regresa al hombre como centro de su estructura adoptando perspectivas lineales unidas en un punto de fuga. 
Otras técnicas como el Barroco y Rococó son de importante mención en esta época donde resalta la ornamentación cargada, curvas y contrastes.

Con la revolución francesa se da paso a la edad contemporánea. Aquí predomina el materialismo sobre lo estético y la practicidad de las construcciones prefabricadas. Con la industrialización de la época se comienzan a ver las primeras edificaciones de hierro, que se acomodan a la forma de vida de la población. Uno de los movimientos previos al actual es la arquitectura orgánica, es decir, busca la armonía entre la naturaleza y el ser humano, de esta manera todos los predios y sus conexiones urbanas se encuentran en armonía con el medio ambiente.

En el mundo de la construcción actual se tiene lo más conocido como High Tech, donde se incluyen, dentro de las construcciones, componentes de tecnología y componentes funcionales para los diferentes usos de las mismas. Se utiliza mayormente prefabricado, paredes de vidrio, estructuras de acero, técnicas antisísmicas, preocupación por lo estético, lo sostenible y la seguridad. Estas son algunas de las características que las construcciones de hoy en día se preocupan en promover en favor a las exigencias de los clientes y las últimas tendencias mundiales.

En el Perú, a lo largo de la historia se dio el crecimiento horizontal en las grandes ciudades, especialmente centrándose en la ciudad de Lima. Este centralismo no solo llevó al crecimiento poblacional de la zona urbana, sino que impulsó al nacimiento de nuevas poblaciones en forma de invasión en las afueras de la ciudad. En determinado momento, el crecimiento en la ciudad no dejaba más “espacios”, por lo que se empezó a dar de forma vertical en forma de edificios o grandes unidades familiares que albergan a gran parte de la población que establece a Lima como su ciudad para vivir.

Debido a la sofisticación de la tecnología y la llegada de las nuevas tendencias por la globalización, las construcciones en Lima ya hablan en términos eco amigable, antisísmico y 
funcional. Con el aumento de los inversores públicos y privados, así como el apoyo del Gobierno, grandes, pequeños y medianos proyectos tienen igual aceptación y demanda en el país. (Fernández, A., 2015)

\subsection{Determinación del problema u oportunidad}

En la actualidad mundial se viene experimentando una recuperación de la economía, por lo cual los índices de crecimiento mundial han venido incrementándose paulatinamente, especialmente en los últimos dos años y proyectándose a mantener la misma tendencia en los años venideros.

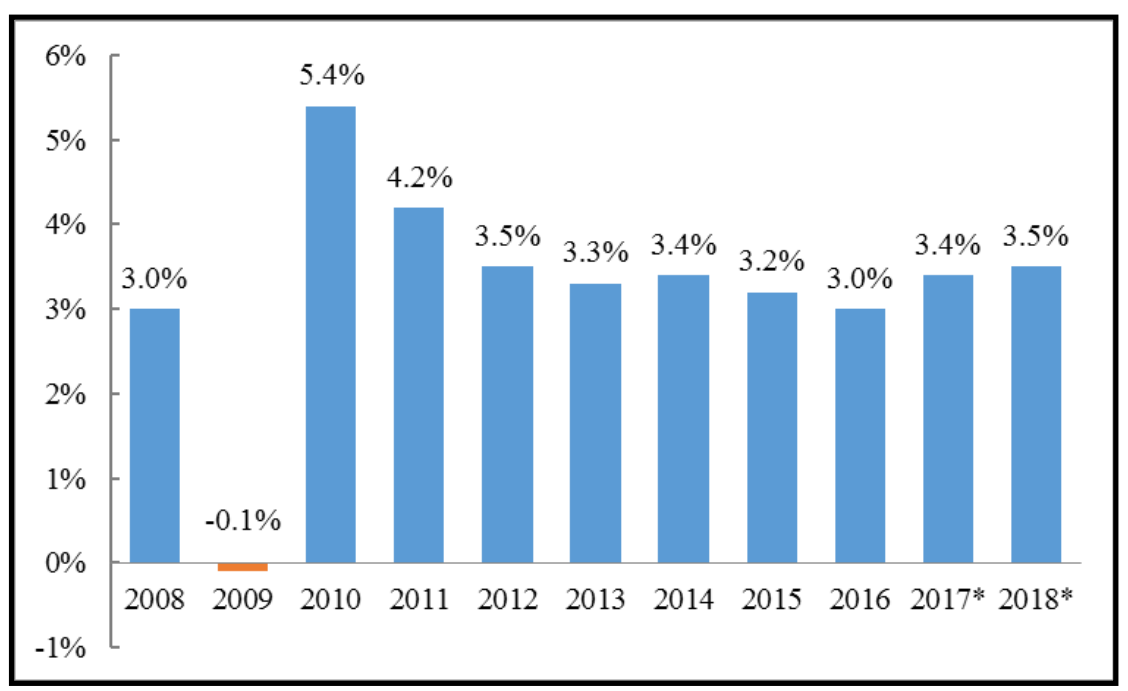

Figura 6. Crecimiento anual del PBI mundial (\%). Tomado de: BCRP,FMI y Consensus Forecast, 2016. Recuperado de http://www.consensuseconomics.com

Esta recuperación se ha dado básicamente debido a varios factores, uno de ellos es el incremento de los precios de los commodities por la recuperación de Estados Unidos, como consecuencia de ello las exportaciones superaron las importaciones en el 2016 conllevando a un superávit en los próximos años.

El escenario en América Latina se muestra favorecedor para el 2017, en el cual las economías de todos los países se recuperan básicamente por la baja de las presiones inflacionarias, pero a su vez se mantienen conservadores respecto al crecimiento fundamentalmente por el incremento de la tasa de la FED. 
Tabla 1.

Crecimiento del PBI (Variación porcentual)

\begin{tabular}{lr|lr}
\multicolumn{1}{r}{$\mathbf{2 0 1 6}$} & \multicolumn{2}{c}{2017} \\
\hline Perú & 4.0 & Perú & 4.3 \\
Bolivia & 3.7 & Bolivia & 3.8 \\
Paraguay & 3.6 & Paraguay & 3.6 \\
México & 2.0 & México & 2.9 \\
Colombia & 2.0 & Colombia & 2.5 \\
Chile & 1.6 & Chile & 2.1 \\
Uruguay & 0.5 & Uruguay & 1.7 \\
Ecuador & -2.0 & Ecuador & 1.3 \\
Argentina & -2.3 & Argentina & 0.8 \\
Brasil & -3.4 & Brasil & 0.7 \\
Venezuela & -10.7 & Venezuela & -3.0
\end{tabular}

Nota. Tomado de: Latin American Consensus Forecast y BCRP para Perú, 2016. http://www.consensuseconomics.com

A pesar del liderazgo en crecimiento del PBI de Perú respecto a la región, según el Banco Mundial (2017), existen ciertos factores de la realidad peruana que resaltan de manera contrastante a esta realidad. Uno de estos factores es la demanda de viviendas dentro del sector construcción inmobiliario.

Año tras año, se ha mantenido baja la oferta de viviendas y ha ido incrementando considerablemente el número de familias que desean adquirir una vivienda debido al crecimiento del poder adquisitivo y la concentración de la población en algunas regiones del Perú.

Esta demanda, que en algunos sectores ha llegado a razón de 10 veces más frente a la oferta, se concentra principalmente en la ciudad de Lima, en donde el metro cuadrado libre escasea y tiene un costo elevado, es por esto que muchos de los edificios son construidos sobre terrenos que fueron grandes casas familiares.

Según la consultora HGP (2017), existe un déficit habitacional bastante amplio, llegando a tener una demanda insatisfecha de 450,000 viviendas, el $80 \%$ por un valor mayor 
a los S/ 80,000.00, alrededor de 400,000 viviendas. La mitad de este déficit se da principalmente por un tema de calidad en materiales de construcción y servicios básicos.

La otra mitad del déficit se da en compra de una nueva vivienda, en donde se ha encontrado un mercado potencial desatendido en Magdalena del Mar, uno de los distritos con precio promedio por metro cuadrado dentro de un rango accesible y se cuenta con el terreno para elaborar la edificación; además del planteamiento de los dueños del mismo, para realizar el estudio de evaluación de la rentabilidad para llevar a cabo un proyecto inmobiliario en este espacio.

Tabla 2.

Población total por tipo de vivienda

\begin{tabular}{|c|c|c|}
\hline \multirow[b]{2}{*}{ TOTAL } & PERÚ & \multirow{2}{*}{$\begin{array}{c}\text { PROVINCIA LIMA } \\
\mathbf{7 , 5 3 1 , 2 3 3}\end{array}$} \\
\hline & $27,057,199$ & \\
\hline Casa independiente & $23,880,623$ & $6,224,018$ \\
\hline Departamento en edificio & $1,144,856$ & 865,168 \\
\hline Vivienda en quinta & 435,187 & 205,882 \\
\hline Vivienda en casa de vecindad & 354,431 & 85,595 \\
\hline Choza o cabaña & 886,504 & 500 \\
\hline $\begin{array}{l}\text { Vivienda improvisada } \\
\text { Local no destinado para }\end{array}$ & 296,861 & 118,837 \\
\hline hab.humana & 30,931 & 13,080 \\
\hline Otro tipo & 27,806 & 18,153 \\
\hline
\end{tabular}

Nota. Tomado de: Datos estadísticos. Ministerio de Vivienda, 2016. http://www.vivienda.gob.pe.

Particularmente en la zona de Lima Moderna, donde el movimiento comercial es bastante dinámico y a la vez es una zona urbana, la demanda de viviendas es amplia y presenta el mismo patrón de cantidad de ofertas de Lima Metropolitana, y, además se encuentra como segunda zona de precios por $\mathrm{m}^{2}$ de departamentos de la ciudad. 


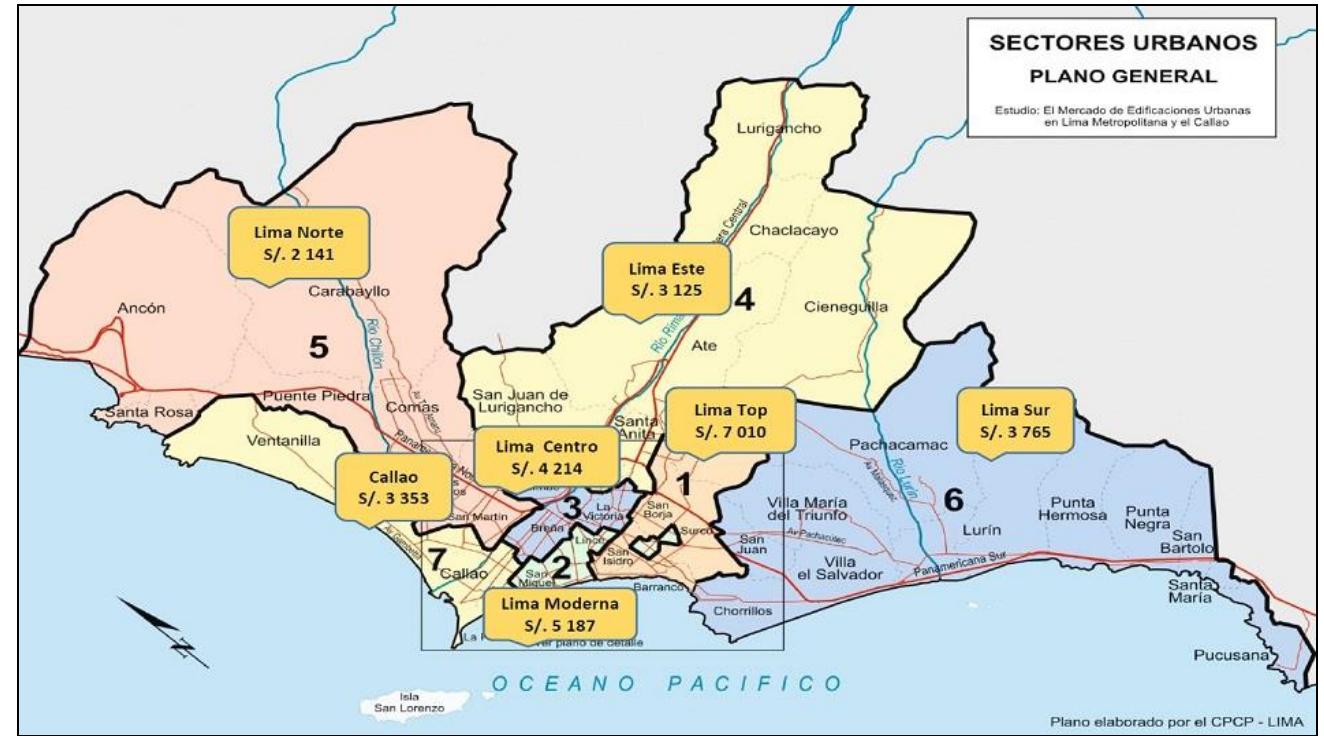

Figura 7. Precio por metro cuadrado ciudad de Lima. Tomado de: http://rpp.pe/economia

Según la Cámara Peruana de la Construcción (CAPECO), la demanda efectiva de los distritos de preferencia para comprar una vivienda se encuentra en Lima moderna, y se puede apreciar en la siguiente figura que, dentro de los distritos de preferencia, se encuentra Magdalena del Mar, representando una gran oportunidad el contar con el terreno del proyecto ubicado en esta zona.

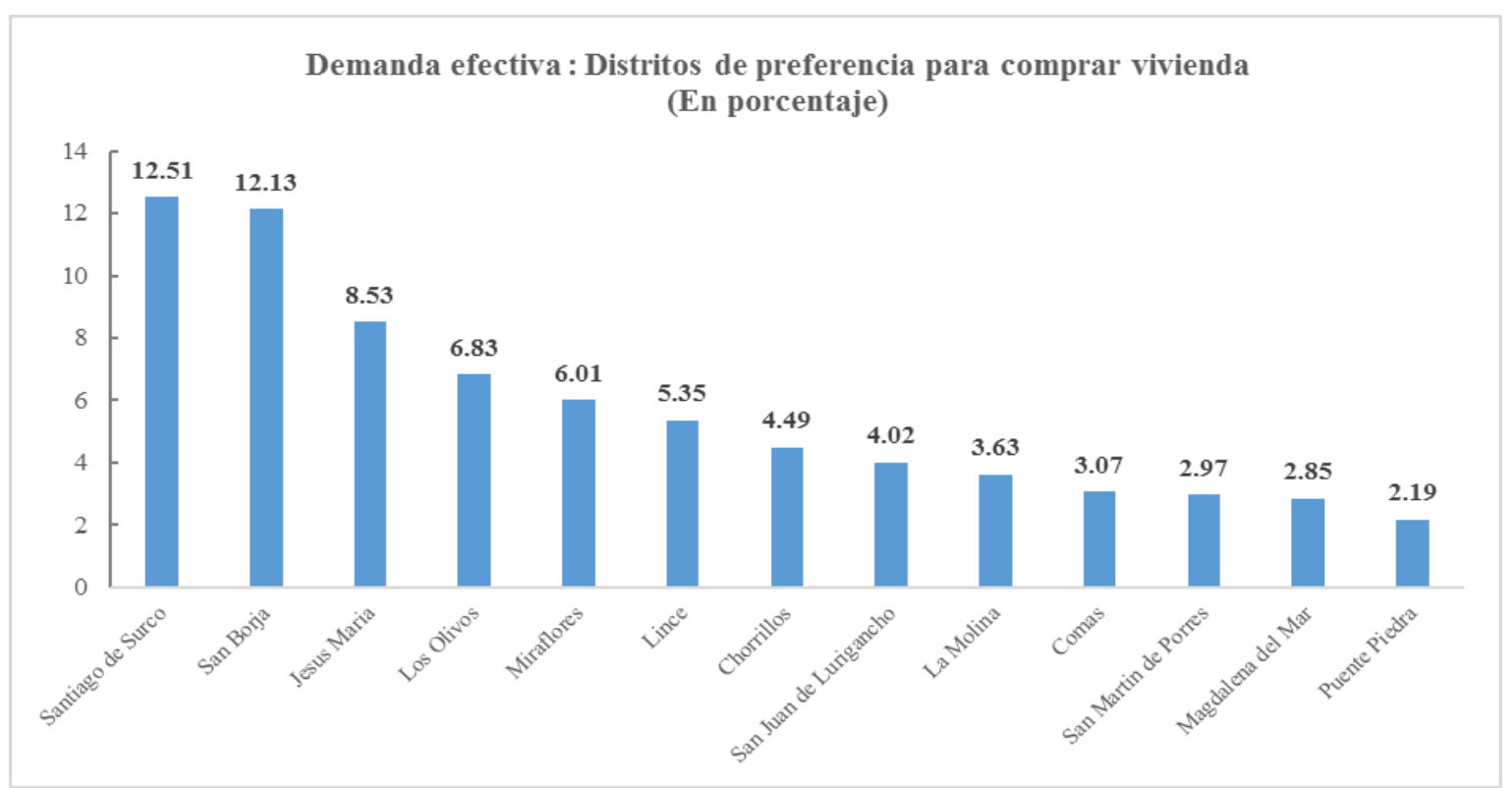

Figura 8. Distritos de preferencia para comprar vivienda. Tomado de CAPECO. 
Luego de analizar la composición de la población por tipo de vivienda, se puede ver que existe una marcada oportunidad para las viviendas de tipo departamento en edificio ya que, la preferencia por este tipo de vivienda es la segunda en número de población que cuenta con departamento, como se muestra en la Tabla 3 a continuación:

Tabla 3.

Población total por tipo de vivienda - Magdalena

\begin{tabular}{lrr}
\cline { 2 - 3 } TOTAL & PROVINCIA LIMA & MAGDALENA \\
\cline { 2 - 3 } & $\mathbf{7 , 5 3 1 , 2 3 3}$ & $\mathbf{1 2 6 , 1 2 0}$ \\
\hline Casa independiente & $6,224,018$ & 70,327 \\
Departamento en edificio & 865,168 & 37,208 \\
Vivienda en quinta & 205,882 & 12,037 \\
Vivienda en casa de vecindad & 85,595 & 6,171 \\
Choza o cabaña & 500 & 0 \\
Vivienda improvisada & 118,837 & 149 \\
Local no destinado para hab.humana & 13,080 & 169 \\
Otro tipo & 18,153 & 59
\end{tabular}

Nota. Tomado de: Datos estadísticos. Ministerio de Vivienda, 2016. http://www.vivienda.gob.pe

Es entonces en este distrito donde se encuentra la oportunidad latente de construir un proyecto inmobiliario que sea exitoso, si se encuentra dentro de los estándares de calidad esperada que el mercado exige y manteniendo una ventaja competitiva que diferencie el proyecto de los existentes en el mercado.

\subsection{Justificación del Proyecto}

El actual proyecto busca crear una empresa nueva, "La Inmobiliaria”, con el fin de realizar el proyecto de inversión Edificio Multifamiliar Arequipa como único proyecto a la venta, con el cual se pretende obtener una determinada rentabilidad para los propietarios del terreno, de esta forma se buscará satisfacer una parte de la necesidad insatisfecha detectada como oportunidad potencial ofreciendo como valor diferencial principal la sostenibilidad de sus materiales, es decir, será un proyecto Ecoamigable. En consecuencia, este proyecto va a 
generar puestos de trabajo en el país y contribuyendo con activar la economía del distrito, a la vez que se pretende incrementar la calidad de vida de la población, se buscará modernizar la zona urbana potenciando el espacio físico para que más familias vivan en el distrito.

Además, el objetivo de este trabajo es aplicar todos los conocimientos adquiridos a lo largo de la maestría, para así demostrar nuestra capacidad profesional al poder llevar a cabo un plan de negocios exitoso.

\subsection{Objetivos generales y específicos}

\subsubsection{Objetivo general del proyecto:}

Crear una PYME 1lamada "La Inmobiliaria” destinada a la venta directa del proyecto Multifamiliar Arequipa compuesto por departamentos sostenibles en la ciudad de Lima, en el distrito de Magdalena, iniciando gestiones en el año 2018 para, de esta manera, generar la rentabilidad esperada por los accionistas.

\subsubsection{Objetivos específicos del proyecto:}

- Analizar el macro y micro entorno de Lima dentro del sector construcción.

- Realizar un estudio de mercado para conocer el potencial de proyectos inmobiliarios multifamiliares.

- Determinar el tamaño y comprobar la preferencia para la locación del proyecto inmobiliario "Arequipa”.

- Análisis de la rentabilidad y factibilidad de realizar un proyecto sostenible en Magdalena.

\subsection{Alcances y limitaciones de la investigación.}

\subsubsection{Alcances:}

El alcance del proyecto consiste en crear una PYME con el fin de realizar la venta directa de departamentos sostenibles del proyecto 
Multifamiliar Arequipa en el distrito de Magdalena del Mar, en la ciudad de Lima.

\subsubsection{Limitaciones:}

- La información del sector que se encuentra es bastante acotada y desfasada en términos de tiempo.

- No se tiene acceso libre a la información de las grandes empresas constructoras.

- Existe un sinnúmero de proyectos independientes, similares al presente, con casi nulo acceso a la información de los mismos.

- Población disponible para la investigación de mercados. Es decir, los horarios para la investigación cualitativa.

- La falta de tiempo y recursos para hacer una investigación de mercado más detallada.

- La creación de la empresa solo se limita al periodo de vida comprendido desde la inversión hasta la venta de todos los departamentos del edificio. 


\section{Capítulo II. Estructura Económica del Sector}

\subsection{Descripción del estado actual de la industria}

En la tabla 4 se aprecia el comportamiento de la actividad edificadora en $\mathrm{m}^{2}$ desde el año 1996 al 2016. Desde el año 2002 se incrementó hasta llegar a su punto máximo en el año 2014 con 6.8 millones de $\mathrm{m}^{2}$ construidos.

A partir del año 2014, el Perú se volvió un mercado muy atractivo a nivel de Latinoamérica para los inversores inmobiliarios. Se debe tomar en cuenta que, para que esta tendencia siga avanzando, existe la necesidad de dar solución a las temas regulatorios y legales como son planes de desarrollo urbano, burocracia para la entrega de los permisos de construcción, y el registro de propiedad de inmuebles. Además, el hecho de ofrecer características que beneficien al consumidor y al medio ambiente a largo plazo, es un factor que puede incrementar la atractividad de este tipo de viviendas.

Para 2016, la actividad inmobiliaria registró 5, 344,994 $\mathrm{m}^{2}$ de construcción, 11.44\% por debajo del 2015

Tabla 4

Actividad edificadora en Lima Metropolitana y el Callao 2014-2016

\begin{tabular}{lccccc}
\hline \multicolumn{1}{c}{ Concepto } & $\mathbf{2 0 1 4}\left(\mathbf{m}^{\mathbf{2}}\right)$ & $\mathbf{2 0 1 5}\left(\mathbf{m}^{\mathbf{2}}\right)$ & $\begin{array}{c}\text { Variación \% } \\
\mathbf{2 0 1 4 - 2 0 1 5}\end{array}$ & $\mathbf{2 0 1 6}\left(\mathbf{m}^{\mathbf{2}}\right)$ & $\begin{array}{c}\text { Variación \% } \\
\mathbf{2 0 1 4 - 2 0 1 5}\end{array}$ \\
\hline Oferta de Edificaciones & $3,421,108$ & $2,927,356$ & -14.43 & $2,732,147$ & -6.67 \\
Edificaciones Vendidas & $2,048,556$ & $1,307,682$ & -36.16 & $1,348,443$ & 3.12 \\
Edificaciones no Comercializables & $1,505,725$ & $1,800,746$ & 19.59 & $1,264,404$ & -29.78 \\
\hline Total Actividad Edificadora & $6,975,389$ & $6,035,784$ & -13.47 & $5,344,994$ & -11.44 \\
\hline
\end{tabular}

Nota: Tomado de CAPECO.

La vivienda constituye el $65.01 \%$ del total de la actividad edificatoria. Seguida con $22.96 \%$ se encuentra el rubro otros destinos (hoteles, centros educativos, religiosos, centros deportivos, esparcimiento). 
Tabla 5

Distribución de la Actividad edificadora según destinos 2015-2016

\begin{tabular}{|c|c|c|c|c|c|c|}
\hline \multirow[b]{2}{*}{ Destino } & \multicolumn{2}{|c|}{2014} & \multicolumn{2}{|l|}{2015} & \multicolumn{2}{|l|}{2016} \\
\hline & $\mathbf{m}^{2}$ & $\%$ & $\mathbf{m}^{2}$ & $\%$ & $\mathbf{m}^{2}$ & $\%$ \\
\hline Vivienda & $4,735,363$ & 67.89 & $3,777,154$ & 62.58 & $3,474,791$ & 65.01 \\
\hline Locales Comerciales & 158,401 & 2.27 & 114,104 & 1.89 & 143,728 & 2.69 \\
\hline Oficinas & $1,087,475$ & 15.59 & 899,161 & 14.9 & 499,502 & 9.34 \\
\hline Otros Destinos & 994,150 & 14.25 & $1,245,365$ & 20.63 & $1,226,973$ & 22.96 \\
\hline Total & $6,975,389$ & 100 & $6,035,784$ & 100 & $5,344,994$ & 100 \\
\hline
\end{tabular}

Por otro lado, según el censo realizado en el 2016 se registró 2,732,147 $\mathrm{m}^{2}$ en proceso de construcción y destinados para la venta, de los cuales el $75.42 \%$ estaban destinadas para vivienda siendo en viviendas 24,519 unidades de las cuales 24,116 estaban destinadas a departamento y solo 403 para casa.

Tabla 6

Oferta total de edificaciones según destino 2015-2016

\begin{tabular}{lrrrr}
\hline & \multicolumn{2}{c}{$\mathbf{2 0 1 5}$} & \multicolumn{2}{c}{$\mathbf{2 0 1 6}$} \\
\hline \multicolumn{1}{c}{ Destino } & $\mathbf{m}^{\mathbf{2}}$ & \multicolumn{1}{c}{$\boldsymbol{\%}$} & \multicolumn{1}{c}{$\mathbf{m}^{\mathbf{2}}$} & \multicolumn{1}{c}{} \\
\hline Vivienda & $2,089,558$ & 71.38 & $2,060,454$ & 75.42 \\
Locales Comerciales & 13,469 & 0.46 & 45,459 & 1.66 \\
Oficinas & 503,873 & 17.21 & 213,681 & 7.82 \\
Otros Destinos & 320,456 & 10.95 & 412,553 & 15.10 \\
\hline Total & $2,927,356$ & 100 & $2,732,147$ & 100 \\
\hline
\end{tabular}

Nota Tomado de CAPECO.

Tabla 7

Oferta de vivienda en Lima

\begin{tabular}{lrrrrrr}
\hline & \multicolumn{2}{c}{ Oferta Inmediata } & \multicolumn{2}{c}{ Oferta Futura } & \multicolumn{2}{c}{ Oferta Total } \\
\hline \multicolumn{1}{c}{ Tipo de Vivienda } & \multicolumn{1}{c}{ Unidades } & \multicolumn{1}{c}{$\boldsymbol{\%}$} & \multicolumn{1}{c}{ Unidades } & \multicolumn{1}{c}{$\boldsymbol{\text { Unidades }}$} & $\boldsymbol{\%}$ \\
\hline Casas & 403 & 1.7 & - & 0 & 403 & 1.6 \\
Departamentos & 23,577 & 98.3 & 539 & 100 & 24,116 & 98.3 \\
Total & $\mathbf{2 3 , 9 8 0}$ & $\mathbf{1 0 0}$ & $\mathbf{5 3 9}$ & $\mathbf{1 0 0}$ & $\mathbf{2 4 , 5 1 9}$ & $\mathbf{1 0 0}$ \\
\hline
\end{tabular}

Nota. Tomado de CAPECO. 
La distribución por sectores urbanos indica que la mayor oferta del sector se encontró en el sector urbano Lima moderna con 8,309 unidades, seguida por Lima top con 5,880 unidades.

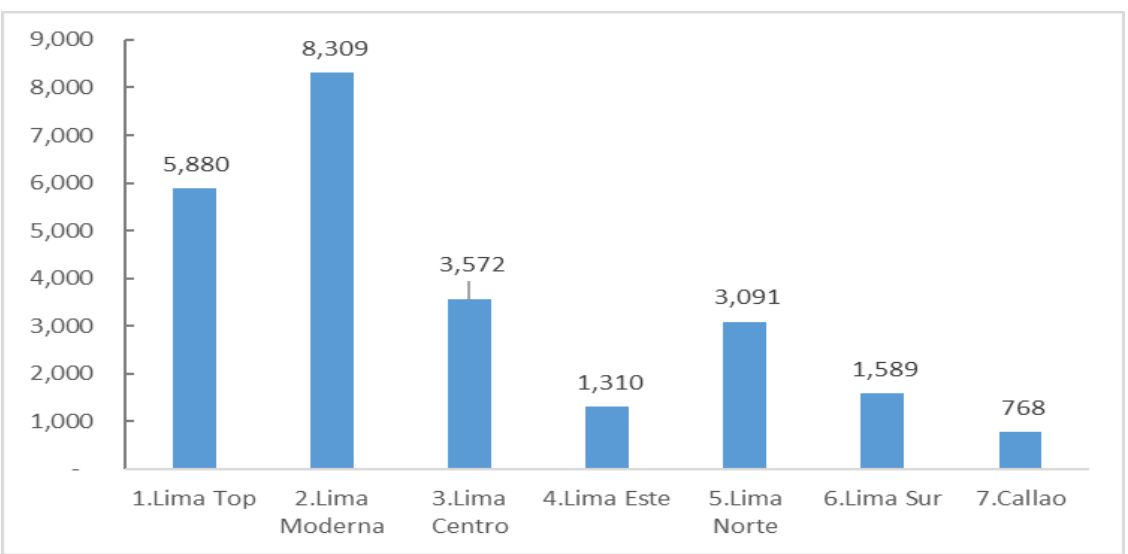

Figura 9. Oferta total de vivienda según sector urbano. Tomado de CAPECO.

Entre los sectores urbanos tenemos :

- Lima Top: Miraflores, San Isidro; La Molina, Santiago de Surco, San Borja,

Barranco

- Lima Moderna: Jesús María, Lince, Magdalena del Mar, San Miguel, Pueblo Libre, Surquillo

- Lima Centro: Cercado de Lima, Breña, La Victoria, Rímac, San Luis

- Lima Este: Ate, Cieneguilla, Chaclacayo, Lurigancho, Santa Anita, El Agustino, San Juan de Lurigancho

- Lima Norte: Carabayllo, Cómas, Independencia, Los Olivos, Puente Piedra, San Martín de Porres, Ancón, Santa Rosa

- Lima Sur: Chorrillos Lurín, Pachacámac, San Juan de Miraflores, Villa El Salvador, Villa María del Triunfo, Pucusana, Punta Hermosa, Punta Negra, San Bartolo, Santa María del Mar

- Callao: Bellavista, Callao, Carmen de la Legua, La Perla, La Punta, Ventanilla 
El precio promedio por metro cuadrado mayor en todo Lima se encontró en Lima Top con S/. 7,010 por $\mathrm{m}^{2}$ seguida por Lima Moderna con S/. 5,187 por $\mathrm{m}^{2}$.

Tabla 8

Estructura de la oferta total de departamentos

\begin{tabular}{lrcrr}
\hline \multicolumn{1}{c}{ Sector Urbano } & Unidades & $\begin{array}{c}\text { Precio Medio } \\
\text { (S/. Soles) }\end{array}$ & $\begin{array}{c}\text { Área } \\
\text { Promedio } \\
\mathbf{m}^{\mathbf{2}}\end{array}$ & $\begin{array}{c}\text { Precio por } \mathbf{~ m}^{\mathbf{2}} \\
(\mathbf{S} / \text {. Soles })\end{array}$ \\
\hline 1.Lima Top & 5,856 & 858,897 & 121.1 & 7,010 \\
2.Lima Moderna & 8,309 & 407,418 & 78.1 & 5,187 \\
3.Lima Centro & 3,572 & 275,376 & 65.2 & 4,214 \\
4.Lima Este & 1,299 & 221,750 & 71.6 & 3,125 \\
5.Lima Norte & 2,723 & 141,260 & 65.3 & 2,141 \\
6.Lima Sur & 1,589 & 279,247 & 72.0 & 3,765 \\
7.Callao & 768 & 209,091 & 62.4 & 3,353 \\
\hline Total & $\mathbf{2 4 , 1 1 6}$ & $\mathbf{4 4 2 , 6 7 6}$ & $\mathbf{8 3 . 9}$ & $\mathbf{4 , 8 7 8}$ \\
\hline
\end{tabular}

Respecto a los tamaños de vivienda tipo departamentos, la mayor oferta se encontró en departamentos entre $71 \mathrm{~m}^{2}$ a $80 \mathrm{~m}^{2}$ con 5,106 unidades (20.83\%), seguido las viviendas entre $61 \mathrm{~m}^{2}$ a $70 \mathrm{~m}^{2}$ con 5,073 unidades $(20.69 \%)$ y en el rango entre $81 \%$ a $100 \mathrm{~m}^{2}$ con 4336 unidades y $17.68 \%$.

Se estima en 2,261,879 familias que conforman los demandantes potenciales. En cuanto a la demanda por nivel de estrato socioeconómico, la mayor demanda se encontró en el estrato medio con $37.44 \%$, seguido por el sector medio bajo con $32.15 \%$ y el estrato medio alto con $16.11 \%$.

Tabla 9

Distribución de los hogares según estrato socioeconómico

\begin{tabular}{lc}
\hline \multicolumn{1}{c}{ Estrato } & $\mathbf{\%}$ \\
\hline Alto & 5.20 \\
Medio Alto & 16.11 \\
Medio & 37.44 \\
Medio Bajo & 32.15 \\
Bajo & 9.10 \\
\hline Total & $\mathbf{1 0 0}$ \\
\hline \multicolumn{2}{c}{ Nota: }
\end{tabular}


La demanda efectiva se localizó en 473,730 familias, de las cuales el 50.71\% (240,228 familias) pertenece al estrato socioeconómico medio bajo, mientras que el $41.38 \%$ (196,034 familias) pertenece al estrato medio.

En cuanto a los precios de vivienda en función de la demanda efectiva, el $20.87 \%$ se ubica en rango de precio hasta de S/. 80,000.00, el 67.47\% se localiza entre S/ 80,001.00 a S/. 270,000, y un 1.66\% se única en más de S/. 270,000.00.

La demanda insatisfecha de acuerdo al estudio realizado se encontró en 473,730 familias de los cuales el $21.95 \%$ se concentra en viviendas de precios por debajo de S/. 80,000 , pero la mayor demanda se encuentra entre S/ 80,001.00 a S/. 390,000.00 con $77.72 \%$. (Confederación nacional de instituciones empresariales privadas (CONFIEP), 2016)

La esperada recuperación del sector inmobiliario para el 2017 se encontrará aplazada hasta el 2018. Este comportamiento se da en gran parte porque en los segmentos de viviendas y oficinas ha habido una desaceleración en la venta del stock de estas mismas sin alquilar.

A pesar de que en el año 2016 se esperaba que con el retiro del 25\% de las AFP existiera un impulso por la compra de viviendas, las personas terminaron invirtiendo en cancelar sus créditos hipotecarios.

Según la CAPECO (2016), su proyección de crecimiento anual de ventas de unidades de vivienda paso de ser del 5\% a mediados del 2016 al ser del 1\% a finales del 2016. El factor principal para esta desaceleración (el que ha sido confirmado por el sector privado, indicando que los números de CAPECO son optimistas) ha sido el que la Superintendencia de Banca y Seguros (SBS) haya promovido mayores restricciones para que el sub segmento población de clase $\mathrm{C}$ acceda a un crédito.

Respecto a la tasa de oficinas vacías actualmente se encuentra en un $27 \%$ sin embargo a finales del 2017 seguirá incrementándose hasta llegar al 30\%. (Benza, 2017). 


\subsubsection{Segmentación de la industria}

De acuerdo a la Clasificación Industrial Internacional Uniforme (CIIU) de todas las actividades económicas, el rubro del negocio pertenece a:

- Sección L: Actividades inmobiliarias

- División 68: Actividades inmobiliarias

- Grupo 618: Actividades inmobiliarias realizadas con bienes propios o arrendados

- Clase 6810: Actividades inmobiliarias realizadas con bienes propios o arrendados

De acuerdo al Reglamento Nacional de Edificaciones (RNE), las edificaciones están clasificadas como se muestra a continuación: 
Tabla 10

Clasificación de las edificaciones según el RNE

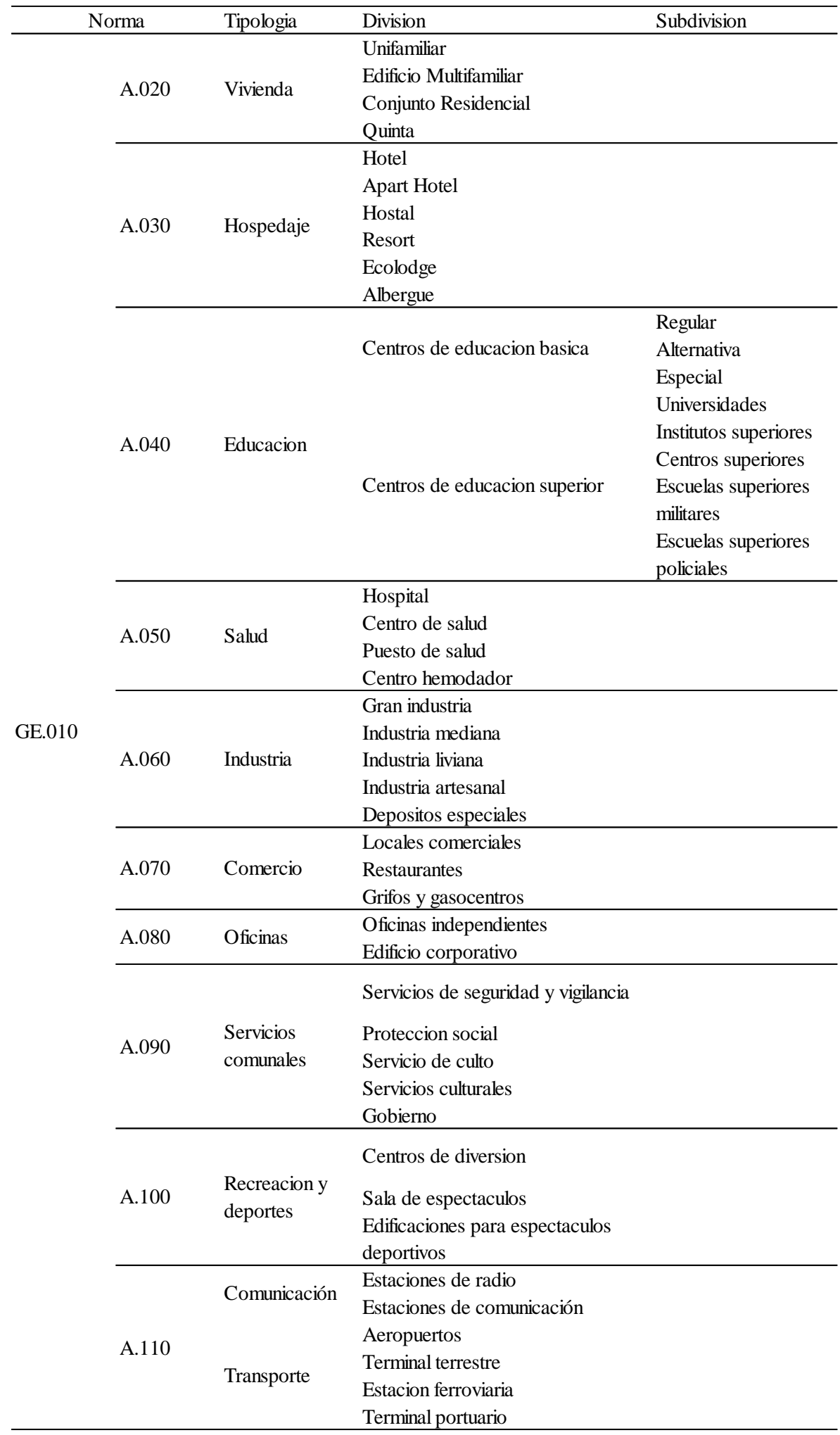

Nota. Recopilado de la Asociación de Desarrolladores Inmobiliarios del Peru http://www.adiperu.pe/ 


\subsubsection{Empresas que la conforman}

Son muchas las empresas que conforman este sector, sin embargo, de acuerdo a la Tabla 11 se muestran las principales en Lima y Callao.

Tabla 11

Principales Empresas Inmobiliarias a Nivel de Lima y Callao

\begin{tabular}{|c|c|c|c|c|}
\hline Razón Social & Dirección Fiscal & $\begin{array}{l}\text { Número de } \\
\text { Trabajadores }\end{array}$ & $\begin{array}{l}\text { Número de } \\
\text { proyectos a } \\
\text { la fecha }\end{array}$ & $\begin{array}{l}\text { Distritos de Lima y Callao en } \\
\text { los que tiene presencia }\end{array}$ \\
\hline Besco S.A.C. & $\begin{array}{l}\text { Av. Paseo de la } \\
\text { Republica } 3245 \text { int. 1101, } \\
\text { San Isidro }\end{array}$ & 153 & 4 & $\begin{array}{l}\text { La Perla, Callao, Chaclacayo, } \\
\text { Barranco }\end{array}$ \\
\hline Inversiones El Pino S.A.C. & $\begin{array}{l}\text { Av. Primavera 871, San } \\
\text { Borja }\end{array}$ & 129 & 1 & Chaclacayo \\
\hline Enacorp S.A & $\begin{array}{l}\text { Av. Jose Pardo } 231 \text { int. } \\
\text { 502, Miraflores }\end{array}$ & 18 & 3 & Carabayllo, Ate y Surco \\
\hline $\begin{array}{l}\text { Inversiones Centenario } \\
\text { S.A.A. }\end{array}$ & $\begin{array}{l}\text { Av. Victor Andres } \\
\text { Belaunde nro. } 147 \text {,San } \\
\text { Isidro }\end{array}$ & 197 & 7 & $\begin{array}{l}\text { Breña, San Miguel, Puente } \\
\text { Piedra, Callao, Cercado de } \\
\text { Lima y Ate }\end{array}$ \\
\hline Gerpal S.A.C. & $\begin{array}{l}\text { Av. Alfredo Benavides } \\
768 \text { dpto. } 1301, \\
\text { Miraflores }\end{array}$ & 83 & 2 & Cercado de Lima y Miraflores \\
\hline Cosapi Inmobiliaria S.A. & $\begin{array}{l}\text { Av. República de } \\
\text { Colombia 791, San Isidro }\end{array}$ & n.d. & 3 & Breña, Jesus Maria y Lince \\
\hline $\begin{array}{l}\text { Grupo Inmobiliario Caral } \\
\text { SAC. }\end{array}$ & Av. Arica 156, Barranca & n.d. & 3 & Ate, San Miguel, Magdalena \\
\hline Imagina Corp S.A.C. & $\begin{array}{l}\text { Av. del Pinar 134, } \\
\text { Santiago de Surco }\end{array}$ & n.d. & 14 & $\begin{array}{l}\text { San Miguel, Cercado de Lima, } \\
\text { Pueblo Libre, Lince, San } \\
\text { Isidro, Surquillo, Miraflores y } \\
\text { Barranco }\end{array}$ \\
\hline JJC Edificaciones S.A.C. & $\begin{array}{l}\text { Av. Alfredo Benavides } \\
768 \text { int. } 603 \text {, Miraflores }\end{array}$ & 34 & 2 & Miraflores \\
\hline $\begin{array}{l}\text { Lider Inversiones y } \\
\text { Proyectos S.A. }\end{array}$ & $\begin{array}{l}\text { Av. Manuel Olguín } 501 \\
\text { dpto. 1301, Santiago de } \\
\text { Surco }\end{array}$ & 231 & 5 & $\begin{array}{l}\text { Comas, San Martin de Porres, } \\
\text { Chaclacayo y San Juan de } \\
\text { Lurigancho }\end{array}$ \\
\hline $\begin{array}{l}\text { Constructores } \\
\text { Interamericano S.A.C. }\end{array}$ & $\begin{array}{l}\text { Av. La Molina 140, Santa } \\
\text { Anita }\end{array}$ & 309 & 3 & Callao y Breña \\
\hline Los Portales S.A. & $\begin{array}{l}\text { Jr. Mariscal La Mar 991, } \\
\text { Magdalena del Mar }\end{array}$ & 3517 & 4 & $\begin{array}{l}\text { Cercado de Lima, Chaclacayo, } \\
\text { San Miguel y Carabayllo }\end{array}$ \\
\hline Viva GYM S.A. & $\begin{array}{l}\text { Av. Petit Thouars } 4957 \text {, } \\
\text { Miraflores }\end{array}$ & 300 & 13 & $\begin{array}{l}\text { Ancón, Callao, Carabayllo, } \\
\text { Comas, San Martin de Porrres, } \\
\text { Villa el Salvador, San Miguel y } \\
\text { Miraflores }\end{array}$ \\
\hline $\begin{array}{l}\text { Wescon Desarrollo } \\
\text { Inmobiliario S.A.C. }\end{array}$ & $\begin{array}{l}\text { Av. Javier Prado Este } 560 \\
\text { int. 2301, San Isidro }\end{array}$ & 98 & 3 & $\begin{array}{l}\text { San Martin de Porres, } \\
\text { Carabayllo y Cercado de Lima }\end{array}$ \\
\hline Viviendas del Peru S.A.C. & $\begin{array}{l}\text { Av. República de } \\
\text { Colombia 791, San Isidro }\end{array}$ & 102 & 5 & $\begin{array}{l}\text { Miraflores, Jesus Maria, Pueblo } \\
\text { Libre y San Miguel }\end{array}$ \\
\hline
\end{tabular}

Nota. Recopilado de la Asociación de Desarrolladores Inmobiliarios del Peru http://www.adiperu.pe/ 


\subsection{Tendencias de la industria}

Según lo indicado por el presidente ejecutivo de la consultora Total Market Solutions (TMS), Solon King (2017), Jesús María y Pueblo Libre, son los distritos que presentan mayor demanda y oferta en la industria inmobiliaria. En estos distritos los precios se elevarían entre un $2 \%$ y $3 \%$. En los años venideros habrá una gran demanda insatisfecha primordialmente en los sectores socioeconómicos C y D. Sin embargo, también crecerá la demanda de la clase media, y las empresas constructoras ofrecerán productos para satisfacer este sector.

Por su parte Mijalou Davalos (2017) indicó, que de los proyectos multifamiliares el $70 \%$ de los ofertados tienen entre 100 y 150 departamentos, mientras que un $25 \%$ son proyectos de menos de 100 departamentos y que solo un $5 \%$ son de más de 150 departamentos.

Cabe resaltar que en los últimos años el área de los departamentos ha venido reduciéndose, la razón principal ha sido por el incremento de los precios por metro cuadrado, con la finalidad de que aun sigan al alcance de los compradores se reduce el área para mantener el precio de venta total. Esto se ha registrado en especial en distritos como Barranco, San Isidro, Santiago de Surco y San Borja. Por otro lado, la oferta de unidades inmobiliarias del tipo departamentos de uno y dos viene expandiéndose.

La expansión de clase media y la gran demanda insatisfecha promoverá en un mediano plazo el crecimiento del mercado inmobiliario.

\subsection{Análisis Estructural del Sector Industrial}

Este análisis se realizó mediante el modelo de las Cinco Fuerzas de Porter, que es un modelo que permite crear estrategias en diversas industrias. La competencia es más agresiva en industrias de bajas ganancias. Según Porter, en una industria, la esencia de la competitividad estaría conformada por cinco fuerzas: Amenazas de nuevos competidores, 
amenazas de productos sustitutos, poder de negociación de los consumidores, poder de negociación de los proveedores, rivalidad entre competidores. (David, 2013)

\subsubsection{Amenaza de nuevos competidores}

Hay la probabilidad de que nuevas empresas ingresen fácilmente a un mercado en particular y por lo tanto hacen que la intensidad de la competencia aumente. Para ello aparecen barreras que pueden incluir la obtención de tecnología y conocimiento, la falta de experiencia de los nuevos competidores, lealtad de los clientes, entre otros. A pesar de ello hay nuevas empresas que logran ingresar al mercado, ya sea por tener mejores precios de ventas, fuertes estrategias de marketing o productos de alta calidad. Esto constituye una amenaza para el proyecto ya que, a más oferta, existe más posibilidad de cambio o elección por parte del cliente.

En el proyecto de inversión esta fuerza se reflejaría en lo siguiente:

- Venta de terrenos por parte de propietarios para que las inmobiliarias compren y realicen nuevos proyectos en la zona.

- Surgimiento en la zona o alrededores de inmobiliarias de renombre, lo que podría dificultar las ventas.

- Terrenos en la zona de mayor área que puedan ser comprados por grandes inmobiliarias, lo que les permita dar un mejor producto en áreas comunes y hacer más atractivos sus proyectos. 
Tabla 12

Matriz de atractividad amenaza de nuevos competidores.

\begin{tabular}{|c|c|c|c|c|c|}
\hline & Amenaza de nuevos Competidores. & Si (+) & Medio & No ( - ) & Notas \\
\hline 1 & $\begin{array}{l}\text { ¿Las compañías de gran tamaño llevan } \\
\text { ventaja en cuanto al costo o el } \\
\text { rendimiento? }\end{array}$ & + & & & Respaldo económico y apalancamiento \\
\hline 2 & $\begin{array}{l}\text { ¿Hay diferencias en patentes en los } \\
\text { productos de la industria? }\end{array}$ & & & - & $\begin{array}{l}\text { Los productos en base a la necesidad del cliente } \\
\text { son similares }\end{array}$ \\
\hline 3 & $\begin{array}{l}\text { ¿Existen inmobiliarias con marcas } \\
\text { establecidas en el mercado? }\end{array}$ & + & & & Inmobiliarias estrategia de marketing solida \\
\hline 4 & $\begin{array}{l}\text { ¿De variar de proveedor los clientes } \\
\text { caerán en gastos significativos? }\end{array}$ & & $\mathrm{x}$ & & $\begin{array}{l}\text { Solo si ya están enganchados con algún } \\
\text { producto }\end{array}$ \\
\hline 5 & $\begin{array}{l}\text { ¿Se requiere mucha inversión para } \\
\text { ingresar en el mercado? }\end{array}$ & + & & & Financiamiento o capital propio \\
\hline 6 & $\begin{array}{l}\text { ¿En cuanto a los canales de distribución } \\
\text { el acceso es fácil? }\end{array}$ & & & - & Son bienes inmuebles \\
\hline 7 & ¿Existe curva de enseñanza? & + & & & $\begin{array}{l}\text { Mayor cantidad de años en el mercado mayor } \\
\text { experiencia }\end{array}$ \\
\hline 8 & $\begin{array}{l}\text { ¿Hay dificultad en acceder a gente } \\
\text { capacitada, materiales o insumos? }\end{array}$ & & & - & Los recursos se encuentran en el mercado \\
\hline 9 & $\begin{array}{l}\text { ¿El producto que ofrece tiene } \\
\text { características que lo hagan único? }\end{array}$ & & $\mathrm{x}$ & & $\begin{array}{l}\text { Depende de los objetivos que se tracen para la } \\
\text { comercialización }\end{array}$ \\
\hline 10 & $\begin{array}{l}\text { ¿Existen dificultad en la obtención de } \\
\text { licencias, certificaciones o pólizas? }\end{array}$ & + & & & $\begin{array}{l}\text { Licencia de construcción, estándares de } \\
\text { seguridad para la construcción, etc. }\end{array}$ \\
\hline 11 & $\begin{array}{l}\text { ¿Enfrenta el nuevo entrante la posibilidad } \\
\text { de contraataque por parte de las empresas } \\
\text { establecidas? }\end{array}$ & + & & & $\begin{array}{l}\text { Tienen ya estudiado el mercado, pueden mejorar } \\
\text { la oferta. }\end{array}$ \\
\hline
\end{tabular}

$6+\quad 2 \times \quad 3-\quad$ Es favorable a la atractividad de la industria

\subsubsection{Amenaza de Productos sustitutos}

El precio de venta de un producto se encuentra limitado por la presencia de productos sustitutos, ya que hasta cierto límite el consumidor estará dispuesto a pagar por el producto, luego de ello optará por cambiar a un producto sustituto. La competitividad que surge por la presencia de los productos sustitutos aumenta a medida que el precio de estos disminuye.

Las amenazas de productos sustitutos en el proyecto son: 
- $\quad$ Empresas que desarrollen productos de viviendas del tipo

arrendamiento o Alquiler- Venta de acuerdo a la Ley de Arrendamiento (DL

$\left.\mathrm{N}^{\mathrm{o}} 1177\right)$.

- $\quad$ Personas que ofrezcan departamentos de estreno como arrendamiento o

Alquiler- Venta de acuerdo a la Ley de Arrendamiento (DL No 1177).

Tabla 13

Matriz de atractividad amenaza de productos sustitutos.

\begin{tabular}{|c|c|c|c|c|c|}
\hline & Amenaza de productos sustitutos. & $\mathbf{S i}(+)$ & Medio & No ( - ) & Notas \\
\hline 1 & $\begin{array}{l}\text { Los sustitutos presentan restricciones } \\
\text { en cuanto al rendimiento que no } \\
\text { justifican su bajo costo, o en cuanto al } \\
\text { funcionamiento no se justifica por su } \\
\text { alto costo. }\end{array}$ & & $\mathrm{x}$ & & $\begin{array}{l}\text { Los precios se mantienen en el promedio, los } \\
\text { consumidores tienen la información al alcance. }\end{array}$ \\
\hline 2 & $\begin{array}{l}\text { El cliente incurre en costos al cambiar } \\
\text { un sustituto }\end{array}$ & & & - & $\begin{array}{l}\text { Por el contrario la garantía inicial es menor a la } \\
\text { cuota inicial }\end{array}$ \\
\hline 3 & $\begin{array}{l}\text { Su cliente no tiene un sustituto } \\
\text { verdadero }\end{array}$ & + & & & $\begin{array}{l}\text { Si lo hay sin embargo son sustitutos con } \\
\text { características similares mas no iguales }\end{array}$ \\
\hline \multirow[t]{2}{*}{4} & $\begin{array}{l}\text { Es improbable que el comprador alterne } \\
\text { a otro producto }\end{array}$ & + & & & $\begin{array}{l}\text { Es diferente un departamento alquilado que un } \\
\text { departamento propio }\end{array}$ \\
\hline & & $2+$ & $1 \mathrm{x}$ & $1-$ & Es favorable a la atractividad de la industria \\
\hline
\end{tabular}

\subsubsection{Poder de negociación de los consumidores}

Esta fuerza es más importante e intensa cuando los compradores están concentrados, o, si son un gran número. También aumenta el poder cuando el producto que se ofrece es estandarizado o no hay mucha diferencia. Para el caso del presente trabajo, debido a que existe la ventaja diferencial de la sostenibilidad para el primer proyecto, $\mathrm{y}$, siendo esta característica bastante novedosa en el sector, hace bastante atractivo al rubro.

En la industria este poder se puede manifestar en los siguientes puntos:

- Servicios específicos que busquen los compradores en los productos ofrecidos

(Piscina, áreas verdes, áreas de juego, espacios de reunión). 
- Los precios y características de los productos ofrecidos están publicados, lo que le permite al comprador poder comparar y escoger el producto que mejor le convenga y convenza.

Tabla 14

Matriz de atractividad Poder de negociación de los consumidores.

\begin{tabular}{|c|c|c|c|c|}
\hline Poder de negociación de los consumidores & Si (+) & Medio & No ( - ) & Notas \\
\hline $\begin{array}{ll}\text { ¿Existe un volumen grande de } \\
1 \text { consumidores en comparación al número } \\
\text { de competidores? }\end{array}$ & + & & & $\begin{array}{l}\text { La demanda es muy grande en } \\
\text { comparación a la oferta }\end{array}$ \\
\hline $\begin{array}{l}2 \text { ¿Su empresa tiene muchos compradores, } \\
\text { con consumes pequeños? }\end{array}$ & + & & & $\begin{array}{l}\text { Lo compradores usualmente buscan un } \\
\text { solo departamento }\end{array}$ \\
\hline $\begin{array}{l}\text { El cliente incurre en costos elevados al } \\
\text { cambiar por otro producto }\end{array}$ & & $\mathrm{x}$ & & $\begin{array}{l}\text { Es posible solo si ha separado su } \\
\text { departamento con un monto }\end{array}$ \\
\hline $\begin{array}{l}4 \text { ¿El comprador necesita mucha } \\
\text { información importante? }\end{array}$ & + & & & $\begin{array}{l}\text { Debe invertir tiempo en revisar las } \\
\text { características de los departamentos }\end{array}$ \\
\hline 5 ¿Puede el cliente integrarse hacia atrás? & & & - & El proceso es muy especializado \\
\hline 6 Sensibilidad de sus compradores & + & & & $\begin{array}{l}\text { Los precios por metro cuadrado son muy } \\
\text { similares }\end{array}$ \\
\hline $\begin{array}{l}\text { ¿Tiene su producto cierto grado de } \\
\text { particularidad o tiene ya una marca } \\
\text { reconocida en el mercado? }\end{array}$ & & & - & $\begin{array}{l}\text { Los productos en base a la necesidad del } \\
\text { cliente son similares }\end{array}$ \\
\hline \multirow{2}{*}{ (200m } & & & - & $\begin{array}{l}\text { Usualmente son personas dependientes } \\
\text { con sueldo sustentable }\end{array}$ \\
\hline & $4+$ & $2 x$ & $3-$ & $\begin{array}{l}\text { Es favorables a la atractividad de la } \\
\text { industria }\end{array}$ \\
\hline
\end{tabular}

\subsubsection{Poder de negociación de los Proveedores:}

Esta fuerza afecta en mayor frecuencia cuando existe un gran número de proveedores, cuando las materias primas sustitutas son limitadas o cuando el costo para cambiar a otra materia prima sustituta es alto. Se va haciendo más frecuente que los vendedores forjen alianzas estratégicas con proveedores con la finalidad de reducir costos de inventarios y logística, mejorar la capacidad de respuesta para la entrega de las materias primas, reducir los índices de defectos, y por supuesto forzar ahorros significativos en los costos. El poder de negociación de los proveedores para la industria en estudio se mostraría en: 
- Condiciones que pongan las entidades bancarias para financiar el proyecto, negoción de las tasas de interés.

- El manejo de los precios de los subproductos por parte de las empresas constructoras es muy reservado, ya que dependen no solo de los insumos en el mercado sino también de la productividad de la mano de obra y equipos.

\section{Tabla 15}

Matriz de atractividad Poder de negociación de los proveedores.

\begin{tabular}{|c|c|c|c|c|}
\hline Poder de negociación de los Proveedores. & $\mathbf{S i}(+)$ & Medio & No ( - ) & Notas \\
\hline $\begin{array}{l}1 \text { Las materias que utilizo son estándares más } \\
\text { que únicos o diferenciados }\end{array}$ & + & & & $\begin{array}{l}\text { De no haber un material de una marca } \\
\text { especifica se puede buscar uno similar a } \\
\text { en otra marca. }\end{array}$ \\
\hline $\begin{array}{l}\text { Cambiar de distribuidores no cuesta mucho } \\
\text { y no gasta demasiado tiempo }\end{array}$ & & $\mathrm{x}$ & & $\begin{array}{l}\text { Siempre que no se haya comenzado con } \\
\text { la construcción }\end{array}$ \\
\hline $\begin{array}{l}3 \text { Mis proveedores encuentran difícil entrar a } \\
\text { mi negocio. }\end{array}$ & + & & & La competencia es fuerte entre proveedores \\
\hline 4 Puedo cambiar los insumos realmente & + & & & $\begin{array}{l}\text { De no encontrar un insumo se puede } \\
\text { cambiar por uno similar }\end{array}$ \\
\hline 5 Tengo muchos proveedores potenciales & + & & & $\begin{array}{l}\text { Hay una gran cantidad de empresas } \\
\text { constructoras }\end{array}$ \\
\hline $6 \begin{array}{l}\text { Mi empresa es indispensable para mis } \\
\text { distribuidores }\end{array}$ & + & & & $\begin{array}{l}\text { Dependen de proyectos de edificación } \\
\text { para la supervivencia de sus negocios }\end{array}$ \\
\hline \multirow[t]{2}{*}{$\begin{array}{l}\text { Los costos de mis materias primas no } \\
7 \text { impactan de manera significativa en el total } \\
\text { de mis costos }\end{array}$} & & & - & $\begin{array}{l}\text { Si lo insumos tienen costo elevado eso } \\
\text { repercute directamente en el costo total }\end{array}$ \\
\hline & $5+$ & $1 \mathrm{x}$ & $1-$ & $\begin{array}{l}\text { Favorable a la atractividad de la } \\
\text { industria }\end{array}$ \\
\hline
\end{tabular}

\subsubsection{Rivalidad entre los competidores:}

Las estrategias de una empresa solo pueden tener éxito si estas les dan alguna ventaja sobre la competencia. Cambios de estrategias en una empresa puede traer consigo cambios de estrategia en la competencia como respuesta. La intensidad de la competencia aumenta a medida que aumentan los competidores, así también crece cuando los consumidores tienen la información para comparar precios. En el proyecto de inversión esta fuerza se reflejaría en lo siguiente:

-Las ofertas de viviendas, así como sus características están publicadas tanto en medios físicos como en medios virtuales. 
-Empresas que tienen mayor tiempo en el mercado, tienen mejores costos de sus proveedores por acuerdos comerciales.

Tabla 16

Matriz de atractividad Rivalidad entre competidores.

\begin{tabular}{|c|c|c|c|c|}
\hline Rivalidad entre competidores. & $\mathbf{S i}(+)$ & Medio & No ( - ) & Notas \\
\hline 1 La industria está creciendo rápidamente & + & & & $\begin{array}{l}\text { El sector inmobiliario se encuentra } \\
\text { en crecimiento }\end{array}$ \\
\hline $\begin{array}{l}\text { La industria no es rotacional y es } \\
\text { intermitente }\end{array}$ & & & - & \\
\hline $\begin{array}{l}\text { Los costos fijos son una pequeña } \\
\text { porción del costo total }\end{array}$ & + & & & $\begin{array}{l}\text { En comparación con los costos } \\
\text { directos variables }\end{array}$ \\
\hline $4 \begin{array}{l}\text { Existe grandes diferencias entre } \\
\text { productos con los competidores }\end{array}$ & & & - & $\begin{array}{l}\text { Los clientes buscan viviendas que } \\
\text { satisfagan su necesidad antes que } \\
\text { marca }\end{array}$ \\
\hline $\begin{array}{l}\text { La competencia se encuentra } \\
5 \text { diversificado más que apunten a un } \\
\text { producto especifico }\end{array}$ & & & - & Todos los productos son viviendas \\
\hline $\begin{array}{l}\text { No es complicado retirarse de la } \\
\text { industria ya que no existen prácticas } \\
\text { especializadas, servicios o contratos } \\
\text { largo plazo }\end{array}$ & & & - & $\begin{array}{l}\text { Existen normatividad que protege al } \\
\text { consumidor }\end{array}$ \\
\hline $\begin{array}{l}7 \text { El cliente incurre en costos elevados al } \\
\text { cambiar por otro producto }\end{array}$ & & $\mathrm{x}$ & & $\begin{array}{l}\text { Es posible solo si ha separado su } \\
\text { departamento con un monto }\end{array}$ \\
\hline $\begin{array}{l}\text { El producto no es fácil de comprender el } \\
8 \text { comprador necesita de información } \\
\text { detallada. }\end{array}$ & & & - & $\begin{array}{l}\text { El producto final se acomoda al } \\
\text { entendimiento del cliente }\end{array}$ \\
\hline \multirow[t]{2}{*}{9 e } & & & - & $\begin{array}{l}\text { Muchos son de mayor tamaño que } \\
\text { la nuestra }\end{array}$ \\
\hline & $2+$ & $1 \mathrm{x}$ & $6-$ & $\begin{array}{l}\text { Es desfavorable a la atractividad } \\
\text { de la industria }\end{array}$ \\
\hline
\end{tabular}

A modo de resumen, en la siguiente figura, se puede apreciar cómo las cinco principales fuerzas de Porter definirán la atractividad del sector, según a lo analizado por cada una de ellas: 


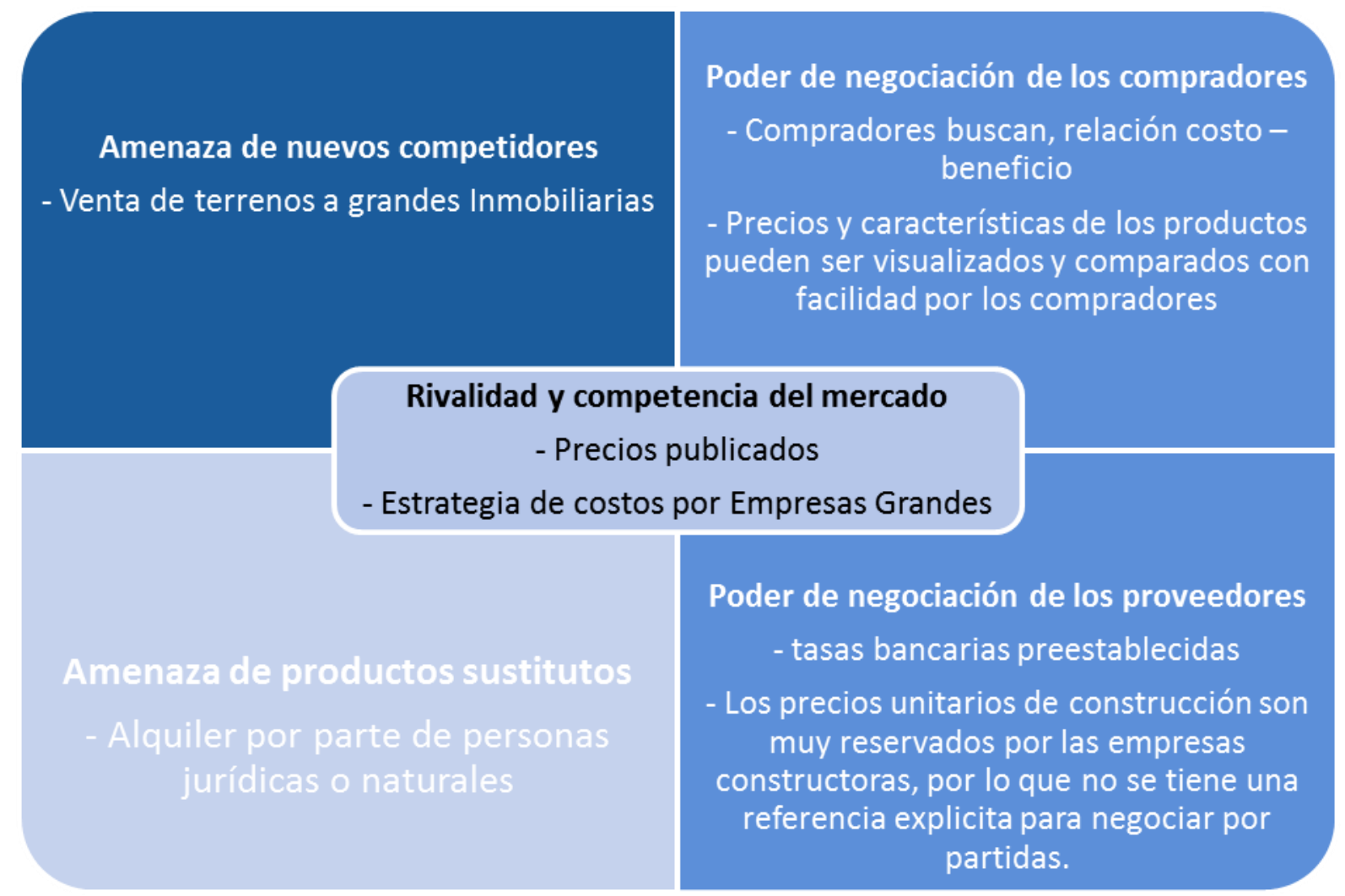

Figura 10. Diagrama de las cinco fuerzas de Porter para el análisis de sector.

\subsection{Análisis de la Competencia}

\subsubsection{Empresas que of recen el mismo producto o servicio}

Se realizó una búsqueda de las empresas que ofrecen unidades de departamentos en la zona de influencia del proyecto (distrito de Magdalena y distritos aledaños) y se listan a continuación en la Tabla 17. 
Tabla 17

Empresas con proyectos en la zona de influencia

\begin{tabular}{|c|c|c|c|c|c|c|}
\hline Razón Social & Proyecto & Distrito & Pisos & Unid & $\begin{array}{l}\text { A. Min. } \\
\text { (m2) }\end{array}$ & $\begin{array}{c}\text { A. } \\
\text { Máxima } \\
(\mathrm{m} 2)\end{array}$ \\
\hline Grupo T\&C & Varela & Breña & 10 & 89 & 40 & 74 \\
\hline Grupo T\&C & NEOCITY & Pueblo Libre & 19 & 76 & 71 & 145 \\
\hline Marcan & Tandem & Pueblo Libre & 16 & 212 & 33.51 & 104.24 \\
\hline Plenium Inmobiliaria & Diana & Pueblo Libre & 20 & 146 & 75 & 96 \\
\hline EF Grupo Inmobiliario & Urban Tower & Pueblo Libre & 20 & 72 & 50.78 & 119.75 \\
\hline EF Grupo Inmobiliario & Neo Tower & $\begin{array}{l}\text { Magdalena del } \\
\text { Mar }\end{array}$ & 17 & 78 & 42 & 87 \\
\hline Edificaciones Inmobiliarias & Parque San Martin II & Pueblo Libre & 17 & 68 & 45 & 106 \\
\hline Edificaciones Inmobiliarias & Los Nogales & $\begin{array}{l}\text { Magdalena del } \\
\text { Mar }\end{array}$ & 8 & 32 & 58 & 89 \\
\hline Senda Inmobiliaria & Zentro & Jesus Maria & 20 & 136 & 55 & 83 \\
\hline Senda Inmobiliaria & Fly & Jesus Maria & 23 & 156 & 35 & 81 \\
\hline $\begin{array}{l}\text { Neovida Construcciones } \\
\text { SAC }\end{array}$ & $\begin{array}{l}\text { Residencial Santa } \\
\text { Elena }\end{array}$ & $\begin{array}{l}\text { Magdalena del } \\
\text { Mar }\end{array}$ & 11 & 25 & 57.6 & 120 \\
\hline Inveb Inmobiliaria & $\begin{array}{l}\text { Urban Collection } \\
\text { Magdalena }\end{array}$ & $\begin{array}{l}\text { Magdalena del } \\
\text { Mar }\end{array}$ & 10 & 81 & 55.44 & 143.02 \\
\hline HPC inmobiliaria & Ocean Illari 2 & $\begin{array}{l}\text { Magdalena del } \\
\text { Mar }\end{array}$ & 17 & 74 & 51.29 & 87.6 \\
\hline HPC inmobiliaria & Ocean Line & $\begin{array}{l}\text { Magdalena del } \\
\text { Mar }\end{array}$ & 20 & 74 & 62.15 & 96.17 \\
\hline Abril Grupo Inmobiliario & Abedul & $\begin{array}{l}\text { Magdalena del } \\
\text { Mar }\end{array}$ & 19 & 162 & 42.73 & 81.8 \\
\hline Grupo inmobiliario Mattings & Residencial Tenerife & $\begin{array}{l}\text { Magdalena del } \\
\text { Mar }\end{array}$ & 14 & 50 & 73.7 & 81.9 \\
\hline M\&W Construcciones SAC & Torre Brasil & $\begin{array}{l}\text { Magdalena del } \\
\text { Mar }\end{array}$ & 23 & 90 & 49 & 177 \\
\hline Home Lima & Las Palmas de Perla & $\begin{array}{l}\text { Magdalena del } \\
\text { Mar }\end{array}$ & 15 & 90 & 57.8 & 76.2 \\
\hline Grupo Caral & Coral Tower & $\begin{array}{l}\text { Magdalena del } \\
\text { Mar }\end{array}$ & 18 & 45 & 49.53 & 153.27 \\
\hline JVG Inmobiliaria & Residencial Saray & $\begin{array}{l}\text { Magdalena del } \\
\text { Mar }\end{array}$ & 10 & 36 & 58.21 & 59.73 \\
\hline Grupo Sol & $\begin{array}{l}\text { Residencial Las } \\
\text { Acacias }\end{array}$ & $\begin{array}{l}\text { Magdalena del } \\
\text { Mar }\end{array}$ & 9 & 35 & 64.3 & 99.12 \\
\hline Capac Asociados & Malecón Castilla 241 & $\begin{array}{l}\text { Magdalena del } \\
\text { Mar }\end{array}$ & 16 & 112 & 69.51 & 90.92 \\
\hline
\end{tabular}

Nota. Adaptado de http://www.adondevivir.com/ y http://urbania.pe/

Las empresas que se mencionan realizan proyectos inmobiliarios que se asemejan en tener acabados muy similares en cuanto a calidad y materialidad, sin embargo, la gran diferencia se da en la cantidad de unidades de departamentos que ofrecen y los servicios $u$ áreas adicionales que han incluido en cada proyecto. 
En primer lugar, hay empresas que realizan proyectos del tipo conjuntos residenciales, donde se realizan dos o más edificios en un mismo terreno y ofrecen productos adicionales como grandes espacios de áreas verdes, áreas de recreación para adultos y niños, gimnasio, piscina, terraza y área de parrillas, sala de reuniones, sala de cine. Estos proyectos se realizan en terrenos que son hasta 10 veces más grande que el terreno del proyecto.

GRUPO T\&C y Marcan son las empresas que desarrollan este tipo de proyectos en la zona.

En segundo lugar, se encuentran aquellas empresas que desarrollan proyectos del tipo multifamiliar que, a pesar de no tener grandes espacios de áreas verdes, incluyen dentro de sus proyectos de áreas de recreación como son salas de uso múltiples, sala de cines, terraza y áreas de parrillas, piscina. Entre las empresas tienen este tipo de proyectos en la zona están Plenium, EF grupo inmobiliario, Senda inmobiliaria, HPC inmobiliaria, Abril grupo inmobiliario, M\&W Construcciones SAC, Grupo Caral.

Finalmente están Edificaciones Inmobiliarias, Neovida Construcciones SAC, Inveb Inmobiliaria, Grupo inmobiliario Mattings, Homes Lima, JVG Inmobiliaria, Grupo Sol y Capac Asociados, que son empresas en las que los productos que ofrecen sus proyectos tienen áreas de recreación reducidas o nulas, estas últimas empresas son las desarrollan proyectos similares a los que desarrollara la actual empresa ya que, por las áreas reducidas de los terrenos, no permite realizar áreas comunes extensas.

\subsubsection{Participación de mercado de cada uno de ellos}

Con la información recabada de las unidades de departamentos ofrecidas por cada empresa, se realizó un cuadro en el que se puede apreciar la participación de estas empresas dentro del mercado en estudio. 


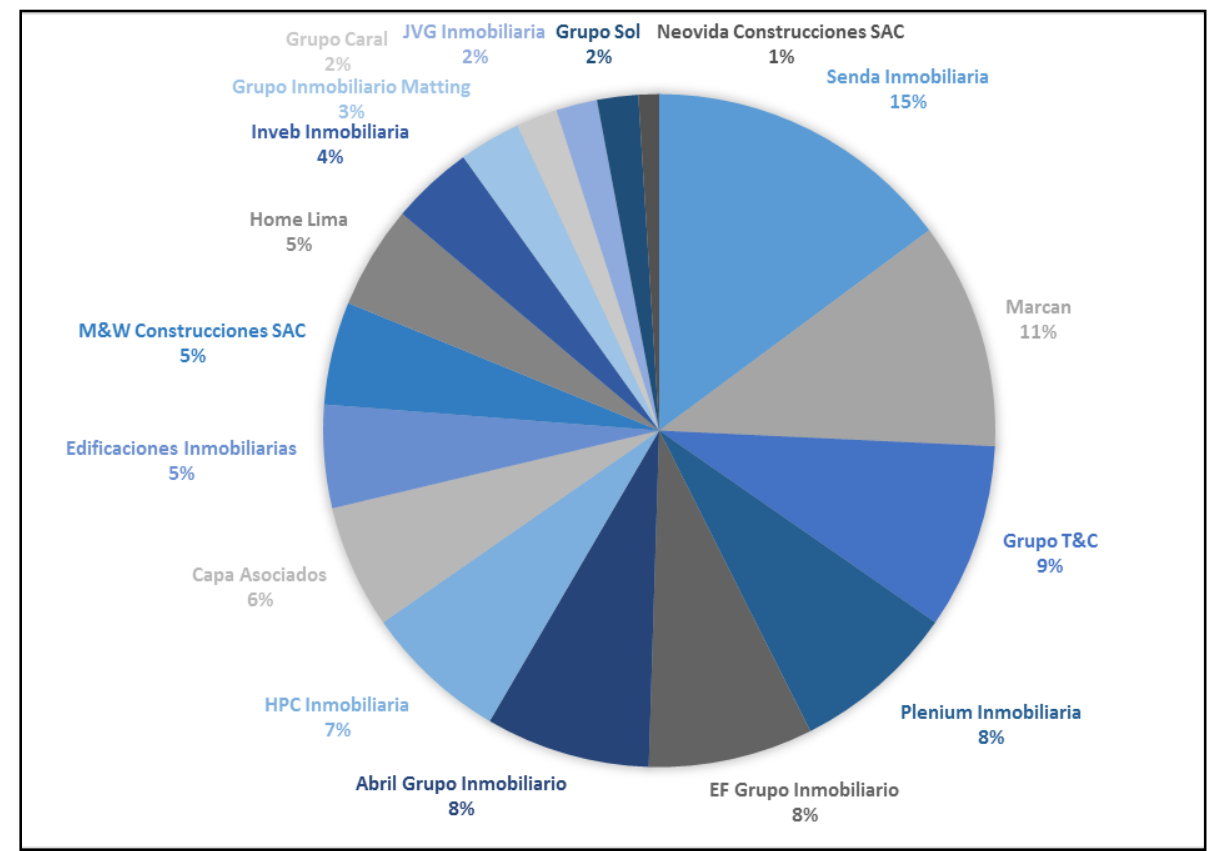

Figura 11. Participación en el mercado de las empresas inmobiliarias. Adaptado de http://www.adondevivir.com/, http://urbania.pe/

De acuerdo a la figura 11 se aprecia que las empresas que tienen mayor participación son Senda con 15\%, le sigue Marcan con 11\%, Grupo T\&C con 9\%, continuando entre $8 \%$ y $7 \%$ Plenium, EF grupo inmobiliario, Abril Inmobiliario y HPC. El resto presenta porcentajes relativamente más bajos. 


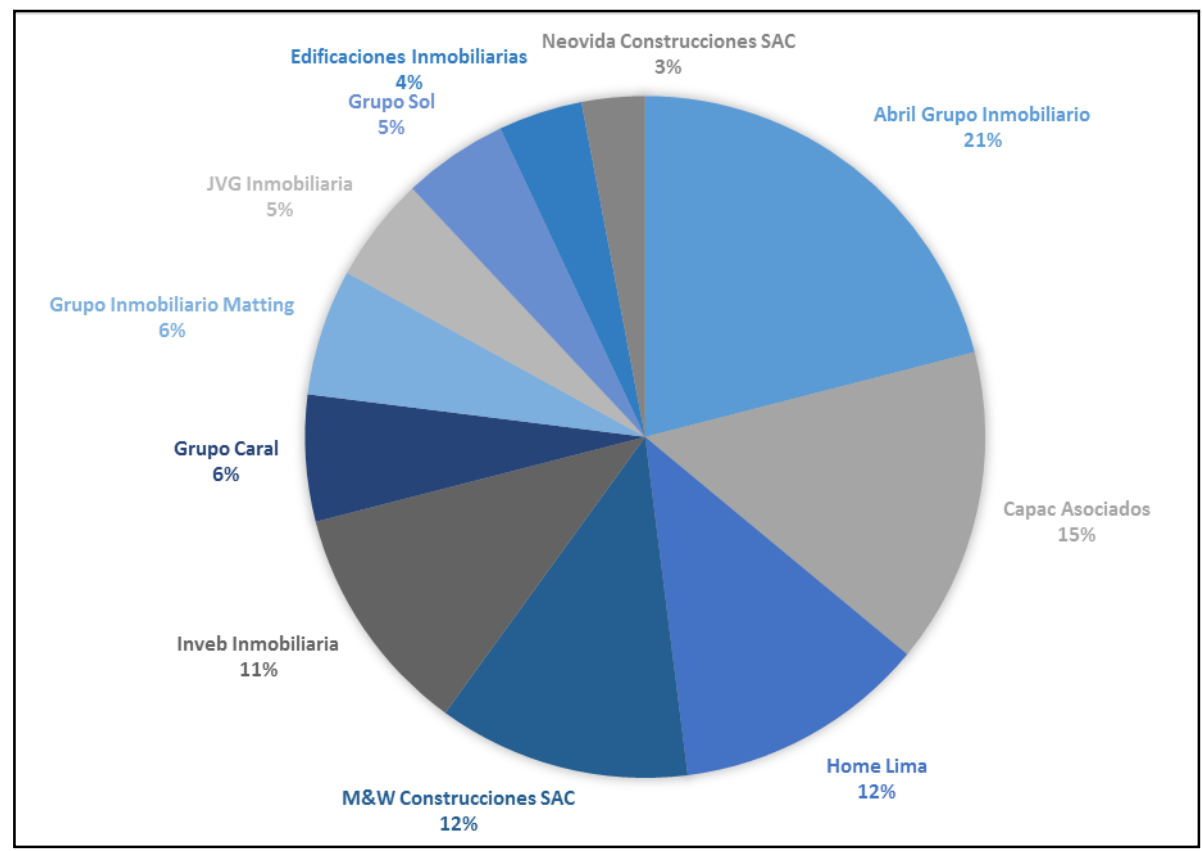

Figura 12. Participación de proyectos multifamiliares en la zona de influencia. Adaptado de http://www.adondevivir.com/, http://urbania.pe/

Si se analiza solo los proyectos del tipo multifamiliares y que se encuentran en la zona de influencia, como muestra en la figura 12, podemos notar que el mercado se reparte más equitativamente, liderando la partición en el mercado Abril Grupo inmobiliario, seguido por Capac asociados, M\&W construcciones, Home Lima e Inveb inmobiliaria.

\subsubsection{Matriz de perfil competitivo}

Esta matriz nos sirve de guía para poder identificar cuáles son los principales factores críticos de fortaleza de cada uno de nuestros competidores. 
Tabla 18

Matriz de perfil competitivo entre las empresas con proyectos en la zona de influencia

\begin{tabular}{|c|c|c|c|c|c|c|c|c|c|c|c|c|c|}
\hline \multirow{2}{*}{ Peso } & \multicolumn{2}{|c|}{$\begin{array}{c}\text { Calidad del } \\
\text { producto } \\
25 \%\end{array}$} & \multicolumn{2}{|c|}{$\begin{array}{c}\text { Estructura de la } \\
\text { organización } \\
10 \%\end{array}$} & \multicolumn{2}{|c|}{$\begin{array}{c}\text { Publicidad } \\
15 \%\end{array}$} & \multicolumn{2}{|c|}{$\begin{array}{c}\text { Competitividad } \\
\text { de precios } \\
25 \% \\
\end{array}$} & \multicolumn{2}{|c|}{$\begin{array}{c}\text { Participación } \\
\text { del mercado } \\
10 \%\end{array}$} & \multicolumn{2}{|c|}{$\begin{array}{c}\begin{array}{c}\text { Experiencia } \\
\text { en el rubro }\end{array} \\
15 \% \\
\end{array}$} & \multirow{2}{*}{$\begin{array}{c}\text { Puntaje TOTAL } \\
100 \% \\
\end{array}$} \\
\hline & Calif. & & Colif & Punt & Calif. & & Calif. & Punt & Colif & Punt & Calif & Punt & \\
\hline Grupo T\&C & 1 & 0.25 & 4 & 0.4 & 4 & 0.6 & 2 & 0.5 & 4 & 0.4 & 4 & 0.6 & 2.75 \\
\hline Marcan & 4 & 1 & 4 & 0.4 & 4 & 0.6 & 2 & 0.5 & 4 & 0.4 & 4 & 0.6 & 3.50 \\
\hline Plenium Inmobiliaria & 4 & 1 & 4 & 0.4 & 4 & 0.6 & 2 & 0.5 & 3 & 0.3 & 4 & 0.6 & 3.40 \\
\hline Senda Inmobiliaria & 4 & 1 & 3 & 0.3 & 4 & 0.6 & 1 & 0.25 & 4 & 0.4 & 3 & 0.45 & 3.00 \\
\hline Neovida Construcciones SAC & 3 & 0.75 & 3 & 0.3 & 1 & 0.15 & 4 & 1 & 1 & 0.1 & 1 & 0.15 & 2.45 \\
\hline Inveb Inmobiliaria & 4 & 1 & 3 & 0.3 & 2 & 0.3 & 4 & 1 & 1 & 0.1 & 1 & 0.15 & 2.85 \\
\hline HPC inmobiliaria & 4 & 1 & 3 & 0.3 & 3 & 0.45 & 2 & 0.5 & 3 & 0.3 & 3 & 0.45 & 3.00 \\
\hline Abril Grupo Inmobiliario & 4 & 1 & 4 & 0.4 & 4 & 0.6 & 1 & 0.25 & 3 & 0.3 & 4 & 0.6 & 3.15 \\
\hline JVG Inmobiliaria & 3 & 0.75 & 2 & 0.2 & 1 & 0.15 & 2 & 0.5 & 1 & 0.1 & 1 & 0.15 & 1.85 \\
\hline Grupo Sol & 3 & 0.75 & 2 & 0.2 & 1 & 0.15 & 4 & 1 & 1 & 0.1 & 1 & 0.15 & 2.35 \\
\hline Capac Asociados & 4 & 1 & 3 & 0.3 & 1 & 0.15 & 1 & 0.25 & 2 & 0.2 & 2 & 0.3 & 2.20 \\
\hline
\end{tabular}


Del análisis se visualiza que las empresas con mejor ratio de competitividad son Marcan y Plenium, seguidas por Abril, Senda y HPC. Esto se da básicamente porque además de no presentar denuncias según Instituto Nacional de Defensa de la Competencia y de la Protección de la Propiedad Intelectual (INDECOPI), tienen una fuerte estrategia de publicidad y manteniendo los costos de venta en el rango promedio.

En el caso de Empresas como Grupo T\&C, Grupo Caral, M\&W

Construcciones SAC, las denuncias presentadas por consumidores ante INDECOPI, hacen que el producto no sea tan competitivo.

En el caso de empresas como Grupo el sol, JVG inmobiliaria y edificaciones inmobiliarias, además de no tener mucha publicidad, sus costos están por encima del promedio, por lo que su calificación baja.

\subsection{Análisis del Contexto Actual y Esperado}

Existen seis fuerzas que conforman las oportunidades y definen las amenazas de la empresa y de todos los agentes que interactúan en un macroentorno. (Armstrong \& Kotler, 2013). Estas fuerzas son: político-gubernamental, económica, legal, cultural, tecnológica y ecológica.

\subsubsection{Análisis Político-Gubernamental}

Consiste en analizar las leyes, los organismos gubernamentales y los grupos de presión que influyen o limitan a las diversas organizaciones e individuos de una determinada sociedad (Armstrong\&Kotler, 2013).

En la actualidad se puede apreciar los siguientes sucesos políticosgubernamentales:

- El Estado autorizó destinar 174,978,053 soles a favor del Fondo Mivivienda para la ejecución del Bono Familiar Habitacional en las 
modalidades de Mejoramiento de Vivienda y Construcción en Sitio Propio (Larepublica.pe,2017)

- El ministerio de economía y finanzas (MEF), lanzará en dos semanas un nuevo paquete de medidas económicas que facilitarán las inversiones públicas y cofinanciadas, promoverá el empleo formal e incluirá un plan de vivienda a nivel nacional. (primerapaginaperu.com, 2017)

- El gobierno peruano promoverá la construcción de 90,000 viviendas en 2017 mediante los programas mi vivienda y techo propio para acceso a la casa propia.

\subsubsection{Análisis Económico}

El entorno económico está compuesto por los factores que afectan al poder adquisitivo de los consumidores y a su comportamiento para gastar. Existen países que tienen una economía de subsistencia, en la que los pobladores consumen lo que producen para subsistir. Por otro lado, están los países de economías industriales, constituidos por los mercados para una variedad grande de bienes. Existen principales variables como son los ingresos, los egresos, los tipos de interés, los patrones de ahorro y endeudamiento. (Armstrong \& Kotler, 2013).

En el Perú, dentro de los sectores no primarios, el sector más dinámico es el de la construcción ya que, las actividades que este realiza, involucran muchas industrias afines y esto se asocia principalmente al desarrollo y crecimiento económico de un país. 


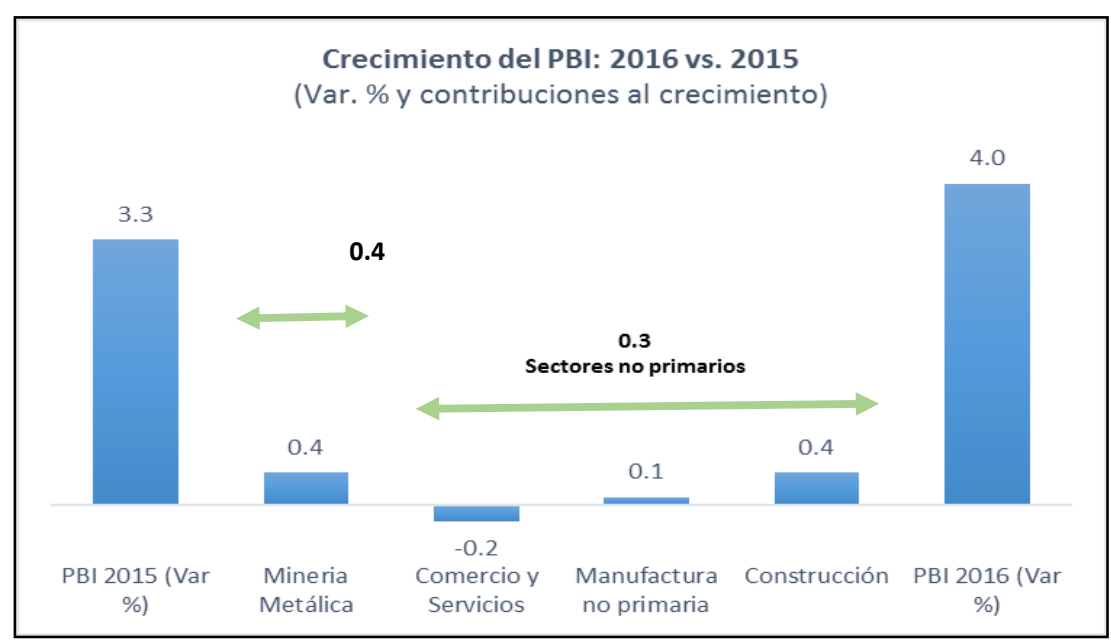

Figura 13. Crecimiento del PBI. Tomado de : Reporte de inflación diciembre 2016. Banco

Central de Reserva del Perú. http://www.bcrp.gob.pe/

Adicionalmente a esto cabe resaltar que, las empresas que se desarrollan en el sector construcción, no tienen una planta fija ni producen un mismo producto siempre. Los proyectos difieren uno de otro, sea por ubicación, metraje, número de departamentos, y muchas otras variables que convierten el mismo en un sector altamente productivo pero riesgoso. Pese a esto la recuperación de su crecimiento es notable en el siguiente gráfico:

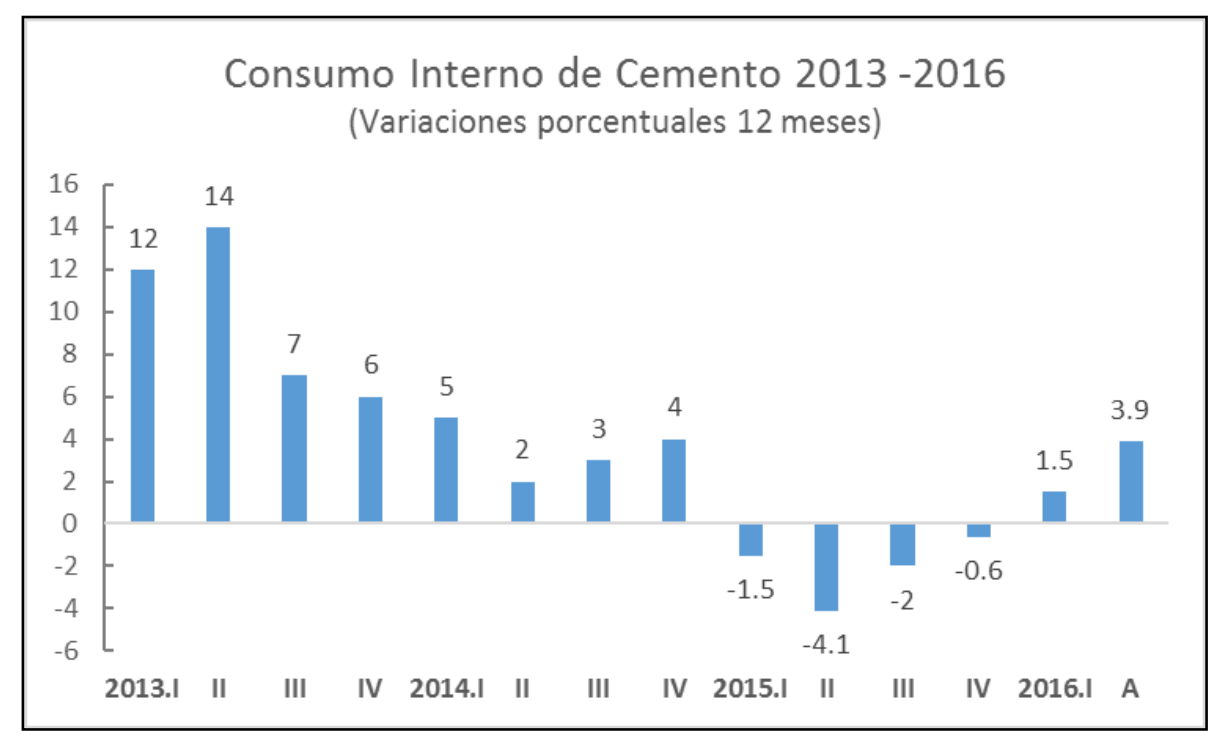

Figura 14. Consumo interno de Cemento 2013-2016. Reporte de inflación diciembre 2016. Banco Central de Reserva del Perú. http://www.bcrp.gob.pe/ 
La conjunción de factores macroeconómicos, representa una gran oportunidad para el sector construcción, en donde la reactivación de la economía mundial sumada a la demanda latente local, está marcando la tendencia de consumo dentro de nuestro país.

Según Córdova (2012), el creciente boom poblacional de la ciudad de Lima por el fenómeno de la centralización desde los 1990s ha ocasionado que más del 65\% de la población peruana se concentre en Lima, por ende, la urbanización acelerada de la capital ha dado pie a una demanda que se encuentra muy por encima de la oferta, exceptuando los casos de invasiones y hogares en viviendas precarias que no cuenta con las condiciones de vida básicas indispensables. Prueba de ello es el porcentaje de Producto Bruto Interno (PBI) nacional que se concentra en el departamento de Lima respecto de los demás departamentos del Perú.

Actualmente, existe un programa relacionado por tres entidades en el Perú, las cuales son el Estado y los sectores inmobiliario y financiero, que busca impulsar el acceso a la propiedad de una vivienda para los sectores más necesitados del país, mediante la institución del programa Mi vivienda, por la cual se otorgan créditos, subsidios y facilidades de pago para que la población tenga un mayor acceso a una casa propia y un mejor nivel de vida.

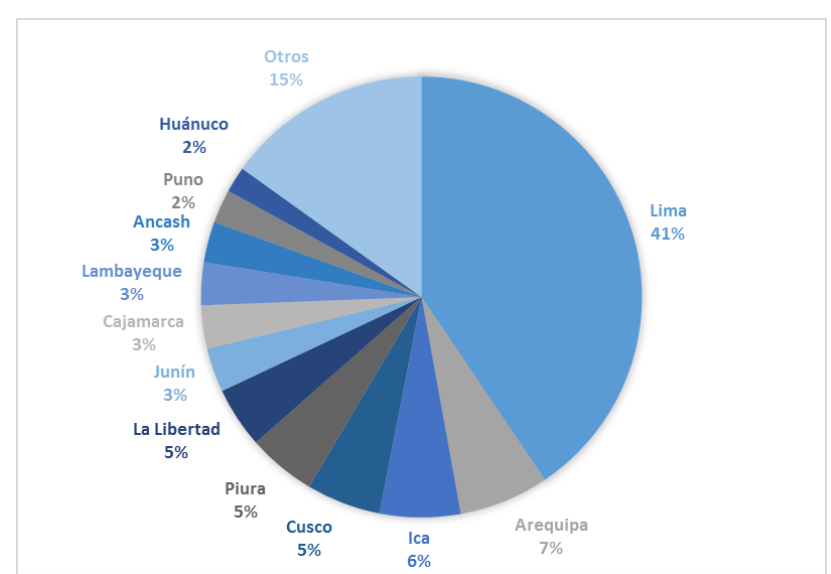

Figura 15. PBI por departamentos. Tomado de: INEI 
Además de esto, debido al crecimiento de las inversiones privadas en el Perú, el crecimiento económico lo acompañó dejando a la población un importante poder adquisitivo el cual reactivó la economía, creando oportunidades ideales para las nuevas familias y el crecimiento del nivel de vida.

En la actualidad el crecimiento del sector construcción es un hecho que no ha pasado desapercibido y las cifras lo respaldan (Instituto Nacional de Estadística e Información, 2016). A pesar que, en los últimos años, este crecimiento se ha dado de forma moderada, sigue representando una oportunidad de inversión debido básicamente al bajo nivel de demanda satisfecha en el mercado peruano.

Tabla 19

PBI por Sectores Económicos

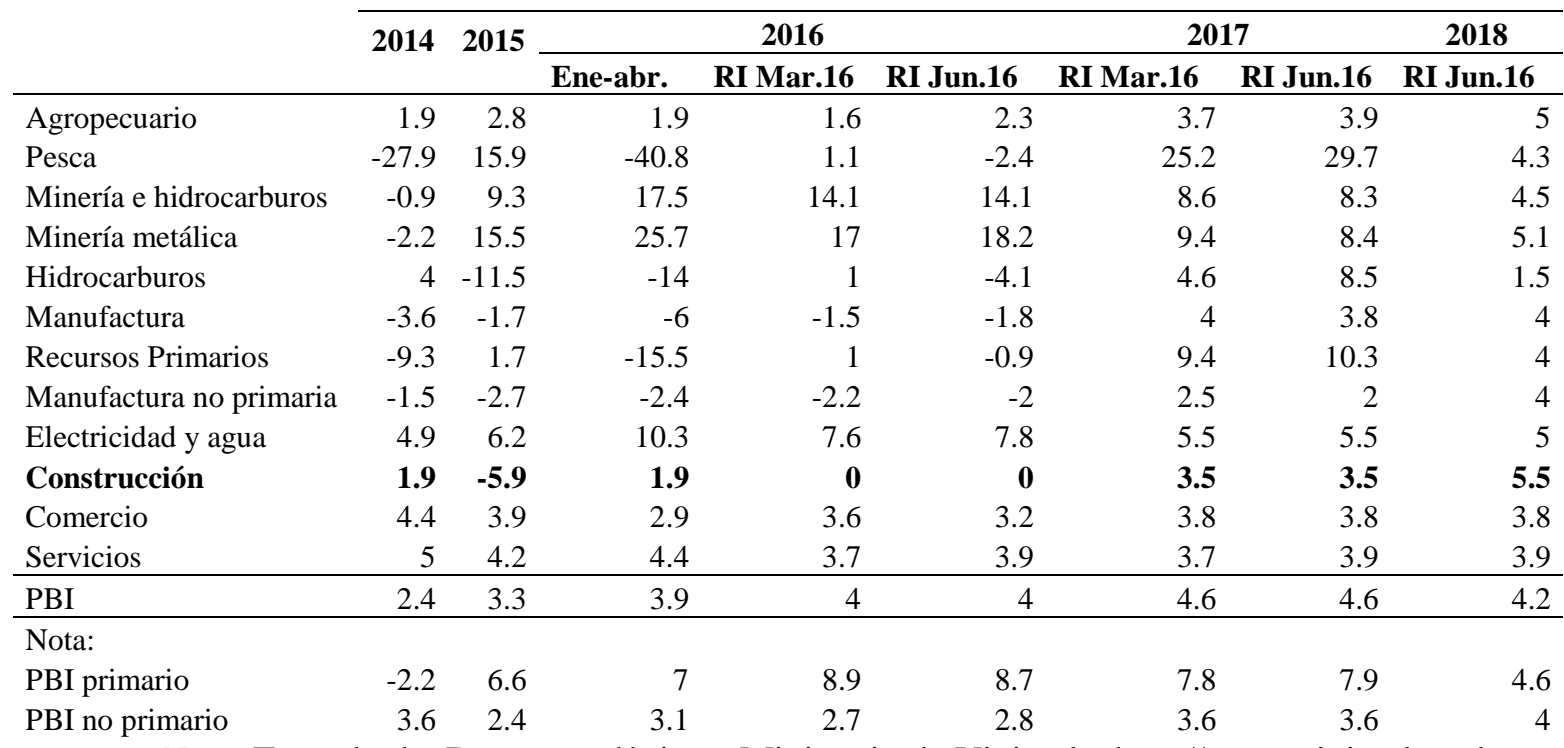

Nota. Tomado de: Datos estadísticos. Ministerio de Vivienda. http://www.vivienda.gob.pe

En la actualidad se resumen los siguientes sucesos económicos:

- El Riesgo país de Perú subió tres puntos básicos a 1.66 puntos porcentuales

(Gestion.pe, 2017c) 
- Perú ha registrado un déficit fiscal de $2.6 \%$ en base al producto bruto interno (PBI) en 2016, esta es la mayor brecha en 15 años (Gestion.pe, 2017a)

- El BCRP indicó que como proyección en el 2017 Perú presentaría un PBI de 4.3\%. Sin embargo, en febrero del 2017 El MEF modificó la proyección del producto bruto interno (PBI) reduciéndola de 5\% al 3.7\%. (voltairenet.org)

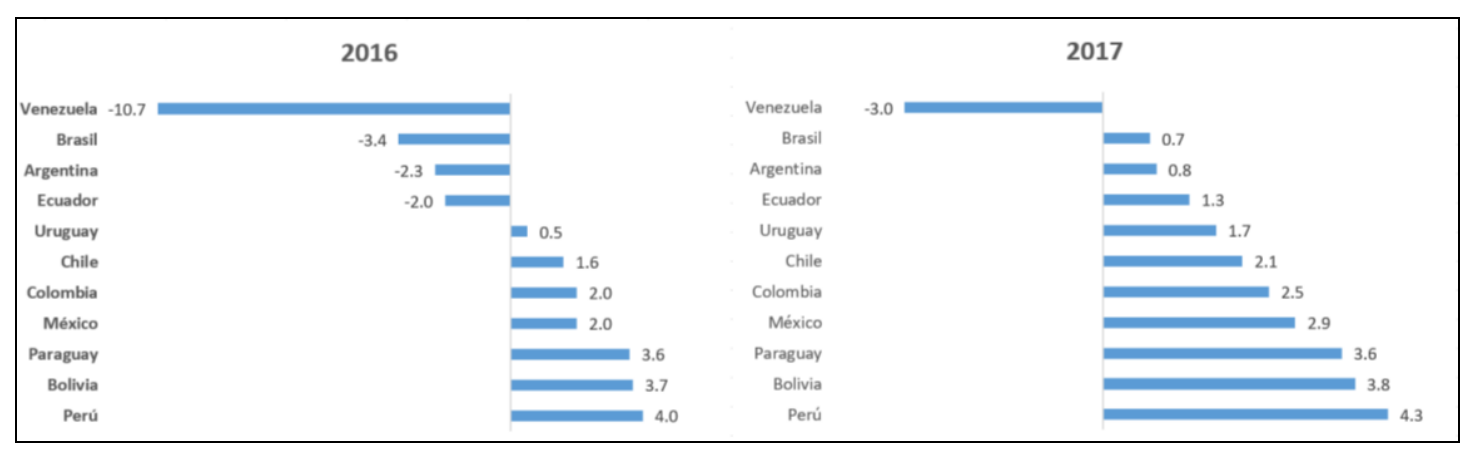

Figura 16. Crecimiento del PBI 2016-2017. Reporte de inflación diciembre 2016. Banco Central de Reserva del Perú. http://www.bcrp.gob.pe/

- $\quad$ Los precios de los materiales de construcción subieron 3,19\% el 2016. (elcomercio.pe, 2017)

- A octubre del 2016 el Índice de confianza del consumidor de Apoyo Consultoría para Lima Metropolitana fue de 51\%, disminuyendo así cinco puntos en comparación con el trimestre anterior (más de 50\% la perspectiva del consumidor es optimista, menos de 50\% es la percepción del consumidor es pesimista). (Gestion.pe, 2017e)

- De acuerdo a las proyecciones del BCRP en cuanto a la balanza comercial el superávit comercial ascendería a niveles de más de US\$2 mil millones por año, a causa del crecimiento de las exportaciones por mayores volúmenes y precios de commodities. 
Tabla 20

Balanza comercial 2015-2018

\begin{tabular}{|c|c|c|c|c|c|c|c|c|c|}
\hline \multicolumn{10}{|c|}{$\begin{array}{l}\text { BALANZA COMERCIAL } \\
\text { (Millones de US\$) }\end{array}$} \\
\hline & \multicolumn{2}{|c|}{2015} & \multicolumn{3}{|c|}{ 2016* } & \multicolumn{2}{|c|}{$2017 *$} & \multicolumn{2}{|c|}{ 2018* } \\
\hline & Ene. - Set. & ñ̃o & Ene. - Set. & RI Set. 16 & RI Dic. 16 & RI Set. 16 & RI Dic. 16 & RI Set. 16 & RI Dic. 16 \\
\hline $\begin{array}{l}\text { EXPORTACIONES } \\
\text { De las cuales: }\end{array}$ & 25,029 & 34,236 & 25,749 & 35,299 & 36,062 & 38,524 & 40,252 & 40,675 & 41,986 \\
\hline Productos Tradicionales & 17,124 & 23,291 & 18,109 & 24,871 & 25,371 & 57,628 & 29,265 & 29,091 & 30,200 \\
\hline Productos No Tradicionales & 7,840 & 10,857 & 7,572 & 10,328 & 10,598 & 10,793 & 10,902 & 11,476 & 11,695 \\
\hline $\begin{array}{l}\text { IMPORTACIONES } \\
\text { De las cuales: }\end{array}$ & 28,045 & $\mathbf{3 7 , 3 8 5}$ & 25,897 & 35,741 & 35,395 & 38,156 & 37,798 & 40,025 & 39,734 \\
\hline Bienes de consumo & 6,488 & 8,791 & 6,326 & 8,786 & 8,595 & 9,112 & 8,897 & 9,393 & 9,233 \\
\hline Insumos & 12,151 & 15,923 & 11,127 & 15,157 & 15,225 & 16,405 & 16,738 & 17,252 & 17,585 \\
\hline Bienes de capital & 8,975 & 12,007 & 8,230 & 11,426 & 11,297 & 12,580 & 12,269 & 13,297 & 13,061 \\
\hline BALANZA COMERCIAL & $-3,017$ & $-3,150$ & -148 & -442 & 667 & 367 & 2,454 & 649 & 2,252 \\
\hline
\end{tabular}

Nota. Reporte de inflación diciembre 2016. Banco Central de Reserva del Perú. http://www.bcrp.gob.pe/

- La tasa de interés de referencia hasta el cierre del reporte de inflación del BCRP a diciembre del 2016 se mantuvo en $4.25 \%$.

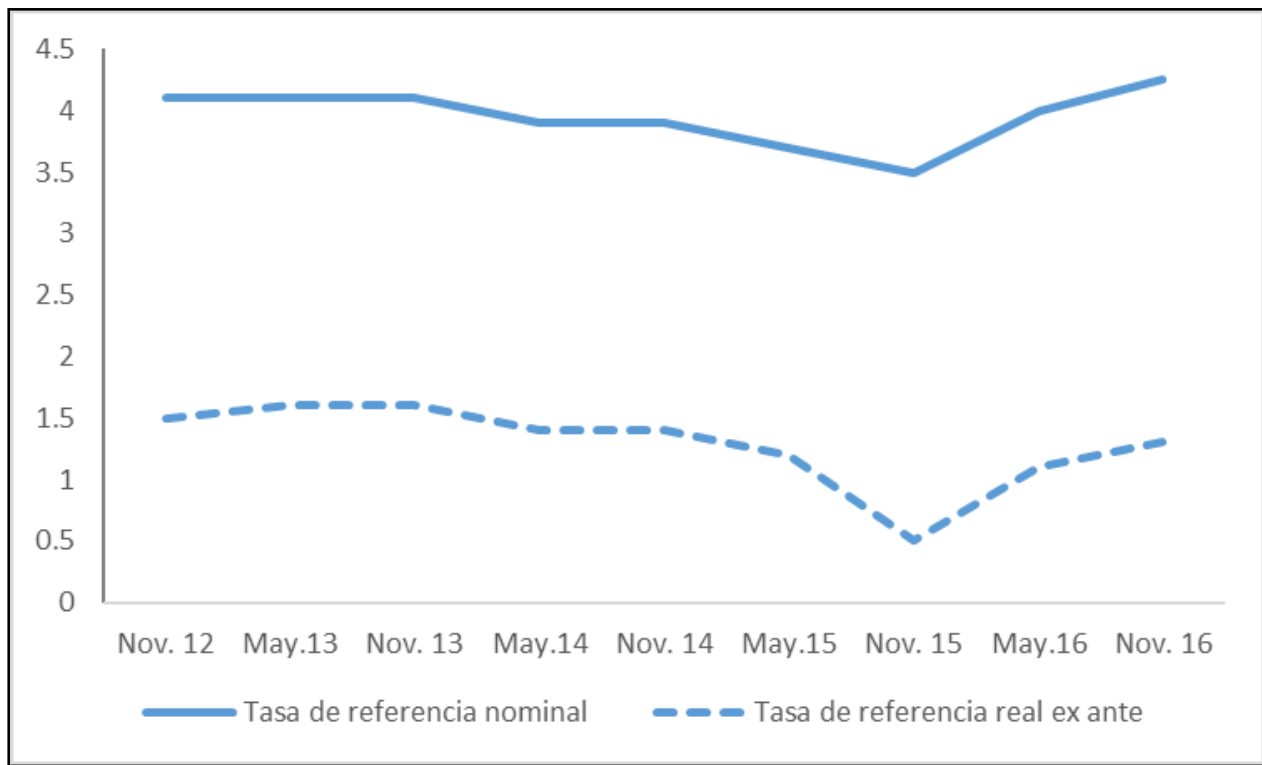

Figura 17. Tasa de interés de referencia nominal y real 2015-2016. Reporte de inflación diciembre 2016. Banco Central de Reserva del Perú. http://www.bcrp.gob.pe/

- Se proyecta que la inflación converja hacia 2\% entre los años 2017 y 2018, esto dado por el incremento inesperado de los precios de la energía y los alimentos. 


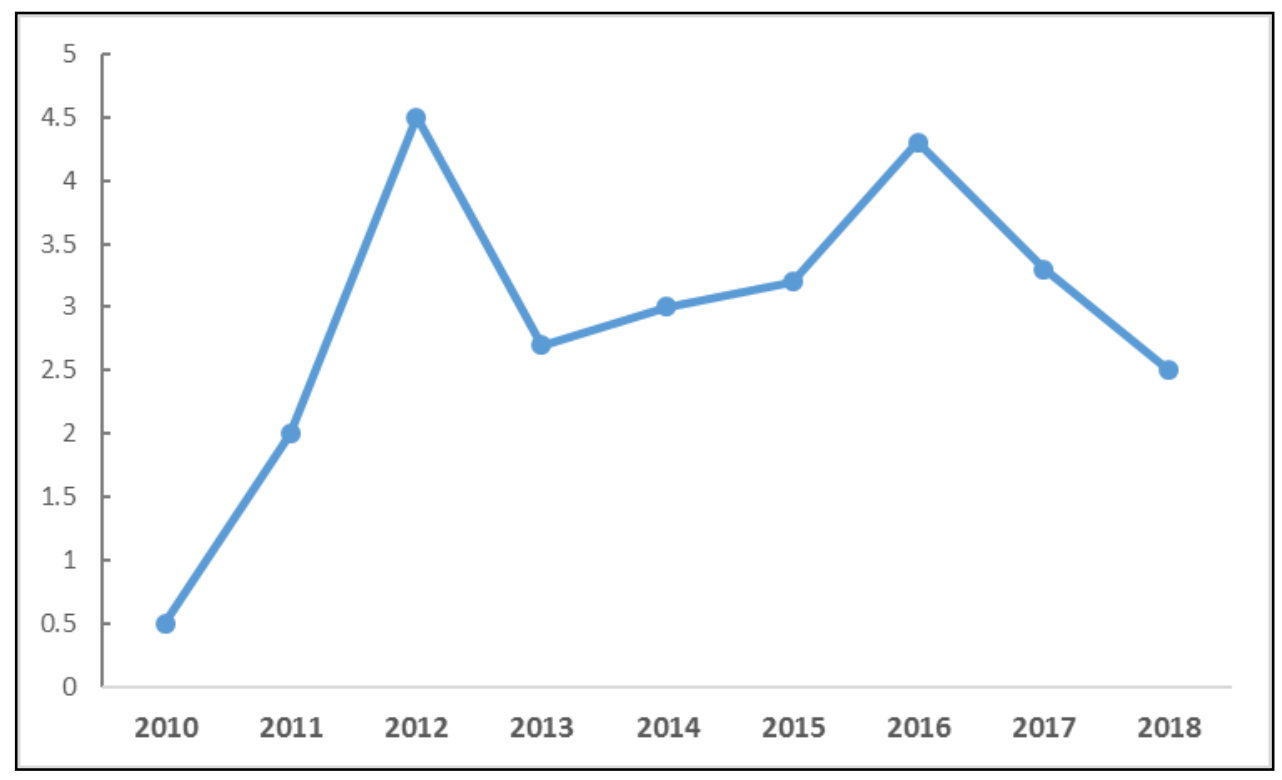

Figura 18. Proyección de la inflación 2010-2018. Reporte de inflación diciembre 2016.

Banco Central de Reserva del Perú. http://www.bcrp.gob.pe/

El tipo de cambio cerro al alza en el mes de febrero del 2017 a S/. 3.263 y de la misma manera durante la primera semana de marzo se ha mantenido la tendencia. (Gestion.pe, 2017b)

- La CAPECO y la Federación de Trabajadores en Construcción Civil del Perú (FTCCP) acordaron incrementar los salarios hasta en $4.78 \%$ como parte de la suscripción del Acta Final de Negociación Colectiva en Construcción Civil 20162017. (elperuano.com.pe, 2016)

\subsubsection{Análisis Legal}

Consiste en analizar las leyes y normatividad actual que rigen en nuestro entorno, tales como el código civil, los decretos supremos, las resoluciones ministeriales, resoluciones municipales, y reglamentos nacionales.

En el ámbito inmobiliario y de construcción, la normatividad que aplica es la siguiente: 
- $\quad$ Reglamento Nacional de Edificaciones, que es la norma técnica rectora y de aplicación obligatoria en el territorio nacional que establece los derechos y responsabilidades de los actores que intervienen en el proceso edificatorio. Tiene por objeto normar los criterios y requisitos mínimos para el diseño y ejecución de las habilitaciones urbanas y las edificaciones.

- $\quad$ Ley N 29090 - Ley de regulación de habilitaciones urbanas y de edificaciones y sus modificaciones, la cual tiene por objeto establecer la regulación jurídica de los procedimientos administrativos para la obtención de las licencias de habilitación urbana y de edificación.

- $\quad$ El cuatro de diciembre del 2009 se publicó la ley Na 29476, Ley que modifica y complementa la Ley núm. 29090, Ley de regulación de habilitaciones urbanas y de edificaciones

- $\quad$ El dos de agosto del 2016 se publicó la ley N³0494 que modifica la Ley 29090 de Regulación de Habilitaciones Urbanas y de Edificaciones, en la cual se establece como "barrera burocrática ilegal" a requerimientos adicionales a la norma. (RPP.pe, 2017)

- Mediante decreto legislativo se estableció reducir el impuesto general a las ventas (IGV) a partir del primero de julio del 2017 siempre que se alcance el 7.2\% del PBI al 31 de mayo del 2017 la recaudación anualizada del IGV total neto de sus devoluciones internas (Gestion.pe, 2017d)

- $\quad$ El 19 de marzo del 2016 se aprobó el Decreto Supremo Nº 003-2016TR que aprueba el Reglamento del Decreto Legislativo $\mathrm{N}^{\circ} 1187$, que previene y sanciona la violencia en la actividad de construcción civil (el peruano.com.pe, 2016) 


\subsubsection{Análisis Cultural}

Consiste en analizar las instituciones y las otras fuerzas que afectan los valores básicos, las percepciones de preferencias y las conductas de una sociedad. Las personas crecen en determinada sociedad que conforma sus creencias y sus valores básicos. (Armstrong \& Kotler, 2013).

En cuanto al análisis cultural se encuentra:

- $\quad$ El $60 \%$ del sector edificación es realizado por el autoconstrucción, lo que significa realizar una construcción sin un expediente técnico y sin ningún profesional que garantice un adecuado proceso. (larepublica.pe, 2016a)

- $\quad$ Por otro lado, en la actualidad las familias pobres que no tienen una propiedad comúnmente invaden terrenos, que finalmente por posesión el estado después de un tiempo termina dándoles los títulos de propiedad.

\subsubsection{Análisis Tecnológico}

Es probablemente el área de mayor impacto que está conformando nuestro destino en la actualidad. El entorno tecnológico cambia de manera rápida. Las nuevas tecnologías crean nuevos mercados y oportunidades. (Armstrong \& Kotler, 2013).

Respecto al aspecto tecnológico se observa que:

- Existe una tendencia en el aumento de la utilización de una metodología de trabajo llamada Building Information Modeling (BIM) o modelado de información en construcción. (elcomercio.pe, 2015).

\subsubsection{Análisis Ecológico}

El interés mundial en relación a los problemas ambientales como el calentamiento global y la contaminación del agua continúan creciendo se está dando cuenta de la relación entre una buena gestión ecológica y la economía de una empresa. (Armstrong \& Kotler, 2013). 
En el aspecto ecológico podemos indicar que:

- A junio del 2016 ya existen 31 edificios sostenibles (edificios verdes), y más 130 en proceso de construcción. (larepublica.pe, 2016b)

- En el 2015 se creó el Código Técnico de la Construcción Sostenible para promover esta en el sector público y privado. (elcomercio.pe, 2016)

\subsubsection{Análisis Demográfico}

Debido al crecimiento de la economía peruana, la población aumenta su poder adquisitivo y las tendencias de consumo varían de acuerdo a sus preferencias.

De la misma forma, en los últimos años, se ha podido apreciar una tendencia al consumo de departamentos, debido a lo anteriormente explicado en el capítulo 1, la población migra a la capital, donde el crecimiento se ve forzado a realizarse de forma vertical, representando una oportunidad para el proyecto planteado. 


\subsection{Oportunidades y Amenazas}

Tabla 21

Matriz PESTE

Criterio

Incremento del salario de

1 Político -Gubernamental construcción civil hasta en $4.78 \%$

S/. 174,978,053.00 nuevos

2 Político-Gubernamental soles serán destinados para la ejecución del Bono Familiar Habitacional.

Ingreso de paquete de

3 Político-Gubernamental medidas económicas para promover un plan de vivienda a nivel nacional

El gobierno promoverá la construcción de 90,000

4 Político-Gubernamental los programas mi vivienda y techo propio

5 Económico

Riesgo país de Peru subió a $1.66 \%$

Peru Registró un déficit

6 Económico fiscal de $2.6 \%$, la mayor brecha en 15 años

Proyección del crecimiento

7 Económico económico paso de $5 \%$ a $3.7 \%$

Precios de los materiales de

8 Económico construcción subió $3.16 \%$ en el 2016

Reducción del IGV a 17\% si y solo si la recaudación anual al 31 de mayo alcance el $7.2 \%$ del PBI

Modificación de la ley ${ }^{\circ}$ 29090 mediante ley ${ }^{\circ} 30494$

10 Legal en la que se establece como barrera burocrática ilegal a requerimiento adicionales a la norma

Oportunidad/Amenaza Comentario

Amenaza

Amenaza

Oportunidad

Oportunidad

Oportunidad

Amenaza

Amenaza

Amenaza

Oportunidad
Afecta al costo del producto por lo que se tendrá que reajustar los valores de venta para ser competitivo

Indirectamente generará una sensación de dinamismo en el mercado inmobiliario

Normas que ayudarán a facilitar las inversiones y promover la construcción de viviendas.

Incentivo por el apoyo del estado hacia el sector privado para incrementar la oferta de vivienda. Los consumidores tendrán mayores oportunidades para poder obtener una vivienda propia.

tendencia al incremento de los costos de créditos, así como también disminución de las facilidades de acceso a créditos bancarios para los consumidores.

Aumento de las tasas de interés para los consumidores. Generación de presiones inflacionarios, lo que tendera al aumento del precio de los materiales.

Aumento de la inflación, aumento de la tasa de desempleo y por lo tanto disminuye la capacidad adquisitiva de los consumidores

Afecta al costo del producto por lo que se tendrá que reajustar los valores de venta para ser competitivo

Esta medida causa incertidumbre tanto en la oferta como en la demanda ya que esta condicionada a una meta

Ayuda a destrabar los procedimientos y normatividades ya establecidas, poniendo un alto a requerimiento extraoficiales 
Aprobación del reglamento del decreto legislativo $\mathrm{n}^{\circ}$

11 Legal

12 Cultural

13 Ecológico

14 Ecológico

15 Demográfico

16 Demográfico
1187, se previene y sanciona Oportunidad la violencia en la actividad de la construcción civil

$60 \%$ de las edificaciones es realizado por la autoconstrucción

Amenaza

Al 2016 existen 31 edificios sostenibles y mas de 130 en proceso de construcción

Oportunidad

Creación del código técnico de la construcción sostenible en Perú

Oportunidad

Tendencia de la población a vivir en zonas urbanas de fácil acceso

Oportunidad

Aumento del poder adquisitivo del segmento objetivo
Estabiliza los costos incurridos por paz social, al tener mecanismo de respuesta contra la violencia en construcción civil

La informalidad siempre trae como consecuencia impactos negativos en el mercado formal porque la competencia es desleal, ya que este ultimo utiliza recursos como profesionales y un expediente elaborado por los cuales se paga un costo y además impuestos.

Es una oportunidad porque podemos rescatar la experiencia de los usuarios y realizar una mejora continua para optimizar los elementos necesarios para que un edificio sea sostenible

El tener una normatividad permite establecer parámetros limites que ayudan a determinar los requerimientos suficientes para que un edificio sea considerado sostenible. Ayuda a no incurrir en costos innecesarios.

Representa una oportunidad debido a que aumenta la demanda por vivir en una zona urbana de fácil acceso y que este rodeada de movimiento comercial, que cumple con las características donde se desarrollará el proyecto.

Es una oportunidad por el rango de precio de los inmuebles del proyecto, los cuales están dirigidos a un segmento con un poder adquisitivo medio - alto, con lo que aumenta el potencial de clientes objetivo. 


\section{Capítulo III: Estudio de Mercado}

La investigación de mercados consiste en identificar y analizar la información recopilada a fin de elegir la mejor alternativa y oportunidades de un negocio. (Malhotra, 2008).

En este capítulo se realizó el estudio del mercado para poder delimitar el mercado objetivo y estudiar la posibilidad y percepción de los potenciales consumidores con respecto al proyecto final.

\subsection{Descripción del servicio o producto}

La empresa inmobiliaria ofrece la venta de departamentos que van desde $60 \mathrm{~m}^{2}$ hasta $137 \mathrm{~m}^{2}$. Para ello se seleccionaron dos terrenos contiguos para realizar el edificio multifamiliar que contendrá dichos departamentos. Estos se encuentran ubicados en el Jr. Arequipa número 242 y 248, distrito de Magdalena del Mar, Lima Perú. De acuerdo a la partida registral de los terrenos tienen un área $170.07 \mathrm{~m}^{2}$ y $232 \mathrm{~m}^{2}$ respectivamente. La acumulación de los terrenos da como resultado un terreno único de $402.07 \mathrm{~m}^{2}$. Según el certificado de parámetros urbanísticos de los terrenos presentan una zonificación del tipo Residencial Densidad Alta (RDA) por lo que tienen uso compatible para realizar una vivienda multifamiliar, con frente mínimo de diez metros lineales, 24 metros lineales de altura y no necesita retiro frontal. El mismo certificado exige que por cada 1.5 departamentos, el edificio debe contar con un estacionamiento.

De acuerdo a la información obtenida del terreno, el proyecto cuenta con aproximadamente tres departamentos por piso en una altura de ocho pisos, sin embargo, en el primer piso solo existen dos departamentos, con lo cual da un total de 23 departamentos. En cuanto a los estacionamientos se tienen 12 en un semisótano y cuatro en el frontis del 
edificio, dando un total de 16 estacionamientos, estando este número por encima del exigible por la normatividad.

Así también se incluyó dentro del diseño, parámetros necesarios para que el edificio sea considerado como un edificio sostenible de acuerdo al Código Técnico de Construcción Sostenible aprobado mediante Decreto Supremo № 015-2015-VIVIENDA. Estos parámetros incluyen la utilización de tecnología led para todo lo referente en cuanto a la iluminación, utilización de aparatos sanitarios y griferías ahorradores, y el uso de materiales térmicos y acústicos para la construcción del edificio.

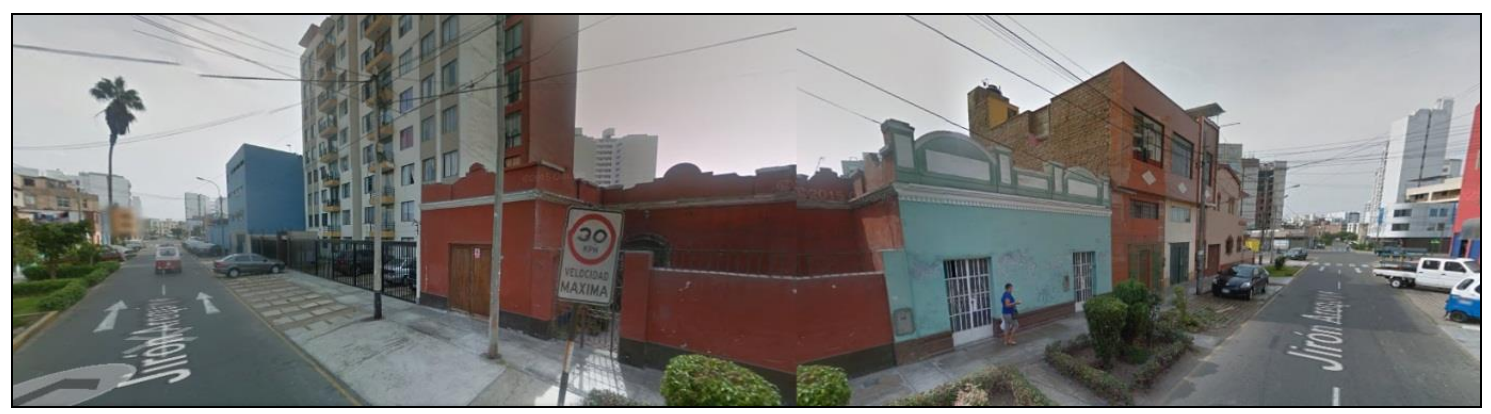

Figura 19. Foto Panorámica Situación Actual Del Terreno

Las vías de acceso aledañas al terreno que permite conectar a los distritos aledaños tales como San Miguel, Pueblo Libre, Jesús María, Miraflores, San Isidro son las siguientes:

- Av. La Marina

- Av. José Antonio de Sucre

- Av. Brasil

- Av. Javier Prado

- Circuito de playas 


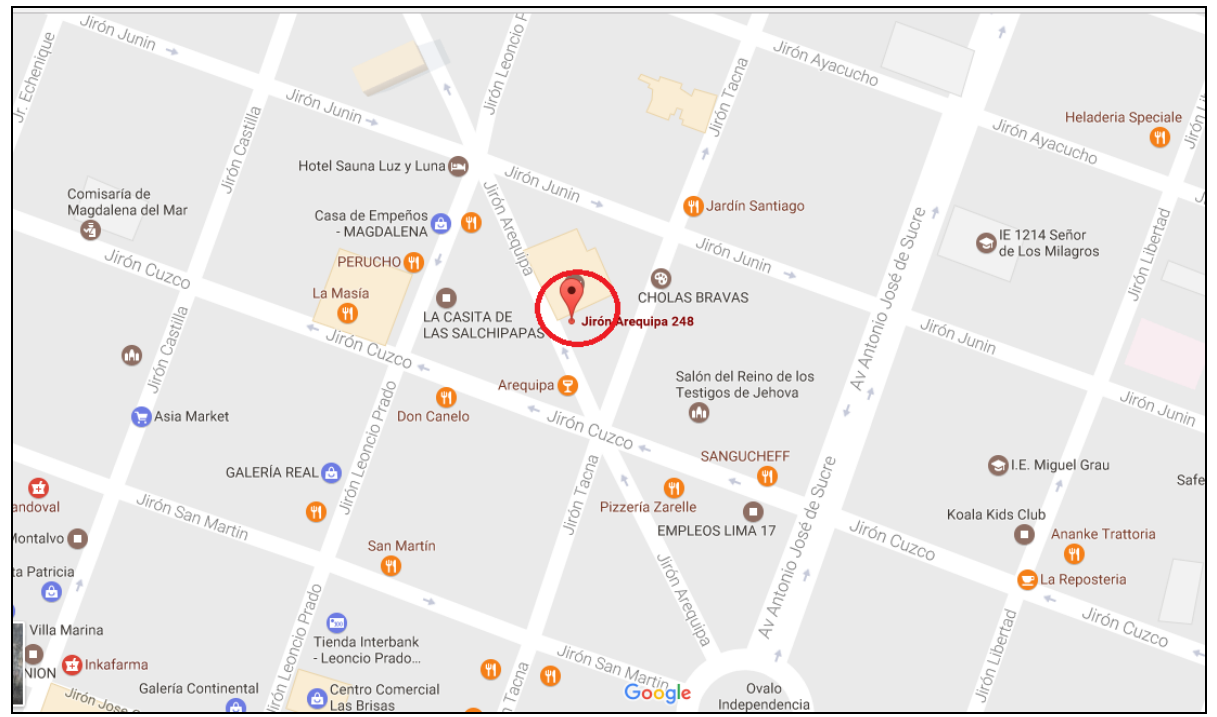

Figura 20. Mapa de ubicación del terreno. Tomado de Google Maps

Se procede a elaborar el perfil preliminar del proyecto, a fin de ver la factibilidad del mismo, considerando para ello todas las variables que intervienen en su desarrollo.

\subsection{Selección del segmento de mercado}

La segmentación del mercado es un proceso que consiste en dividir un mercado en sub mercados que asocien a distintos clientes que compartan necesidades afines. (Kotler $\&$ Armstrong, 2003). Para realizar la selección del segmento de mercado se analizó las siguientes variables según Kotler \& Lane, (2012):

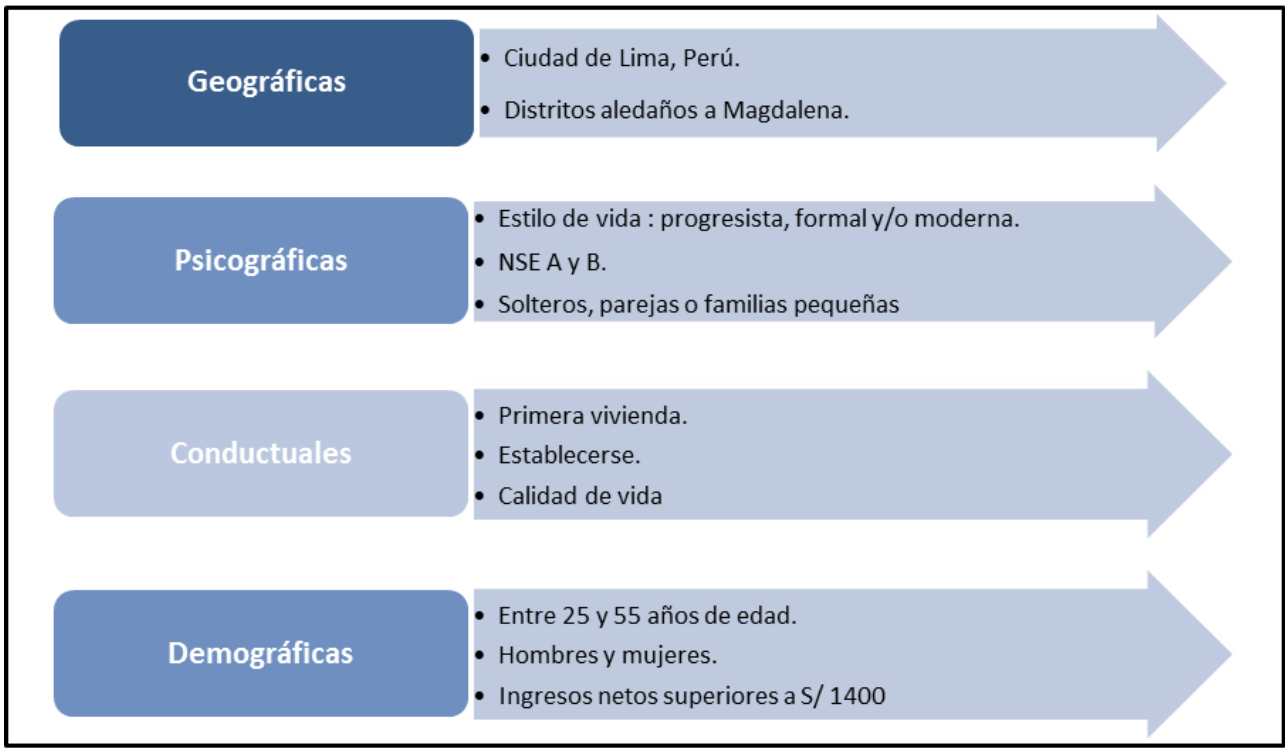

Figura 21. Segmentación del mercado 
Para las variables geográficas, se toma en cuenta el producto, que ya está delimitado dentro de la Ciudad de Lima en el distrito de Magdalena, es por esto que el segmento al que se puede seleccionar podría estar dentro de las zonas de influencia cercanas a este distrito.

Para las variables demográficas, para este producto es indistinto si el cliente es hombre o mujer. Se está delimitando la edad en función a la población económicamente activa para tener un ingreso mínimo del cliente y así evaluar su poder adquisitivo y acceso a la compra del producto. Además, también se encuentra en función del acceso al crédito hipotecario, tomando en cuenta la edad de permanencia máxima de 75 años (cubierto con seguro) con un rango de plazo de 20 años en promedio.

Para las variables psicográficas, según los estilos de vida de Arellano (2016), se toma en cuenta a los progresistas, los formales y las modernas quienes por sus características calzan dentro del segmento meta. Además, los Niveles Socios Económicos (NSE) se limitan al A y B, básicamente por el valor de la vivienda, la ventaja diferencial y su ubicación geográfica. En términos de espacio y características del producto, estará dirigido a solteros, parejas o familias pequeñas.

En el anexo se puede apreciar, de una manera más técnica, en la ficha de base para la segmentación las mismas variables delimitadas para el segmento meta.

\subsection{Investigación Cualitativa}

En la investigación cualitativa no se cuenta con orden definido para el análisis, y es del tipo exploratorio porque tiene como finalidad brindar información general, y opiniones en algunos casos, para analizar un problema específico, según Malhotra, (2008).

Según Benassini (2014), la investigación cualitativa es complementaria a la investigación secundaria (investigación hecha en base a la literatura científica fundada en criterios metodológicos y/o experimentales) y ayuda a tener una visión más clara y amplia del problema a investigar. 
El objetivo general de la investigación cualitativa para el proyecto es el de buscar información más amplia que permita evaluar diferentes aspectos para tomar en cuenta y lograr el éxito del mismo. A la vez también adaptar las sugerencias de acuerdo a los resultados obtenidos de la investigación.

Según la clasificación de los procedimientos de investigación cualitativa, se tiene dos enfoques diferenciados y las técnicas para el análisis de información. Para la presente investigación se optó por el enfoque directo, que consiste en indicar al individuo el propósito del proyecto (Malhotra, 2008).

Las técnicas empleadas para la presente tesis fueron la sesión de grupo y entrevista a profundidad.

a. Sesión de grupo, consiste en una entrevista no estructurada de grupo reducido de individuos dirigida por un moderador (Malhotra, 2008). Según el segmento meta, se entrevistarán cuatro grupos de ocho personas que se ciñan a las características anteriormente descritas. En el diseño de la herramienta, se tiene la ficha de sesión de grupo, en la cual se podrá apreciar las características de cada sesión de grupo y su respectiva guía de pautas.

- Objetivo: Determinar las aspiraciones y nivel de aceptación del segmento objetivo respecto al producto ofrecido. Conocer el atractivo del producto y las variantes que podrían surgir de acuerdo a ciertas exigencias del cliente potencial.

b. Entrevista en profundidad, consiste en realizar un conversatorio con un individuo con amplia experiencia en un tema a fin de conocer sus expectativas y opiniones, está a cargo de un entrevistador (Malhotra, 2008). Para el caso del presente trabajo de investigación se entrevistará a cuatro expertos en distintas materias asociadas y del rubro inmobiliario. En el diseño de la herramienta se 
tiene la ficha de perfil del entrevistado en la cual se podrá apreciar las características de los participantes, así como las preguntas que se realizarán a cada uno de ellos.

- Objetivo: Seleccionar información complementaria y más detallada acerca del mercado y las últimas tendencias del sector, así como datos de evolución del mercado que manejan los entrevistados y que puedan servir para asentar el proyecto de una mejor manera. Tomar juicios expertos para las proyecciones y posibles características del producto.

\subsubsection{Proceso de muestreo}

De acuerdo a Benassini (2014), dentro de los métodos de muestreo para la investigación cualitativa existen dos el probabilístico y no probabilístico.

Dentro del análisis trabajado para la presente tesis se tomó en cuenta el método de muestreo que se ajuste a cada técnica elegida.

a) Sesiones de grupo o focus group: el método seleccionado para esta técnica fue el muestreo probabilístico estratificado, es decir, el criterio de selección de participantes para las sesiones de grupo se determinó según las variables que determinaron el segmento meta. Ver anexo 2. Dentro del método probabilístico estratificado se utilizó el método de cálculo proporcional al tamaño del estrato.

b) Entrevista en profundidad: el método seleccionado para esta técnica fue el muestreo no probabilístico de juicio, ya que se tomó en cuenta opiniones personales de las personas entrevistadas para profundizar en el sector que se considera relevante. Se tomó cinco personas de diferentes rubros ligados al sector que tengan como referencia las siguientes características mínimas: 
- $\quad$ Experiencia mínima de siete años en el rubro.

- Conocimientos solidos acerca del tema que se investiga.

- $\quad$ Formación Académica de acuerdo al perfil requerido.

- Disposición a participar en la investigación.

Los datos personales de cada participante se encuentran en las fichas técnicas de cada entrevista indicada en el Anexo 4.

\subsubsection{Diseño de instrumento}

a) La sesión de grupo, se desarrollará cuatro sesiones con la participación de ocho personas en cada sesión. El cuestionario se muestra en el anexo 5.

Tabla 22

Ficha de investigación cualitativa sesión de grupo

\begin{tabular}{ll}
\hline \multicolumn{2}{l}{ FICHA TÉCNICA- INVESTIGACION CUALITATIVA } \\
\hline Técnica de investigación & Sesión de grupo \\
\hline Número de sesiones realizadas & $\begin{array}{l}\text { Se efectuaron cuatro sesiones en Lima, } \\
\text { conformada por siete y ocho participantes por sesión. }\end{array}$ \\
\hline Participantes & Conformado por hombres y mujeres entre los 25 y 55 años \\
\hline Reclutamiento & Participantes 25-35 años, NSE A y B \\
\hline Fecha de realización del trabajo de campo & Del 28/02 al 28/03 \\
\hline Recolección de información & Guion semiestructurado en guía de pautas \\
\hline Lugar de realización de las sesiones & Sala de reuniones \\
\hline Duración & Entre 45 y 60 minutos \\
\hline Equipo de trabajo & Cada sesión se contó con un moderador \\
\hline
\end{tabular}

b) Entrevista en profundidad con expertos, se entrevistará a cuatro expertos en el rubro. El cuestionario y ficha técnica de cada uno de los entrevistados se muestra en el anexo 4. 
Tabla 23

Ficha de investigación cualitativa entrevista en profundidad.

\begin{tabular}{|c|c|}
\hline \multicolumn{2}{|c|}{ FICHA TÉCNICA- INVESTIGACION CUALITATIVA } \\
\hline Técnica de investigación & Entrevista en profundidad \\
\hline Número de entrevistas realizadas & Cuatro entrevistas \\
\hline Participantes & Expertos en el rubro inmobiliario \\
\hline Reclutamiento & $\begin{array}{l}\text { Se convocó a personas que tengan experiencia en el rubro } \\
\text { como gerentes, especialistas. }\end{array}$ \\
\hline Ámbito de investigación & Lima metropolitana \\
\hline Fecha de realización del trabajo de campo & Del 28/02 al 28/03 \\
\hline Recolección de información & Guion semiestructurado \\
\hline Lugar de realización de la entrevista & $\begin{array}{l}\text { Las entrevistas se realizaron en los lugares de trabajo de los } \\
\text { entrevistados }\end{array}$ \\
\hline Duración & De acuerdo a la disponibilidad de cada participante \\
\hline Equipo de trabajo & Entrevistador, guía de entrevista y equipo de audio \\
\hline
\end{tabular}

\subsubsection{Análisis y procesamiento de datos}

a. Entrevistas a profundidad: la idea de central de los expertos entrevistados coincide básicamente en ciertos aspectos como:

- Demanda insatisfecha latente: la situación del mercado inmobiliario en general parece tener indicios de mejora, pero existirá aún una demanda insatisfecha, la cual debe ser trabajada de la mano con el Estado para poder sacar adelante proyectos que permitan el desarrollo de la sociedad.

- Acceso al crédito: el apetito de riesgo que tienen las entidades financieras y la rentabilidad que obtendrían respecto a brindar créditos con mayores facilidades sería un factor determinante para poder adquirir viviendas. Aunque en la actualidad aún se mantienen ciertos criterios de evaluación duros, la tendencia del mercado está empujando a flexibilizarlos, una cuestión que, por demanda, puede hacer que los bancos tomen otro tipo de medidas. 
- Cumplimiento de políticas de construcción: es muy importante conocer los requerimientos mínimos para empezar un proyecto de construcción, en especial aquellos que se dan en zonas de preferencia por los consumidores, debido a que la amplia demanda, el costo del suelo, y el precio final serán los factores determinantes de la venta exitosa. Los tiempos y segmentación de mercado meta es muy importante al momento de elegir los atributos que tendrá el proyecto para que este sea rentable.

b. Sesión de grupo:

- Hombres y Mujeres, de 25 a 35 años, NSE A:

- Es importante el factor ubicación del proyecto, se dio opinión positiva acerca de la zona.

- El factor tamaño de los espacios interiores es determinante. El departamento debería tener al menos dos dormitorios.

- Es importante contar con cochera, una o dos dependiendo del tamaño de departamento.

- El precio por el beneficio de la sostenibilidad, y el ahorro por ella, es considerado justo.

- Sería necesario un espacio común para diversión como un área de parrillas, reuniones, cine, etc.

○ Ideal si se cuenta con un consejero de diseño por el tema de los materiales eco amigables.

- Hombres y Mujeres, de 25 a 35 años, NSE B: 
- Hubo interés por compra de departamento entre dos personas (room mate).

- Recalcaron mucho la cercanía al centro de trabajo y avenidas principales para conmutarse rápidamente.

- Decisivo contar con zona recreativa para sus eventos sociales.

- Los departamentos debían ser entre uno y tres dormitorios.

○ El área común debía ser espaciosa.

- Departamentos podían venir con o sin cochera.

- Sostenibilidad como característica importante para ahorrar costos.

- Debía tener buena iluminación para simular amplitud.

- Proyecto asociado a financiamiento de Banco, de preferencia Banco de Crédito o Interbank.

○ No debían tener muchos vecinos, 25 máximo, a comparación de los edificios multifamiliaries de la zona.

- Hombres y Mujeres, de 36 a 55 años, NSE A

○ El grupo en general se encontró conforme y le gusta el lugar donde vive. Una de las variables más importantes es la facilidad o dificultad que tienen para salir de su residencia y la distancia hacia su trabajo u otros lugares que concurren.

○ Otra ventaja es la seguridad de su distrito. Una desventaja es la falta de estacionamientos para los visitantes.

- La mayoría no tenía muy claro cuánto podían pagar por un departamento sin embargo dieron algunas variables. 
- Respecto a la cuota mensual la decisión fue muy divida, estuvieron muy repartidos entre 2200 a 4000 soles, y una minoría por debajo y por encima de estos montos.

- Una gran mayoría indicaba que mínimo el departamento debería tener tres dormitorios, por otro lado, una minoría tendía a cuatro y dos dormitorios. Otro atributo importante eran las dimensiones de los departamentos, sugerían que los departamentos sean lo más cuadrados posibles para no perder área en corredores.

○ La mayoría del grupo indicó que si había solicitado una evaluación financiera

○ En mayor cantidad el grupo optó por entidades bancarias resaltando los bancos BCP y el Interbank

- En cuanto a la opinión del distrito de Magdalena del Mar las opiniones estuvieron repartidas, sobre todo por los temas de seguridad ciudadana, unos indicaban que era una zona tranquila y otros que la zona no era muy segura.

- Coincidieron en señalar las avenidas principales del distrito, como son las avenidas Sucre, La Costanera, La Marina, Brasil. Y en cuanto a los atractivos turísticos resaltaron las mejoras en la costa frente al mar y una heladería muy conocida de la zona.

○ En su mayoría no fueron reacios en adquirir uno de los departamentos del proyecto, tanto para primera vivienda, para segunda vivienda o para alquiler. 
- Sugieren retiran de las fachadas los dicroicos en los volados y todo lo que es vegetación ya que no se asegura el mantenimiento y por lo tanto cavia la posibilidad que se deteriore el aspecto de la fachada.

- Otra sugerencia es que exista una cochera por departamento.

- La mayoría sugirió que en cuanto al sistema de bombeo de agua sea del tipo cisterna - tanque elevado.

- Así también sugirieron que la altura de piso a techo sea un poco más alta al estándar, para darle mayor amplitud y flujo de aire.

- Para la mayoría el hacer el edificio sostenible es atractivo, siempre que el costo no varíe demasiado.

- Hombres y Mujeres, de 36 a 55 años, NSE B

○ De tres dormitorios como mínimo para sus hijos.

- Debe tener una cocina bien equipada y sala comedor amplio para el tiempo familiar.

○ Los acabados de la cocina y baños deberían ser acorde a los materiales sostenibles.

○ Los departamentos deben tener depósito para guardar sus cosas.

○ Ideal si se cuenta con dos cocheras, para el esposo y la señora.

- Debe contar con zona recreativa para los niños y gimnasio y/o zona de parrillas para las reuniones familiares. 
- Debe tener una administradora de edificio para poder llevar bien el mantenimiento.

○ Consideran la sostenibilidad como una forma de ahorro.

Vital la conexión a gas.

\subsection{Investigación Cuantitativa}

Para el caso de la investigación cuantitativa, se tomó el muestreo no probabilístico ya que, según este método, "se desconoce la oportunidad de seleccionar un elemento determinado de la población” (Benassini 2014, p. 138).

Dentro del muestreo probabilístico existe el muestreo aleatorio simple, es decir, se seleccionan los elementos al azar por la practicidad y facilidad de medición. En concordancia con el segmento seleccionado anteriormente, la muestra debe guardar homogeneidad con la población que contiene esas características.

Se tiene entonces, como punto de partida, la población o universo compuesta por elementos que tienen características similares y que conforman el universo para el estudio, que en este caso sería la población de la ciudad de Lima: 8`445,211 y de acuerdo a las herramientas de investigación cualitativa elegidas tenemos:

La técnica empleada para desarrollar la investigación cuantitativa del presente estudio fue la encuesta, para determinar la cantidad de encuestas a desarrollar se calculó el tamaño de muestra extraída de la población.

La encuesta es "una técnica de investigación cuya finalidad es obtener información de los individuos que forman parte de la muestra de una población determinada, está compuesta por un cuestionario estructurado." (Malhotra, 2008, p.183). 
Luego de analizar las diversas técnicas para realizar el muestreo, para el análisis de datos de la presente investigación se empleó la técnica del muestro probabilístico aleatorio simple.

Las encuestas se desarrollaron de manera online mediante survey monkey y tuvieron la finalidad de extraer información que permita conocer las necesidades de los individuos que forman parte del público objetivo.

\subsubsection{Proceso de muestreo}

El tamaño de muestra para el estudio cuantitativo de acuerdo a que se conoce el tamaño de la población sigue los siguientes pasos

a) Determinar cuánto es el error máximo aceptable a realizar en el cálculo.

b) Determinar cuál es la probabilidad de que se realice el evento y que no se realice.

c) Determinar el intervalo de confianza mínimo que debe tener el cálculo.

d) Aplicar la fórmula:

$$
n=\frac{Z^{2} p q}{E^{2}}
$$

Donde se tiene:

$$
\begin{aligned}
& \mathbf{Z} \text {, valor de nivel de confianza } \\
& \mathbf{P} \text {, como variable positiva } \\
& \mathbf{Q} \text {, como variable negativa (1-p) } \\
& \mathbf{E} \text {, como \% de error. }
\end{aligned}
$$

Para el caso puntual el cálculo a realizar se estimará con un intervalo de confianza de $95 \%$ (valor de $Z=1.96$ ) y un error máximo de $5 \%$. Al no conocer 
las probabilidades de éxito o error del evento se utilizará un 50\%/50\%. Como no se cuenta con el dato de la población se obtiene el cálculo siguiente:

$$
\begin{aligned}
& \mathbf{n}=\frac{(1.96)^{2} * 50 \% * 50 \%}{(0.05) 2} \\
& \mathbf{n}=384
\end{aligned}
$$

Una vez conocido el tamaño de la muestra se aplicó la encuesta la cual es analizada en el punto correspondiente dentro de la presente tesis. Para la aplicación de la encuesta se utilizará el método de bola de nieve o referidos.

\subsubsection{Diseño de instrumento}

Se elaboró una encuesta que permita realizar un análisis cruzado considerando fundamentalmente los resultados de la investigación cualitativa que revele la información deseada de acuerdo a los objetivos planteados. El modelo se muestra en el anexo 5.

En esta encuesta se utilizaron escalas:

\section{a) Básicas:}

- Intervalo: para conocer rangos de precio y gastos.

- De proporciones: para conocer la disposición de pago del cliente.

\section{b) No comparativas:}

- Escala de Likert: para conocer el grado de aceptación. 
Tabla 24

Ficha de investigación cuantitativa encuesta

\section{FICHA TÉCNICA- INVESTIGACION CUANTITATIVA}

\begin{tabular}{ll}
\hline Técnica de investigación & Encuesta personal \\
\hline Objetivo & Determinar las características generales y necesidades de los compradores. \\
\hline Tipo de cuestionario & Estructurado de 18 preguntas cerradas \\
\hline Universo & Residentes de Lima con edades entre los 25 y 55 años \\
\hline Ámbito Geográfico & Lima \\
\hline Elementos del Muestreo & Personas entre los 25 y 55 años de NSE A y B. \\
\hline Tipo de muestreo & Muestreo aleatorio simple \\
\hline Tamaño muestral & 384 unidades muestrales válidas \\
\hline Nivel de confianza & $95 \%$ \\
\hline Margen de error & $5.00 \%($ Universo $>100.000)$ \\
\hline Tipo de preguntas & $\begin{array}{l}\text { Dicotómicas, de opción múltiple, con Escala de Likert, Escala } \\
\text { de importancia y Escala de intención de compra }\end{array}$ \\
\hline Administración & Se realizará vía web por el servidor Survey Monkey. \\
\hline Fecha de recolección de datos & 15 Marzo de 2017 \\
\hline
\end{tabular}

\subsubsection{Análisis y procesamiento de datos}

Se aplicó la encuesta a 410 personas por el método de bola de nieve. La administración de la encuesta se hizo mediante internet web site, utilizando la herramienta de encuestas gratuitas de survey monkey. Según los datos recabados tenemos y de acuerdo con el segmento elegido, las respuestas por edades fueron:

- Pregunta 1 Edad: según el segmento elegido, únicamente serían validas 368 encuestas ya que se encuentran dentro del rango de 25 a 55 años.

Tabla 25

Cantidad de encuestados según su edad

\begin{tabular}{lr}
\hline \multicolumn{1}{c}{ Rango de Edades } & Cantidad de Encuestados \\
\hline$[0$ a 24] & 17 \\
{$[25$ a 30] } & 134 \\
{$[31$ a 40] } & 142 \\
{$[41$ a 55] } & 92 \\
{$[55$ a más $]$} & 25 \\
\hline \multicolumn{1}{c}{ Total general } & 410 \\
\hline
\end{tabular}




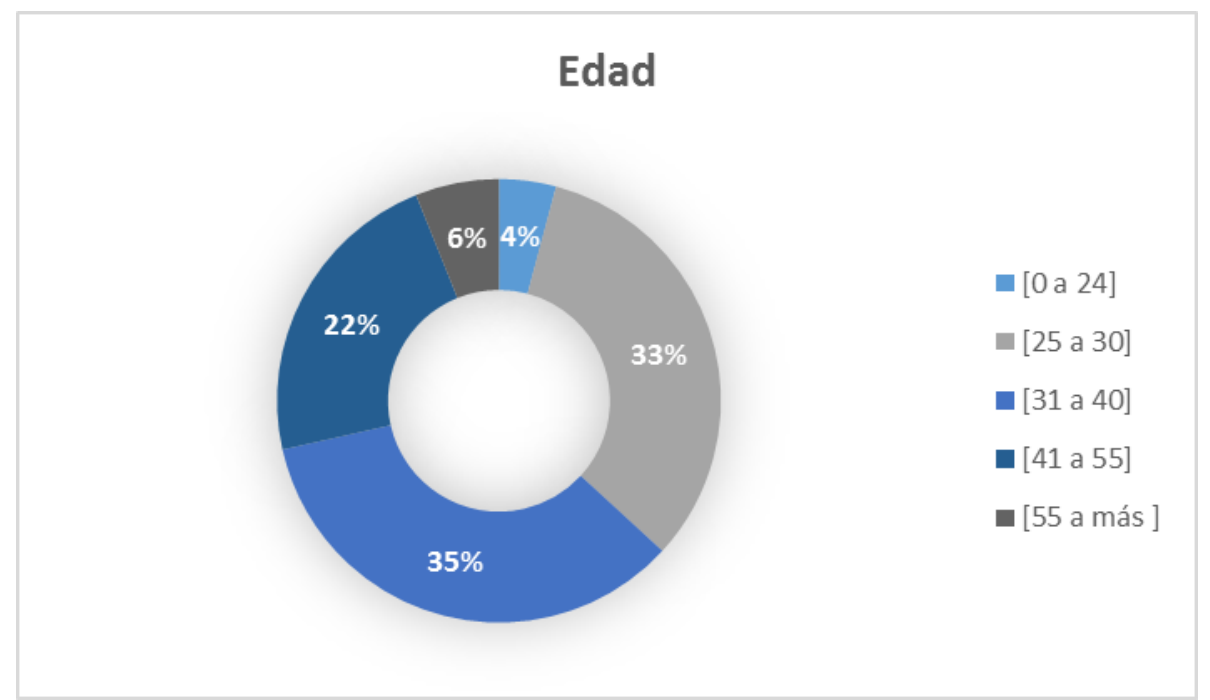

Figura 22. Porcentaje de encuestados por Edad.

- Pregunta 2 Género: según el segmento elegido, la respuesta para el género masculino fue de $34 \%$ y para femenino fue de $66 \%$. Este dato no discrimina la cantidad de encuestas.

Tabla 26

Cantidad de encuestados según su género

\begin{tabular}{lr}
\hline Género & Cantidad de Encuestados \\
\hline Femenino & 244 \\
Masculino & 124 \\
\hline \multicolumn{1}{c}{ Total general } & 368 \\
\hline
\end{tabular}

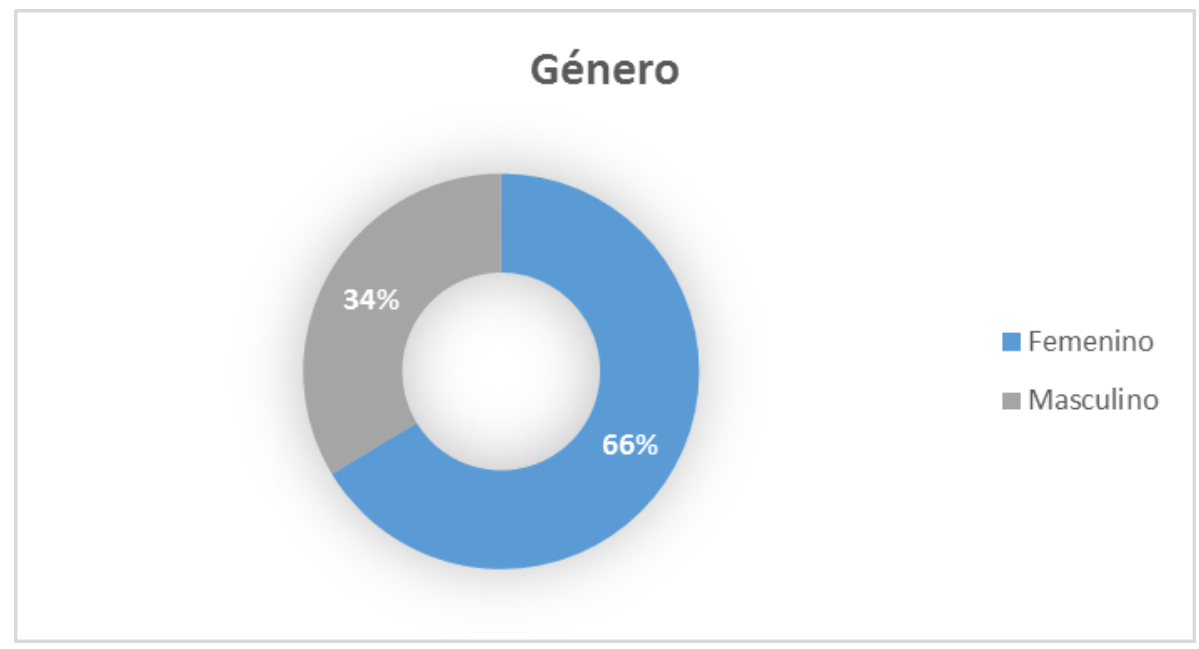

Figura 23. Porcentaje de encuestados por Género 
- Pregunta 3 Estado Civil: la respuesta se centró mayoritariamente en los casados o convivientes con un $68 \%$. Este dato no discrimina la cantidad de encuestas realizadas.

Tabla 27

Cantidad de encuestados según su Estado Civil

\begin{tabular}{lr}
\hline Estado Civil & Cantidad de Encuestados \\
\hline Casado / Conviviente & 249 \\
Soltero & 109 \\
Viudo & 3 \\
Divorciado & 8 \\
\hline \multicolumn{1}{c}{ Total general } & 368 \\
\hline
\end{tabular}

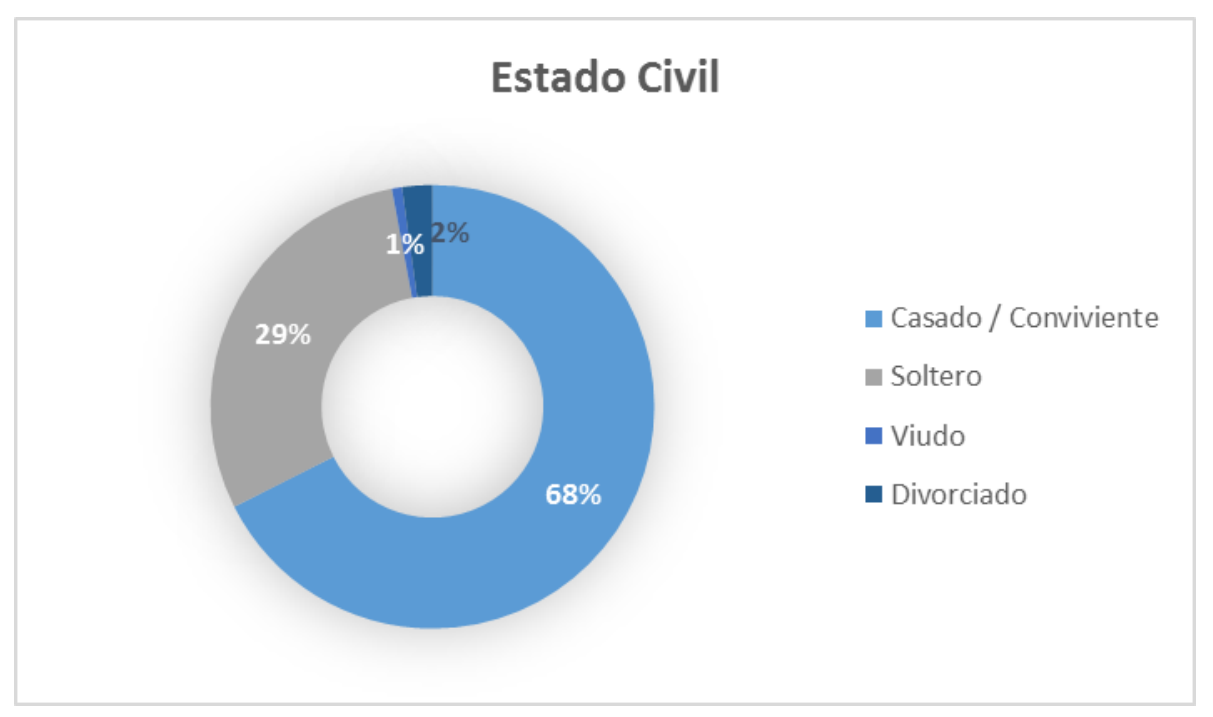

Figura 24. Porcentaje de encuestados por Estado Civil

- Pregunta 4, 5, 6 y 7 NSE: una serie de respuestas discriminatorias acerca de las facilidades para poder identificar el NSE de los encuestados dio como resultado que los NSE A con $25 \%$ y el NSE B con $55 \%$. 
Tabla 28

Cantidad de encuestados según su NSE

\begin{tabular}{lr}
\hline NSE & Cantidad de Encuestados \\
\hline NSE A & 78 \\
NSE B & 156 \\
NSE C & 40 \\
NSE D & 8 \\
\hline \multicolumn{2}{r}{ Total general } \\
\hline
\end{tabular}

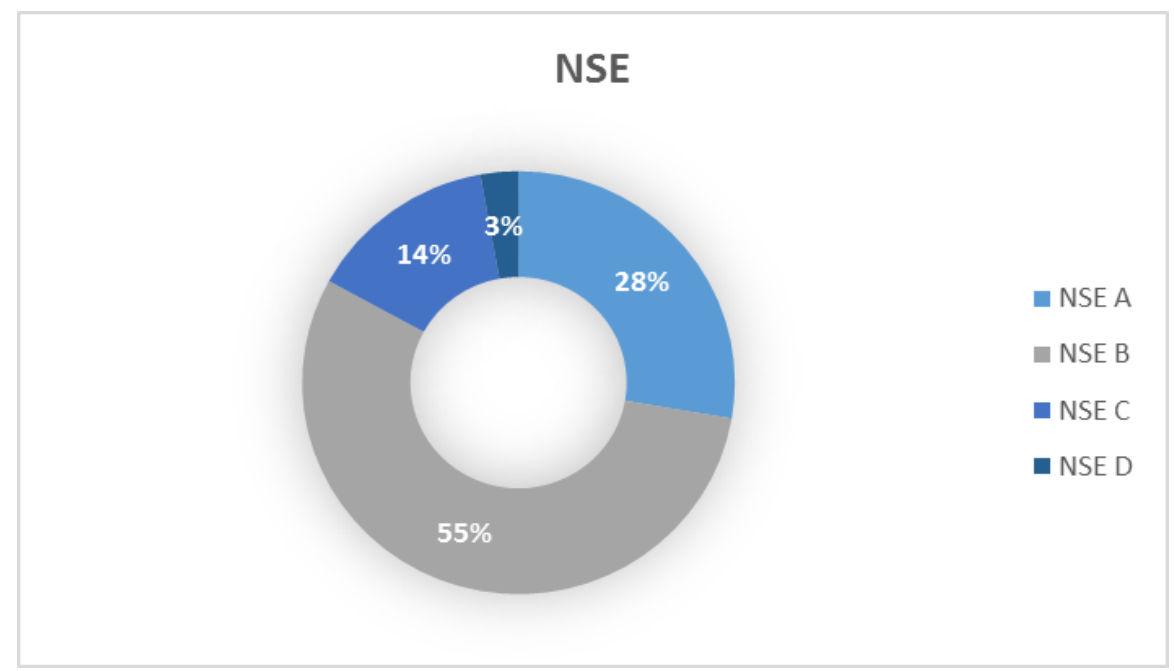

Figura 25. Porcentaje de encuestados por NSE

- Pregunta 8 Intención de compra: del total de encuestas dentro del rango etario el 52\% respondió positivamente a la intención de compra de una vivienda, reduciendo el número de encuestas válidas para el estudio a 190.

\section{Tabla 29}

Cantidad de encuestados según su intención de compra

\begin{tabular}{|c|c|}
\hline Desea comprar vivienda & Cantidad de Encuestados \\
\hline NO & 178 \\
\hline SI & 190 \\
\hline Total general & 368 \\
\hline
\end{tabular}




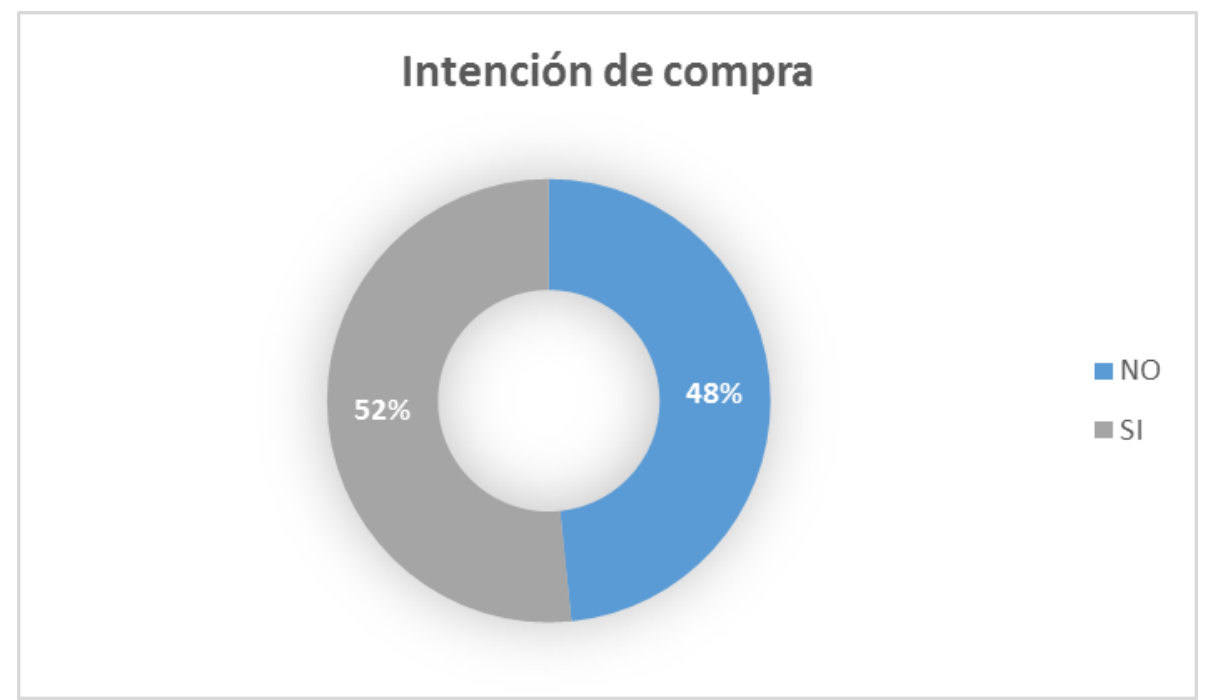

Figura 26. Porcentaje de encuestados por Intención de compra.

- Pregunta 9 Situación de vivienda: el $84 \%$ de los encuestados no cuenta con vivienda propia, aun así, no se discrimina el 16\% restante.

Tabla 30

Cantidad de encuestados según su situación de vivienda

\begin{tabular}{lr}
\hline Situación de vivienda & Cantidad de Encuestados \\
\hline Vivienda Alquilada & 47 \\
Vivienda de mis padres & 57 \\
Vivienda Familiar & 55 \\
Vivienda Propia & 30 \\
\hline Total general & 190 \\
\hline
\end{tabular}




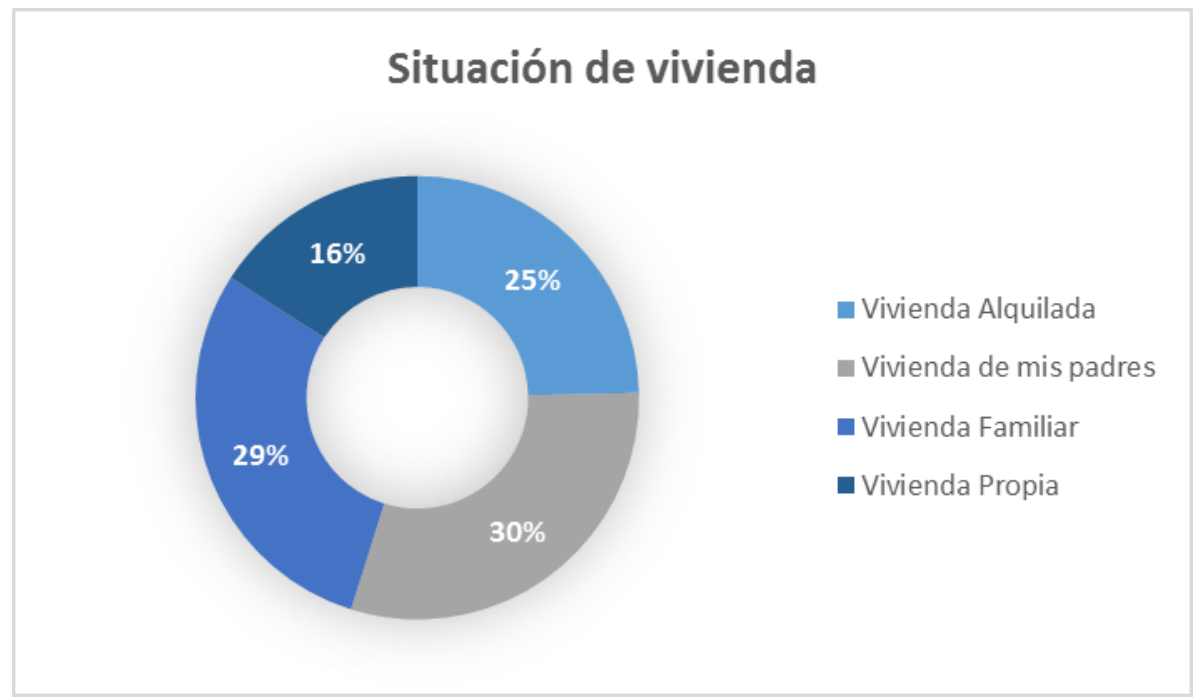

Figura 27. Porcentaje de encuestados por situación de vivienda

- Pregunta 10 Nivel de satisfacción: la respuesta mayoritaria en forma general indica que el nivel de satisfacción con su vivienda actual es bajo.

Tabla 31

Cantidad de encuestados según su nivel de satisfacción

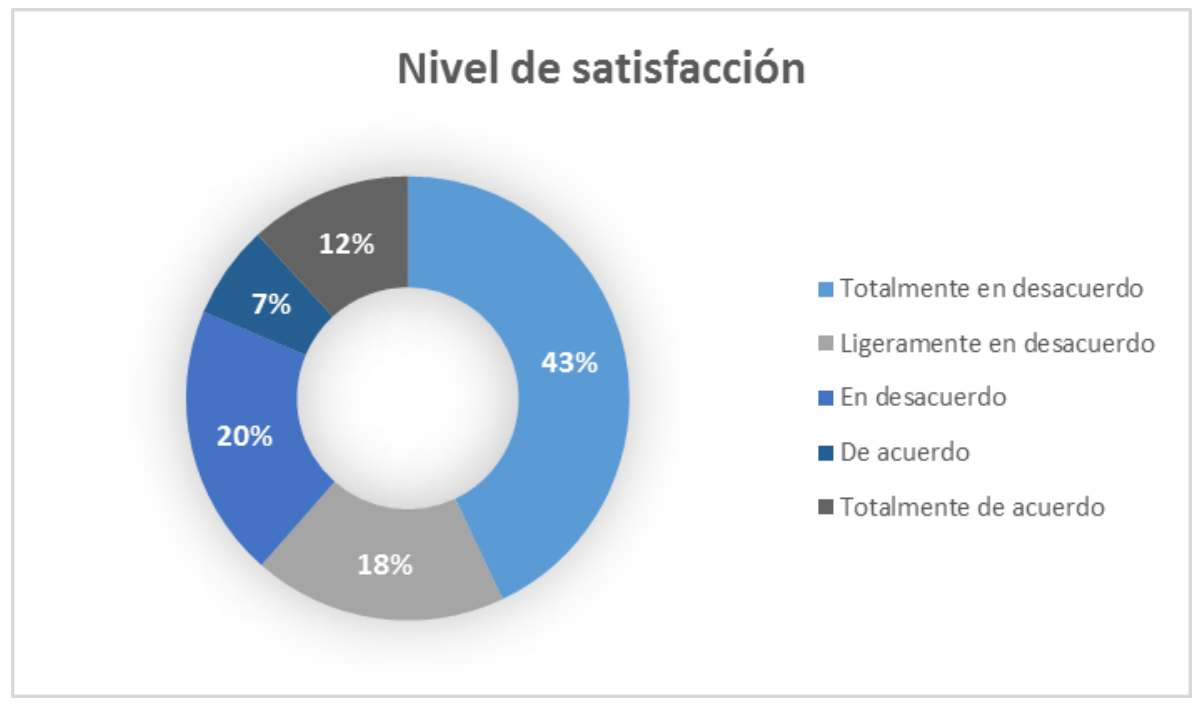

Figura 28. Porcentaje de encuestados por nivel de satisfacción

- Pregunta 11 Pago por vivienda: un $50 \%$ de los encuestados está dispuesto a pagar entre S/ 300,000 y S/ 600,000, rango en el que se encuentra comprendido el precio promedio del producto. 
Tabla 32

Cantidad de encuestados según su pago por vivienda

\begin{tabular}{lr}
\hline Pago por vivienda & Cantidad de Encuestados \\
\hline [Menos de S/. 300,000.00] & 43 \\
[S/ 300,000.00 - S/ 400,000.00] & 55 \\
[S/ 400,001.00 - S/ 500,000.00] & 40 \\
[S/ 500,000.00 - S/ 600,000.00] & 24 \\
[Más de 600,000.00 soles] & 28 \\
\hline Total general & 190 \\
\hline
\end{tabular}

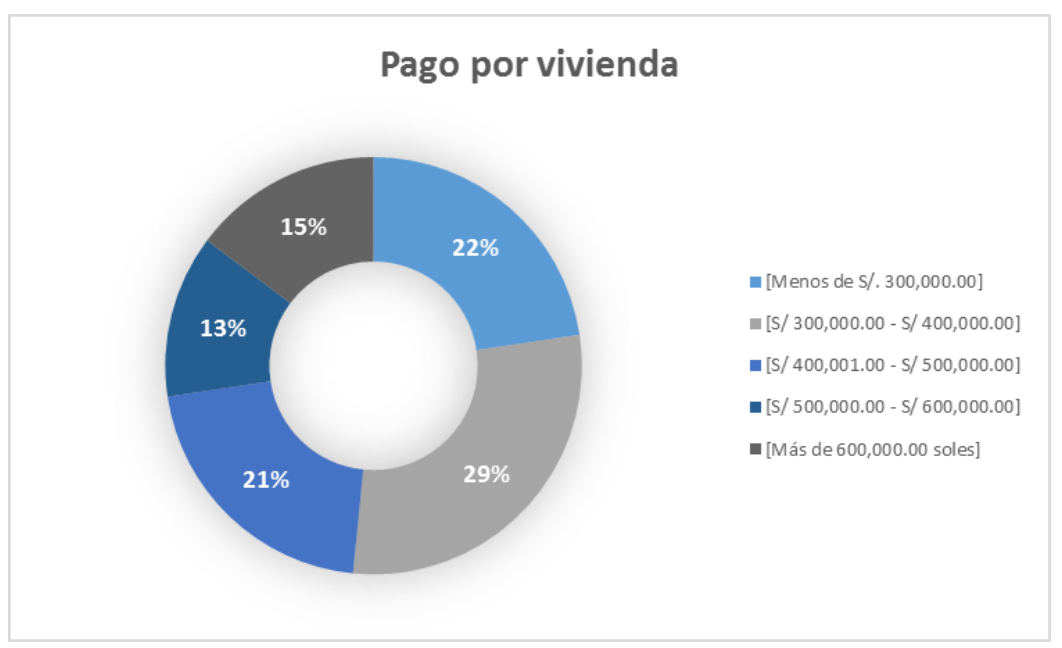

Figura 29. Porcentaje de encuestados por pago por vivienda.

- Pregunta 12 Pago mensual vivienda: el $49 \%$ de los encuestados respondió que destinaría más de S/ 3,000 al mes para el pago de su vivienda.

Tabla 33

Cantidad de encuestados según su pago mensual vivienda

\begin{tabular}{lr}
\hline Pago mensual de vivienda & $\begin{array}{c}\text { Cantidad de } \\
\text { Encuestados }\end{array}$ \\
\hline [Menos de S/.2,00.00] & 55 \\
{$[$ De S/. 2,000.00 a 3,000.00] } & 29 \\
[De S/. 3,001.00 a 4,000.00] & 13 \\
[De S/. 4,001.00 a 5,000.00] & 87 \\
{$[$ S/.5,000.01 a más] } & 6 \\
\hline \multicolumn{1}{c}{ Total general } & 190 \\
\hline
\end{tabular}




\section{Pago mensual por vivienda}

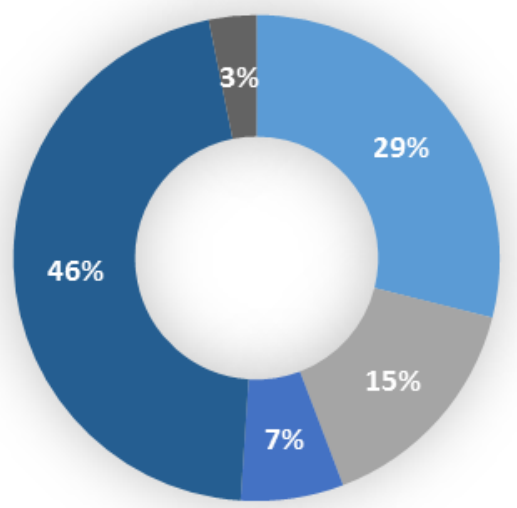

- [Menos de S/.2,00.00]

ㅁ [De S/. 2,000.00 a 3,000.00]

- [De S/. 3,001.00 a 4,000.00]

- [De S/. 4,001.00 a 5,000.00]

— [S/.5,000.01 a más]

Figura 30. Porcentaje de encuestados por pago mensual vivienda.

- Pregunta 13 Número de vecinos: en el atributo de la relevancia acerca del número de vecinos con los que contaría el edificio el 74\% consideró este aspecto como muy relevante.

Tabla 34

Cantidad de encuestados según preferencia de vecinos

\begin{tabular}{|c|c|}
\hline Número de vecinos & Cantidad de Encuestados \\
\hline No & 49 \\
\hline SI & 141 \\
\hline Total general & 190 \\
\hline
\end{tabular}

Número de vecinos

$26 \%$

$\square$ No

- SI

$74 \%$ 
Figura 31. Porcentaje de encuestados por número de vecinos

- Pregunta 14 Vivienda sostenible: en la pregunta de la ventaja diferencial del proyecto, acerca de si les parecía interesante una vivienda sostenible, el $56 \%$ de los encuestados respondió positivamente.

Tabla 35

Cantidad de encuestados según su preferencia por vivienda sostenible

\begin{tabular}{|c|c|}
\hline Vivienda sostenible & Cantidad de Encuestados \\
\hline No & 83 \\
\hline SI & 107 \\
\hline Total general & 190 \\
\hline
\end{tabular}

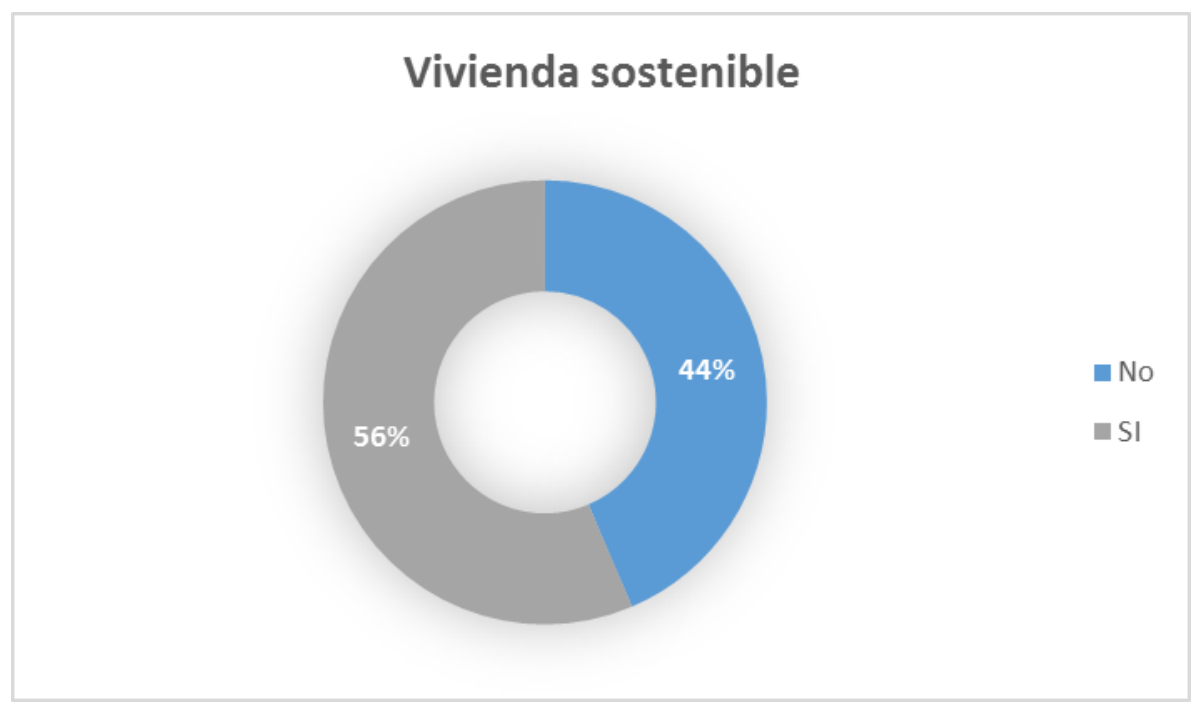

Figura 32. Porcentaje de encuestados por preferencia vivienda sostenible

- Pregunta 15 Metraje de vivienda: el 62\% de los encuestados respondió que desea una vivienda superior a los $87 \mathrm{~m}^{2}$.

Tabla 36

Cantidad de encuestados según metraje de vivienda

\begin{tabular}{lr}
\hline Metraje de vivienda & Cantidad de Encuestados \\
\hline Entre $40 \mathbf{~ m}^{\mathbf{2}}$ a $\mathbf{4 9} \mathbf{~ m}^{\mathbf{2}}$ & 2 \\
Entre 50 y $\mathbf{7 4} \mathbf{~ m}^{\mathbf{2}}$ & 26 \\
Entre 75 y $87 \mathbf{~ m}^{\mathbf{2}}$ & 47
\end{tabular}




\begin{tabular}{ll} 
Más de $87 \mathbf{~ m}^{\mathbf{2}}$ & 115 \\
\hline Total general & 190 \\
\hline
\end{tabular}

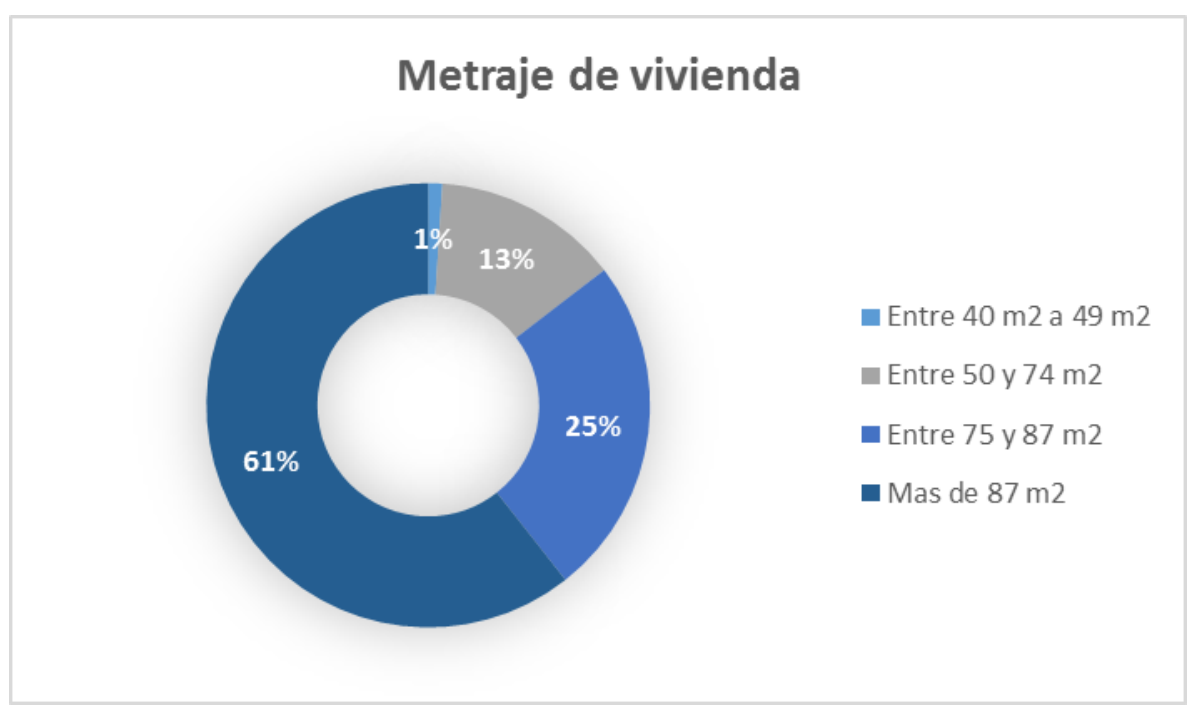

Figura 33. Porcentaje de encuestados por metraje de vivienda

- Pregunta 16 Ubicación de vivienda: dentro de los distritos ofrecidos como probabilidad de ubicación de vivienda el 54\% prefirió Magdalena del Mar.

Tabla 37

Cantidad de encuestados según ubicación de vivienda

\begin{tabular}{lr}
\hline Ubicación Magdalena del Mar & Cantidad de Encuestados \\
\hline No prefiero & 87 \\
Prefiero & 103 \\
\hline Total general & 190 \\
\hline
\end{tabular}




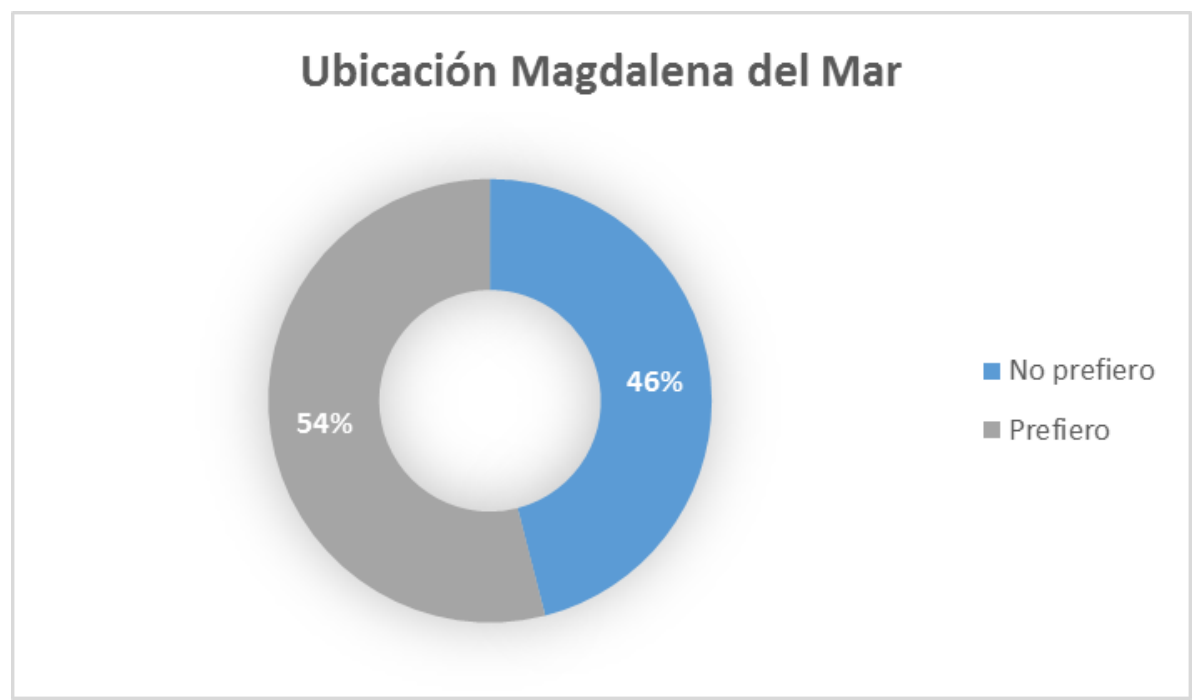

Figura 34. Porcentaje de encuestados por ubicación Magdalena

- Pregunta 17 Estacionamiento: como un atributo final se consultó si sería relevante que la vivienda cuente con cochera, a lo que $87 \%$ consideró que es muy relevante.

Tabla 38

Cantidad de encuestados según preferencia por estacionamiento

\begin{tabular}{lr}
\hline Con Cochera & Cantidad de Encuestados \\
\hline No & 26 \\
SI & 164 \\
\hline Total general & 190 \\
\hline
\end{tabular}

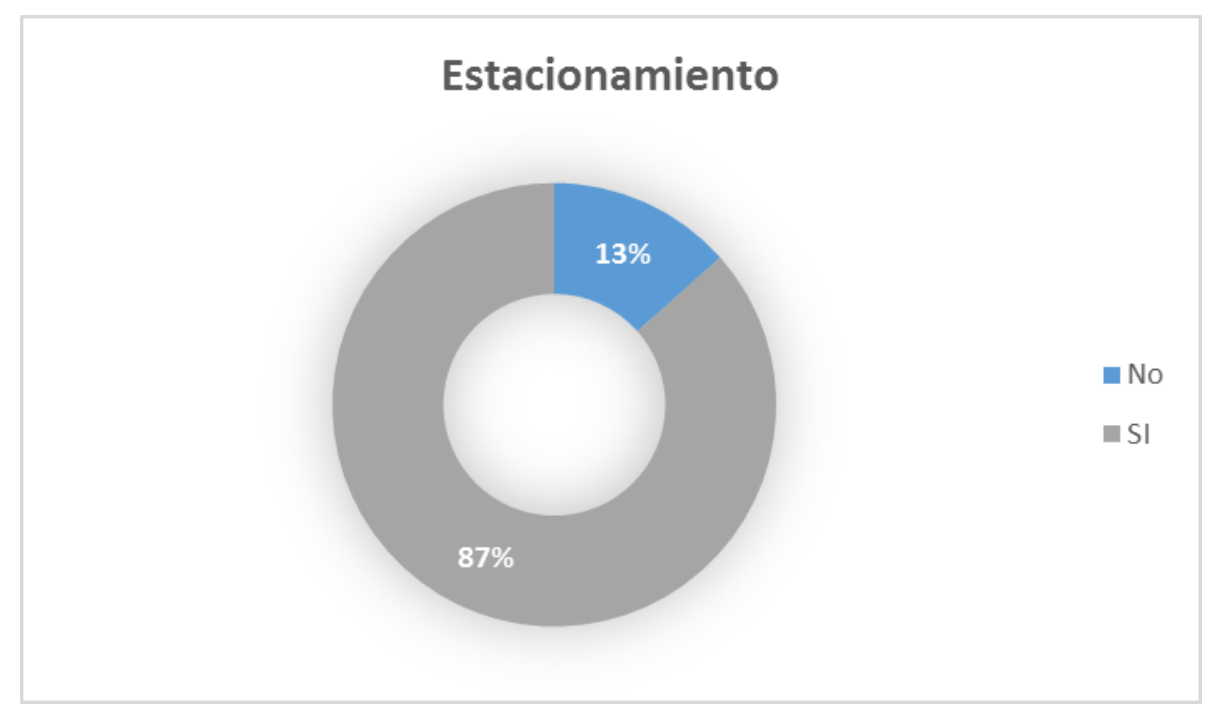

Figura 35. Porcentaje de encuestados por estacionamiento 


\subsection{Conclusiones y recomendaciones del Estudio Cualitativo y Cuantitativo}

Conclusiones:

- El segmento más joven opta por la mudanza en conjunto (pareja o roomate) por lo que el departamento más pequeño debe tener al menos dos habitaciones.

- El segmento adulto, considera importante la cochera, por lo que los departamentos con más metrajes deben considerar como mínimo esta característica.

- La ventaja diferencial de la sostenibilidad juega un rol importante en la decisión de compra ya que, es percibido como un beneficio a largo plazo.

- En general, los departamentos no pueden ser muy pequeños (arriba de los $50 \mathrm{~m}^{2}$ de preferencia), ni tampoco muy amplios por el precio de venta.

- La localización del proyecto es buena, el distrito de Magdalena del Mar es bastante bien percibido por los potenciales clientes como una buena zona para vivir o tener un bien inmueble.

\section{Recomendaciones}

- Se recomienda tener un mix de departamentos en cuanto a metraje que permita satisfacer las necesidades de los distintos perfiles.

- No ceñirse mucho a los atributos de uno u otro grupo, pues puede sesgar la preferencia de compra de un segmento.

- Se recomienda combinar de la mejor manera los atributos para brindarlos en "paquete" dependiendo del perfil del comprador potencial.

- El metraje de los departamentos debe maximizar la utilización del espacio y la ganancia por terreno. 


\subsection{Perfil del consumidor tipo y sus variantes}

Basados en el estudio del focus group y los resultados de las encuestas pudimos obtener dos perfiles de los consumidores tipo bastante marcados:

\section{a. Perfil 1:}

- Jóvenes profesionales o emprendedores, solteros, socialmente activos.

- NSE A y B de Lima.

- Trabajan de manera dependiente o independiente.

- Edades entre 25 a 35 años

- Ingresos promedio mensual desde $\mathrm{S} / 4,500$

- Necesidad específica: Vivir en un espacio pequeño, pero bien equipado, que esté cercano a su entorno diario (trabajo, estudio, amistades) y se sientan dueño de su propio espacio.

\section{b. Perfil 2:}

- Matrimonios o familias nucleares.

- NSE A y B de Lima.

- Cuentan con un patrimonio que les permite realizar la compra de un departamento.

- Ingreso promedio mensual por hogar desde S/ 10,000. Del análisis se infiere que $15 \%$ de los hogares de NSE A y $10 \%$ del NSE B pueden tener un ingreso mensual familiar igual o mayor a S/10,000.

- Etapa del ciclo de vida en Expansión, Consolidación, estabilización y desmembramiento.

- Necesidades específicas: Amplios espacios, compartir su tiempo con los amigos y la familia. 


\section{Capítulo IV: Proyección Del Mercado Objetivo}

Existe dificultad para pronosticar el comportamiento futuro de la demanda, por lo que es necesario emplear métodos de proyección como técnicas complementarias.

Una vez que se ha seleccionado el segmento sobre el cual se realizó la aplicación de los métodos de investigación, se debe delimitar a cuantos y cuales se dirigirán los esfuerzos de marketing para lograr la venta del producto (Kottler \& Keller, 2012).

\subsection{El ámbito de la proyección.}

El ámbito de proyección se basa en factores de la situación pasada, presente y proyectada.

\section{a) Información:}

- $\quad$ Calidad: la calidad de la información depende de las fuentes consultadas. En el caso de la calidad de información del presente trabajo solo se ha consultado información validada como fidedigna, no solo en cuanto a cifras históricas, sino como también a bases teóricas referenciadas y opiniones avaladas por expertos.

- $\quad$ Fuentes: pueden ser primarias o secundarias. En este caso, se ha buscado que la información se extraiga tanto de libros, textos y revistas físicas y online, como de opiniones de expertos.

Segmentación: se realiza sobre ciertos criterios de fuente de información, no se toma cualquier fuente como válida.

\section{b) Proyección:}

Elección del método depende de:

- Calidad de información

- $\quad$ Antecedentes disponibles

- $\quad$ Resultados esperados 
Efectividad del método se evalúa sobre:

- $\quad$ Precisión: ya que cualquier error conllevará a un costo asociado.

- $\quad$ Sensibilidad: la estabilidad debe adecuarse al entorno cambiante.

- $\quad$ Objetividad: porque la información debe ser válida y oportuna.

\section{c) Resultados:}

- $\quad$ Lo que se obtiene son solo indicadores que deben complementarse con el juicio y apreciaciones cualitativas del análisis

\subsection{Selección del método de proyección.}

Para lograr una segmentación eficaz hay que seguir ciertos criterios según Kottler (2012), a continuación, se detallan:

- Medibles: tamaño, poder de compra y número de habitantes.

- Sustanciales: poblaciones aledañas al distrito elegido.

- Accesible: segmentos de fácil contacto.

- Diferenciable: el nivel socioeconómico meta es fácilmente diferenciable.

- Accionable: se pueden crear estrategias para atraer al segmento.

Existen diversas técnicas que permiten efectuar predicciones para determinar la existencia de un mercado potencial para el producto o servicio motivo de análisis.

Estas técnicas de proyección se clasifican en: métodos cualitativos y cuantitativos.

\section{a) Métodos cualitativos}

Se basan generalmente en información cualitativa y en opiniones de expertos. Se emplea cuando los datos no son confiables para predecir un comportamiento futuro.

Para la presente tesis se ha desarrollado el método de Investigación de mercado que se basa en el análisis de la información obtenida de los cuestionarios 
aplicados a los clientes potenciales y/o a los expertos en el rubro del sector construcción.

\section{b) Métodos cuantitativos}

Basada en técnicas cuantitativas de predicción, emplean series de tiempo y modelos causales y matemáticos.

Dentro del análisis de investigación de mercados el método cuantitativo elegido es el modelo de regresión simple, el cual utilizará como datos de entrada las respuestas a las encuestas realizadas a los clientes potenciales.

\subsubsection{Mercado Potencial.}

Está conformado por todos los individuos que cumplen con las características determinada en la etapa de selección del segmento de mercado, es decir personas de 25 a 55 años del NSE A y B.

\subsubsection{Mercado Disponible.}

Está conformado por un porcentaje del mercado potencial. La medición se realizó en la pregunta cinco: ¿Ud. está interesado en adquirir algún inmueble?

$\mathrm{Al}$ responder positivamente en esta pregunta, el grupo de clientes expresa una intención de compra del producto que se ofrece. Para el caso de la encuesta aplicada un número de 190 personas respondieron que sí.

\subsubsection{Mercado Efectivo.}

Está conformado por una parte del mercado disponible por las personas que comprarían el departamento ofrecido según su capacidad de endeudamiento. La medición se realizó en la pregunta: ¿Cuánto está dispuesto a pagar por la compra de un departamento? (pregunta 11 de la encuesta). Como resultado el $50 \%$ está dentro del rango del costo de departamento ofrecido. La cantidad de personas que eligieron un rango de precio dentro del posible precio del producto fue de 92 personas. 


\subsubsection{Mercado Objetivo.}

Está conformado por un porcentaje del mercado efectivo, a su vez se determina en base a criterios como el área del departamento y la renta mensual dispuesto a pagar contenidos en la pregunta 15 y 12 .

La pregunta 12 en la cual se pretende saber cuál es el porcentaje de gasto mensual que destinaria al pago del departamento fue respondido por $49 \%$ personas encuestadas con un monto superior a los $\mathrm{S} / 3,000$.

La pregunta 15 en la cual se detalla el tamaño del producto según lo evaluado para el proyecto fue respondido de manera positiva por $62 \%$ desea una vivienda superior a $\operatorname{los} 80 \mathrm{~m}^{2}$

\subsection{Pronóstico de Ventas}

El pronóstico de ventas consiste en realizar una proyección de las ventas futuras en términos de cantidad o de monto del producto propuesto a la venta para un determinado horizonte de tiempo.

El método que se utilizará para la presente tesis será el de ventas potenciales del sector o del mercado. Es decir, las tendencias de venta que marca el sector según el avance del mercado y tomar estas como referencia para poder calcular las ventas del producto actual.

La variable principal para determinar el retorno de inversión es el tiempo en la cual se venda todos los departamentos. Se ha elaborado una estimación del tiempo y vida del proyecto y se ha hecho en fases de acuerdo a las distintas etapas de venta del proyecto:

- Etapa de preventa: en esta etapa el producto físico no existe, pero si el espacio físico en donde se construirá. Al ser una etapa previa a la elaboración del producto, el precio será relativamente menor. Se calcula, por tendencias del mercado y exigencias del Banco acreditador del proyecto que en esta etapa se venda el $30 \%$ de los departamentos, es decir un total de ocho departamentos con 
un monto total aproximado de S/ 2,270,871.61. Con esta venta se estaría financiando el inicio de la ejecución del proyecto.

- Etapa puesta en marcha: en esta etapa ya se empieza la construcción del producto y se va recibiendo clientes con ventas a precios un poco más altos para poder generar margen. Se estima que un 50\% adicional de los departamentos se vendan en esta etapa.

- Etapa producto terminado: una vez terminado el proyecto, se pone en venta el $20 \%$ restante de los productos terminados, donde el precio aumenta por estar totalmente construido y listo para la entrega. Las ventas generadas en esta etapa son íntegramente ganancia.

\subsection{Aspectos críticos que impactan el pronóstico de ventas}

Según Rivadeneira (2012), existen factores que pueden afectar el pronóstico de ventas. Estos pueden ser factores externos o factores internos.

\subsubsection{Factores Externos}

\section{a. Variables económicas:}

- Tipo de cambio: el tipo de cambio determinará el costo de los materiales de construcción, por lo que si se incrementa podría restar rentabilidad.

- Inflación: debido a que tiene una relación directa con el poder adquisitivo del cliente, esta puede incluir en su decisión de compra.

- Índice de Precios al Consumidor: debido a que afecta directamente a las necesidades primarias del cliente, puede influir de manera directa en la prioridad en la decisión de compra del cliente.

- Índice de Confianza del Consumidor: de acuerdo a las perspectivas políticas y económicas del país, se crea la confianza para poder invertir con estabilidad. 
b. Situación de la industria: la desaceleración de las ventas de inmuebles en los últimos años ha sido importante para tomar en consideración ciertas características del producto.

c. Competencia: el crecimiento de la oferta para el sector puede representar una fuerte competencia por economías de escala y poder de negociación.

d. Tecnología: la reciente y continuamente cambiante tecnología hace que algunas características de los departamentos queden como "obsoletas" al cabo de algún tiempo.

e. Políticas gubernamentales: existen ciertas regulaciones que impactan a la empresa por su tamaño y poco poder de negociación con instituciones gubernamentales.

\subsubsection{Factores Internos}

\section{a. Producción}

- El proceso de producción: se puede ver afecta por ciertos cambios en tecnología y/o modificaciones de último momento para mantener ciertos parámetros mínimos de construcción segura de acuerdo al avance de la obra.

- La combinación de materiales y mano de obra: de acuerdo a la sostenibilidad ecoamigable del proyecto, el correcto engranaje de los materiales y su instalación determinarán el éxito del proyecto.

\section{b. Marketing}

- Política de promoción de ventas: cambios en la estrategia de comercialización y mercadeo, pueden traer problemas al momento de publicitar el proyecto, por ende, la venta puede frenarse. 
- Cambios en los pagos de comisiones: dependiendo de los cambios estos pueden ser beneficiosos para acelerar la venta del proyecto. 


\section{Capítulo V: Ingeniería Del Proyecto}

\subsection{Estudio de ingeniería}

El estudio de ingeniería es un proceso iterativo ya que al avanzar en la optimización de las distintas áreas y actividades del proyecto se hará evidente que es necesario realizar ciertas modificaciones a determinaciones que ya se habían hecho. A la hora de optimizar y optimizar la creatividad estar presente. Las técnicas y métodos de análisis que se emplean son intuitivos y dependen de la capacidad para crear, innovar y criterio del ingeniero.

El propósito general del estudio de ingeniería del proyecto es resolver todo lo que respecta a la instalación y funcionamiento de la planta; es decir, la descripción del proceso, la adquisición de los equipos y maquinaria, la determinación de la distribución óptima de la planta y la definición de la estructura jurídica y de organización que tendrá la misma. (Baca,

\subsubsection{Modelamiento y selección de procesos productivos}

El proceso productivo es el procedimiento técnico que se emplea en el proyecto para obtener los bienes y servicios a partir de insumos, y se identifica como la transformación de una serie de materias primas para convertirlas en artículos a través de una determinada función de fabricación. En esta parte del estudio, el ingeniero deberá elegir una determinada tecnología de fabricación, considerar la flexibilidad de los procesos y equipos para procesar varias clases de insumos y adquirir equipo y maquinaria. (Baca, 2013)

Para el caso de la empresa La Inmobiliaria estos son los procesos claves:

- Buscar bienes inmuebles para los proyectos inmobiliarios 
- Obtener y analizar de los documentos de los bienes inmuebles potenciales para los proyectos (partida registral, certificado de parámetro, certificado de zonificación y vías)

- Generar y ofrecer propuesta de negocio inmobiliario al propietario del bien inmueble seleccionado para el proyecto

- Generación de los contratos entre la empresa y el propietario del inmueble

- Selección de proveedores para el proyecto (Entidad financiera, desarrollares del expediente técnico, constructores e instaladores)

- Ofrecimiento y venta del producto in situ (caseta de ventas en el inmueble)

- Servicio de post-venta

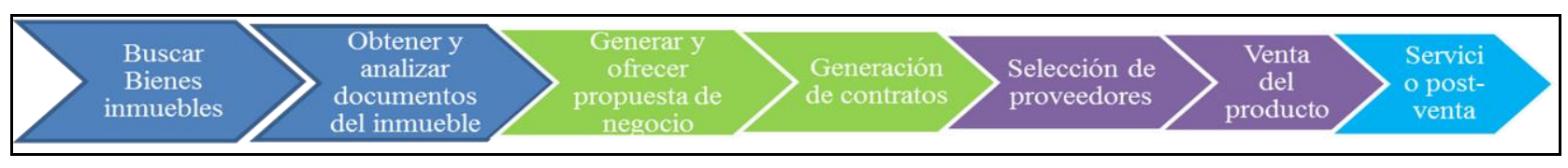

Figura 36. Cadena de valor del negocio

\subsubsection{Selección del equipamiento}

Al momento de decidir sobre la adquisición de equipo y maquinaria, se debe tomar en cuenta una serie de factores que afectan directamente la elección, a saber: el proveedor, el precio, las dimensiones, la capacidad, la flexibilidad, la mano de obra que se requiere, el costo de mantenimiento, el consumo de energía eléctrica o de otro tipo, la infraestructura necesaria, equipos auxiliares, costo de fletes y seguros, costo de instalación y puesta en marcha y la existencia de piezas de repuesto en el país. (Baca, 2013) 
Para el proyecto se realizó el listado del equipamiento a requerir entre los cuales se necesitaban en su mayoría muebles de escritorio y computadoras, tal como se puede apreciar en la tabla 39:

Tabla 39

Requerimiento de equipos y mobiliario para la oficina

\begin{tabular}{|c|c|c|c|c|c|c|}
\hline \multirow{2}{*}{$\begin{array}{c}\text { Descripción } \\
\text { Escritorio recto en MDF }\end{array}$} & \multirow{2}{*}{$\begin{array}{c}\text { Características } \\
0.60 \mathrm{~m} \text { de ancho x } 0.90 \mathrm{~m} \text { de largo }\end{array}$} & \multirow{2}{*}{$\frac{\text { Cantidad }}{3}$} & \multicolumn{2}{|c|}{$\begin{array}{l}\text { Costo Total sin } \\
\text { IGV }\end{array}$} & \multicolumn{2}{|c|}{$\begin{array}{l}\text { Costo Total } \\
\text { con IGV }\end{array}$} \\
\hline & & & $\mathrm{S} /$. & 381 & $\mathrm{~S} /$. & 450 \\
\hline Escritorio en L en MDF & $0.60 \mathrm{~m}$ de ancho $\times 1.10 \mathrm{~m}$ de largo & 1 & S/. & 186 & $\mathrm{~S} /$. & 220 \\
\hline Escritorio en L en MDF & $0.60 \mathrm{~m}$ de ancho x $1.60 \mathrm{~m}$ de largo & 1 & $\mathrm{~S} /$. & 212 & $\mathrm{~S} /$. & 250 \\
\hline $\begin{array}{l}\text { Juego de mesa redonda en } \\
\text { MDF con } 4 \text { sillas }\end{array}$ & $0.80 \mathrm{~m}$ de diámetro & 1 & S/. & 297 & $\mathrm{~S} /$. & 350 \\
\hline Sillas simples con respaldar & Color Negro & 8 & $\mathrm{~S} /$. & 339 & $\mathrm{~S} /$. & 400 \\
\hline Sillas ejecutivas con rueda & Color Negro & 2 & $\mathrm{~S} /$. & 254 & $\mathrm{~S} /$. & 300 \\
\hline Sillas modelo gerencial & Color Negro & 2 & $\mathrm{~S} /$. & 508 & $\mathrm{~S} /$. & 600 \\
\hline Estantes & $1.20 \mathrm{~m}$ de ancho $\mathrm{x} 1.80 \mathrm{~m}$ de alto & 4 & $\mathrm{~S} /$. & 508 & $\mathrm{~S} /$. & 600 \\
\hline Laptop * (incluye software) & $\begin{array}{l}\text { Lenovo B50-80 Core I7 - 5ta Gen } \\
\text { 2.4ghz 15.6p 8gb 1tb }\end{array}$ & 1 & $\mathrm{~S} /$. & 2,288 & $\mathrm{~S} /$. & 2,700 \\
\hline Computadora & $\begin{array}{l}\text { Core i7, RAM 16gb, disco duro de } \\
1 \mathrm{~TB}\end{array}$ & 3 & $\mathrm{~S} /$. & 5,593 & $\mathrm{~S} /$. & 6,600 \\
\hline Total & & 26 & S/. & 10,568 & . & 12,470 \\
\hline
\end{tabular}

\subsubsection{Lay out}

Una correcta distribución de la planta es aquella que proporciona condiciones de trabajo favorables y permite la operación más económica, al mismo tiempo que mantiene las condiciones óptimas de seguridad y bienestar para los trabajadores. Al considerar la distribución de la planta, se debe tener en cuenta los siguientes aspectos:

a) Integración total: integrar todos los factores concernientes a la distribución a fin de tener una visión de todo el conjunto y conocer la importancia de cada factor.

b) Mínima distancia de recorrido: reducir, en lo posible, el manejo de materiales trazando el mejor flujo.

c) Uso del espacio cúbico: considerar el espacio vertical y utilizarlo al máximo, sobre todo cuando se tiene espacios reducidos. 
d) Seguridad y bienestar para el personal: el objetivo principal de toda distribución.

e) Flexibilidad: la distribución debe tener la capacidad de reajustarse fácilmente a los cambios que exija el medio. (Baca, 2013)

Para el caso de La Inmobiliaria, la planta es la oficina, desde donde se realiza toda la operación de los proyectos inmobiliarios, sin embargo, la producción se ejecuta en los terrenos donde se levantarán los edificios.

En la figura 37 podemos ver el layout del departamento que se alquila como oficina para las operaciones de la empresa. Consiste en un espacio de ocho metros de ancho por nueve metros y medio de largo, dando un total de $76 \mathrm{~m}^{2}$. El área cuenta con un espacio de ingreso, una kitchenette, tres ambientes internos y dos baños.

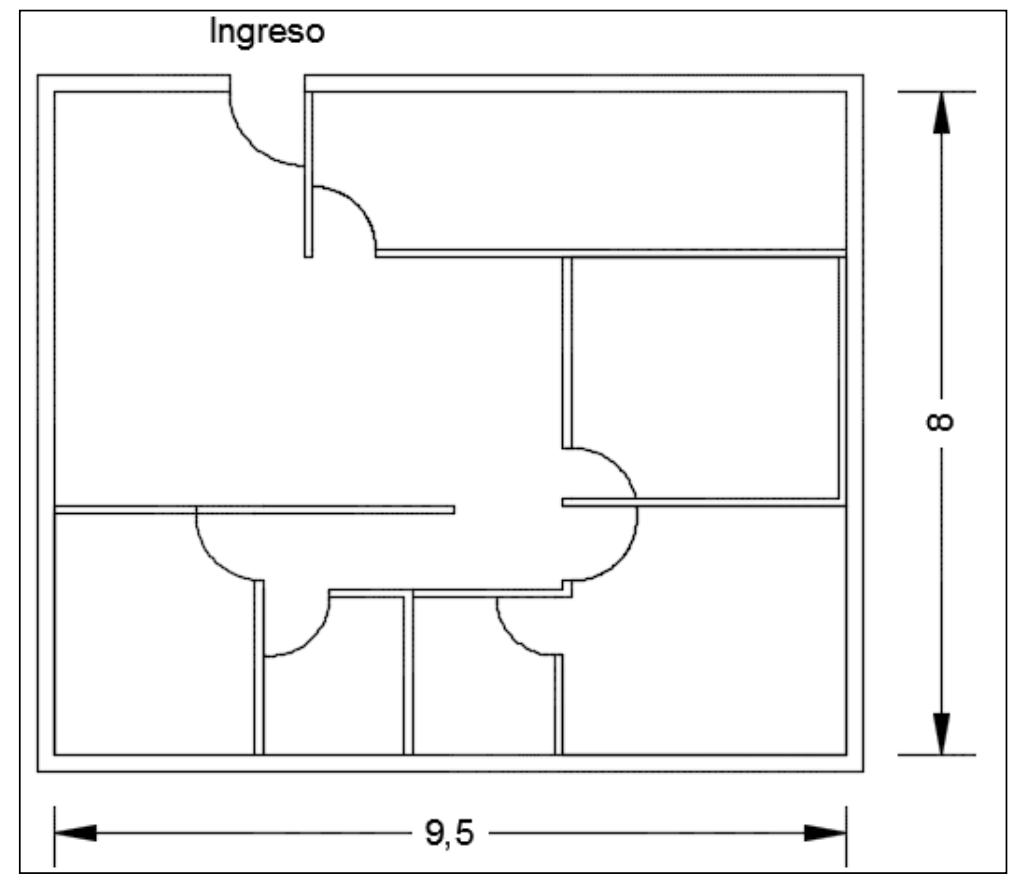

Figura 37. Distribución de espacios de la oficina

\subsubsection{Distribución de equipos y maquinarias}

Existen dos tipos de distribución de equipos y maquinaria: distribución por proceso y distribución por producto. El primero consiste en reducir al mínimo posible el costo del manejo de materiales, ajustando el tamaño y modificando la ubicación de 
las áreas de acuerdo al volumen y cantidad de flujo de los productos. El segundo consiste en aprovechar al máximo la efectividad del trabajador agrupando el trabajo secuencial en módulos de operación que producen un alto rendimiento de la mano de obra y del equipo, con un mínimo de tiempo muerto. (Baca, 2013)

De acuerdo a la figura 38, el ambiente que en su forma es casi un cuadrado permite tener una buena distribución del personal con sus respectivos equipos de trabajo.

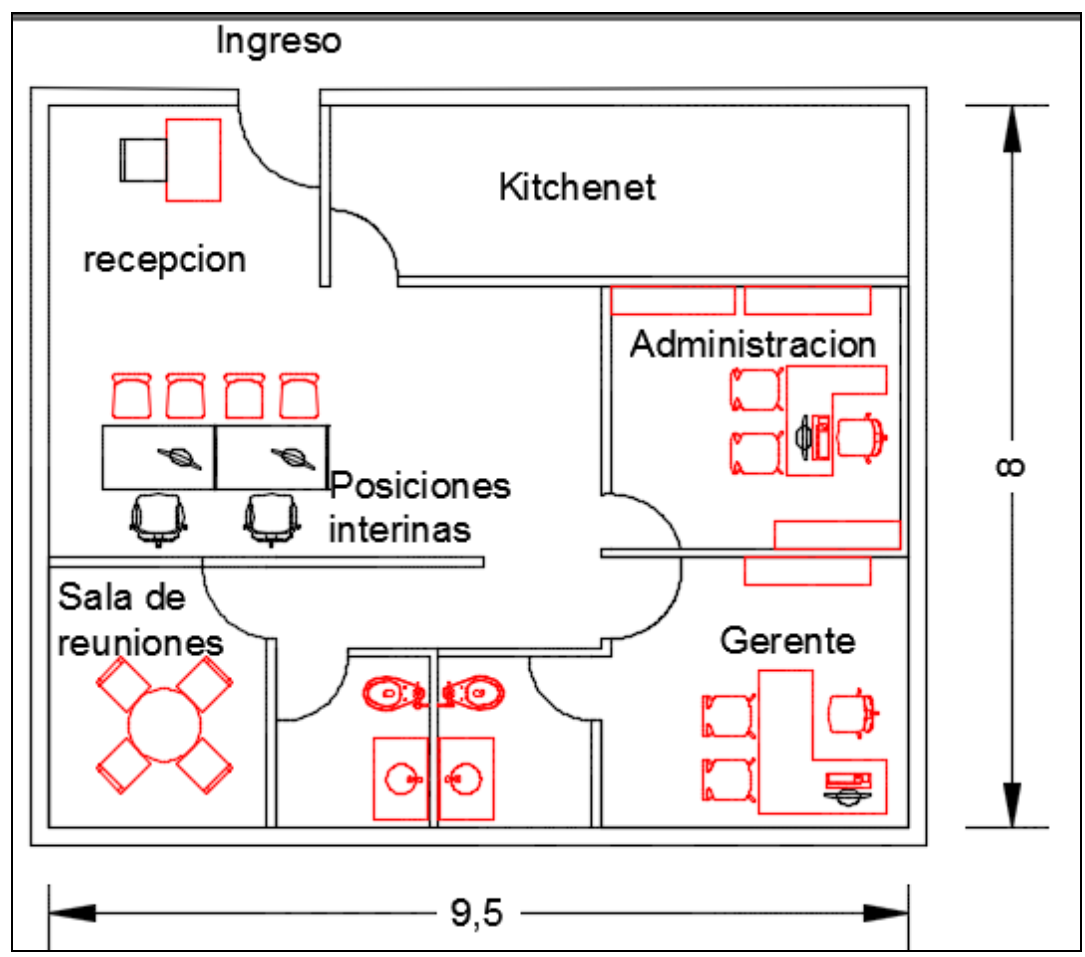

Figura 38. Distribución equipo y maquinarias

\subsection{Determinación del Tamaño}

El tamaño óptimo de la planta es su capacidad instalada y se expresa en unidades de producción por año. Se considera óptimo cuando opera al menor costo total o la máxima rentabilidad económica. Determinar el tamaño óptimo de la planta requiere conocer con precisión los tiempos predeterminados o tiempos y movimientos del proceso, además de una buena dosis de ingenio y buen criterio. (Baca, 2013). 


\subsubsection{Proyección de crecimiento}

En esta sección cabe mencionar dos métodos para la proyección de crecimiento: el Método de Lange y el Método de Escalación. El primero define la relación funcional que existe entre el monto de la inversión y la capacidad productiva del proyecto, lo cual permite considerar la inversión inicial como medida directa de la capacidad de producción (tamaño). El segundo determina la capacidad óptima de producción al considerar la capacidad de los equipos disponibles en el mercado y así analizar las ventajas y desventajas de trabajar cierto número de turnos de trabajo y sobretiempo. (Baca, 2013)

Para la empresa inmobiliaria el crecimiento es único, un solo proyecto de vivienda multifamiliar realizado en toda la vida de la empresa, por lo que la proyección de crecimiento será a tres años.

\subsubsection{Recursos}

Contar con la cantidad y calidad suficiente de materias primas es un aspecto fundamental en el desarrollo de un proyecto. Muchas grandes empresas se han visto frenadas por la falta de recursos. En etapas más avanzadas del proyecto, es recomendable tener tanto las cotizaciones como el compromiso escrito de los proveedores para abastecer las cantidades necesarias de material para la producción. De no contar con dicha provisión, se recomienda buscarla en el extranjero, cambiar de tecnología o, en el peor de los casos, abandonar el proyecto. (Baca, 2013).

En el caso del proyecto, se sub contratarán los servicios para transformar las materias primas en subproductos que finalmente convergerán en el producto final, que es el edificio multifamiliar Arequipa. Es por ello que lo que más predomina es el uso de servicios realizados por terceros. 


\subsubsection{Tecnología}

La tecnología y los equipos tienden a limitar el tamaño del proyecto al mínimo de producción necesario para ser aplicables. Las relaciones entre el tamaño y la tecnología influyen en las relaciones entre tamaño, inversiones y costo de producción. En efecto, dentro de determinados límites de operación y a mayor escala, estas relaciones propiciarán un menor costo de inversión por unidad de capacidad instalada y un mayor rendimiento por trabajador, lo que contribuirá a disminuir el costo de producción, aumentar las utilidades y elevar la rentabilidad del proyecto. (Baca, 2013)

Como se mencionó en el acápite anterior se subcontratarán los servicios para transformar las materias primas en subproductos. Para la ejecución del mismo se utilizará el programa Autodesk Revit para detectar incompatibilidades en el proyecto con la finalidad de resolverlas a tiempo, y evitar así posibles adicionales de obra y re trabajos que terminen en retrasos en los tiempos estipulados de entrega.

\subsubsection{Flexibilidad}

La planta debe tener una estructura flexible y fácilmente adaptable a los cambios, de manera que permita futuras ampliaciones. (Baca, 2013).

Los 76 metros cuadrados con los que cuenta la oficina permiten realizar distribuciones alternas en las que se añadan mayor cantidad de posiciones de requerirse. Se puede prescindir de la sala de reuniones para que en ese espacio se traslade la administración o la gerencia y así tener un ambiente adicional para otras funciones.

\subsubsection{Selección del tamaño ideal}

La determinación del tamaño ideal de la planta está directamente relacionada con el financiamiento del proyecto. Si los recursos financieros no son suficientes para atender las necesidades de inversión de la planta de tamaño mínimo, no se podrá 
ejecutar el proyecto. Si los recursos económicos propios y ajenos permiten elegir entre varios tamaños para producciones similares, lo recomendable es escoger aquel que se financie con mayor comodidad y seguridad y ofrezca los mejores costos y un alto rendimiento de capital. (Baca, 2013).

Para el caso de La Inmobiliaria, el tamaño de la planta está limitado a la cantidad de departamentos que tiene el proyecto "Arequipa”, en este caso al ser la proyección total de ventas en tres años, el tamaño de la planta es de ocho departamentos por año.

\subsection{Estudio de localización.}

El objetivo del estudio de localización es determinar la ubicación más adecuada del proyecto teniendo en cuenta la situación de los puntos de venta o mercados de consumidores, puntos de abastecimiento para el suministro de materias primas o productos intermedios, la interacción con otras posibles plantas, etc. La localización ordenada de la planta puede determinar el éxito o fracaso del proyecto. (Baca, 2013)

\subsubsection{Definición de factores locacionales.}

Entre los factores locacionales que se pueden considerar para determinar la ubicación de la planta, se encuentran los siguientes:

- Factores geográficos: aquellos relacionados con las condiciones naturales que rigen las distintas zonas del país, como el clima, los niveles de contaminación y desechos, conectividad, comunicaciones (carreteras, vías férreas y rutas aéreas), entre otros.

- Factores institucionales: aquellos que se relacionan con los planes y las estrategias de desarrollo y descentralización industrial.

- Factores sociales: aquellos relacionados con la adaptación del proyecto al entorno y a la comunidad. Se refieren al nivel general de los servicios sociales 
con los que cuenta la comunidad como, por ejemplo, escuelas, hospitales, centros recreativos, instalaciones culturales, etc.

- Factores económicos: se refieren a los costos de los suministros e insumos en la localidad de la planta, como la mano de obra, las materias primas, servicios básicos (luz, agua, teléfono, internet, etc.), la infraestructura disponible, los terrenos y la cercanía de los mercados y materias primas. (Baca, 2013)

\subsubsection{Consideraciones legales}

En todo país existe un conjunto de normas y reglamentos que rigen los actos del gobierno en el poder, como de las instituciones e individuos. A esas normas le sigue una serie de códigos de diversa índole como el civil, penal, tributario, etc. y una serie de reglamentos locales o regionales afines. Es evidente que estas normas repercuten, de alguna manera, en un proyecto y, por lo tanto, deben tomarse en cuenta ya que toda actividad empresarial y lucrativa se encuentra incorporada a un determinado marco jurídico. (Baca, 2013)

\subsubsection{Identificación del marco legal}

Todo proyecto, por muy rentable que sea, debe acatar las disposiciones jurídicas vigentes. Desde la primera actividad al poner en marcha un proyecto, que es la constitución legal de la empresa, la ley dicta los distintos tipos de sociedades permitidos, su funcionamiento, sus restricciones, etc. Es por ello que la primera decisión jurídica que se toma es el tipo de sociedad que operará la empresa y la forma en la que ésta se administrará. En segundo lugar, se determinará la forma de participación extranjera, si la hubiere. (Baca, 2013).

De acuerdo a la ley general de trabajo peruana y el tamaño planteado para la empresa según sus ventas anuales, esta sería catalogada como PYME, con sociedad del tipo S.R.L. Al estar bajo el régimen especial MYPE se exime del 
pago CTS, gratificaciones, pago de utilidades, seguro de vida, asignación familiar, sobretasa de trabajo nocturno.

\subsubsection{Ordenamiento jurídico de la empresa}

Algunos aspectos legales que son relevantes para el buen manejo de las empresas y el alcance de sus objetivos trazados son los siguientes:

a) Mercado: legislación sanitaria, elaboración y funcionamiento de contratos con proveedores y clientes, permisos de factibilidad y sanitarios para el transporte de productos, entre otros.

b) Localización: litigios, prohibiciones, contaminación ambiental, gastos notariales, determinación de honorarios de especialistas o profesionales, inscripción en Registros Públicos, etc.

c) Estudio técnico: transferencia de tecnología compra de marcas y patentes, aranceles, leyes contractuales, entre otros.

d) Administración y organización: leyes que regulan la contratación de personal y pago de utilidades, vacaciones, incentivos, ayuda social, leyes sobre seguridad industrial, entre otros.

e) Contabilidad y finanzas: Ley de Impuesto a la Renta, préstamos a instituciones bancarias, etc. (Baca, 2013)

En el ámbito inmobiliario y de construcción, la normatividad que aplica es la siguiente:

- Reglamento Nacional de Edificaciones, que es la norma técnica rectora y de aplicación obligatoria en el territorio nacional que establece los derechos y responsabilidades de los actores que intervienen en el proceso edificatorio. Tiene por objeto normar los criterios y requisitos mínimos para el diseño y ejecución de las habilitaciones urbanas y las edificaciones. 
- $\quad$ Ley N 29090 - Ley de regulación de habilitaciones urbanas y de edificaciones y sus modificaciones, la cual tiene por objeto establecer la regulación jurídica de los procedimientos administrativos para la obtención de las licencias de habilitación urbana y de edificación.

- $\quad$ Ley $\mathrm{N}^{\circ} 29476$, Ley que modifica y complementa la Ley $\mathrm{N}^{\circ} 29090$, Ley de regulación de habilitaciones urbanas y de edificaciones

- $\quad$ Ley N 30494 que modifica la Ley 29090 de Regulación de Habilitaciones Urbanas y de Edificaciones, en la cual se establece como "barrera burocrática ilegal" a requerimientos adicionales a la norma.

\subsection{Determinación de la localización óptima.}

La determinación de la localización óptima es lo que contribuye en mayor medida a que se logre la mayor tasa de rentabilidad sobre el capital (criterio privado) o a obtener el costo unitario mínimo (criterio social). Para ello, se emplea un método cualitativo y un método cuantitativo, donde el primero asigna factores cuantitativos a una serie de factores que se consideran relevantes (cualitativos) para la localización de la planta, y el segundo analiza los costos de transporte, materias primas o productos terminados. (Baca, 2013).

Para el caso de la empresa inmobiliaria, el proyecto tiene una localización específica en el distrito de Magdalena del Mar, la localización y descripción del mismo se encuentran en el capítulo tres. Esto responde a que se cuenta con el terreno como parte del capital de los accionistas para realizar el edificio multifamiliar, además de haberse demostrado la preferencia de la zona por las personas encuestadas y entrevistadas. 


\section{Capítulo VI: Aspectos Organizacionales}

\subsection{Caracterización de la cultura organizacional deseada}

La cultura organizacional, de acuerdo a Jones (2013), define de alguna manera el comportamiento de las personas que participan dentro de la organización. El vínculo que ellas mismas crean con la empresa hace que se pueda identificar una oportunidad para mejorar o implementar estrategias basadas en las particularidades de cada una de ellas.

Entiéndase que esta cultura organizacional no es estática, el cambio constante es parte de la naturaleza de su definición según la necesidad de adaptación al contexto interno o externo.

Por lo general, la cultura organizacional comprende los valores, principios, hábitos, formas de pensar y actuar de todos los integrantes de una empresa. (Cujar, 2013).

Según Cruz y Torres (2015) se puede caracterizar a una organización bajo el modelo de Cameron y Quinn (1999) mediante cuatro dimensiones: clan, adhocrática, de mercado y jerarquizada.

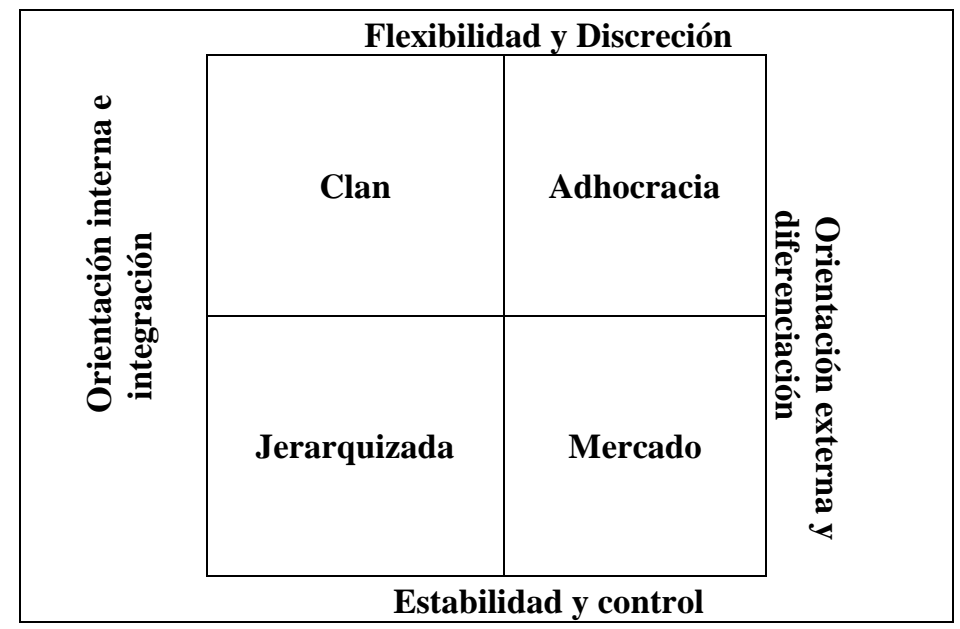

Figura 39. Las cuatro dimensiones de Cameron Quinn. Tomado de Cruz y Torres (2015) 
Para el caso de la empresa La Inmobiliaria que llevará a cabo del proyecto multifamiliar se pretende lograr una empresa tipo adhocrática, constituida con un fin puntual, en la cual prima la orientación externa, la estabilidad y control y la integración de todos los miembros del equipo para cumplir con un mismo objetivo. Este tipo de organizaciones son las que se desenvuelven en un entorno o sector altamente dinámico y cambiante como es el de la inmobiliaria hoy en día.

\subsubsection{Visión}

La visión, de acuerdo a David (2013), se define como la perspectiva a futuro de lo que una empresa quiere llegar a ser, teniendo en cuenta a un objetivo a largo plazo y esta debe ser lo más breve posible. Esta afirmación debe responder a la pregunta “¿En qué queremos convertirnos?”. Se puede inferir entonces, que la visión da un sentido de dirección a la empresa y esto lo que ayuda a la organización a centrarse en una meta o foco. David también hace énfasis en el hecho de que la visión debe ser de un punto de vista global no únicamente financiero, así la organización encuentra un sentido de pertenencia.

Para el caso de la empresa inmobiliaria creada con la finalidad de llevar a cabo la venta del proyecto multifamiliar Arequipa, esta visión se establece tomando en cuenta el periodo de vida de la empresa y el objetivo bastante delimitado de la misma, por lo cual, luego de diversas formulaciones llegamos a la visión propuesta:

Nuestra visión es ser una empresa con gran capacidad para maximizar la rentabilidad de proyectos inmobiliarios.

La razón por la cual la visión está delimitada en términos financieros, es básicamente porque la empresa ha sido creada en función del proyecto, el cual se basa 
en un terreno de personas individuales quienes buscan la maximización de la rentabilidad de su propiedad

\subsubsection{Misión}

Según David (2013), la misión de una empresa "Es la base de sus prioridades, estrategias, planes y asignación de tareas. Es el punto de partida para el diseño del trabajo gerencial y, sobre todo, para el diseño de las estructuras gerenciales.” (p.46) Esta afirmación debe responder a la pregunta “¿Cuál es nuestro negocio?” ya que, es el punto de partida para poder definir la responsabilidad de las estrategias.

A diferencia de la visión, David (2013) expone que la misión puede variar en términos de longitud, parámetros, y contenido. Además, debe tomar en consideración nueve elementos esenciales que son: clientes, productos, mercados, tecnología, preocupación por la supervivencia, el crecimiento y la rentabilidad, la filosofía, el auto concepto, la imagen pública y los empleados.

Entre las principales características de una misión tenemos:

- No especificar montos, porcentajes u objetivos fijos.

- Debe ser de extenso alcance, pero no debe ser mayor de 250 palabras.

- Debe dar a conocer la responsabilidad social y ambiental de la empresa.

- Debe considerar los nueve componentes esenciales.

- Debe inspirar, ser indulgente y perenne.

Luego de lo anteriormente expuesto entonces se puede decir que la misión de la empresa inmobiliaria del proyecto familiar Arequipa será:

"Somos una empresa inmobiliaria centrada en la elaboración y venta de un proyecto de viviendas multifamiliar que reúna las características necesarias 
que satisfagan a nuestros clientes, siempre cuidando la responsabilidad con el medio ambiente, nuestros accionistas y nuestros colaboradores."

En este sentido entonces, se cumplen los supuestos establecidos con la teoría, incluyendo a los nueve elementos y respondiendo a la pregunta ¿Cuál es nuestro negocio?, y delimitando de una manera amplia pero clara los objetivos de la empresa.

\subsubsection{Principios.}

Según David (2013), la cultura organizacional abarca distintas dimensiones las cuales abarcan todas las áreas de la empresa. En tal sentido, descubrir los valores y creencias que se encuentran bastante arraigados desde la historia de la empresa es todo un arte. Este conjunto de valores, creencias y principios forman parte de la estrategia de la empresa ya que, dependiendo del comportamiento organizacional, es como se pueden fijar las mejores herramientas para conseguir los diferentes objetivos de la empresa

Se puede deducir entonces que, el logro de los objetivos de la empresa, se encuentra estrechamente ligado a una fuerte cultura organizacional que permita a la organización innovar de acuerdo a las necesidades cambiantes del mercado.

Debido a la naturaleza y objetivo de la empresa se tiene como principios fundamentales:

- Pensamiento estratégico: se analizó el mercado actual y se plantearon planes de acción en función a las tendencias y principales consideraciones a tomar en cuenta. En adelante, a lo largo del proyecto, se buscará trabajar en función a estos planes. 
- Responsabilidad social y ambiental: de acuerdo a las últimas tendencias del mundo empresarial, la inmobiliaria no escapará de sus responsabilidades con el medio ambiente teniendo mucho cuidado en el tratamiento de los materiales utilizados para la construcción.

- Compromiso con la rentabilidad: en función a los resultados a obtener, los objetivos deben velar siempre por la rentabilidad esperada por los propietarios del terreno, quienes facilitarán la materia prima para la puesta en marcha del proyecto.

- Honestidad en los procedimientos sensibles: debido a la operatividad de la empresa y su constante relacionamiento con proveedores, la honestidad es un tema esencial para la práctica de un correcto funcionamiento de procesos y eficiencias.

- Excelencia y calidad en el trabajo: en cuanto al tema de excelencia y calidad es brindarle al cliente un servicio adhoc, el cual pueda diferenciarse por temas de información, asesoría, y pruebas. La calidad de los acabados del proyecto debe ir de la mano con la calidad del servicio de la empresa inmobiliaria.

- Cumplimiento a los clientes: no solamente cumplir, sino también superar las expectativas del cliente a nivel de servicio y producto. La intención es generar una experiencia positiva en los clientes del proyecto. 


\subsection{Formulación de Estrategias del Negocio}

\section{a) Evaluación Externa:}

De acuerdo a lo que dicta la teoría de la matriz de evaluación de factores externos se realizará en función de listar los factores externos clave que son de vital importancia para la empresa como oportunidades.

Tabla 40

Matriz de evaluación de factores externos

\begin{tabular}{|c|c|c|c|}
\hline EFE & $\begin{array}{l}\text { PONDERACION } \\
\text { P }\end{array}$ & VALOR Q & $\begin{array}{l}\text { VALOR } \\
\text { TOTAL } \\
\text { Px Q }\end{array}$ \\
\hline \multicolumn{4}{|l|}{ AMENAZAS } \\
\hline Incremento del salario de construcción civil hasta en $4.78 \%$ & 0.07 & 2 & 0.14 \\
\hline Riesgo país de Peru subió a $1.66 \%$ & 0.07 & 1 & 0.07 \\
\hline $\begin{array}{l}\text { Peru Registró un déficit fiscal de } 2.6 \% \text {, la mayor brecha en } 15 \\
\text { años }\end{array}$ & 0.07 & 3 & 0.21 \\
\hline Proyección del crecimiento económico paso de $5 \%$ a $3.7 \%$ & 0.07 & 2 & 0.14 \\
\hline $\begin{array}{l}\text { Precios de los materiales de construcción subió } 3.16 \% \text { en el } \\
2016\end{array}$ & 0.07 & 3 & 0.21 \\
\hline $\begin{array}{l}\text { Reducción del IGV a } 17 \% \text { si y solo si la recaudación anual al } 31 \\
\text { de mayo alcance el } 7.2 \% \text { del PBI }\end{array}$ & 0.04 & 3 & 0.12 \\
\hline $60 \%$ de las edificaciones es realizado por la autoconstrucción & 0.04 & 3 & 0.12 \\
\hline \multicolumn{4}{|l|}{ OPORTUNIDADES } \\
\hline $\begin{array}{l}\text { S/. 174,978,053.00 nuevos soles serán destinados para la } \\
\text { ejecución del Bono Familiar Habitacional. }\end{array}$ & 0.07 & 3 & 0.21 \\
\hline $\begin{array}{l}\text { Ingreso de paquete de medidas económicas para promover un } \\
\text { plan de vivienda a nivel nacional }\end{array}$ & 0.09 & 4 & 0.36 \\
\hline $\begin{array}{l}\text { El gobierno promoverá la construcción de } 90,000 \text { viviendas en } \\
2017 \text {, mediante los programas mi vivienda y techo propio }\end{array}$ & 0.08 & 4 & 0.32 \\
\hline $\begin{array}{l}\text { Modificación de la ley } n^{\circ} 29090 \text { mediante ley } n^{\circ} 30494 \text { en la que } \\
\text { se establece como barrera burocrática ilegal a requerimiento } \\
\text { adicionales a la norma }\end{array}$ & 0.03 & 1 & 0.03 \\
\hline $\begin{array}{l}\text { Aprobación del reglamento del decreto legislativo n }{ }^{\circ} 1187 \text {, se } \\
\text { previene y sanciona la violencia en la actividad de la } \\
\text { construcción civil }\end{array}$ & 0.03 & 1 & 0.03 \\
\hline $\begin{array}{l}\text { Al } 2016 \text { existen } 31 \text { edificios sostenibles y mas de } 130 \text { en } \\
\text { proceso de construcción }\end{array}$ & 0.06 & 2 & 0.12 \\
\hline $\begin{array}{l}\text { Creación del código técnico de la construcción sostenible en } \\
\text { Perú }\end{array}$ & 0.06 & 2 & 0.12 \\
\hline $\begin{array}{l}\text { Tendencia de la población a vivir en zonas urbanas de fácil } \\
\text { acceso }\end{array}$ & 0.06 & 3 & 0.18 \\
\hline \multirow[t]{2}{*}{ Aumento del poder adquisitivo del segmento objetivo } & 0.09 & 4 & 0.36 \\
\hline & 1 & & 2.74 \\
\hline
\end{tabular}


Tomando en cuenta los resultados obtenidos, se puede inferir entonces que, la empresa inmobiliaria está en capacidad de responder ligeramente por encima del promedio a las exigencias de la industria.

Como principal factor de amenaza se tiene al stock de proyectos y departamentos en Lima, que es amplio y estos proyectos están principalmente hechos por grandes constructoras, por lo que representa una amenaza a la empresa inmobiliaria.

Como principal oportunidad está la demanda insatisfecha en el tipo de proyectos con el rango de precios que tiene la empresa inmobiliaria.

\section{b) Evaluación Interna:}

Según la matriz de evaluación de factores internos, se trabajará la misma en función de descubrir cuáles son los principales factores que determinen las fortalezas para el desarrollo de la empresa.

Tabla 41

Matriz de evaluación de factores internos

\begin{tabular}{lccc}
\hline \multicolumn{1}{c}{ EFI } & PONDERACION & VALOR & VALOR TOTAL \\
& P & Q & Q \\
\hline DEBILIDADES & 0.1 & 3 & 0.3 \\
\hline Presupuesto limitado para acciones comerciales. & 0.1 & 3 & 0.3 \\
Poca experiencia en elaboración de proyectos inmobiliarios & 0.06 & 4 & 0.24 \\
Crecimiento sostenido de la demanda por viviendas & 0.06 & 4 & 0.24 \\
Centrados en segmentos de NSE bajo & 0.05 & 3 & 0.15 \\
Margen reducido por el nivel de riesgo del segmento & & & 0.2 \\
\hline FORTALEZAS & 0.1 & 2 & 0.1 \\
\hline Enfocado en un solo proyecto & 0.1 & 1 & 0.12 \\
Tiene un numero de departamentos menor a proyectos similares & 0.06 & 2 & 0.2 \\
Se encuentra ubicado en un lugar estratégico & 0.1 & 2 & 0.14 \\
Terreno propio. & 0.07 & 2 & 0.2 \\
Viviendas de un metraje estándar. & 0.1 & 2 & 0.2 \\
Precios accesibles. & 0.1 & 2 & $\mathbf{2 . 3 9}$ \\
De fácil acceso a crédito Mi Vivienda. & $\mathbf{1}$ & \\
\hline
\end{tabular}


De acuerdo al resultado obtenido de la ponderación de factores internos se puede deducir que la posición de la empresa es débil internamente, básicamente por el tamaño y la experiencia de la misma.

En términos culturales la empresa se encuentra bien estructurada, la principal debilidad es el tamaño de la misma, lo cual impide que se destine mucho presupuesto para promocionar la existencia del proyecto, y esta es una de las claves para darlo a conocer y poder contar con el número de departamentos en preventa requeridos como mínimo para el financiamiento del proyecto por la entidad financiera.

\section{c) Estrategia del Negocio:}

Luego de la evaluación de los resultados de la matriz EFE y EFI, podemos tener una idea de la posición interna de la empresa y en la industria. Según David (2013), existen distintas estrategias a aplicar en una empresa o combinaciones de las mismas. Generalmente las empresas grandes son las que aplican este tipo de estrategias combinadas.

Entre las principales estrategias tenemos:

- Estrategias integrativas: como su nombre lo dice, en esta estrategia, la empresa busca integrarse con proveedores y/o distribuidores e inclusive competidores, para ganar control y/o expandir mercados, reducir costos o brindar un servicio más completo. Entre las estrategias integrativas se tiene:

- Integración hacia adelante: consiste en integrar a distribuidores o vendedores y así lograr tener control en términos de rapidez, calidad de servicio y 
seguimiento de las actividades que están estrechamente ligadas al cliente.

- Integración hacia atrás: consiste en integrar a proveedores y así lograr tener control en términos de calidad de insumos o servicios y en términos de costo. Dentro de la cadena de valor, el aporte puede ser bastante significativo.

- Estrategias intensivas: recibe este nombre ya que supone un esfuerzo extra para lograr mejorar un producto o el posicionamiento de la empresa para ganar más ventas o participación de mercado. Entre las estrategias intensivas están:

- Penetración de mercado: en esta estrategia básicamente se busca ganar participación de mercado mediante la explotación de las herramientas de marketing.

- Desarrollo de mercados: para este caso, lo que se hace básicamente es explorar nuevos mercados o buscar presencia en nuevas zonas geográficas donde no existía el producto o servicio anteriormente.

- Desarrollo de producto: esta estrategia, como su nombre lo indica, busca desarrollar el producto o servicio que ofrece la empresa para generar más ventas. Es decir, la innovación es el recurso clave y es 
aquí donde la investigación y desarrollo tienen un papel importante.

- Estrategias de diversificación: lo que busca básicamente este tipo de estrategias es salir del core de la empresa e introducirse en otros rubros y/o tipos de productos y/o segmentos. Este tipo de estrategias actualmente ya no se dan, debido a que últimamente las empresas buscan centrarse en su actividad central para ser más productivos en ella. Entre ellas están:

- Diversificación relacionada: se les llama así a las empresas que las actividades dentro de su cadena de valor se encuentran estrechamente relacionadas.

- Diversificación no relacionada: por el contrario, a las relacionadas, se les dice así, porque las actividades dentro de su cadena de valor no guardan una relación en absoluto.

- Estrategias defensivas: como su nombre lo indica estas estrategias están hechas para ser tomadas en caso de supervivencia del negocio. Existen tres tipos de estrategias defensivas:

- Recorte de gastos: básicamente se trata de un tema de eficiencias para poder generar un ahorro que revierta la caída de las ventas y los márgenes de ganancia. 
- Desinversión: es una forma de recolectar capital o como parte de recorte de gastos que sirvan para hacer otras inversiones estratégicas futuras.

- Liquidación: reconocer que la empresa ha fracaso y liquidar o vender por parte los activos es también una estrategia defensiva. esta estrategia se da en función de continuar perdiendo y generar algún tipo de liquidez al vender los activos a precio de mercado y contar con un valor de recupero.

Luego del análisis de la empresa y las opciones que plantea la teoría como estrategias posibles se ha analizado y la empresa por su y características quedaría en la estrategia de desarrollo de producto.

\subsection{Determinación de las ventajas competitivas críticas}

Según Porter (citado en David, 2013), las estrategias genéricas permiten que las empresas tengan una ventaja competitiva a partir de tres ejes fundamentales:

- Liderazgo en costos: donde se hace hincapié en que el precio por unidad de producto sea bastante bajo, con lo cual se satisfaga a los consumidores que basan su decisión de compra en unos centavos de diferencia. Generalmente se da en empresas de consumo masivo.

- Diferenciación: a diferencia de liderazgo en costos, esta estrategia busca tener productos únicos, que no tengan como factor determinante el precio ya que, para el segmento objetivo, este sería irrelevante. Esta es la ventaja principal del proyecto de La Inmobiliaria ya que, será el primer proyecto sostenible del distrito. 
- Enfoque: como su nombre lo dice, se basa en ofrecer un producto orientado a satisfacer las necesidades de un nicho o segmento en particular, ofreciendo las características que este grupo de consumidores necesita

\subsection{Diseño de la estructura organizacional deseada}

De acuerdo a Jones (2013), “el diseño organizacional es el proceso mediante el cual los gerentes seleccionan y administran aspectos de la estructura y cultura, de tal forma que la organización controle las actividades necesarias para alcanzar sus metas” (p.23). Es decir, los altos mandos toman la estructura y cultura organizacional como los instrumentos que harán posible la consecución de las metas y el diseño organizacional marca las pautas del cómo se realizará esta tarea en todo nivel de la organización.

El comportamiento de toda la organización está en función del diseño organizacional y los principios o valores de la empresa. Este comportamiento permite hacerle frente tanto al frente interno como externo, dependiendo de lo que demande la coyuntura de la empresa y el ambiente respectivamente.

Un buen diseño de la cultura y estructura organizacional asegura la supervivencia de la organización y, además, una respuesta rápida al contexto cambiante actual.

Para comenzar con el diseño organizacional se debe analizar los ápices estratégicos según el tamaño de la organización, el nivel de jerarquía y los componentes administrativos.

Se debe tener en cuenta la cadena mínima de mando y el espacio de control que cada nivel jerárquico supone. Según Jones (2013), la cadena mínima de mando debe estar en función a las metas de la empresa y debe mantenerse lo más horizontal posible para evitar las burocracias y reducir costos en recursos de control de personal.

Según Jones, el proceso de diferenciación se utiliza para establecer los recursos necesarios quienes realizarán las diferentes tareas dentro de la organización. Dentro de los tipos existe la diferenciación baja, que se da en las organizaciones simples donde las tareas no 
son tan complejas y pueden ser desarrolladas por pocas personas de tal forma que se simplifica las coordinaciones.

Uno de los grandes desafíos de este tipo de organización es la confusión de funciones y no se tiene bien claro la responsabilidad de los actores dentro de la empresa.

Teniendo en cuenta que la empresa será una Pequeña Empresa (PYME), y, según lo indicado por Jones, la estructura organizacional planteada para la organización sería de diferenciación baja ya que, tanto la división de trabajo como las tareas asignadas, son pocas y simples. Para esto tendríamos tres niveles jerárquicos: un gerencial general, un administrador general y dos vendedores. Cabe resaltar que la construcción del proyecto Arequipa será tercerizada mediante licitación.

De acuerdo a la ley general de trabajo peruana y el tamaño planteado para la empresa según sus ventas anuales, esta sería catalogada como PYME, existe ciertos criterios generales a tomar en cuenta las cuales se detallan en la siguiente tabla:

Tabla 42

Constitución de una MYPE

\begin{tabular}{ll}
\hline & Constitución de Empresa \\
\hline Tipo & PYME \\
Sociedad & S.R.L \\
Giro & Inmobiliaria \\
El tiempo de duración & Plazo fijo \\
Inicio a las actividades comerciales & Jun-18 \\
Domicilio comercial & Magdalena \\
Razón social de la sociedad. & La Inmobiliaria \\
Administrador General & Juan Pérez \\
Régimen tributario & Régimen Mype Tributario 2017 \\
Cantidad de trabajadores & 4 \\
Ventas brutas anuales & S/. 1,500,000.00 \\
& \\
Régimen Laboral & Especial MYPE excluye: pago CTS, gratificaciones, \\
& pago de utilidades, seguro de vida, asignación \\
& familiar, sobretasa de trabajo nocturno. \\
\end{tabular}


Por lo anteriormente indicado, la estructura de la organización de la inmobiliaria quedaría como sigue:

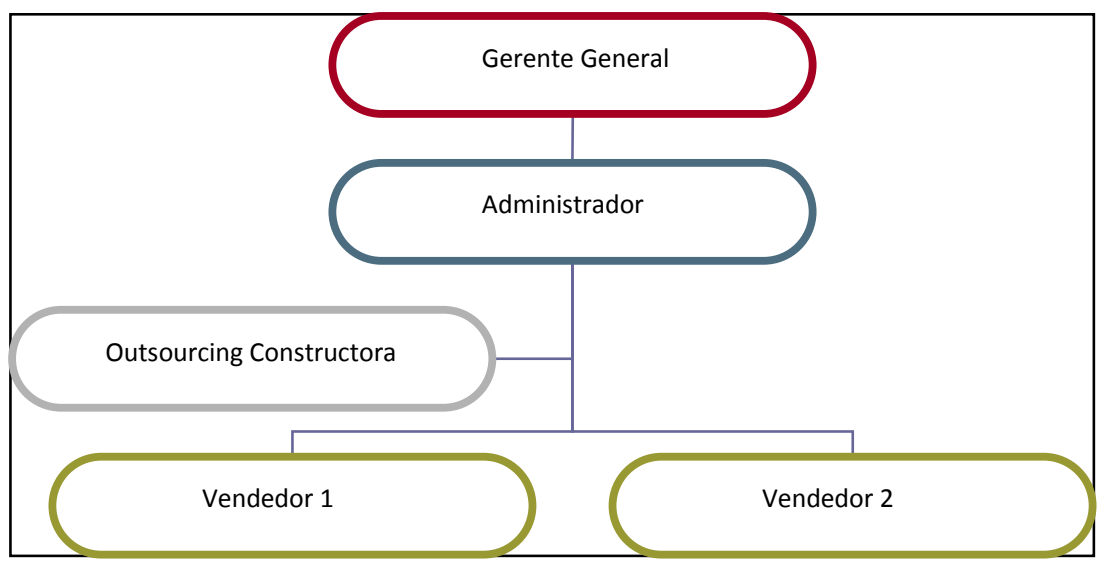

Figura 40. Estructura organizacional de la inmobiliaria.

Debajo del administrador general se encontrará el outsourcing, quienes estarían controlados por el mismo y bajo las directivas del gerente general. Las funciones y definiciones de los roles de cada uno de los puestos serán definidos en el próximo acápite.

\subsection{Diseño de los perfiles de puestos clave}

En el punto anterior se realizó la creación de la estructura organizacional bajo la cual se definieron los cargos más importantes de la empresa. En este punto se revisará el diseño de los perfiles de estos puestos clave.

Según los bloques de construcción de la diferenciación de Jones (2013), existe un bloque básico que es el del rol organizacional, en el cual se define el comportamiento de un individuo dentro de la organización para realizar una determinada tarea.

Como subunidades se presentan las funciones y/o divisiones. Las funciones son subunidades donde se encuentran personas que realizan una misma actividad o actividades similares y las divisiones agrupan las funciones de responsabilidades similares. 


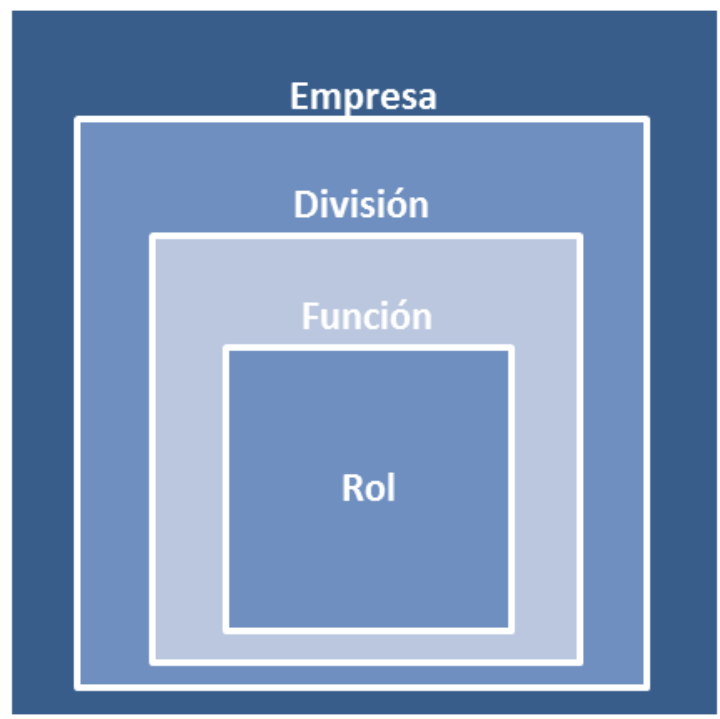

Figura 41. Bloques de construcción de diferenciación organizacional.

Según lo expuesto en la estructura organizacional existen tres puestos clave por rol dentro de la empresa:

\title{
- Gerente General
}

\begin{tabular}{|l|}
\hline Puesto: \\
\hline Área: \\
\hline Reporta a: \\
\hline Funciones: \\
\hline Estudios:
\end{tabular}

\author{
Gerente General \\ Directiva \\ Accionistas
}

Realizar evaluaciones periódicas acerca del cumplimiento de las funciones del personal de la empresa y el outsourcing. Planear y desarrollar metas a corto y largo plazo junto con los objetivos generales de la empresa. Velar por la integridad del proyecto.

Titulado de las especialidades de Ingeniería Industrial, Economía y/o administración. De preferencia con especialización en Inmobiliarias

\section{Experiencia:}

Mínima de cinco años (05) en:

- Experiencia en la Gestión de proyectos, de preferencia en el sector inmobiliario

\section{Conocimientos:}

- Conocimiento de Materiales de uso en la industria constructora

- Conocimiento de Ofimática

- Capacidad para organizar personal a cargo.

- Dominio del idioma Inglés a nivel: Avanzado

\section{Competencias}




\begin{tabular}{|c|c|}
\hline \multicolumn{2}{|l|}{ Requeridas: } \\
\hline & - $\quad$ Habilidad de Negociación. \\
\hline & - $\quad$ Sólida Formación en Valores. \\
\hline & - $\quad$ Capacidad para trabajar en equipo. \\
\hline Sueldo: & \multirow[t]{2}{*}{ S/ 6,000.00 (Sueldo Bruto Fijo) } \\
\hline $\begin{array}{l}\text { Lugar de Trabajo y } \\
\text { Horario: }\end{array}$ & \\
\hline & Lima - Magdalena \\
\hline & \multirow[t]{2}{*}{ Lunes a Sábado de 8.30 am a 5.30 pm } \\
\hline Beneficios: & \\
\hline & Planilla de la empresa \\
\hline
\end{tabular}

\section{- Administrador General}

\begin{tabular}{l} 
Puesto: \\
\hline Área: \\
\hline Reporta a: \\
\hline Funciones: \\
\hline \\
\hline Estudios:
\end{tabular}

Administrador General

Administrativa

Gerente General

Representar a la empresa en las actividades legales, ceremoniales y simbólicas. Escuchar y entrenar al personal. Asignar recursos. Dar instrucciones correctivas y capacitar. Evaluar el desempeño. Elaborar la planilla de pagos al personal. Realizar la contabilidad y finanzas de la empresa. Controlar la relación con el outsourcing, Supervisar el avance de la obra. Manejo de inconvenientes de diversa índole.

Bachiller de las especialidades de Ingeniería Industrial, Economía y/o administración. De preferencia con especialización en Inmobiliarias

\section{Experiencia:}

Mínima de Diez años (10) en:

- $\quad$ Experiencia en la Gestión de proyectos, de preferencia en el sector inmobiliario

\section{Conocimientos:}

\section{Competencias \\ Requeridas:}

- Conocimiento de Materiales de uso en la industria constructora

- Conocimiento de Ofimática

- Capacidad para organizar personal a cargo.

- Dominio del idioma Inglés a nivel: Intermedio

- Habilidad de Negociación.

- Sólida Formación en Valores.

- Capacidad para trabajar en equipo. 


\begin{tabular}{l|l} 
Sueldo: & S/ 3,5000.00 \\
\hline $\begin{array}{l}\text { Lugar de Trabajo y } \\
\text { Horario: }\end{array}$ & \\
& Lima - Magdalena \\
& Lunes a Sábado 8 am -6.00 pm
\end{tabular}

- Vendedor

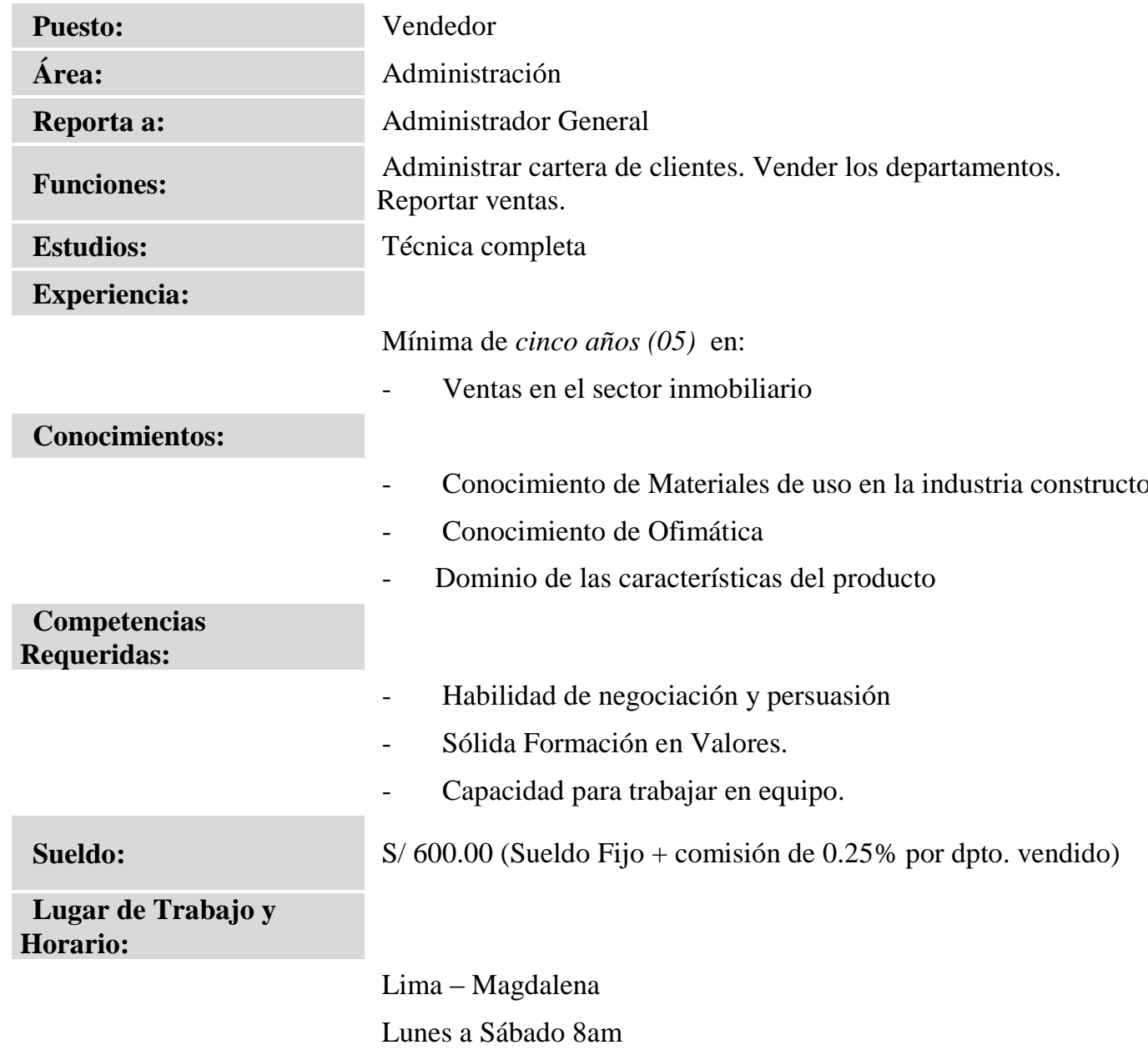

\subsection{Remuneraciones, compensaciones e incentivos}

Dessler (2015), define remuneración como "todas las formas de retribuciones destinadas al personal las cuales se derivan de su empleo" (p.296), es decir, la remuneración es el pago al trabajador por los servicios prestados a la empresa. 
Según Dessler, este pago consta de dos partes: remuneración monetaria directa o dinero y remuneración monetaria indirecta o beneficios sociales. Existe el tipo de pago por tiempo y por desempeño.

Dentro de las formas de remuneración existen las fijas y las variables y/o una combinación de ambas.

Según la política remunerativa del Régimen Especial MYPE se debe cumplir las siguientes consideraciones indicadas en la Tabla 43:

Tabla 43

Consideraciones para la remuneración de una PYME.

\begin{tabular}{|c|c|}
\hline Concepto & Pequeña Empresa \\
\hline Remuneración Mínima Vital & 600.00 Nuevos Soles \\
\hline \multicolumn{2}{|l|}{ Jornada, horario de trabajo, } \\
\hline sobretiempo, descansos semanales y feriados & $\begin{array}{l}\text { ocho horas diarias o } 48 \text { horas semanales Sobretasa no aplica } \\
\text { en la jornada nocturna habitual }\end{array}$ \\
\hline \multicolumn{2}{|l|}{ Sobretasa nocturna } \\
\hline Asignación familiar & No aplica \\
\hline Descanso Vacacional & 15 días del año \\
\hline \multirow{2}{*}{ Compensación por tiempo de servicio } & 15 remuneraciones diarias por año \\
\hline & Tope: 90 remuneraciones diarias \\
\hline Gratificaciones & $1 / 2$ remuneración mensual en julio y diciembre \\
\hline Indemnización por despido & 20 remuneraciones diarias por año \\
\hline \multirow[t]{2}{*}{ injustificado } & Tope: 120 remuneraciones diarias \\
\hline & (cuatro sueldos) \\
\hline Seguro de Vida & Si aplica \\
\hline Utilidades & Si aplica \\
\hline Salud & ESSALUD ( $9 \%$ de la remuneración) \\
\hline \multirow[t]{2}{*}{$\begin{array}{l}\text { Seguro Complementario de } \\
\text { Trabajo y de Riesgo (SCTR) }\end{array}$} & Si, cuando corresponda \\
\hline & No afiliado: afiliación obligatoria al \\
\hline \multirow[t]{2}{*}{ Pensiones } & SNP o SPP \\
\hline & Afiliado: aporte obligatorio \\
\hline
\end{tabular}

\subsection{Política de recursos humanos}

Según Barrena (2016), las políticas organizativas o de recursos humanos han ido adaptándose a medida que el cambio del entorno lo exija, de la misma forma, que guarde 
relación con la cultura organizacional interna que se consideran de mucha importancia para la conservación de la empresa.

Cuando se relaciona con las normas y valores de la sociedad y medio ambiente existe un conjunto una mejor obtención de recursos, mejores ventas, y compromiso de los clientes, proveedores y empleados.

De acuerdo a la Ley General de Trabajo, la política de recursos humanos de la empresa se regirá por:

- Del contrato de trabajo: el trabajador está obligado a prestar servicios al empleador bajo su mando a cambio de un salario. Este contrato se celebrará por escrito, con duración según lo acordado entre ambas partes siendo este de clase por obra determinada o servicio específico.

- Igualdad de derecho: todos los trabajadores se encuentran en igualdad de derecho y beneficios que por ley se le otorgue según lo estipulado bajo el tipo de empresa.

- Derechos sociales: todos los trabajadores son sujetos al recibir los derechos sociales del primero de mayo, vacaciones equivalentes al régimen especial, y pago adelantado de derechos sociales cumpliendo lo que la ley exponga.

- Régimen de seguridad social: todos los trabajadores son sujetos al régimen de seguridad social de salud y el sistema de pensiones según lo que establece la ley.

- Derechos de los trabajadores: los trabajadores tienen derecho a ocupar un cargo dentro de la empresa, proteger su vida e integridad física dentro del trabajo, el respeto a su integridad, honor e intimidad, protección contra acoso sexual y otras ofensas similares, pago puntual e íntegro de su remuneración y beneficios, no ser despedido sin causa justa, ejercer los derechos colectivos de sindicación, negociación colectiva y huelga, ser informado de sus obligaciones y derechos. 
- Obligaciones de los trabajadores: realizar las labores asignadas, cumplir el reglamento interno de trabajo, guardar una conducta apropiada y respetar y mantener el orden y la disciplina del centro de trabajo, guardar respeto al empleador y representantes, cumplir normas de seguridad e higiene dentro del centro de labores, tener bajo confidencialidad información del empleador, no trabajar para beneficio propio en actividades idénticas, proporcionar al empleador información veraz, presentarse a sus labores bajo el horario y lugar asignados, cuidar los instrumentos y útiles brindados, participar en actividades de capacitación.

\section{a) Reglamento de Interno de trabajo}

De acuerdo a lo estipulado en la Ley General de Trabajo, la empresa está obligada a entregar el reglamento de trabajo a todos los colaboradores de la empresa. El mismo que para esta empresa se encuentra en el Anexo 6

\section{b) Manual de Funciones}

Se encuentra en el Anexo 7. 


\section{Capitulo VII. Plan de Marketing}

El plan de marketing es de vital importancia para el proyecto, puesto que en él se definirán no solamente las estrategias de mercadeo, sino también que productos y atributos serán vendidos para maximizar su rentabilidad. Además, las técnicas de publicidad implementadas en este capítulo, marcarán la pauta para la venta rápida de los departamentos y así poder obtener la rentabilidad deseada con un periodo de recuperación corto.

\subsection{Estrategias de marketing}

De acuerdo a lo expuesto por Kotler y Amstrong (2013), la estrategia de marketing dicta el método por el cual la empresa creará valor para el cliente. Ya seleccionado el segmento meta, es necesario saber el cómo se dará el servicio para poder satisfacer a ese segmento.

Entonces, bajo esta premisa, en los resultados obtenidos de la investigación de mercado y teniendo nuestro segmento meta definido se procederá a realizar la estrategia de marketing bajo el esquema táctico de las cuatro P de Jerome McCarthy.

Para poder lograr un mejor impacto en el cliente final se tendrá en cuenta el método de las comunicaciones integradas de marketing (CIM). Según Clow y Baak (2011), la comunicación integral de marketing hace referencia a una coordinación e integración de herramientas, vías, fuentes y medios que maximicen y garanticen un impacto sobre los clientes y/o las personas interesadas en el producto.

\subsubsection{Estrategia de Producto}

El producto es todo bien o servicio (o combinación de ambos) que la empresa brinda al cliente. En el caso de la presente tesis, el producto final son los departamentos sostenibles del proyecto multifamiliar. (Kotler y Amstrong, 2013)

Según la definición del Programa de las Naciones Unidas para el Medio Ambiente (PNUMA) (Holcin, 2017), se entiende por construcción sostenible o 
sustentable una forma, dentro del sector de la construcción, de proceder y realizar los proyectos encaminados hacia el logro del desarrollo sostenible, lo que implica tener en cuenta aspectos medio ambientales, socioeconómicos y culturales. Concretamente, involucra cuestiones tales como diseño y administración de edificaciones, construcción y rendimiento de materiales y uso de recursos para la construcción de determinadas estructuras.

En cuanto al aspecto del medio ambiente, este se vincula al hecho de preservar y valorizar los recursos naturales. La no utilización de recursos que puedan dañar la naturaleza, es un parámetro a tener en cuenta.

Sobre la sociedad, implica que los seres humanos deben ser capaces de satisfacer sus necesidades primarias, sin detrimento del bien común. El uso de materiales aisladores de sonidos, es uno de los ejemplos que aplican para el caso.

Acerca de la economía, implica el impulsar el desarrollo y producción de los países en vías de desarrollo para lograr la misma calidad y nivel de vida que los países desarrollados.

Cabe resaltar que, existirán subproductos diferenciados por metraje y atributos, teniendo todos listados en la siguiente tabla:

Tabla 44

Tipos de producto y sus características:

\begin{tabular}{cccc}
\hline Producto & Atributos & Metraje $\left.\mathbf{( m}^{\mathbf{2}}\right)$ & Cochera \\
\hline Departamento 1 & Tres cuartos & 132.5 & $\mathrm{Si}$ \\
Departamento 2 & Tres cuartos & 110.94 & $\mathrm{Si}$ \\
Departamento 3 & Dos cuartos & 85.4 & $\mathrm{Si}$ \\
Departamento 4 & Dos cuartos & 75.21 & $\mathrm{Si}$ \\
Departamento 5 & Dos cuartos & 61.2 & No \\
\hline
\end{tabular}




\subsubsection{Estrategia de Precio}

El precio es la valoración monetaria del producto o servicio que los clientes deben de pagar por obtener el bien. Este precio debe estar en relación al valor percibido por el cliente para que lo tome como un beneficio. (Kotler y Amstrong, 2013)

Se tomará como referencia los precios del mercado para la fijación del precio de los productos, pero estarán por debajo de los establecidos para lograr una diferenciación.

Estos mismos estarán en función del área y la ubicación de piso de los departamentos como sigue en la tabla a continuación:

Tabla 45

Fijación de Precios por unidad de departamento:

\begin{tabular}{cccr}
\hline Producto & Metraje $\left(\mathbf{m}^{2}\right)$ & $\begin{array}{c}\text { Costo (S/) } \\
\text { sin IGV }\end{array}$ & $\begin{array}{c}\text { Costo (S/) } \\
\text { con IGV }\end{array}$ \\
\hline Departamento 1 & 132.5 & S/. 784,858 & S/. 926,133 \\
Departamento 2 & 110.94 & S/. 657,148 & S/. 775,435 \\
Departamento 3 & 85.4 & S/. 505,863 & S/. 596,919 \\
Departamento 4 & 75.21 & S/. 445,503 & S/. 525,694 \\
Departamento 5 & 61.2 & S/. 362,516 & S/. 427,768 \\
\hline
\end{tabular}

Por lo que el precio promedio por departamento es de S/ 550,000 (sin IGV) se encuentra en el precio promedio de los departamentos del mismo metraje de la zona sin la diferenciación de ser sostenible.

Debido a la naturaleza del producto, y el análisis del método para su adquisición, este resulta ser un producto que será, en su mayoría, financiado por un préstamo bancario.

El producto tiene una ventaja diferencial que, al encontrarse dentro de un rango de precios asequible, calza dentro de los rangos de financiamiento del Fondo 
MiVivienda, por lo cual, al mantener un buen record de pagos, el fondo otorga un Bono de Buen Pagador, subvencionando así su compra y recibiendo un descuento en el pago del predio.

Adicionalmente, el Fondo MiVivienda, otorga un bono especial para proyectos sostenibles, como el de La Inmobiliaria. Para este caso, el fondo "devuelve" el 4\% del valor del financiamiento descontando el Bono del Buen Pagado si existiese si el proyecto cuenta con la calificación 2 .

Esto hace aún más atractiva la oferta del departamento, ya que "abarata" su costo, incrementando aún más la posibilidad de la venta rápida y mejorando la rentabilidad del proyecto mediante la disminución del periodo de recuperación.

\subsubsection{Estrategia de distribución}

La distribución son los medios por los cuales la empresa hace que el producto este a disposición de los consumidores finales. (Kotler y Amstrong, 2013)

Para la presente tesis, debido a la naturaleza del producto, se entenderá la estrategia de distribución como estrategia de comercialización. Debido a que se trata de un proyecto único y de une empresa pequeña, la estrategia comercializadora está basada en una buena comunicación publicitaria, a través de los principales canales, y la atención de la fuerza de ventas dentro y fuera del punto de obra.

- Oficina principal: Una persona estará a disposición para la atención de consultas y solicitudes de posibles clientes y clientes de cartera.

- FFVV directa: dos personas encargadas de buscar Clientes del grupo objetivo en campo y ofrecer los productos del proyecto.

- Digital: Sección "Contáctanos" en la web site de La Inmobiliaria, con el Formulario respectivo que realizará la toma de datos básicos del Cliente para prospectarlos. También se capturará clientes potenciales desde la cuenta Facebook. 
- Central 500-0000: Atención de consultas y clientes potenciales para canalizar su atención con la fuerza de venta directa.

\subsubsection{Estrategia de promoción y publicidad}

La promoción y publicidad abarca todas las actividades que comunican la existencia del producto a los clientes meta para que lo adquieran. (Kotler y Amstrong, 2013)

Para el caso del proyecto se ha realizado una estrategia de manera integral en los diversos canales publicitarios existentes. La mayoría de los canales propuestos son los digitales, debido a su bajo costo y rápida difusión masiva.

Se utilizará:

- Actividades Above The Line (ATL): son todas aquellas actividades de publicidad que utilizan medios masivos. (Conexión ESAN, 2015)

- Cuatro anuncios al año en Clasificados del Diario El Comercio.

- Tres anuncios al año en Revista Habitad.

- Panel ubicado en zona aledaña (Javier Prado con Paseo Parodi)

- Actividades Below The Line (BTL): son las actividades de marketing que utiliza canales más directos para comunicar la oferta a sus potenciales clientes. (Conexión ESAN, 2015)

- Volanteo del Proyecto en Centro Comercial Real Plaza Salaverry y Plaza San Miguel.

- Díptico con información del proyecto.

\section{- Digital}

- Web site de La Inmobiliaria que incluye información de la empresa y el proyecto (diseño y precios). 
- Redes sociales, principalmente Facebook con un fan page donde se exhibirán las imágenes del proyecto.

- Banner especial del proyecto para viralización en Facebook

\section{- Marketing directo}

- A principales clientes que dejen sus datos de contacto en web site.

\subsection{Estrategia de ventas}

\subsubsection{Plan de ventas}

De acuerdo a Jobber y Lancaster (2012), el plan de ventas está expuesto a ciertos factores de tipo conductual, tecnológico y administrativo que influyen de alguna manera en la forma en cómo se realizará la venta y su respectiva administración.

A continuación, se relacionará cada factor de acuerdo a la realidad del proyecto de inversión:

- En los factores de tipo conductual tenemos:

- Las expectativas del cliente: lo que el cliente espera del proyecto o de su vivienda futura es determinante para poder venderle los beneficios correctos.

- La satisfacción del cliente: es importante lograr su satisfacción para evitar futuras quejas o posibles pérdidas por no brindar el servicio/producto idóneo debido a malas interpretaciones del cliente con respecto a lo ofrecido con el producto.

- Evasiones del cliente: cada vez más la tendencia es dejar a los intermediarios realizar todo el trámite de compra venta y poder así "evitar" el contacto con el vendedor y caer en errores documentarios que puedan retrasar su compra.

- El poder de expansión de clientes: existe un número importante de clientes con demanda para el producto, lo cual puede repercutir en 
una exigencia por precios bajos y así dañar el margen de ganancia que se pretende.

- La globalización y fragmentación de los mercados: al existir la fragmentación de mercados el cliente puede recurrir a un mercado que se ajuste de una mejor manera a sus requerimientos con costo de cambio relativamente bajo o nulo en algunos casos.

- En los factores de tipo tecnológico:

- Automatización de fuerza de ventas: implica tanto herramientas de hardware como software, que hacen más rápida la atención del cliente y la interacción de la fuerza de ventas con la empresa.

- Oficinas virtuales de ventas: donde necesariamente no existe espacio físico para atender a los clientes, se hace a través de sitios web. Esta dentro de las propuestas de estrategia de distribución, pero únicamente como un tema informativo más no transaccional.

- Canales electrónicos de ventas: son las herramientas que puede brindar la plataforma de internet y las compras por teléfono, que para el caso no serían aplicables.

- En los factores administrativos:

- Marketing directo: son las herramientas de publicidad y comunicación con el cliente virtuales, como el correo electrónico y el telemarketing.

- Fusión de ventas y marketing: donde se ha creado plataformas intermedias entre la fuerza de venta, la empresa, los clientes y proveedores para brindar un servicio más rápido.

Tomando en cuenta estos factores y la elección del mejor canal de ventas por segmento y producto se trabajará en base de realizar la venta a través del canal que 
genere mayor rentabilidad para cierto producto, por lo que se ha creado una matriz de ventas según estas variables:

Tabla 46

Distribución de metas

\begin{tabular}{|c|c|c|c|c|c|c|c|}
\hline \multirow[t]{2}{*}{ Año } & \multirow[t]{2}{*}{ Cantidad } & $\begin{array}{c}\text { Precio } \\
\text { Promedio }\end{array}$ & \multicolumn{2}{|c|}{$\begin{array}{l}\text { Comisión por } \\
\text { departamento }\end{array}$} & $\begin{array}{l}\text { Total en } \\
\text { comisiones }\end{array}$ & \multicolumn{2}{|c|}{$\begin{array}{l}\text { Comisiones } \\
\text { al mes }\end{array}$} \\
\hline & & 545,836 & & $0.25 \%$ & S/. $31,385.59$ & $\mathrm{~S} /$. & 872 \\
\hline Año 0 & 8 & & S/. & 1,365 & 10,985 & S/. & 915 \\
\hline Año 1 & 8 & & S/. & 1,365 & 10,985 & $\mathrm{~S} /$. & 915 \\
\hline Año 2 & 7 & & S/. & 1,365 & 9,416 & S/. & 785 \\
\hline
\end{tabular}

\subsubsection{Políticas de servicios y garantías.}

\section{a. Política de servicios}

La Inmobiliaria trabajará principalmente para satisfacer las necesidades de todos sus clientes manteniendo una continua mejora en los aspectos de funcionamiento de la empresa incluyendo un compromiso de cumplimiento de los requisitos legales y reglamentarios del rubro.

La Política de Calidad establece los principios y la orientación de todo el personal que trabaja en La Inmobiliaria y es referencia para establecer y revisar los objetivos de calidad siempre pensando en la satisfacción de todos sus clientes.

La Inmobiliaria proporcionará en cada momento los recursos necesarios, tanto materiales como humanos, para implantar, mantener y mejorar los procesos del sistema de gestión y lograr y aumentar la satisfacción del cliente. Desarrolla y gestiona los factores físicos y humanos del entorno de trabajo necesarios para lograr la conformidad del servicio prestado. 


\section{b. Política de garantías}

Las políticas de garantías se encuentran definidas por dos tipos de garantías:

- Garantía por defectos de construcción: los departamentos en venta, se encontrarán cubiertos contra defectos de calidad y/o fabricación de los materiales por un plazo de 12 meses a partir de la entrega de los mismos a los propietarios. Esta garantía no incluye fallas por mal uso de los materiales y/o instalaciones.

- Garantía por vicios de la construcción: De acuerdo al RNE Norma G.30 Derechos y Responsabilidades, articulo 54, La Inmobiliaria será responsable y responderá frente al cliente por la propiedad vendida según comprende los defectos y daños materiales indicados a continuación:

○ Por destrucción total o parcial, o cuando presente evidente peligro de ruina o graves defectos por vicio de la construcción, por daños materiales causados en el producto de la construcción por vicios o defectos que afecten la cimentación, las estructuras, o todo aquel elemento o subconjunto que afecte directamente a las estructuras, comprometa la resistencia mecánica, la estabilidad, y el tiempo de la vida útil de la obra.

○ Por los daños materiales causados en la obra por vicios o defectos de los elementos constructivos o de las instalaciones, ocasionados por el incumplimiento de los requisitos de calidad de los materiales. 
○ Por los daños materiales por vicios o defectos de ejecución que afecten a elementos no estructurales o por defecto del suelo, si es que hubiera suministrado o elaborado los estudios, planos y demás documentos necesarios para la ejecución de la obra y que forman parte del producto de la construcción.

\section{c. Política de Gestión de reclamos}

La gestión de reclamos se presenta en los procesos de la construcción del proyecto, para eliminar o prevenir los reclamos se debe llevar un control de calidad de las adquisiciones y revisión de los contratos con terceros a fin no tener ocurrencias o sorpresas durante el desarrollo del proyecto

\section{- Identificación del reclamo.}

Se debe tener un completo conocimiento del alcance de los trabajos y de los términos contractuales para poder identificar cambios en el alcance o en los términos contractuales y se requiera un ajuste al contrato.

La identificación adecuada incluye no solamente una interpretación de lo que requiere el contrato sino también una descripción documentada de la actividad considerada como extra, con respecto a lo requerido en el contrato.

\section{- Cuantificación del reclamo.}

Una vez que una de las actividades haya sido revisada y tomada la decisión que es digna de ser considerada un Reclamo, el siguiente paso es solucionarlo, para que no se convierta en términos 
monetarios o pérdidas que pongan en riesgo la rentabilidad del proyecto.

\section{- Prevención del reclamo.}

A fin de mantener una política de total calidad, antes de presentar algún reclamo es mejor prevenir. El cierre de un buen contrato, donde el alcance esté muy bien definido, los riesgos localizados, y sea ejecutado correctamente, dará como resultado una alta probabilidad de que no se originen reclamos.

De esta manera se estará minimizando el riesgo.

\section{- Resolución del reclamo.}

Según la política de calidad total de la empresa, la meta es resolver los reclamos en el menor tiempo y al más bajo nivel de la organización como sea posible.

\section{Capitulo VIII. Planificación Financiera}

El objetivo principal de una empresa es crear valor, según Ross (2012). Para poder obtener ese "valor" es necesario pasar por distintos procesos desde la inversión, pasando por el flujo operativo y el análisis de la rentabilidad obtenida por toda la operatividad de la empresa.

Luego de haber fijado la meta principal de la empresa, se debe hacer una planificación para poder lograrla y es aquí donde se buscará los pasos para poder llegar a los objetivos y metas propuestos inicialmente. 
La planificación financiera tiene como objetivo principal equilibrar económicamente todos los procesos de la empresa. Entonces, la planificación financiera es la encargada de dar la estructura en base a lo que busca el negocio, utilizando la contabilidad como herramienta principal de operación y las finanzas como análisis de los resultados obtenidos. Es aquí donde la plana administrativa tiene una idea clara de sus ingresos, egresos y rentabilidad por cada unidad monetaria invertida.

En el presente capítulo se tangibilizan las ideas captadas y propuestas evaluadas en los capítulos anteriores, para dar paso a la evaluación de la viabilidad del proyecto en términos de valor para los accionistas.

\subsection{La Inversión}

La inversión es el desembolso de efectivo, o colocación de capital, en un momento dado, con el propósito de adquirir nuevos medios de producción (edificios, maquinarias y equipos, tecnologías, estudios, entre otros) y así generar una ganancia a futuro.

Toda inversión supone un riesgo, un rendimiento esperado y un determinado tiempo de recuperación.

\subsubsection{Inversión pre-operativa}

La inversión pre-operativa, o también conocida como inversión inicial, es aquella que se realiza antes del inicio de las actividades.

En la etapa pre-operativa se debe contar con el capital de trabajo, el fondo de maniobra que sirve para costear los activos corrientes que harán posible el inicio de la etapa operativa del proyecto.

\subsubsection{Inversión en capital de trabajo}

Según el Prof. Javier Gutiérrez de la Univ. Federico Villareal ("Estudio de Inversión", 2016) el capital de trabajo es el dinero en efectivo (o activo corriente) que 
la empresa requiere para la adquisición de bienes y servicios (remuneraciones, alquileres, pago de servicios públicos, etc.), los cuales son necesarios para la operación normal del proyecto durante un ciclo productivo, para una capacidad utilizada y un tamaño determinado.

Por lo general, incluye los activos que se convertirán nuevamente en dinero a corto plazo. En términos contables, el capital de trabajo se subdivide en existencias, monto exigible y monto disponible.

Para el caso de La Inmobiliaria tenemos como principales los siguientes conceptos como inversión en capital de trabajo los gastos pre operativos que incluyen todas las tasas municipales para realizar la construcción, los gastos para constituir la empresa que son la principal fuente de intangibles y los gastos de oficina para empezar a operar.

El detalle de cada uno se muestra en las siguientes tablas:

Tabla 47

Gastos pre operativos

\begin{tabular}{|c|c|c|c|c|}
\hline Concepto & Cost & al Sin IGV & $\operatorname{Cos}$ & al Con IGV \\
\hline Elaboración del expediente técnico & $\mathrm{S} /$. & 67,340 & $\mathrm{~S} /$. & 79,462 \\
\hline Presupuesto por la ejecución del proyecto & $\mathrm{S} /$. & $3,028,547$ & $\mathrm{~S} / \mathrm{.}$ & $3,573,686$ \\
\hline Tramites notariales iniciales & S/. & 16,949 & S/. & 20,000 \\
\hline Tasa por el trámite de la acumulación de terrenos & $\mathrm{S} /$. & 323 & $\mathrm{~S} / \mathrm{s}$ & 381 \\
\hline Tasa por la licencia de demolición Municipalidad + CIP & $\mathrm{S} /$. & 1,394 & S/. & 1,645 \\
\hline Tasa por anteproyecto en consulta & $\mathrm{S} /$. & 2,544 & S/. & 3,002 \\
\hline Tasa por la licencia de edificación Municipalidad + CAP + CIP & $\mathrm{S} /$. & 5,097 & $\mathrm{~S} / \mathrm{s}$ & 6,014 \\
\hline Tasa por conformidad de obra y declaratoria de fabrica & $\mathrm{S} /$. & 5,092 & $\mathrm{~S} / \mathrm{s}$ & 6,008 \\
\hline Tasa para la obtención la factibilidad de agua & $\mathrm{S} /$. & 2,173 & $\mathrm{~S} / \mathrm{s}$ & 2,564 \\
\hline Tasa para la obtención la factibilidad de eléctrica & $\mathrm{S} /$. & 25,424 & $\mathrm{~S} / \mathrm{.}$ & 30,000 \\
\hline Total & $\mathbf{S} /$. & $3,154,882$ & $\mathrm{~S} /$. & $3,722,762$ \\
\hline
\end{tabular}

Los gastos más relevantes, de los pre operativos, son las tasas municipales para poder empezar la obra. Sin estos gastos no es viable empezar el proyecto. Además, como se 
contratará a una empresa constructora para la producción de los departamentos, también se considera como un gasto pre operativo.

Tabla 48

Gastos de constitución de empresa

\begin{tabular}{lcrrr}
\hline \multicolumn{1}{c}{ Concepto } & \multicolumn{2}{c}{ Costo Total Sin IGV } & \multicolumn{2}{c}{ Costo Total Con IGV } \\
\hline Reserva nombre SUNARP * & $\mathrm{S} /$. & 9 & $\mathrm{~S} /$. & 9 \\
Constitución de persona jurídica* $^{*}$ & $\mathrm{~S} /$. & 23 & $\mathrm{~S} /$. & 23 \\
Reserva de marca INDECOPI* & $\mathrm{S} /$ & 250 & $\mathrm{~S} /$. & 250 \\
Licencia de funcionamiento* $_{\text {Minuta y escritura pública de constitución de empresa }}$ & $\mathrm{S} /$. & 279 & $\mathrm{~S} /$. & 279 \\
Total & $\mathrm{S} /$. & 678 & $\mathrm{~S} /$. & 800 \\
\hline
\end{tabular}

Los gastos de constitución de empresa, son los que por ley están ya establecidos y toda empresa formal debe realizar para poder empezar operaciones.

Tabla 49

Gastos de oficina

\begin{tabular}{|c|c|c|c|c|}
\hline \multirow[b]{2}{*}{ Alquiler de oficina } & \multicolumn{2}{|c|}{ Costo Total Sin IGV } & \multicolumn{2}{|c|}{ Costo Total Con IGV } \\
\hline & $\mathrm{S} /$. & 10,169 & $\mathrm{~S} /$. & 12,000 \\
\hline Gastos de Oficina mensual & $\mathrm{S} /$. & 5,085 & S/. & 6,000 \\
\hline Pago de Luz & $\mathrm{S} /$. & 559 & $\mathrm{~S} /$. & 660 \\
\hline Pago de Agua & $\mathrm{S} /$. & 254 & S/. & 300 \\
\hline Pago de internet & $\mathrm{S} /$. & 1,017 & $\mathrm{~S} /$. & 1,200 \\
\hline Pago de mantenimiento de edificio & $\mathrm{S} /$. & 712 & $\mathrm{~S} /$. & 840 \\
\hline Total Presupuesto de Gastos administrativos & $\mathrm{S} /$. & 17,797 & $\mathrm{~S} /$. & 21,000 \\
\hline
\end{tabular}

Dentro de los gastos de oficina, te toma el costo de los principales gastos fuera de planillas en los que se incurrirá para el funcionamiento de la parte administrativa.

Adicionalmente se tomó en cuenta el método del déficit acumulado para poder calcular a cuanto ascendía el mayor déficit acumulado a lo largo de los años de existencia del proyecto y la empresa. Para lo cual, es la siguiente tabla, se encuentra el cálculo año a año. 
Tabla 50

Déficit acumulado Año 0

\begin{tabular}{|c|c|c|c|c|c|c|c|c|c|c|c|c|c|c|}
\hline \multirow[b]{2}{*}{ Meses } & & & \multicolumn{12}{|c|}{ Año 0} \\
\hline & \multicolumn{2}{|r|}{$\mathbf{J}$} & \multicolumn{2}{|r|}{$\mathbf{J}$} & \multicolumn{2}{|r|}{$\mathbf{A}$} & \multicolumn{2}{|r|}{$\mathbf{S}$} & \multicolumn{2}{|r|}{$\mathbf{O}$} & \multicolumn{2}{|r|}{$\mathbf{N}$} & \multicolumn{2}{|r|}{ D } \\
\hline Ingresos por Departamentos & S/. & 545,836 & $\mathrm{~S} /$. & 545,836 & S/. & 545,836 & $\mathrm{~S} /$. & 545,836 & $\mathrm{~S} /$. & 545,836 & $\mathrm{~S} /$. & 545,836 & $\mathrm{~S} /$. & $1,091,673$ \\
\hline Ingresos por Estacionamientos & $\mathrm{S} /$. & 45,000 & $\mathrm{~S} /$. & 45,000 & $\mathrm{~S} /$. & 45,000 & $\mathrm{~S} /$. & 45,000 & $\mathrm{~S} /$. & 45,000 & $\mathrm{~S} /$. & 45,000 & $\mathrm{~S} /$. & 90,000 \\
\hline Total Ingresos & $\mathrm{S} /$. & 590,836 & S/. & 590,836 & $\mathrm{~S} /$. & $\mathbf{5 9 0 , 8 3 6}$ & $\mathbf{S} /$. & 590,836 & $\mathrm{~S} /$. & 590,836 & S/. & 590,836 & $\mathrm{~S} /$. & $1,181,673$ \\
\hline Egresos & & & & & & & & & & & & & & \\
\hline Costos directos & $\mathrm{S} /$. & 429,190 & & & & & & & & & & & & \\
\hline Sueldos & $\mathrm{S} /$. & 14,316 & $\mathrm{~S} /$. & 14,316 & S/. & 14,316 & $\mathrm{~S} /$. & 14,316 & $\mathrm{~S} /$. & 14,316 & $\mathrm{~S} /$. & 14,316 & $\mathrm{~S} /$. & 14,316 \\
\hline Gastos de oficina & $\mathrm{S} /$. & 3,000 & $\mathrm{~S} /$. & 3,000 & $\mathrm{~S} /$. & 3,000 & $\mathrm{~S} /$. & 3,000 & $\mathrm{~S} /$. & 3,000 & $\mathrm{~S} /$. & 3,000 & $\mathrm{~S} /$. & 3,000 \\
\hline Compra de ascensor & & & & & & & & & & & & & & \\
\hline Gastos de marketing & $\mathrm{S} /$. & 5,543 & $\mathrm{~S} /$. & 5,543 & $\mathrm{~S} /$. & 5,543 & $\mathrm{~S} /$. & 5,543 & $\mathrm{~S} /$. & 5,543 & $\mathrm{~S} /$. & 5,543 & $\mathrm{~S} /$. & 5,543 \\
\hline Impuesto a la renta & S/. & 174,297 & $\mathrm{~S} /$. & 174,297 & $\mathrm{~S} /$. & 174,297 & $\mathrm{~S} /$. & 174,297 & $\mathrm{~S} /$. & 174,297 & $\mathrm{~S} /$. & 174,297 & $\mathrm{~S} /$. & 348,593 \\
\hline Liquidación de IGV & $\mathrm{S} /$. & - & $\mathrm{S} /$. & - & $\mathrm{S} /$. & - & $\mathrm{S} /$. & - & $\mathrm{S} /$. & - & $\mathrm{S} /$. & - & $\mathrm{S} /$. & - \\
\hline Total Egresos & $\mathrm{S} /$. & 626,345 & S/. & 197,156 & $\mathrm{~S} /$. & 197,156 & $\mathrm{~S} /$. & 197,156 & $\mathrm{~S} /$. & 197,156 & $\mathrm{~S} /$. & 197,156 & $\mathrm{~S} /$. & 371,453 \\
\hline Maximo deficit acumulado & $\mathrm{S}$ & $35,509.13$ & $\mathrm{~S} /$. & 393,681 & $\mathrm{~S} /$. & 393,681 & $\mathrm{~S} /$. & 393,681 & $\mathrm{~S} /$. & 393,681 & $\mathrm{~S} /$. & 393,681 & $\mathrm{~S} /$. & 810,220 \\
\hline
\end{tabular}

Para el año 0 , se pudo identificar un primer déficit. Se toma en cuenta que la empresa iniciará operaciones a mediados del año 0 y aquí se realizarán los gastos más fuertes.

En el primer mes (junio 2018), el déficit cumulado, descontando todos los gastos nos da el primer negativo que se mantiene por todo el año 0.

Se toma en referencia el cierre de déficit del año 0 para iniciar el año uno, y de la misma forma se procede para calcular el déficit del año dos. En las siguientes tablas se aprecia: 
Tabla 51

Déficit acumulado Año 1

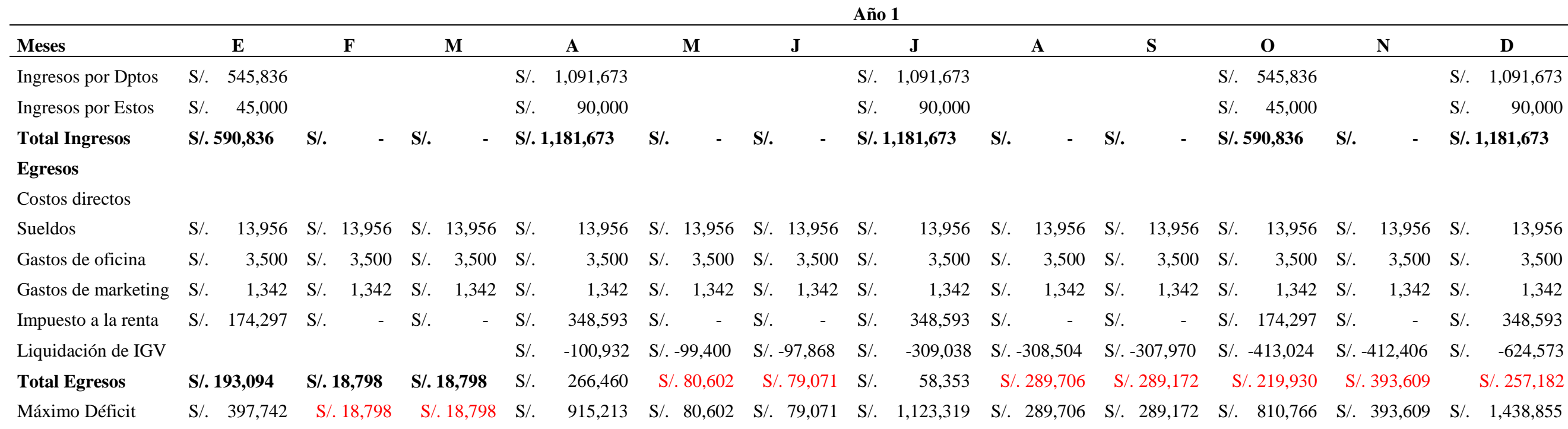


Tabla 52

Déficit acumulado Año 2

\begin{tabular}{|c|c|c|c|c|c|c|c|c|c|c|c|c|}
\hline & \multicolumn{12}{|c|}{ Año 2} \\
\hline Meses & $\mathbf{E}$ & $\mathbf{F}$ & $\mathbf{M}$ & $\mathbf{A}$ & $\mathbf{M}$ & $\mathbf{J}$ & $\mathbf{J}$ & $\mathbf{A}$ & $\mathbf{S}$ & $\mathbf{O}$ & $\mathbf{N}$ & D \\
\hline Ingresos por Deptos & S/. 545,836 & S/. 0 & S/. 0 & S/. 1,091,673 & S/. 0 & S/. 0 & S/. 1,091,673 & S/. 0 & S/. 0 & S/. 545,836 & $\mathrm{S} / .0$ & S/. 1,091,673 \\
\hline Ingresos por Estos & & & & & & & & & & & & \\
\hline Total Ingresos & S/. 545,836 & S/. 0 & S/. 0 & S/. 1,091,673 & S/. 0 & S/. 0 & S/. 1,091,673 & S/. 0 & S/. 0 & S/. 545,836 & $\mathrm{S} / \mathrm{O}$ & S/. 1,091,673 \\
\hline Egresos & & & & & & & & & & & & \\
\hline Costos directo & & & & & & & & & & & & \\
\hline Sueldos & S/. 13,147 & S/. 13,147 & S/. 13,147 & S/. 13,147 & S/. 13,147 & S/. 13,147 & S/. 13,147 & S/. 13,147 & S/. 13,147 & S/. 13,147 & S/. 13,147 & S/. 13,147 \\
\hline Gastos de oficina & S/. 3,500 & S/. 3,500 & S/. 3,500 & S/. 3,500 & S/. 3,500 & S/. 3,500 & S/. 3,500 & S/. 3,500 & S/. 3,500 & S/. 3,500 & S/. 3,500 & S/. 3,500 \\
\hline Gastos de marketing & S/. 417 & S/. 417 & S/. 417 & S/. 417 & S/. 417 & S/. 417 & S/. 417 & S/. 417 & S/. 417 & S/. 417 & S/. 417 & S/. 417 \\
\hline Impuesto a la renta & S/. 161,022 & S/. 0 & S/. 0 & S/. 322,043 & S/. 0 & S/. 0 & S/. 322,043 & S/. 0 & S/. 0 & S/. 161,022 & $\mathrm{~S} / .0$ & S/. 322,043 \\
\hline Liquidación de IGV & S/. 721,527 & S/. 720,993 & S/. 720,460 & S/. 916,427 & S/. 915,893 & S/. 914,596 & S/. 1,110,563 & S/. 1,110,030 & S/. 1,109,496 & S/. 1,207,212 & S/. 1,206,678 & S/. 1,402,646 \\
\hline Total Egresos & S/. 543,442 & S/. 703,929 & S/. 703,395 & S/. 577,319 & S/. 898,829 & S/. 897,532 & S/. 771,456 & S/. 1,092,965 & S/. 1,092,432 & S/. 1,029,126 & S/. 1,189,614 & S/. 1,063,538 \\
\hline Máximo déficit & S/. 2,395 & S/. 703,929 & S/. 703,395 & S/. 514,353 & S/. 898,829 & S/. 897,532 & S/. 320,217 & S/. 1,092,965 & S/. 1,092,432 & S/. 483,290 & S/. 1,189,614 & S/. 28,135 \\
\hline
\end{tabular}

Déficit Acumulado

-S/. $1,189,614$

Luego de analizar los resultados obtenidos, se detecta que el máximo déficit acumulado es del flujo del año 2, por lo cual se toma este como el dato que se necesita para el cálculo de los demás flujos.

Es necesario también, realizar la liquidación del IGV, donde se tomará en cuenta el ingreso por la preventa de los departamentos en el primer mes del primer año luego del año de inversión. 
Esto representa la disminución en su mayoría del crédito fiscal, logrando a obtener este concepto hasta el mes 18 del proyecto. El hecho de tener crédito fiscal aún por más de un año representa una oportunidad de tener un escudo fiscal que pueda ayudar frente a los gastos.

Tabla 53

Liquidación del IGV

\begin{tabular}{|c|c|c|c|c|c|c|c|c|c|c|c|c|c|}
\hline & \multirow[b]{2}{*}{ ( } & \multicolumn{12}{|c|}{ AÑNO 1 } \\
\hline & & Mes 1 & Mes 2 & Mes 3 & Mes 4 & Mes 5 & Mes 6 & Mes 7 & Mes 8 & Mes 9 & Mes 10 & Mes 11 & Mes 12 \\
\hline IGV Ventas & $\mathrm{S} / .0$ & S/. 957,155 & $\mathrm{S} / .0$ & $\mathrm{~S} / .0$ & S/. 212,701 & S/. 0 & $\mathrm{~S} / .0$ & $\mathrm{~S} / . \mathbf{2 1 2 , 7 0 1}$ & $\mathrm{S} / .0$ & S/. 0 & S/. 106,351 & S/. 0 & S/. 212,701 \\
\hline IGV Costos Indirectos & S/. 5,919 & S/. 998 & S/. 998 & S/. 998 & S/. 998 & S/. 998 & S/. 998 & S/. 998 & S/. 0 & S/. 0 & S/. 763 & S/. 84 & S/. 0 \\
\hline IGV Gasto Administrativo & S/. 1,902 & S/. 534 & S/. 534 & S/. 534 & S/. 534 & S/. 534 & S/. 534 & S/. 534 & S/. 534 & S/. 534 & S/. 534 & S/. 534 & S/. 534 \\
\hline IGV Activo Fijo & S/. 328,793 & & & S/. 20,227 & & & & & & & & & \\
\hline IGV Inversión Intangible & S/. 705,957 & & & & & & & & & & & & \\
\hline IGV Neto Resultante & & S/. 955,623 & S/. $-1,532$ & S/. $-21,759$ & S/. 211,169 & S/. $-1,532$ & S/. $-1,532$ & S/. 211,169 & S/. -534 & S/. -534 & S/. 105,054 & S/. -618 & S/. 212,167 \\
\hline Crédito Fiscal & S/. 1,042,571 & & & & & & & & & & & & \\
\hline IGV Neto a Pagar & & S/. -86,947 & S/. -88,479 & $\mathrm{S} / .-110,238$ & S/. 100,932 & $\mathrm{S} / . \mathbf{9 9 , 4 0 0}$ & S/. 97,868 & $\mathrm{S} / \mathbf{3 0 9 , 0 3 8}$ & S/. 308,504 & S/. 307,970 & S/. 413,024 & S/. 412,406 & S/. 624,573 \\
\hline
\end{tabular}

\begin{tabular}{|c|c|c|c|c|c|c|c|c|c|c|c|c|}
\hline & \multicolumn{12}{|c|}{ AÑ̃ 2} \\
\hline & Mes 13 & Mes 14 & Mes 15 & Mes 16 & Mes 17 & Mes 18 & Mes 19 & Mes 20 & Mes 21 & Mes 22 & Mes 23 & Mes 24 \\
\hline IGV Ventas & $\mathrm{S} / . \mathbf{9 8 , 2 5 1}$ & S/. 0 & S/. 0 & S/. 196,501 & S/. 0 & S/. 0 & S/. 196,501 & S/. 0 & S/. 0 & S/. 98,251 & S/. 0 & S/. 196,501 \\
\hline IGV Costos Indirectos & S/. 763 & S/. 0 & S/. 0 & $\mathrm{~S} / .0$ & S/. 0 & S/. 763 & S/. 0 & $\mathrm{~S} / .0$ & S/. 0 & S/. 0 & $\mathrm{~S} / .0$ & S/. 0 \\
\hline $\begin{array}{l}\text { IGV Gasto Administrativo } \\
\text { IGV Activo Fijo }\end{array}$ & S/. 534 & S/. 534 & S/. 534 & S/. 534 & S/. 534 & S/. 534 & S/. 534 & S/. 534 & S/. 534 & S/. 534 & S/. 534 & S/. 534 \\
\hline $\begin{array}{l}\text { IGV Inversion Intangible } \\
\text { IGV Neto Restulante } \\
\text { Crédito Fiscal }\end{array}$ & S/. 96,954 & S/. -534 & S/. -534 & S/. 195,967 & S/. -534 & S/. $-1,297$ & S/. 195,967 & S/. -534 & S/. -534 & S/. 97,717 & S/. -534 & S/. 195,967 \\
\hline IGV Neto a Pagar & S/.721,527 & $/ .720,993$ & $\mathrm{~S} / . \mathbf{7 2 0 , 4 6 0}$ & S/. 916,427 & S/. 915,893 & S/. 914,596 & S/. 1,110,563 & $\mathrm{S} / . \mathbf{1 , 1 1 0 , 0 3 0}$ & S/. 1,109,496 & S/. 1,207,212 & S/. 1,206,678 & S/. 1,402,646 \\
\hline
\end{tabular}




\subsubsection{Costo del proyecto}

La estimación de costos es un proceso que consiste en desarrollar una aproximación de los recursos monetarios que se necesitarán para realizar las actividades que demandará el proyecto. Es una predicción que se hace en base a la información que se tiene disponible en un momento determinado.

La estimación del costo del proyecto está en base a la construcción de los departamentos, sus costos asociados y gastos administrativos.

Tabla 54

Gastos de oficina

\begin{tabular}{llrrrlr}
\hline Concepto & \multicolumn{2}{c}{ Año 0 } & \multicolumn{2}{c}{ Año 1 } & \multicolumn{2}{c}{ Año 2 } \\
\hline Depreciación & S/. & - & S/. & 2,114 & S/. & 28,634 \\
Amortización de intangibles & S/. & - & S/. & 38,487 & S/. & 38,487 \\
Sueldos Administrativos & S/. & 100,214 & S/. & 167,472 & S/. & 157,769 \\
Alquiler de oficina & S/. & 12,000 & S/. & 24,000 & S/. & 24,000 \\
Gastos de Oficina mensual & S/. & 6,000 & S/. & 12,000 & S/. & 12,000 \\
Pago de Luz & S/. & 660 & S/. & 1,320 & S/. & 1,320 \\
Pago de Agua & S/. & 300 & S/. & 600 & S/. & 600 \\
Pago de internet & S/. & 1,200 & S/. & 2,400 & S/. & 2,400 \\
Pago de mantenimiento de edificio & S/. & 840 & S/. & 1,680 & S/. & 1,680 \\
\hline Total & S/. & $\mathbf{1 2 1 , 2 1 4}$ & S/. & $\mathbf{2 5 0 , 0 7 3}$ & S/. & $\mathbf{2 6 6 , 8 9 0}$ \\
\hline & & & & & &
\end{tabular}

Tabla 55

Costo del proyecto

\begin{tabular}{|c|c|c|c|c|c|}
\hline Concepto & & о 0 & & Año 1 & Año 2 \\
\hline Servicio de construcción & $\mathrm{S} /$. & 302,855 & $\mathrm{~S} /$. & $2,725,693$ & \\
\hline Depreciación & & & S/. & 2,114 & 30,747 \\
\hline Ascensor & & & S/. & 112,373 & \\
\hline Total & S/. & 302,855 & S/. & $2,840,179$ & S/. $\quad 30,747$ \\
\hline
\end{tabular}

Como los gastos principales de funcionamiento se toma en cuenta los gastos de oficina, los intangibles de constitución de empresa y pre operativos y las planillas de todos los años. 
Tabla 56

Inversión en tangibles

\begin{tabular}{lrlrrr}
\hline Concepto & Cantidad & \multicolumn{2}{c}{ Precio sin IGV } & \multicolumn{2}{c}{ Precio con IGV } \\
\hline Terreno & 402.07 & S/. & $1,703,686$ & S/. & $2,010,350$ \\
Ascensor & 1 & S/. & 112,373 & S/. & 132,600 \\
Equipamiento oficina & 26 & S/. & 10,568 & S/. & 12,470 \\
\hline Total & & S/. & $\mathbf{1 , 8 2 6 , 6 2 7}$ & S/. & $\mathbf{2 , 1 5 5 , 4 2 0}$ \\
\hline
\end{tabular}

Adicionalmente se toma en cuenta la inversión en tangibles, como son: el terreno, el ascensor y el equipamiento de las oficinas administrativas.

\subsubsection{Inversiones futuras}

Para el caso del proyecto no se presentarán inversiones futuras.

\subsection{Financiamiento}

El financiamiento es la operación mediante la cual se obtienen los recursos necesarios para asumir los costos de inversión de un proyecto. Cuando se conoce el monto de dinero que se requiere para poner en marcha el proyecto, el siguiente paso es identificar las fuentes de las cuales se puede obtener los recursos necesarios para realizar la inversión inicial.

Por lo general, un nuevo proyecto dispone de tres fuentes de financiamiento: la entidad financiera, ahorros personales y el socio capitalista.

Para el caso del proyecto se tiene dos fuentes de financiamiento: capital propio y deuda financiera.

\subsubsection{Endeudamiento y condiciones}

El endeudamiento es el tamaño proporcional de la deuda (pasivo total) con relación al tamaño total de la deuda (activo total). De acuerdo con Salazar López (2016), el endeudamiento es uno de los elementos más importantes de un análisis financiero, junto a la liquidez y la rentabilidad.

Según lo analizado, de acuerdo al costo del proyecto la estructura de deuda capital requerida será como sigue: 
Tabla 57

Estructura Deuda-Capital

\begin{tabular}{lrrrrrr}
\hline & \multicolumn{2}{c}{ Capital propio } & \multicolumn{2}{c}{ Banco de Crédito } & \multicolumn{2}{c}{ Total } \\
\hline Activos fijos & S/. & $1,703,686$ & & & S/. & $1,703,686$ \\
$\begin{array}{l}\text { Gasto Preoperativo e intangible } \\
\text { Capital de Trabajo }\end{array}$ & S/. & 300,000 & S/. & 667,819 & S/. & 967,819 \\
\hline Total & & & S/. & $1,189,614$ & S/. & $1,189,614$ \\
\hline & S/. & $\mathbf{2 , 0 0 3 , 6 8 6}$ & S/. & $\mathbf{1 , 8 5 7 , 4 3 3}$ & S/. & $\mathbf{3 , 8 6 1 , 1 1 9}$ \\
\hline Financiamiento (\%) & \multicolumn{3}{c}{$\mathbf{5 2 \%}$} & & & \\
\hline
\end{tabular}

De acuerdo con esta estructura, se analizaron las diferentes alternativas en el mercado financiero para poder elegir la alternativa de financiamiento menos costosa y se optó por financiar el proyecto mediante el producto "Crédito a la construcción" del Banco de Crédito del Perú, básicamente por las condiciones generales para el préstamo y la TCEA anual.

Entre otros, los requisitos para acceder a este préstamo son los siguientes:

- Solo se desembolsará como máximo el 90\% del costo del proyecto.

- Garantizar el crédito con el terreno de la construcción.

- Cumplir el 30\% de los departamentos en pre venta para el Banco para el desembolso del préstamo.

- La venta de todos los departamentos debe ser financiada por el Banco de Crédito.

- De no tener más de un año de funcionamiento, se puede avalar el correcto funcionamiento evidenciando la intención de contrato con una empresa proveedora que tenga buena imagen y record crediticio.

- El plazo máximo de préstamo es de cinco años.

- Presentar el flujo de caja proyectado de la empresa. 
Luego de cumplir con lo estipulado por el Banco de Crédito, se pasó a una evaluación la cual arrojó una TCEA de $10.5 \%$, bastante conveniente para el proyecto.

\subsubsection{Capital y costo de oportunidad}

El costo de oportunidad constituye el aporte a las ganancias al cual se renuncia al dejar de utilizar un recurso finito para utilizarlo en el mejor uso alternativo siguiente. Esa oportunidad perdida es un costo que se debe evaluar al momento de tomar decisiones.

Para este caso el costo de oportunidad del proyecto se tomará en cuenta el cálculo del costo promedio de oportunidad según la teoría de Ross, 2012, en el cual se tiene la fórmula:

\section{COK: RF * B(RM-RF)}

Donde:

RF: libre de riesgo

RM: riesgo del Mercado

B: Beta del sector

Para el caso del proyecto se tomará como válida la información encontrada en Damodaran. Se usa como data para el riesgo de mercado los Stocks del mercado americano y para el libre de riesgo los T-Bonds. Para ambos indicadores se usó el promedio aritmético de los últimos 30 años.

Tabla 58

Promedio aritmético

\begin{tabular}{ccc}
\hline Años & $\begin{array}{c}\text { Stocks } \\
\text { RM }\end{array}$ & $\begin{array}{c}\text { T-Bonds } \\
\text { RF }\end{array}$ \\
\hline $1987-2017$ & $4.95 \%$ & $6.55 \%$ \\
\hline
\end{tabular}


Debido a que el proyecto se realizará en Perú, es necesario tomar datos necesarios como el riesgo país y la inflación tanto de Estados Unidos como de Perú, los cuales influyen en el cálculo del costo.

Tabla 59

Riesgo país

\begin{tabular}{lc}
\hline Perú & $\mathbf{2 0 1 7}$ \\
\hline Ene. & 0.0157 \\
Feb. & 0.0152 \\
Marzo & 0.0136 \\
\hline
\end{tabular}

Tabla 60

Inflación promedio

\begin{tabular}{rrr}
\hline Año & Perú & \multicolumn{1}{c}{ EEUU } \\
\hline 2000 & 3.8 & 3.4 \\
2001 & 2.0 & 2.8 \\
2002 & 0.2 & 1.6 \\
2003 & 2.3 & 2.3 \\
2004 & 3.7 & 2.7 \\
2005 & 1.6 & 3.4 \\
2006 & 2.0 & 3.2 \\
2007 & 1.8 & 2.9 \\
2008 & 5.8 & 3.8 \\
2009 & 2.9 & -0.4 \\
2010 & 1.5 & 1.6 \\
2011 & 3.4 & 3.2 \\
2012 & 3.7 & 2.1 \\
2013 & 2.8 & 1.5 \\
2014 & 3.2 & 1.6 \\
2015 & 3.5 & 0.1 \\
2016 & 3.6 & 2.1 \\
\hline Promedio & $\mathbf{2 . 8 1}$ & $\mathbf{2 . 2 3}$ \\
\hline
\end{tabular}

Según el dato de Damodaran, el dato de la Beta desapalancada para el sector (Real State) es de 4.30, pero se realizó el apalancamiento de la misma usando los impuestos de Perú, y se obtuvo: 
Tabla 61

Riesgo país

\begin{tabular}{lc}
\hline \multicolumn{2}{c}{ Beta apalancada } \\
\hline Beta desapalancada & 0.430 \\
Beta apalancada & 0.724 \\
\hline
\end{tabular}

Una vez obtenidos los datos individuales, se procede a calcular el cok del proyecto:

Tabla 62

Cok del proyecto

\begin{tabular}{ll}
\hline Variables & Tasa \\
\hline Rendimiento sin Riesgo: RF (\%) & $6.55 \%$ \\
Rendimiento del Mercado: RM (\%) & $4.95 \%$ \\
Beta apalancada & 0.788 \\
\hline Cok del proyecto & $\mathbf{5 . 2 9 \%}$ \\
\hline
\end{tabular}

Una vez hallado el COK apalancado del proyecto, se procedió a calcular el apalancamiento con los datos de inflación de ambos países y un adicional del 100\% al riesgo del proyecto por la coyuntura actual del sector:

\section{Tabla 63}

Cok apalancado del proyecto

\begin{tabular}{lr}
\hline Variables & Tasa \\
\hline Cok Nominal USA & $5.29 \%$ \\
Cok Real USA & $3.07 \%$ \\
Cok Real Perú & $5.88 \%$ \\
Riesgo del proyecto nuevo & $5.88 \%$ \\
\hline Cok apalancado del proyecto & $\mathbf{1 1 . 7 6 \%}$ \\
\hline
\end{tabular}

Con los cálculos anteriormente mencionados se obtuvo un COK de $11.76 \%$ para el proyecto. 


\subsubsection{Costo de capital promedio ponderado}

El costo de capital promedio ponderado (CCPP) consiste en una ponderación de los pesos de cada una de estas fuentes y realizar un promedio con todas estas. Es utilizada para calcular el costo total que tienen las más importantes fuentes de financiamiento de una empresa., tal como sigue (Ramírez, 2013):

$$
\mathrm{CCPP}=(\mathrm{kd})(\mathrm{pd}) \times(\mathrm{kc})(\mathrm{pc})
$$

Donde:

- KD: costo de la deuda

- PD: proporción de la deuda en la estructura financiera

- KC: costo del capital contable

- PC: proporción del capital contable

Para el caso del presente proyecto tenemos:

Tabla 64

Costo de capital promedio ponderado

\begin{tabular}{lr}
\hline Variables & \multicolumn{1}{c}{ Tasa } \\
\hline Cok Real Perú & $11.76 \%$ \\
Costo deuda & $11.50 \%$ \\
Razón capital & $52 \%$ \\
Razón endeudamiento & $48 \%$ \\
Impuesto a la renta & $29.5 \%$ \\
\hline WACC & $\mathbf{1 1 . 0 3 \%}$ \\
\hline
\end{tabular}

El costo de capital promedio ponderado del proyecto resulta $11.03 \%$ basado el COK real del proyecto y las demás variables anteriormente analizadas. 


\subsection{Presupuestos Base}

Según Calleja (2014), un presupuesto es un estado que hace referencia a una etapa futura de actividades que reflejan la situación financiera, resultados y flujo de efectivo de una empresa.

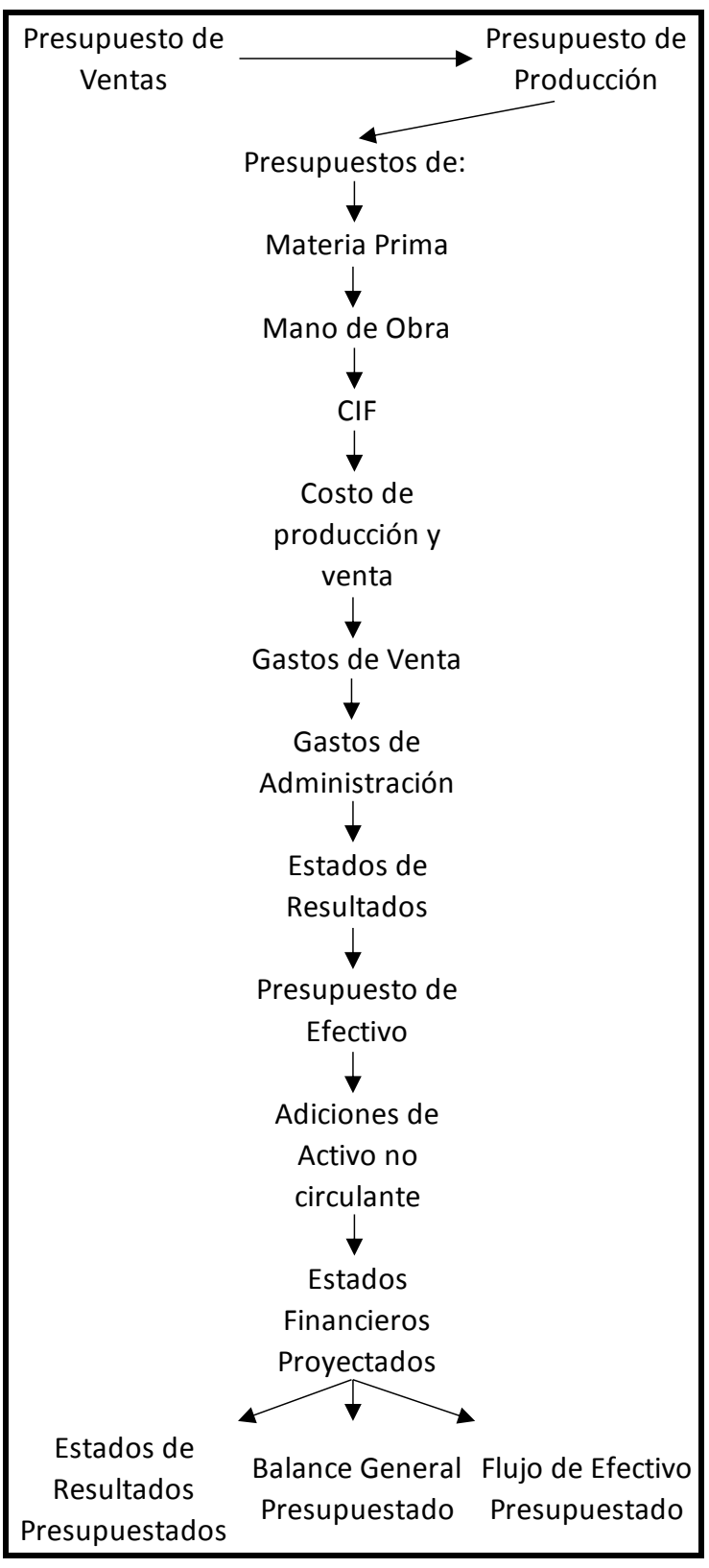

Figura 42. Presupuestos Base. Tomado de Contabilidad Administrativa $\left(9^{\circ}\right.$ ed.) (p. 251), por Ramírez, D., 2013. México: McGraw-Hill. 


\subsubsection{Presupuesto de ventas}

Una empresa como primer paso debe analizar cómo se comportará la demanda del mercado. Para la determinación de este presupuesto se sugiere comenzar estableciendo claramente el objetivo en cuanto al tamaño de la venta que la empresa desea alcanzar, establecer un periodo determinado y las estrategias que se seguirán para lograr dichos objetivos. En segundo lugar, debe realizar un estudio sólido, con datos objetivos acerca del futuro de la demanda. Por ultimo elaborar el presupuesto de ventas, tomando en cuenta los datos del estudio y el juicio de expertos. (Ramirez, 2013)

Con la información normativa obtenida del terreno se procedió a realizar el cálculo de las áreas a vender.

Tabla 65

Calculo de áreas del proyecto

\begin{tabular}{lrr}
\hline \multicolumn{1}{c}{ Concepto } & Cantidad & Unidad \\
\hline Área de terreno & 402.07 & $\mathrm{~m}^{2}$ \\
Altura máxima de edificación & 24 & $\mathrm{ml}$ \\
Altura de entrepiso & 2.5 & $\mathrm{ml}$ \\
Número de pisos & 8 & pisos \\
Numero de estacionamientos & 16 & unid \\
Área Libre requerida según norma & 140.72 & $\mathrm{~m}^{2}$ \\
Área techada máxima permitida (65\%) por piso & 261.35 & $\mathrm{~m}^{2}$ \\
Área comunes techadas (15.13\%) por piso & 39.54 & $\mathrm{~m}^{2}$ \\
Área techada máxima vendible (84.87\%) por piso & 221.81 & $\mathrm{~m}^{2}$ \\
Área a vender según proyecto & 1796.11 & $\mathrm{~m}^{2}$ \\
\hline
\end{tabular}

Adicionalmente, con el costo por $\mathrm{m}^{2}$ se procedió a calcular el presupuesto de ventas del total del proyecto, por lo cual se obtuvo la información de la Tabla 52: 
Tabla 66

Presupuesto de Venta

\begin{tabular}{lcrcrr}
\hline \multicolumn{1}{c}{ Concepto } & \multicolumn{2}{c}{ Costo Total Sin IGV } & Costo Total Con IGV \\
\hline Costo por m2 comercial en la zona & S/. & 5,923 & S/. & 6,990 \\
Venta total de departamentos & S/. & $10,639,183.05$ & S/. & $12,554,236.00$ \\
Venta total de estacionamientos & S/. & $610,169.49$ & S/. & 720,000 \\
\hline Presupuesto de Venta & S/. & $\mathbf{1 1 , 2 4 9 , 3 5 3}$ & S/. & $\mathbf{1 3 , 2 7 4 , 2 3 6}$ \\
\hline
\end{tabular}

\subsubsection{Presupuesto de costos de producción}

Ya elaborado el presupuesto de ventas, sigue la elaboración del presupuesto de costos de producción. Es importante conocer este para planificar todos los recursos que se necesitarán durante el proceso de producción. Se debe incluir en el cálculo las ventas presupuestadas, los inventarios finales e iniciales, todos estos de cada línea de producción. (Ramirez, 2013)

Para el proyecto no se manejará costos de producción ya que, la producción, estará totalmente tercerizada.

\subsubsection{Presupuesto de compras}

Este presupuesto da el marco de referencia para determinar los requerimientos de las diferentes materias primas. En este presupuesto se incluye exclusivamente los insumos directo, ya que los insumos indirectos (lubricantes, accesorios, etc.) se incorporan en el presupuesto de costos indirectos de fabricación. (Ramirez, 2013)

Para el caso del presente proyecto, el único recurso de materia prima que se comprará será el ascensor el cual tiene un costo sin IGV de S/ 112,300, y se realizará el desembolso en el segundo año de construcción.

\subsubsection{Presupuesto de costo de ventas}

Luego de haber hallado el presupuesto de costos de producción es posible obtener el costo de ventas que tendrá la empresa durante el periodo presupuestado, en 
base a: las ventas esperadas para el periodo presupuestado, la política de inventarios de materia prima, el costo de mano de obra directa, los costos indirectos de fabricación, la política de inventario de productos terminados y el costo unitario asignado al producto. (Ramirez, 2013)

Para el presente proyecto se tomaron todas las variables que afectan al costo de ventas, que en su mayoría (participación porcentual) son pago de servicios y tasas municipales para iniciar los trabajos de obra.

Tabla 67

Presupuesto de costo de venta

\begin{tabular}{|c|c|c|c|c|c|c|}
\hline Concepto & \multicolumn{2}{|c|}{ Año 0} & \multicolumn{2}{|r|}{ Año 1} & \multicolumn{2}{|c|}{ Año 2} \\
\hline Servicio de construcción & $\mathrm{S} /$. & 302,855 & S/. & $2,725,693$ & & \\
\hline Depreciación & & & $\mathrm{S} /$. & 2,114 & $\mathrm{~S} /$. & 30,747 \\
\hline Ascensor & & & S/. & 112,373 & & \\
\hline Total & $\mathbf{S} /$. & 302,855 & S/. & $2,840,179$ & S/. & 30,747 \\
\hline
\end{tabular}

\subsubsection{Presupuesto de gastos administrativos}

Los gastos de administración están compuestos por los gastos laborales, de seguros, de alquileres, de materiales, de representación, y útiles de oficina, de depreciación de edificios administrativos y equipos de oficina, de impuestos y otros. (Sapag, 2011)

Se calculó el presupuesto de gastos administrativos para los tres años de operación, los cuales no solo comprenden los gastos de gestión administrativa sino también considera la planilla. Los resultados se obtuvieron en la tabla 54. 
Tabla 68

Presupuesto de gastos administrativos

\begin{tabular}{llrrrlr}
\hline Concepto & \multicolumn{2}{c}{ Año 0 } & \multicolumn{2}{c}{ Año 1 } & \multicolumn{2}{c}{ Año 2 } \\
\hline Depreciación & S/. & - & S/. & 2,114 & S/. & 28,634 \\
Amortización de intangibles & S/. & - & S/. & 38,487 & S/. & 38,487 \\
Sueldos Administrativos & S/. & 100,214 & S/. & 167,472 & S/. & 157,769 \\
Alquiler de oficina & S/. & 12,000 & S/. & 24,000 & S/. & 24,000 \\
Gastos de Oficina mensual & S/. & 6,000 & S/. & 12,000 & S/. & 12,000 \\
Pago de Luz & S/. & 660 & S/. & 1,320 & S/. & 1,320 \\
Pago de Agua & S/. & 300 & S/. & 600 & S/. & 600 \\
Pago de internet & S/. & 1,200 & S/. & 2,400 & S/. & 2,400 \\
Pago de mantenimiento de edificio & S/. & 840 & S/. & 1,680 & S/. & 1,680 \\
\hline Total & S/. & $\mathbf{1 2 1 , 2 1 4}$ & S/. & $\mathbf{2 5 0 , 0 7 3}$ & S/. & $\mathbf{2 6 6 , 8 9 0}$ \\
\hline & & & & & &
\end{tabular}

Para poder elaborar la planilla, primero es necesario calcular el salario variable de ventas, que, como se expuso en el capítulo VII, está en función del valor del departamento vendido.

Para el cálculo de este salario variable, se realizó la estimación sobre el costo promedio de un departamento y sobre la venta proyectada de departamentos año a año, y se obtuvo:

Tabla 69

Cálculo de comisión variable

\begin{tabular}{|c|c|c|c|c|c|c|c|}
\hline \multirow[t]{2}{*}{ Año } & \multirow{2}{*}{$\begin{array}{r}\text { Cantidad } \\
23 \\
\end{array}$} & Precio Promedio & \multicolumn{2}{|c|}{$\begin{array}{l}\text { Comisión por } \\
\text { departamento }\end{array}$} & \multirow{2}{*}{$\begin{array}{l}\text { Total en comisiones } \\
\text { S/. } 31,385.59\end{array}$} & \multicolumn{2}{|c|}{ Comisiones al mes } \\
\hline & & 545,836 & & $0.25 \%$ & & $\mathrm{~S} /$. & 872 \\
\hline Año 0 & 8 & & $\mathrm{~S} /$. & 1,365 & 10,985 & $\mathrm{~S} /$. & 915 \\
\hline Año 1 & 8 & & S/. & 1,365 & 10,985 & $\mathrm{~S} /$. & 915 \\
\hline Año 2 & 7 & & $\mathrm{~S} /$. & 1,365 & 9,416 & $\mathrm{~S} /$. & 785 \\
\hline
\end{tabular}

Una vez obtenido el dato del costo del salario variable promedio de los vendedores de la empresa, se procede a elaborar el costo de las planillas, según el Régimen Especial PYME, revisado en el capítulo seis.

Los resultados del costo laboral a detalle se encuentran en la tabla a continuación: 
Tabla 70

Calculo de costo laboral

\begin{tabular}{llrlrlrrrrr}
\hline \multicolumn{1}{c}{ Cargo } & \multicolumn{2}{c}{ Total/diario } & \multicolumn{2}{c}{ Total/mes } & \multicolumn{2}{c}{ CTS } & \multicolumn{2}{c}{ Pago a Essalud } & \multicolumn{2}{c}{ Gratificación } \\
\hline Gerente General & S/. & 200 & S/. & 6,000 & S/. & 3,000 & S/. & 6,750 & S/. & 6,000 \\
Administrador & S/. & 117 & S/. & 3,500 & S/. & 1,750 & S/. & 3,938 & S/. & 3,500 \\
Vendedores Fijo & S/. & 40 & S/. & 1,200 & S/. & 600 & S/. & 1,350 & S/. & 1,200 \\
Vendedores Variable & S/. & 29 & S/. & 872 & S/. & 436 & S/. & 981 & S/. & 872 \\
\hline
\end{tabular}

La planilla se elabora para cada año tomando en cuenta el costo mensual de cada trabajador, para el caso del año pre operativo, se considera que el personal únicamente laborará los últimos seis meses del año, por lo que la planilla se muestra en menor proporción para ese año.

Para el segundo año de operación, la planilla disminuye básicamente por el salario variable de ventas ya que, para este año, se prevé que quedarán menos departamentos por vender.

Tabla 71

Planilla

\begin{tabular}{lrrrrrr}
\hline \multicolumn{1}{c}{ Cargo } & \multicolumn{2}{c}{ Año 0 } & \multicolumn{2}{c}{ Año 1 } & \multicolumn{2}{c}{ Año 2 } \\
\hline Gerente General & S/. & 43,875 & S/. & 87,750 & S/. & 87,750 \\
Administrador & S/. & 25,594 & S/. & 51,188 & S/. & 51,188 \\
Vendedores Fijo & S/. & 19,760 & S/. & 17,550 & S/. & 9,416 \\
Vendedores Variable & S/. & 10,985 & S/. & 10,985 & S/. & 9,416 \\
\hline & S/. & $\mathbf{1 0 0 , 2 1 4}$ & S/. & $\mathbf{1 6 7 , 4 7 2}$ & S/. & $\mathbf{1 5 7 , 7 6 9}$ \\
\cline { 2 - 7 }
\end{tabular}

\subsubsection{Presupuesto de marketing y ventas}

Los gastos de ventas, están conformados por los gastos laborales, las comisiones de ventas y cobranzas, la publicidad, los empaques, el transporte y el almacenamiento. (Sapag, 2011). 
El presupuesto de marketing comprende las actividades de publicidad y

promoción que se llevarán a cabo para la comunicación del proyecto.

Tabla 72

Presupuesto de marketing

\begin{tabular}{|c|c|c|c|c|c|c|c|}
\hline \multirow{2}{*}{$\begin{array}{l}\text { Actividades de Marketing } \\
\text { Publicidad en Diarios y Revistas }\end{array}$} & \multicolumn{2}{|c|}{ Precio U. sin IGV } & \multicolumn{2}{|c|}{ Precio U. } & \multirow{2}{*}{$\frac{Q}{10}$} & \multirow{2}{*}{$\begin{array}{l}\text { Costo } \\
\text { S/. }\end{array}$} & \multirow{2}{*}{\begin{tabular}{|c|} 
Total Con IGV \\
30,000
\end{tabular}} \\
\hline & $\mathrm{S} /$. & $4,237.29$ & $\mathrm{~S} /$. & 5,000 & & & \\
\hline Publicidad con Banners en TV & $\mathrm{S} /$. & $2,711.86$ & $\mathrm{~S} /$. & 3,200 & 2 & $\mathrm{~S} /$. & 6,400 \\
\hline Participación en ferias & $\mathrm{S} /$. & $3,389.83$ & $\mathrm{~S} /$. & 4,000 & 3 & $\mathrm{~S} /$. & 12,000 \\
\hline Producción de Módulos & $\mathrm{S} /$. & $1,694.92$ & $\mathrm{~S} /$. & 2,000 & 1 & $\mathrm{~S} /$. & 2,000 \\
\hline Merchandising & $\mathrm{S} /$. & 423.73 & $\mathrm{~S} /$. & 500 & 4 & $\mathrm{~S} /$. & 2,000 \\
\hline Volanteo & $\mathrm{S} /$. & 42.37 & $\mathrm{~S} /$. & 50 & 5 & S/. & 250 \\
\hline Diseño e impresión Material POP & $\mathrm{S} /$. & 423.73 & $\mathrm{~S} /$. & 500 & 5 & $\mathrm{~S} /$. & 2,500 \\
\hline Web Site & $\mathrm{S} /$. & $1,271.19$ & $\mathrm{~S} /$. & 1,500 & 1 & S/. & 1,500 \\
\hline Redes Sociales & $\mathrm{S} /$. & 635.59 & $\mathrm{~S} /$. & 750 & 1 & $\mathrm{~S} /$. & 750 \\
\hline Publirreportaje en diarios & S/. & 423.73 & $\mathrm{~S} /$. & 500 & 5 & $\mathrm{~S} /$. & 2,500 \\
\hline Total & & & & & & $\mathrm{S} /$. & 59,900 \\
\hline
\end{tabular}

El gasto de marketing se realizará en diferentes etapas dentro del proyecto, por cada año de realización. El gasto más grande se llevará a cabo en el año de inversión, donde se necesita cumplir con la preventa estipulada por el Banco que otorgará el préstamo. De esta manera se busca impulsar la colocación del porcentaje mínimo de $30 \%$.

Tabla 73

Distribución de gasto de marketing

\begin{tabular}{|c|c|c|c|c|c|c|c|c|c|c|c|}
\hline & Cantidad & & Año 0 & Cantidad & & & ño 1 & Cantidad & & \multicolumn{2}{|c|}{ Año 2} \\
\hline Publicidad en Diarios y Revistas & 3 & $\mathrm{~S} /$. & 15,000 & $\mathrm{~S} /$. & 2 & $\mathrm{~S} /$. & 10,000 & $\mathrm{~S} /$. & 1 & $\mathrm{~S} /$. & 5,000 \\
\hline Publicidad con Banners en TV & 2 & $\mathrm{~S} /$. & 6,400 & & & $\mathrm{~S} /$. & - & & & $\mathrm{S} /$. & - \\
\hline Participación en ferias & 2 & $\mathrm{~S} /$. & 8,000 & $\mathrm{~S} /$. & 1 & $\mathrm{~S} /$. & 4,000 & & & $\mathrm{~S} /$. & - \\
\hline Producción de Módulos & 1 & $\mathrm{~S} /$. & 2,000 & & & $\mathrm{~S} /$. & - & & & $\mathrm{S} /$. & - \\
\hline Merchandising & 4 & $\mathrm{~S} /$. & 2,000 & & & $\mathrm{~S} /$. & - & & & $\mathrm{S} /$. & - \\
\hline Volanteo & 3 & $\mathrm{~S} /$. & 150 & $\mathrm{~S} /$. & 2 & $\mathrm{~S} /$. & 100 & & & $\mathrm{~S} /$. & - \\
\hline Diseño e impresión Material POP & 3 & $\mathrm{~S} /$. & 1,500 & $\mathrm{~S} /$. & 2 & $\mathrm{~S} /$. & 1,000 & & & $\mathrm{~S} /$. & - \\
\hline Web Site & 1 & $\mathrm{~S} /$. & 1,500 & & & $\mathrm{~S} /$. & - & & & $\mathrm{S} /$. & - \\
\hline Redes Sociales & 1 & $\mathrm{~S} /$. & 750 & & & $\mathrm{~S} /$. & - & & & $\mathrm{S} /$. & - \\
\hline Publirreportaje en diarios & 3 & $\mathrm{~S} /$. & 1,500 & $\mathrm{~S} /$. & 2 & $\mathrm{~S} /$. & 1,000 & & & $\mathrm{~S} /$. & - \\
\hline Total & & $\mathbf{S} /$. & $\mathbf{3 8 , 8 0 0}$ & & & $\mathbf{S} /$. & 16,100 & & & $\mathbf{S} /$. & 5,000 \\
\hline
\end{tabular}




\subsubsection{Presupuesto de gastos financieros}

Los gastos financieros están constituidos por los gastos de intereses de los préstamos obtenidos. (Sapag, 2011). Para el caso del proyecto se tomó en cuenta el Crédito a la construcción de dos Bancos: Banco Interbank y Banco de Crédito. Se optó por el Banco de crédito básicamente por la TCEA más baja.

Tabla 74

Cálculo del servicio de deuda

\begin{tabular}{|c|c|c|c|c|c|c|c|c|c|c|}
\hline \multirow{2}{*}{$\begin{array}{r}\text { Periodo } \\
0\end{array}$} & \multicolumn{2}{|r|}{ Inicial } & \multicolumn{2}{|r|}{ Interés } & \multicolumn{2}{|c|}{ Amortización } & \multicolumn{2}{|r|}{ Cuota } & \multicolumn{2}{|c|}{ Final } \\
\hline & & & & & & & & & $\mathrm{S} /$. & $1,857,433$ \\
\hline 1 & S/. & $1,857,433$ & $\mathrm{~S} /$. & 15,519 & $\mathrm{~S} /$. & 70,214 & $\mathrm{~S} /$. & 85,734 & $\mathrm{~S} /$. & $1,787,218$ \\
\hline 2 & S/. & $1,787,218$ & S/. & 14,932 & $\mathrm{~S} /$. & 70,801 & $\mathrm{~S} /$. & 85,734 & $\mathrm{~S} /$. & $1,716,417$ \\
\hline 3 & $\mathrm{~S} /$. & $1,716,417$ & $\mathrm{~S} /$. & 14,341 & $\mathrm{~S} /$. & 71,393 & $\mathrm{~S} /$. & 85,734 & $\mathrm{~S} /$. & $1,645,025$ \\
\hline 4 & S/. & $1,645,025$ & S/. & 13,744 & $\mathrm{~S} /$. & 71,989 & $\mathrm{~S} /$. & 85,734 & $\mathrm{~S} /$. & $1,573,036$ \\
\hline 5 & $\mathrm{~S} /$. & $1,573,036$ & $\mathrm{~S} /$. & 13,143 & $\mathrm{~S} /$. & 72,591 & $\mathrm{~S} /$. & 85,734 & $\mathrm{~S} /$. & $1,500,445$ \\
\hline 6 & $\mathrm{~S} /$. & $1,500,445$ & $\mathrm{~S} /$. & 12,536 & $\mathrm{~S} /$. & 73,197 & $\mathrm{~S} /$. & 85,734 & $\mathrm{~S} /$. & $1,427,248$ \\
\hline 7 & $\mathrm{~S} /$. & $1,427,248$ & $\mathrm{~S} /$. & 11,925 & $\mathrm{~S} /$. & 73,809 & $\mathrm{~S} /$. & 85,734 & $\mathrm{~S} /$. & $1,353,439$ \\
\hline 8 & $\mathrm{~S} /$. & $1,353,439$ & $\mathrm{~S} /$. & 11,308 & $\mathrm{~S} /$. & 74,425 & $\mathrm{~S} /$. & 85,734 & $\mathrm{~S} /$. & $1,279,014$ \\
\hline 9 & $\mathrm{~S} /$. & $1,279,014$ & $\mathrm{~S} /$. & 10,686 & $\mathrm{~S} /$. & 75,047 & $\mathrm{~S} /$. & 85,734 & $\mathrm{~S} /$. & $1,203,967$ \\
\hline 10 & $\mathrm{~S} /$. & $1,203,967$ & $\mathrm{~S} /$. & 10,059 & $\mathrm{~S} /$. & 75,674 & $\mathrm{~S} /$. & 85,734 & $\mathrm{~S} /$. & $1,128,292$ \\
\hline 11 & $\mathrm{~S} /$. & $1,128,292$ & $\mathrm{~S} /$. & 9,427 & $\mathrm{~S} /$. & 76,306 & $\mathrm{~S} /$. & 85,734 & $\mathrm{~S} /$. & $1,051,986$ \\
\hline 12 & $\mathrm{~S} /$. & $1,051,986$ & $\mathrm{~S} /$. & 8,790 & $\mathrm{~S} /$. & 76,944 & $\mathrm{~S} /$. & 85,734 & $\mathrm{~S} /$. & 975,042 \\
\hline 13 & $\mathrm{~S} /$. & 975,042 & $\mathrm{~S} /$. & 8,147 & $\mathrm{~S} /$. & 77,587 & $\mathrm{~S} /$. & 85,734 & $\mathrm{~S} /$. & 897,455 \\
\hline 14 & $\mathrm{~S} /$. & 897,455 & $\mathrm{~S} /$. & 7,498 & S/. & 78,235 & $\mathrm{~S} /$. & 85,734 & $\mathrm{~S} /$. & 819,220 \\
\hline 15 & $\mathrm{~S} /$. & 819,220 & $\mathrm{~S} /$. & 6,845 & S/. & 78,889 & $\mathrm{~S} /$. & 85,734 & $\mathrm{~S} /$. & 740,331 \\
\hline 16 & $\mathrm{~S} /$. & 740,331 & $\mathrm{~S} /$. & 6,186 & S/. & 79,548 & $\mathrm{~S} /$. & 85,734 & $\mathrm{~S} /$. & 660,783 \\
\hline 17 & $\mathrm{~S} /$. & 660,783 & $\mathrm{~S} /$. & 5,521 & S/. & 80,213 & $\mathrm{~S} /$. & 85,734 & $\mathrm{~S} /$. & 580,570 \\
\hline 18 & $\mathrm{~S} /$. & 580,570 & $\mathrm{~S} /$. & 4,851 & S/. & 80,883 & $\mathrm{~S} /$. & 85,734 & $\mathrm{~S} /$. & 499,688 \\
\hline 19 & $\mathrm{~S} /$. & 499,688 & $\mathrm{~S} /$. & 4,175 & S/. & 81,559 & $\mathrm{~S} /$. & 85,734 & $\mathrm{~S} /$. & 418,129 \\
\hline 20 & $\mathrm{~S} /$. & 418,129 & $\mathrm{~S} /$. & 3,494 & S/. & 82,240 & $\mathrm{~S} /$. & 85,734 & $\mathrm{~S} /$. & 335,889 \\
\hline 21 & S/. & 335,889 & $\mathrm{~S} /$. & 2,806 & S/. & 82,927 & $\mathrm{~S} /$. & 85,734 & $\mathrm{~S} /$. & 252,962 \\
\hline 22 & S/. & 252,962 & $\mathrm{~S} /$. & 2,114 & S/. & 83,620 & $\mathrm{~S} /$. & 85,734 & $\mathrm{~S} /$. & 169,342 \\
\hline 23 & S/. & 169,342 & $\mathrm{~S} /$. & 1,415 & S/. & 84,319 & $\mathrm{~S} /$. & 85,734 & S/. & 85,023 \\
\hline 24 & $\mathrm{~S} /$. & 85,023 & $\mathrm{~S} /$. & 710 & S/. & 85,023 & $\mathrm{~S} /$. & 85,734 & $\mathrm{~S} /$. & -0 \\
\hline otal & & & $\mathrm{S} /$. & 200,172 & S/. & 051,986 & $\mathrm{~S} /$. & $2,057,605$ & & \\
\hline
\end{tabular}

El desembolso del préstamo se dará en el último mes del año 0 , donde se proyecta cumplir con la preventa estipulada y, además, donde se prevé el quiebre de presupuesto a cubrir con el aporte de capital social.

En resumen, se obtiene la siguiente tabla con el flujo de la deuda: 
Tabla 75

Flujo de la deuda

\begin{tabular}{|c|c|c|c|c|c|c|}
\hline Concepto & \multicolumn{2}{|c|}{ Año 0} & \multicolumn{2}{|c|}{ Año 1} & \multicolumn{2}{|r|}{ Año 2} \\
\hline Préstamo & $\mathrm{S} /$. & $1,857,433$ & & & & \\
\hline Principal & & & $\mathrm{S} /$. & 882,391 & $\mathrm{~S} /$. & 975,042 \\
\hline Intereses & & & $\mathrm{S} /$. & 146,412 & $\mathrm{~S} /$. & 53,761 \\
\hline Beneficio Tributario & & & $\mathrm{S} /$. & 43,191 & $\mathrm{~S} /$. & $15,859.40$ \\
\hline Total & & & $\mathrm{S} /$. & 985,611 & $\mathrm{~S} /$. & $1,012,943$ \\
\hline
\end{tabular}

\subsection{Presupuestos de Resultados}

Finalmente, el plan maestro debe terminar con la preparación de los estados financieros presupuestados, estos deben reflejar, de acuerdo a los objetivos que se establecieron, donde la administración desea posicionar a la empresa y a cada una de sus áreas. (Ramírez, 2013)

\subsubsection{Estado de ganancias y pérdidas proyectado}

El presupuesto maestro se conforma por el presupuesto de operaciones y el presupuesto financiero. El primero hace referencia a las acciones de producir, vender y administrar una empresa, estas son las actividades comunes mediante las cuales una organización cumple su misión de ofrecer productos o servicios al mercado. Estas actividades originan los presupuestos de ventas, de producción, de compras, de requisitos de materia prima, de mano de obra, de costos indirectos de fabricación, de costo de venta y de gastos de operación. Éstos, a su vez, se consolidan en un informe que permite a la administración conocer hacia dónde se dirigirán los esfuerzos de la empresa, lo cual se logra a través del estado de resultados presupuestado. (Ramírez, 2013) 
Tabla 76

Estado de Ganancias y Pérdidas Proyectado

\begin{tabular}{|c|c|c|c|c|c|c|}
\hline Concepto & & 2019 & & 2020 & & 021 \\
\hline Ventas netas & $\mathrm{S} /$. & $9,453,382$ & $\mathrm{~S} /$. & $4,366,691$ & & \\
\hline Otros Ingresos & & & & & $\mathrm{S} /$. & 5,284 \\
\hline (-) Costo de ventas & $\mathrm{S} /$. & $-2,840,179$ & $\mathrm{~S} /$. & $-30,747$ & & \\
\hline Utilidad bruta & S/. & $6,613,202$ & $\mathrm{~S} /$. & $4,335,944$ & $\mathrm{~S} /$. & 5,284 \\
\hline (-) Gastos administrativos & $\mathrm{S} /$. & 250,073 & $\mathrm{~S} /$. & 266,890 & & \\
\hline (-) Gastos de ventas & $\mathrm{S} /$. & 16,100 & $\mathrm{~S} /$. & 5,000 & & \\
\hline (-) Gastos operativos & $\mathrm{S} /$. & - & $\mathrm{S} /$. & - & & \\
\hline Utilidad operativa & S/. & $6,347,029$ & $\mathrm{~S} /$. & $4,064,054$ & $\mathrm{~S} /$. & 5,284 \\
\hline (-) Gastos financieros & $\mathrm{S} /$. & $-985,611$ & $\mathrm{~S} /$. & $-1,012,943$ & & \\
\hline (-) Depreciación & $\mathrm{S} /$. & $-40,601$ & $\mathrm{~S} /$. & $-67,121$ & & \\
\hline Crédito Fiscal & & & S/. & - & $\mathrm{S} /$. & $-1,293$ \\
\hline Utilidad neta antes de IR & $\mathrm{S} /$. & $5,320,817$ & S/. & $2,983,990$ & $\mathrm{~S} /$. & 3,990 \\
\hline (-) Impuesto a la renta $(29.5 \%)$ & $\mathrm{S} /$. & $1,569,641$ & $\mathrm{~S} /$. & 880,277 & $\mathrm{~S} /$. & 399 \\
\hline Utilidad (o perdida) neta & $\mathrm{S} /$. & $3,751,176$ & S/. & $2,103,713$ & S/. & 3,591 \\
\hline
\end{tabular}

En la tabla se puede analizar que, para el primer año, el costo de ventas es bastante elevado en comparación al segundo año. Básicamente se debe porque en este año se hace el pago total del servicio de construcción a la empresa constructora y se termina el edificio en su totalidad. También se observa que se obtiene un crédito fiscal a favor de la empresa, el cual ingresa como signo positivo luego de la utilidad operativa.

Para el año dos, el costo de ventas básicamente se reduce a la depreciación de los activos tangibles, ya que no se considera como costo de ventas las planillas, que es el único costo adicional de La Inmobiliaria.

Para ambos años se aprecia que, como resultado final, se obtienen cifras positivas, luego de los flujos de entrada y salida, generando una utilidad positiva para los accionistas. 


\subsubsection{Balance proyectado}

El Balance General nos permite ver la situación económica y financiera de la empresa en un momento dado. (Ramirez, 2013).

En este Balance se reflejará la situación de la empresa en el año de inversión y los siguientes años operativos.

Se tomarán en cuenta las preventas en el año uno para efectos tributarios. Adicionalmente, se tomará el año dos como el año final donde si liquida los activos fijos y la empresa. Para La inmobiliaria tenemos: 
Tabla 77

Balance General proyectado

\begin{tabular}{|c|c|c|c|c|c|c|c|c|c|c|c|}
\hline & Año 0 & Año 1 & Año 2 & & Año 3 & & Año 0 & Año 1 & Año 2 & & Año 3 \\
\hline Activo & 2018 & 2019 & 2020 & & 2021 & Pasivo y Patrimonio & 2018 & 2019 & 2020 & & 2021 \\
\hline Activo Corriente & & & & & & Pasivo Corriente & & & & & \\
\hline Caja & S/. $\quad 300,000$ & 843,790 & S/. $2,406,307$ & $\mathrm{~S} /$. & 3,591 & Obligaciones Financieras & & S/. $\quad 1,028,803$ & & & \\
\hline Bancos & S/. $1,857,433$ & & & & & Tributos y remuneraciones por Pagar & & S/. $\quad 850,804$ & 786,004 & & \\
\hline Clientes & & S/. $4,726,691$ & S/. $4,366,691$ & & & & & S/. $\quad-126,652$ & 59,051 & & \\
\hline Ajuste por decimales & & $-\mathrm{S} /$. & 1,553 & & & & & 23,868 & & & \\
\hline Total Activo Corriente & $\mathrm{S} / .2,157,433$ & $\mathrm{~S} / . \mathbf{5 , 5 7 0 , 3 8 3}$ & S/.6,771,445 & S/. & 3,591 & Total Corriente & & $\mathrm{S} / . \mathbf{1 , 7 7 6 , 8 2 3}$ & S/. 845,055 & & \\
\hline Activo No Corriente & & & & & & $\underline{\text { Pasivo no Corriente }}$ & & & & & \\
\hline Terreno & S/. $2,010,350$ & 703,623 & & & & Deudas a Largo Plazo & S/. $1,857,433$ & & & & \\
\hline (-) Depreciación y Amort. & & 40,601 & 67,121 & & & Beneficios Sociales & & & & & \\
\hline Activos Intangibles (neto) & & 127,696 & & & & CTS & & 1,783 & 4,380 & & \\
\hline Otros Activos & & S/. $\quad 132,600$ & & & & Otros Pasivos no Corrientes & & & & & \\
\hline \multirow[t]{8}{*}{ Total Activo No Corriente } & $\mathrm{S} / .2,010,350$ & S/. 923,317 & $-S / . \quad 67,121$ & & & Total Pasivo No Corriente & $\mathrm{S} / \mathbf{. 1 , 8 5 7 , 4 3 3}$ & 1,783 & 4,380 & & \\
\hline & & & & & & Total Pasivo & $\mathrm{S} / \mathbf{. 1 , 8 5 7 , 4 3 3}$ & S/.1,778,606 & S/. 849,435 & & \\
\hline & & & & & & $\underline{\text { Patrimonio }}$ & & & & & \\
\hline & & & & & & Capital Social & S/. $2,010,350$ & S/. $\quad 703,623$ & $\mathrm{~S} /$. & & \\
\hline & & & & & & Capital adicional & S/. $\quad 300,000$ & S/. $\quad 260,296$ & & & \\
\hline & & & & & & Resultados Acumulados & & & S/. $3,751,176$ & & \\
\hline & & & & & & Resultados del Periodo & $\mathrm{S} /$. & S/. $3,751,176$ & S/. $2,103,713$ & $\mathrm{~S} / \mathrm{.}$ & 3,591 \\
\hline & & & & & & Total Patrimonio & $\mathrm{S} / . \mathbf{2 , 3 1 0 , 3 5 0}$ & S/.4,715,094 & $\mathrm{S} / .5,854,889$ & $\mathrm{~S} /$. & 3,591 \\
\hline Total Activo & $\mathrm{S} / .4,167,783$ & $\mathrm{~S} / .6,493,700$ & S/.6,704,324 & $\mathbf{S} /$. & 3,591 & Total Pasivo y Patrimonio & $\mathrm{S} / .4,167,783$ & S/.6,493,701 & S/.6,704,324 & S/. & 3,591 \\
\hline
\end{tabular}




\subsubsection{Flujo de caja proyectado}

Los flujos de caja deben ser diferenciados entre flujos positivos y negativos. Los flujos positivos son los ingresos que genera un proyecto, o bien los ahorros que harán a dicho proyecto ser viable. Por otro lado, los flujos negativos son los egresos originados por el proyecto de inversión.

Este método constituye la diferencia entre ambos flujos, lo que se puede ejemplificar de la siguiente manera:

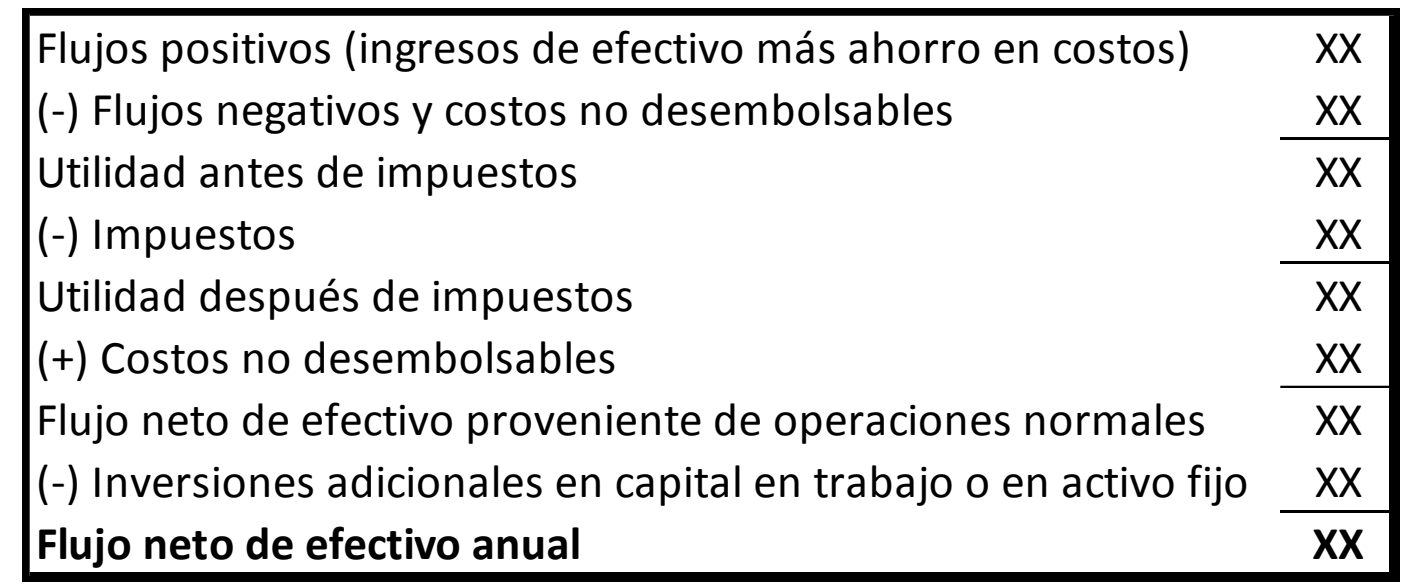

Figura 43. Flujos positivos y negativos. Tomado de:

Algunos proyectos pueden generar flujos positivos al final de su vida útil por la realización de sus activos, aquello que debe tenerse en cuenta como flujo adicional en el último año del proyecto. El mismo caso es en el capital de trabajo, que sirve para que el proyecto genere el desarrollo normal durante periodo de vida. El monto del capital de trabajo debe considerarse como flujo positivo. (Ramirez, 2013)

Para el proyecto de La Inmobiliaria, tendremos flujos de efectivo económico, de inversión, de deuda y financiero. Todos ellos dependerán del flujo operativo y, del resultado final, se desprenderán los indicadores económicos y financieros del mismo para su respectiva evaluación. 
Tabla 78

Flujo de caja del proyecto

\begin{tabular}{|c|c|c|c|c|c|c|c|c|}
\hline \multirow[b]{3}{*}{ Ingresos por Ventas } & \multicolumn{2}{|c|}{ Año 0} & \multicolumn{2}{|r|}{ Año 1} & \multicolumn{2}{|r|}{ Año 2} & \multicolumn{2}{|c|}{ Año 3} \\
\hline & & 2018 & & 2019 & & 2020 & & 21 \\
\hline & $\mathrm{S} /$. & - & $\mathrm{S} /$. & $9,453,382$ & $\mathrm{~S} /$. & $4,366,691$ & & \\
\hline Valor residual & & & & & & & $\mathrm{S} /$. & 5,284 \\
\hline Ingresos Totales & $\mathrm{S} / \mathrm{s}$ & - & $\mathrm{S} /$. & $9,453,382$ & S/. & $4,366,691$ & S/. & 5,284 \\
\hline Servicio Construcción & S/. & 429,190 & & & & & & \\
\hline Salarios administrativos & $\mathrm{S} /$. & 100,214 & $\mathrm{~S} /$. & 167,472 & $\mathrm{~S} /$. & 157,769 & & \\
\hline Gastos administrativos & $\mathrm{S} /$. & 121,214 & $\mathrm{~S} /$. & 250,073 & $\mathrm{~S} /$. & 266,890 & & \\
\hline Gastos de marketing & $\mathrm{S} /$. & 38,800 & $\mathrm{~S} /$. & 16,100 & $\mathrm{~S} /$. & 5,000 & & \\
\hline Impuesto a la renta & & & $\mathrm{S} /$. & $1,569,641$ & $\mathrm{~S} /$. & 880,277 & & \\
\hline Liquidación de IGV & & & $\mathrm{S} /$. & 624,573 & $\mathrm{~S} /$. & $1,402,646$ & & \\
\hline Egresos Totales & S/. & 689,417 & S/. & $2,627,860$ & S/. & $2,712,581$ & S/. & - \\
\hline Flujo de Caja & $\mathrm{S} /$. & $-689,417$ & $\mathrm{~S} /$. & $6,825,521$ & $\mathrm{~S} /$. & $1,654,110$ & $\mathrm{~S} /$. & 5,284 \\
\hline
\end{tabular}

Para el caso del flujo de caja del proyecto, en el año 0 o de pre inversión, es donde se iniciarán las gestiones de la empresa, no solo de constitución, sino de gestión de servicios de construcción inmobiliaria y financiera.

Para poder cumplir con el pago mínimo que exige la empresa de servicios de construcción es necesario contar con el préstamo bancario. Este préstamo, como ya se analizó en el acápite correspondiente, exige para su desembolso, la preventa, o venta en planos, del 30\% del total de los departamentos del proyecto. El 100\% de los financiamientos de estos departamentos irán directamente al Banco para poder garantizar el recupero de capital prestado, por lo que en el año de pre inversión se obtendrá una cifra negativa.

Para el año uno, ya debe iniciar la construcción del proyecto. Por lo cual se contará con el préstamo en su totalidad al finalizar este año. Se proyecta que al finalizar el año dos se haya realizado la venta de otro $35 \%$ de departamentos del proyecto (venta en construcción), por lo cual ya se empieza a generar ingresos. 
Para el año dos, con la totalidad de los departamentos construidos y el proyecto terminado, únicamente queda vender el restante de departamentos (35\%) lo cual generará un flujo de caja positivo, quedando finalmente el valor residual para el año tres.

Es importante notar que, para ambos flujos los resultados son positivos y se analizarán a detalle en el capítulo nueve.

Como primer paso, se calcula el flujo de inversiones:

Tabla 79

Flujo de inversiones

\begin{tabular}{lcccc}
\hline \multicolumn{1}{c}{ Concepto } & & Año 0 & \multicolumn{1}{c}{ Año 1 } \\
\hline Activo Fijo Tangible & S/. & $1,703,686$ & S/. & 112,373 \\
Inversión en Intangibles & S/. & 667,819 & & \\
Capital de Trabajo & S/. & $1,189,614$ & & \\
\hline Flujo de inversiones & -S/. & $\mathbf{3 , 5 6 1 , 1 1 9}$ & -S/. & $\mathbf{1 1 2 , 3 7 3}$ \\
\hline
\end{tabular}

Donde se toma en cuenta el desembolso para intangibles, tangibles y el capital de trabajo, para tener una idea de cuánto dinero se necesita desembolsar en cada año, según los requerimientos del proyecto.

Para calcular el flujo económico se toma en cuenta el flujo operativo anteriormente hallado y el flujo de inversiones:

Tabla 80

Flujo Económico

\begin{tabular}{lrrrrrrrr}
\hline \multicolumn{1}{c}{ Concepto } & \multicolumn{2}{c}{ Año 0 } & \multicolumn{2}{c}{ Año 1 } & \multicolumn{2}{c}{ Año 2 } & \multicolumn{2}{c}{ Año 3 } \\
\hline Flujo Operativo & $-\mathrm{S} /$. & 689,417 & $\mathrm{~S} /$. & $6,825,521$ & $\mathrm{~S} /$. & $1,654,110$ & $\mathrm{~S} /$. & 5,284 \\
Flujo de inversiones & $-\mathrm{S} /$. & $3,561,119$ & $-\mathrm{S} /$. & 112,373 & $\mathrm{~S} /$. & - & $\mathrm{S} /$. & - \\
\hline Flujo Económico & -S/. & $\mathbf{4 , 2 5 0 , 5 3 6}$ & S/. & $\mathbf{6 , 7 1 3 , 1 4 8}$ & S/. & $\mathbf{1 , 6 5 4 , 1 1 0}$ & S/. & $\mathbf{5 , 2 8 4}$ \\
\hline
\end{tabular}

Adicionalmente, se obtuvo, como parte del préstamo bancario el flujo de la deuda: 
Tabla 81

Flujo de la deuda

\begin{tabular}{llrrrrr}
\hline \multicolumn{1}{c}{ Concepto } & \multicolumn{2}{c}{ Año 0 } & \multicolumn{2}{c}{ Año 1 } & \multicolumn{2}{c}{ Año 2 } \\
\hline Préstamo & S/. & $1,857,433$ & S/. & - & S/. & - \\
Principal & S/. & - & S/. & 882,391 & S/. & 975,042 \\
Interés & S/. & - & S/. & 146,412 & S/. & 53,761 \\
Escudo Fiscal & S/. & - & S/. & 43,191 & S/. & 15,859 \\
\hline Flujo de la deuda & S/. & $\mathbf{1 , 8 5 7 , 4 3 3}$ & -S/. & $\mathbf{9 8 5 , 6 1 1}$ & -S/. & $\mathbf{1 , 0 1 2 , 9 4 3}$ \\
\hline
\end{tabular}

Y, finalmente, para poder calcular el flujo de caja financiero se usa el flujo económico y el flujo de la deuda como sigue:

Tabla 82

Flujo de caja financiero

\begin{tabular}{lcccccccc}
\hline \multicolumn{1}{c}{ Concepto } & \multicolumn{1}{c}{ Año 0 } & \multicolumn{1}{c}{ Año 1 } & \multicolumn{2}{c}{ Año 2 } & \multicolumn{2}{c}{ Año 3 } \\
\hline Flujo Económico & $-\mathrm{S} /$. & $4,250,536$ & $\mathrm{~S} /$. & $6,713,148$ & $\mathrm{~S} /$. & $1,654,110$ & $\mathrm{~S} /$. & 5,284 \\
Flujo de deuda & $\mathrm{S} /$. & $1,857,433$ & $-\mathrm{S} /$. & 985,611 & $-\mathrm{S} /$ & $1,012,943$ & $\mathrm{~S} /$. & - \\
\hline Flujo de caja financiero & $-\mathrm{S} /$. & $\mathbf{2 , 3 9 3 , 1 0 3}$ & S/. & $\mathbf{5 , 7 2 7 , 5 3 7}$ & S/. & $\mathbf{6 4 1 , 1 6 6}$ & S/. & $\mathbf{5 , 2 8 4}$ \\
\hline
\end{tabular}

Luego de este análisis, se obtiene como resultado final que el año 0 será un año de déficit, y los subsiguientes años serán positivos.

Para poder analizar de una mejor manera el grado de rentabilidad de estos resultados se procederá a calcular las ratios financieras en el capítulo 9. De esta manera se obtendrá una mejor lectura de las cifras halladas en el presente capitulo. 


\section{Capítulo IX: Evaluación Económico Financiera}

\subsection{Evaluación Financiera}

Para evaluar la factibilidad del proyecto se tomaron en cuenta distintos indicadores como TIR, VAN, ROE y Ratios financieros.

\subsubsection{TIR}

La tasa interna de retorno nos dice la rentabilidad que se obtiene de cobros y pagos a un valor actual, que se darán por una determinada inversión. Si este indicador es alto, supone que el proyecto es muy rentable.

Para el caso de La Inmobiliaria, tenemos:

Tabla 83

Tasa Interna de Retorno Económica

\begin{tabular}{|c|c|c|c|c|}
\hline & Año 0 & Año 1 & Año 2 & Año 3 \\
\hline Flujo económico & -S/. 4,250,536 & S/. $6,713,148$ & S/. $1,654,110$ & 5,284 \\
\hline
\end{tabular}

Tabla 84

Tasa Interna de Retorno Financiera

\begin{tabular}{|c|c|c|c|c|}
\hline & Año 0 & Año 1 & Año 2 & Año 3 \\
\hline Flujo Financiero & -S/. 2,393,103 & S/. 5,727,537 & 641,166 & S/. $\quad 5,284$ \\
\hline TIRF & $150 \%$ & & & \\
\hline
\end{tabular}

Luego de analizar estos resultados se puede apreciar que el proyecto es bastante rentable ya que, tanto la TIRE como la TIRF son positivas y superan el costo de oportunidad del accionista. Adicionalmente, la TIRF es bastante más amplia que la TIRE, lo que nos indica que el nivel y método de endeudamiento 


\subsubsection{VAN}

VAN o valor actual neto, permite traer a valor presente los flujos de caja futuros provenientes de una inversión actual.

Luego del análisis de los flujos descontados de La Inmobiliaria tenemos:

\begin{tabular}{|c|c|c|}
\hline \multicolumn{3}{|l|}{$\begin{array}{l}\text { Tabla } 85 \\
\text { Valor Neto }\end{array}$} \\
\hline & \multicolumn{2}{|c|}{ VAN } \\
\hline & Económico & S/.6,745,911 \\
\hline & Financiero & S/.3,289,480 \\
\hline
\end{tabular}

Para ambos escenarios, tanto el VAN Económico como el VAN Financiero dan positivos, por lo cual se puede decir que el proyecto de acepta.

\subsubsection{ROE}

ROE o Return On Equity, según sus siglas en inglés, mide la rentabilidad sobre cada sol invertido por los accionistas en el proyecto, y este se calcula dividiendo la utilidad neta antes de impuestos sobre el capital propio. Para el caso del presente proyecto obtenemos:

Tabla 86

Return On Equity

\begin{tabular}{|c|c|c|c|}
\hline Indicador & & Año 1 & Año 2 \\
\hline Utilidad Neta & S/. & $3,751,176$ & $2,103,713$ \\
\hline Patrimonio & S/. & $4,715,094$ & $5,854,889$ \\
\hline ROE & & 0.80 & 0.36 \\
\hline
\end{tabular}

Esto significa que, por cada sol invertido, los accionistas reciben 0.80 y 0.36 veces más para los años uno y dos respectivamente, una rentabilidad atractiva. 


\subsubsection{Ratios}

Las ratios financieras proporcionan una relación entre distintos datos financieros dando como resultado un indicador, el cual permitirá evaluar el estado financiero de un determinado periodo y de forma global de una empresa.

Para poder calcular las principales ratios financieros tenemos que tener en cuenta datos tomados del Estado de Ganancias y Pérdidas y el Balance General de cada año de operación de la empresa y obtenemos:

Tabla 87

\section{Ratios Financieros}

\begin{tabular}{|c|c|c|c|}
\hline Ítem & Ratios & Año 1 & Año 2 \\
\hline 1 & $\begin{array}{l}\text { Grado de endeudamiento total } \\
\text { ( Pasivo / Activo) }\end{array}$ & 0.27 & 0.13 \\
\hline 2 & $\begin{array}{l}\text { Solvencia de Patrimonio } \\
\text { (Pasivo / Patrimonio) }\end{array}$ & 0.38 & 0.15 \\
\hline 3 & $\begin{array}{l}\text { Margen Bruto } \\
\text { ( U.b. / Ventas) }\end{array}$ & $70.0 \%$ & $99.3 \%$ \\
\hline 4 & $\begin{array}{l}\text { Margen Operativo } \\
\text { ( U.o. / Ventas) }\end{array}$ & $67.1 \%$ & $93.1 \%$ \\
\hline 5 & $\begin{array}{l}\text { Margen Neto } \\
\text { ( U.n. / Ventas) }\end{array}$ & $56.3 \%$ & $68.3 \%$ \\
\hline 6 & $\begin{array}{l}\text { ROE } \\
\text { (U.neta / Patrimonio) }\end{array}$ & $112.8 \%$ & $51.0 \%$ \\
\hline 7 & $\begin{array}{l}\text { ROA } \\
\text { (U. operativa / Activo) }\end{array}$ & $97.7 \%$ & $60.6 \%$ \\
\hline 8 & $\begin{array}{l}\text { ROI } \\
\text { (U.neta / Activo usado en periodo) }\end{array}$ & $95.5 \%$ & $44.1 \%$ \\
\hline 9 & $\begin{array}{l}\text { Capital de trabajo } \\
\text { (Activo cte. - Pasivo cte.) }\end{array}$ & S/. $\quad 3,793,560.0$ & S/. $\quad 5,926,389.7$ \\
\hline 10 & $\begin{array}{l}\text { Rotación de activo } \\
\text { (Ventas / Activo) }\end{array}$ & $145.6 \%$ & $65.1 \%$ \\
\hline
\end{tabular}

- Grado de endeudamiento total: muestra el grado de dependencia financiera con acreedores externos. Para el caso de La Inmobiliaria, para el primer año se tiene un grado de $27 \%$, donde se puede inferir que la dependencia financiera no es tan amplia, de este modo el apalancamiento de la empresa se encuentra 
principalmente en el aporte de los socios accionistas. Para el segundo año es 13\%, lo cual indica que en este año la independencia financiera es aún mayor.

- Solvencia de patrimonio: nos da el patrimonio neto de los accionistas para hacerle frente a las deudas. Para La inmobiliaria tenemos $38 \%$ en el primer año y $15 \%$ en el segundo año. Lo que nos indica que el patrimonio puede apalancar el funcionamiento de la empresa en el primer año por la tenencia de tangibles y el segundo año disminuye por la venta de los activos.

- Margen Bruto: resultado de dividir la utilidad bruta sobre las ventas lo que nos da las ganancias brutas sobre el costo de ventas. Para el caso de La inmobiliaria, se tiene $70 \%$ para el año uno y $99 \%$ para el año dos. La diferencia radica en que el año dos se da el pago de los servicios de construcción, lo cual contrae significativamente la utilidad bruta, caso que es todo lo contrario en el año 2.

- Margen Operativo: resultado de dividir la utilidad operativa sobre las ventas lo que nos da las ganancias sobre el costo operativo. Para el caso de La inmobiliaria, se tiene $67 \%$ para el año uno y $93 \%$ para el año dos. Por la misma razón del margen bruto, los costos operativos se realizan en su mayoría en el primer año, dejando el segundo año con mucho menos peso de egresos.

- Margen Neto: resultado de dividir la utilidad neta sobre las ventas lo que nos da las ganancias sobre el total de costos. Para el caso de La inmobiliaria, se tiene $56 \%$ para el año uno y $68 \%$ para el año dos. Siguiendo la tendencia de las ratios anteriores, el porcentaje mayor es en el segundo año, por los egresos mínimos.

- ROE: esta ratio nos da la medida de la inversión para generar ingresos. Para el primer año el ROE es $112 \%$, y para el segundo año es de $51 \%$. esto nos da una idea de cuánto recibirán los accionistas por cada sol invertido. 
- ROA: es el beneficio obtenido por la empresa antes de impuesto entre los activos totales. Para el caso de La inmobiliaria en el año uno es 97\%, y en el año dos es de $60 \%$.

- ROI: da como resultado la relación entre la inversión y los beneficios generados. Para el caso de La inmobiliaria es $95 \%$ en el año uno y $44 \%$ en el año dos.

- Capital de trabajo: son los recursos que requiere la empresa para poder operar. En el año uno es S/ 3,793,560. y en el año dos es S/ 5,926,389.

- Rotación de activos: mide el grado de eficiencia de la empresa respecto al uso de sus activos para generar ingresos. En el año uno es de $145 \%$ y en el año dos es de 65\%. En el sector, los activos de la empresa se mueven más rápidamente en los primeros años, que son los años donde se recupera la inversión, es por esto que las ratios obtenidas muestran el nivel de rotación bastante diferente de un año a otro.

\subsection{Análisis de Riesgo}

Para el análisis de riesgo se tomarán en cuenta los escenarios que se obtienen de cambiar ciertos parámetros clave dentro del proyecto y evaluar los resultados que se obtendrían de estos cambios.

La única variable crítica del proyecto es el precio por $\mathrm{m}^{2}$, debido a que todas las demás variables son fijas, tanto número de departamentos como demanda por los mismos.

\subsubsection{Análisis de punto de equilibrio}

En el análisis de punto de equilibrio, se busca saber cuál es el mínimo de unidades vendidas que se requiere para no tener pérdida de la inversión. En la siguiente tabla se muestran los cálculos en términos de cantidades y monetarios. 
Tabla 88

Punto de Equilibrio

\begin{tabular}{lcc}
\hline Concepto & \multicolumn{2}{c}{ Valor } \\
\hline Costo de Venta Unitario Promedio & S/. & 137,990 \\
Precio de Venta Unitario Promedio & S/. & 545,836 \\
Costos Fijos & S/. & $4,264,833$ \\
\hline Punto de Equilibrio & & $\mathbf{1 0}$ \\
\hline Margen de contribución & & $\mathbf{7 5 \%}$ \\
\hline Punto de Equilibrio S/ & S/. & $\mathbf{5 , 7 0 7 , 7 9 6}$ \\
\hline
\end{tabular}

Debido a la naturaleza del proyecto, se recuperará el total de la inversión habiendo vendido un promedio de 10 departamentos (sin contar los estacionamientos). En millones de nuevos soles es de S/ 5,707,796. El margen de contribución para este caso es de 75\%.

\subsubsection{Análisis de sensibilidad}

Como anteriormente se mencionó, la variable critica o principal del proyecto es el precio por $\mathrm{m}^{2}$ los metros cuadrados no pueden variar debido a que el terreno delimitado solo alcanza para cierta cantidad de departamentos según ley, y debido a este punto la demanda no puede variar porque se tiene un número limitado de productos.

Entonces, una vez elegida la variable en estudio, se hizo el análisis de sensibilidad utilizando esta variable en dos escenarios posibles: el cambio de precio en $5 \%$ y $10 \%$ y se obtuvo la siguiente tabla:

Tabla 89

Análisis de Sensibilidad

\begin{tabular}{lrrrrr}
\hline \multicolumn{5}{c}{ Sensibilidad Precio m } \\
\hline \multicolumn{1}{c}{$\mathbf{1 0 \%}$} & \multicolumn{1}{c}{$\mathbf{5 \%}$} & \multicolumn{1}{c}{ Proyecto } & \multicolumn{1}{c}{$\mathbf{- 5 \%}$} & \multicolumn{1}{c}{$\mathbf{- 1 0 \%}$} \\
\hline VANE & S/. 7,283,179 & S/. 7,014,358 & S/. 6,745,911 & S/. 6,477,836 & S/. 6,210,133 \\
TIRE & $83 \%$ & $81 \%$ & $80 \%$ & $78 \%$ & $76 \%$ \\
VANF & S/. $3,622,353$ & S/. 3,455,814 & S/. 3,289,480 & S/. 3,123,352 & S/. 2,957,432 \\
TIRF & $165 \%$ & $158 \%$ & $150 \%$ & $143 \%$ & $135 \%$ \\
\hline
\end{tabular}


En ambos casos se observa que con un ligero incremento del precio tanto las variables VAN como TIR se incrementan exponencialmente, por el contrario, ante una contracción del precio, ambas variables se reducen significativamente.

\subsubsection{Análisis de escenarios}

a) Escenario pesimista: en este escenario, tenemos que los departamentos se vendan a un precio menor al pactado en $5 \%$, por lo cual el margen neto disminuiría notablemente y las ganancias se contraerían a un nivel mínimo de $\%$. Adicionalmente, podría suceder la demora en la preventa del 30\%, lo cual demoraría el desembolso del crédito para continuar la construcción del proyecto.

b) Escenario optimista: en este escenario, tenemos que los departamentos se venden a un precio mayor al pactado por los costos, generando un margen más amplio y una rentabilidad mayor. Adicionalmente, podría darse que en preventa se vendan todos los departamentos, caso en el que se podría prescindir del préstamo bancario y tener un periodo de recuperación más corto.

c) Escenario conservador: este escenario es el planteado en el presente trabajo, en el que se cumple lo que la tendencia del mercado dicta, se recibe un margen entre $30 \%-50 \%$ y se espera terminar el proyecto en dos años luego del año pre operativo. 


\section{CONCLUSIONES Y RECOMENDACIONES}

\section{Conclusiones}

a) El proyecto es económica y financieramente viable. Los resultados de los indicadores evaluados lo respaldan, con un alto índice de TIR y un VAN positivo, además de las ratios financieras anteriormente obtenidos.

b) El proyecto es atractivo para el segmento. Los resultados de los focus group han sido favorables respecto al proyecto, así como las encuestas, en donde se puede evidenciar una clara intención de compra.

c) De acuerdo a los parámetros urbanísticos del terreno, el proyecto "Arequipa" ha sido diseñado para 23 departamentos y 16 cocheras. A pesar de la reducida cantidad de departamentos que tiene el proyecto, se ha demostrado que este es muy rentable, por encima del costo de oportunidad del accionista. Así también de acuerdo al estudio de mercado se comprobó que existe preferencia por la locación del proyecto además que el tener una cantidad reducida de departamentos hace más atractivo el proyecto.

d) Según los resultados de la planificación financiera y la evaluación económica realizada el utilizar materiales que hagan del proyecto un edificio sostenible, tales como son iluminación led, aparatos sanitarios ahorradores de agua y sistemas convencionales de construcción, no incrementan el costo de ventas de manera considerable, por el contrario, la tasa de retorno es muy rentable. El caracterizar el edificio como sostenible hace del proyecto más atractivo para la venta, por lo que concluimos que es factible y recomendable hacer el proyecto sostenible. 


\section{Recomendaciones}

a) Se recomienda integrar una empresa de diseño y decoración con materiales sostenibles para poder dar un valor agregado al proyecto, a pedido del segmento objetivo.

b) Se recomienda incentivar la venta de los departamentos más grandes en la etapa pre operativa, ya que generarán más flujo de efectivo para la empresa, por lo tanto, podría no requerirse un financiamiento muy amplio y generar así más rentabilidad.

c) Con la finalidad de mejorar los costos de venta es recomendable realizar un concurso para la construcción con por lo menos cuatro postores, de esta manera permitirá seleccionar la mejor oferta.

d) Ya que el porcentaje de áreas libres exigible por la municipalidad es considerable (35\% del terreno), área que afecta directamente el área vendible, se recomienda invertir en un buen proyecto de arquitectura para reducir al mínimo la afectación. 
Anexos

Anexo 1: Segmentación de mercado

\begin{tabular}{|c|c|}
\hline \multicolumn{2}{|c|}{ Bases para la segmentación de mercados de consumo } \\
\hline \multicolumn{2}{|l|}{ Geográfica } \\
\hline Región & Perú, Región Central, Lima \\
\hline Tamaño de ciudad o zona metropolitana & $\begin{array}{lll}35.892,49 \mathrm{~km}^{2} & \text { Habitantes } \\
& : & 8^{\prime} 445.211\end{array}$ \\
\hline Urbana o rural & Urbana \\
\hline Clima & Templado, temperatura promedio $21^{\circ} \mathrm{C}$. \\
\hline \multicolumn{2}{|l|}{ Demográfica } \\
\hline Ingreso & Mayor a S/ 1,400 PEN \\
\hline Edad & $25-55$ años \\
\hline Sexo & Hombre y mujer \\
\hline Ciclo vital de la familia & Joven soltero, parejas, familias pequeñas \\
\hline Clase social & Media baja \\
\hline Educación & Secundaria \\
\hline Ocupación & Dependiente o independiente con ingresos \\
\hline Origen étnico & Latinoamericano \\
\hline \multicolumn{2}{|l|}{ Psicográfica } \\
\hline Personalidad & Personas sociables \\
\hline Estilo de vida & Progresista, formal y moderna \\
\hline Valores & Responsabilidad, honestidad, compromiso \\
\hline \multicolumn{2}{|l|}{ Conductuales } \\
\hline Beneficios deseados & Vivienda cómoda, de precio razonable. \\
\hline Tasa de uso & Usuarios constantes \\
\hline
\end{tabular}




\section{Anexo 2: Guía de Pautas Focus Group}

Serán cuatro Focus Group segmentados de la siguiente manera:

\section{Introducción}

\begin{tabular}{|l|c|}
\cline { 2 - 2 } \multicolumn{1}{c|}{} & Peso \\
\hline Hombres y Mujeres, de 25 a 35 años, NSE A & \\
\hline Hombres y Mujeres, de 25 a 35 años, NSE B & \\
\hline Hombres y Mujeres, de 36 a 55 años, NSE A & \\
\hline
\end{tabular}

- Agradecimiento y bienvenida: El moderador agradece y da la bienvenida a los participantes que acudieron al FG.

- Explicar el porqué del FG: El moderador da una pequeña introducción acerca de lo que se hablará en el FG.

- Romper el hielo: El moderador tocará cierto tema de interés común para generar un ambiente de confianza.

- No hay respuestas buenas ni malas

- Filmación: el moderador indicará a los participantes que se les grabará para analizar sus respuestas.

\section{Cuerpo}

\section{Preguntas}

a. Corroborar características demográficas

- ¿Cuál es su opinión respecto al lugar donde vive actualmente?

- ¿Podría indicar brevemente las ventajas y desventajas del lugar donde reside actualmente?

- ¿Qué opinión le merece la actividad comercial, cultural y social cerca de su vivienda?

- ¿Cuál es su grado de satisfacción con referencia a su vivienda actual?

b. Conocer intensión de compra

- ¿Su vivienda actual es alquilada o compartida con familiares?

- ¿Cuánto estaría dispuesto a pagar por un departamento?

- ¿Cuál es, aproximadamente, la cuota mensual que podría pagar por un departamento?

c. Atributos de compra:

- ¿Cuáles considera usted son atributos para una vivienda nueva?

- ¿Cuál es su proyección de tiempo para adquirir su vivienda?

- ¿Ha solicitado evaluación financiera en alguna entidad para determinar su nivel crediticio? ¿Cuál sería la institución por la que optaría?

- Magdalena del Mar es un distrito en desarrollo y estratégicamente ubicado, ¿Qué opinión tiene al respecto?

- ¿Conoce Ud. las avenidas principales y atractivos turísticos del distrito de Magdalena de Mar?

d. Presentación del Proyecto inmobiliario Edificio Multifamiliar Arequipa (El moderador presentara el Proyecto)

- ¿Cuáles son las principales ventajas y desventajas que le ven a este producto? 
- ¿Cuál es la probabilidad de adquirir un departamento de nuestro proyecto?

- ¿Cuál es su opinión de los departamentos y dimensiones que ofrecemos?

- ¿Cree Ud. que podríamos añadir o retirar algún detalle de la edificación y diseño?

3. Cierre: Agradecimiento por participación. 
Anexo 3: Fichas de entrevista a profundidad

\begin{tabular}{ll}
\hline & FICHA TÉCNICA DEL ENTREVISTADO \\
\hline Nombre & Ricardo Bustamante \\
Edad & 45 años \\
Nacionalidad & Peruana \\
Ocupación & Asesor en gestiones inmobiliarias \\
Profesión & Consultor \\
Distrito de Residencia: & Callao \\
& Especialista procesos administrativos públicos, trabaja \\
& como consultor de entidades privadas y personas naturales \\
Breve Reseña: & brindando servicios de asesoría relacionadas a permisos en \\
& diversas entidades y municipalidades en asuntos \\
& inmobiliarios. \\
\hline
\end{tabular}

\section{GUÍA DE ENTREVISTA}

Día: 20/03/2017

Lugar:

Tema:

Introducción:

Pregunta 1:

Respuesta 1:

Pregunta 2:

Respuesta 2:

Pregunta 3:

Respuesta 3:
Hora: 2:20 pm

Comunicación telefónica

Normatividad y procesos administrativos en el sector inmobiliario

Le agradecemos su participación en la entrevista que desarrollaremos a continuación. Dada su trayectoria y conocimiento en el rubro estamos seguros que sus comentarios y recomendaciones enriquecerán los objetivos de nuestro estudio de mercado que estamos desarrollando para nuestro Proyecto de Investigación para la obtención del título de la maestría. Cabe señalar que la información dad en la presente entrevista es con fines únicamente académicos y será grabada para poder recopilar los datos posteriormente.

¿Qué organismos regulatorios son los que reglamentan y fiscalizan la construcción de proyectos inmobiliarios? En sí el marco legal lo dicta el Ministerio de Vivienda y Construcción. Básicamente esta entidad es quien regula todo el tema inmobiliario, tanto obras públicas como privadas en el Perú.

\section{¿Qué función tendrían las municipalidades en toda esta regulación?}

Las municipalidades son gobiernos locales que se encargan de fiscalizar las licencias o las etapas constructivas. No solo otorgan las licencias, sino también se encargan de que estas cumplan el marco regulatorio indicado por el Ministerio de Vivienda y Construcción a través de las ordenanzas que pudiera tener cada municipalidad.

¿Cuál es su apreciación respecto a los procesos administrativos que se deben seguir y los tiempos que duran estos?

En sí, según la ley, los procesos deberían tener bastante dinamismo. Por ejemplo, para obtener una licencia, según la modalidad, la más rápida debería salir en 10 días; unas más 
Pregunta 4:

Respuesta 4:

Pregunta 5:

Respuesta 5:

Pregunta 6:

Respuesta 6:

Pregunta 7:

Respuesta 7:

Pregunta 8:

Respuesta 8:

Pregunta 9:

Respuesta 9: complejas podrían salir hasta en 25 días. En la práctica, a veces pudieran extenderse mucho más tiempo, a veces de dos a tres meses, y esto mucho tiene que ver con la burocracia interna de las municipalidades que piden requisitos más allá de lo exigido por la ley o a veces hacen uso de algunos vacíos que la ley tiene y hacen el proceso más lento. En consecuencia, el perjudicado es el usuario y todas las obras que esperan ser ejecutadas se atrasan dentro de los plazos en que se tenía planeado ejecutarlas.

\section{¿Cuál es la duración aproximada de los procesos administrativos más importantes?}

Por ejemplo, para obtener una licencia de obra, deberíamos tenerla en un plazo máximo de 25 días. A veces también esta licencia de obra tiene ciertas complicaciones; muchas veces los terrenos que están siendo materia de evaluación para algún proyecto no cumplen con los requisitos, quizás debido a que no tienen la zonificación adecuada, hay que efectuar cambios en la zonificación, no tienen habilitación urbana, etc., lo cual implica que los procesos se alarguen un poco más porque primero tendrían que subsanar este hecho y dar las condiciones necesarias para que la comisión técnica evaluadora municipal pueda cumplir los plazos exigidos. Muchas veces, los expedientes son declarados en abandono o a veces, sencillamente, no cumplen el marco normativo y esto se notifica y si no puede ser levantado, finalmente se va a archivo si carece en ese momento de documentos para poder evaluarlo según ley.

¿Cuál es la duración de la aprobación de un anteproyecto? Deberíamos tenerla en un plazo de 15 días hábiles. Si hubiera observaciones durante el proyecto, deberían pasar 15 días más, a lo mucho, porque cada comisión municipal se reúne semanalmente.

¿Y una conformidad de obra?

Una conformidad de obra también es entregada en un plazo de más o menos 15 a 20 días hábiles.

De todos los procesos que hemos mencionado, ¿cuál vendría a ser el principal o más importante que se debe realizar para la ejecución de un proyecto inmobiliario y en qué consistiría este?

El proceso más importante sería obtener la licencia de obra porque sin este documento, obviamente, sería imposible ejecutar un proyecto, puesto que hacerlo sin una licencia de obra está sujeto a una paralización o una multa, lo cual perjudicaría todo el desarrollo del proyecto. Las municipalidades locales ya han adecuado su TUPA (Texto Único del Proceso Administrativo) para que se dinamice más el proceso para obtenerla y evitar que haya más burocracia.

Respecto a la pregunta anterior, ¿cuáles son los pasos a seguir para la obtención de la licencia de construcción? ¿Qué documentos se debe presentar? 
Pregunta 10: Respuesta 10:

Pregunta 11:

Respuesta 11:

Pregunta 12:

Respuesta 12:

Cierre:
En primer lugar, se debe presentar la licencia de habilitación urbana, es decir, un documento que indique que el terreno está habilitado para ejecutar una construcción en una zona urbana. Luego de ello, debemos adjuntar el certificado de parámetros. Posteriormente, según el tipo de construcción o el rubro en que uno desee construir, debemos adjuntar ciertas opiniones favorables del sector -si se trata de un edificio para uso educativo, la entidad a opinar sería el Ministerio de Educación-. En algunos casos, también son exigibles en el sector salud, OSINERGMIN para los grifos o entidades que venden hidrocarburos. Entre otros documentos que pudieran exigirnos también se encuentra el certificado de compatibilidad de uso, ya que al pensar en abrir algún establecimiento se desea que esté operativo para el negocio que uno quiere tener a futuro. Adicionalmente, en la parte técnica, va toda la parte de planos como los de arquitectura (ubicación, memoria descriptiva) planos de seguridad (evaluación de rutas de evacuación y elementos de seguridad que se vayan a instalar en la edificación y que son evaluados por delegados del CNP) y los planos de especialidades para la evaluación de las ingenierías (estructurales, eléctricas, sanitarias).

Finalmente ¿podríamos resumir rápidamente cuáles serían los procedimientos a seguir desde que uno tiene el terreno hasta tener la conformidad de obra?

En principio, desde que el terreno está habilitado para ejecutar un proceso constructivo en una zona urbana, se debe presentar la licencia de obra cumpliendo con los requisitos según ley. Luego, viene la etapa de ejecución del proyecto dentro del periodo de validez del certificado de licencia de obra o edificación. Luego de haber terminado de ejecutar la obra y habiéndose realizado el proceso constructivo a través del Colegio de Ingenieros, se expide un certificado de finalización de obra y luego de ello se realiza lo que se denomina la conformidad de obra y su posterior declaratoria de fábrica en los Registros Públicos. La conformidad de obra puede realizarse con variación o sin variación, dependiendo de cuanta variación haya sido efectuada respecto al proyecto aprobado (si se considera sustancial o no sustancial). Básicamente, la conformidad de obra se debería tramitar apenas concluya la etapa constructiva del proyecto.

Y para realizar la independización de los departamentos, ya que en este caso que se trata de un proyecto multifamiliar, ¿cuál sería el requisito indispensable para este procedimiento? ¿Sería la declaratoria de fábrica?

Sí, la declaratoria de fábrica indicaría en sí que el proyecto ha sido ejecutado y que a la vez este se va a subdividir en unidades inmobiliarias independientes. Esto básicamente tiene que ver con proyectar los servicios (de energía, agua, etc.) para cada unidad inmobiliaria y por eso es importante tener la declaratoria de fábrica.

Agradecemos mucho sus respuestas y tiempo para la presente entrevista. Que tenga un buen día. 


\section{FICHA TÉCNICA DEL ENTREVISTADO}

\begin{tabular}{ll}
\hline Nombre & Franco Colone Amez \\
Edad & 42 años \\
Nacionalidad & Peruana \\
Ocupación & Gerente de Infraestructura UTP \\
Profesión & Ingeniero Civil \\
Distrito de Residencia & San Borja \\
& Ingeniero con amplia experiencia en el gerenciamiento de \\
& proyectos de edificaciones. Trabajó como gerente de \\
edificaciones en los Portales S.A. Actualmente se desempeña \\
Breve Reseña & $\begin{array}{l}\text { como Gerente de Infraestructura en la Universidad Tecnológica } \\
\text { del Perú. }\end{array}$
\end{tabular}

\section{GUÍA DE ENTREVISTA}

Día: 17/03/2017

Lugar:

Tema:

Introducción:

Pregunta 1:

Respuesta 1:

Pregunta 2:

Respuesta 2:

\section{Hora: $5: 30$ pm}

Oficina Principal Universidad Tecnológica del Peru SAC Comportamiento actual del mercado inmobiliario enfocado a las viviendas multifamiliares.

Le agradecemos su participación en la entrevista que desarrollaremos a continuación. Dada su trayectoria y conocimiento en el rubro, estamos seguros de que sus comentarios y recomendaciones enriquecerán los objetivos del estudio de mercado que estamos desarrollando para nuestro Proyecto de Investigación para la obtención del título de la maestría. Cabe señalar que la información dada en la presente entrevista tiene fines únicamente académicos y será grabada para poder recopilar los datos posteriormente.

Coméntenos acerca de su experiencia en cuanto al desarrollo de proyectos inmobiliarios.

Tengo experiencia desarrollando proyectos en los tres sectores, digamos en tres bandas de productos: productos de muy alta calidad dirigidos a los sectores económicos $\mathrm{A}$ a más, proyectos masivos o de alta densidad para los sectores $\mathrm{B}-\mathrm{C}$, vivienda masiva en la banda de recursos económicos escasos, como es el caso de Techo Propio y Mi Vivienda. Estaríamos hablando de aproximadamente unos 10 años de experiencia.

¿Cuáles son los principales riesgos y oportunidades que se enfrentan en el desarrollo de proyectos inmobiliarios? De acuerdo a las tres bandas que te mencioné en la pregunta anterior, en el sector económico alto y de proyectos muy costosos, básicamente se debe ser sensible con la velocidad de venta. Cuando había mucha demanda, todo se vendía en planos y los promotores aprovechaban esto para vender los dúplex al final y con ese precio recuperaban mucha utilidad. Hoy en día ya no se puede vender en planos; ahora el cliente ya no espera el año o año y medio para que le entreguen el departamento, sino que al haber todavía oferta, los precios se han congelado y ahora es mejor vender los dúplex al inicio y los precios de los flats van mejorando para llegar a la rentabilidad que se espera. La 
Pregunta 3:

\section{Respuesta 3:}

demanda se ha reducido bastante porque la gente ya no está pensando en viviendas sino invirtiendo su dinero en otras cosas. En el lado B sigue habiendo oferta, la velocidad de venta sigue siendo una variable importante. Los bancos ahora son más exquisitos respecto a los créditos, por ejemplo antes desde que ingresabas tu solicitud hasta que finalizabas el proceso demorabas de uno a dos meses y ahora demoras seis meses. Antes vendías entre 10 a 15 departamentos por mes hasta llegar a tu cuota de preventa. Ahora se ha reducido a cuatro o cinco departamentos, con los que mi flujo de caja se estira y en vez de empezar una obra en seis meses se empieza en un año. Se debe respetar el compromiso con los propietarios; a pesar de no haber cumplido con la cuota de preventa tienes que mantener la fecha que les prometiste y correr con el financiamiento así el banco no te pueda hacer el desembolso.

En el sector de vivienda masiva, ya no se están ejecutando estos proyectos en Lima, básicamente por el costo del suelo. Los proyectos de Mi Vivienda y Techo Propio se están dando más en provincia. En provincia los bancos grandes ya no están entrando, el financiamiento se da a través de las cajas pero no tienen capacidad de financiar proyectos de gran cantidad de viviendas.

\section{¿Hay mejoras en las regulaciones que faciliten las inversiones} en el rubro?

No. De acuerdo al tipo de producto, los proyectos altos en zonas consolidadas enfrentan dos barreras: la dureza de los parámetros (en terrenos con buenas áreas, las municipalidades te ponen limitaciones en cuanto a las áreas mínimas de los departamentos, áreas libres, alturas, etc.) esto hace que a veces los proyectos con muy buena ubicaciones sean súper caros porque se pueden construir pocas unidades y muy grandes, por ese motivo ya no se está comprando viviendas en el sector alto. En las viviendas del sector B, en distritos consolidados, la disponibilidad de los servicios públicos es muy escasa; las redes de agua y desagüe y eléctricas no están preparadas para un crecimiento tan acelerado como ha venido sucediendo. Esta es una barrera importante, entonces estos proyectos se tienen que presentar con mucha anticipación y vienen condicionados a que uno ejecute parte de las obras de ampliación de las redes exteriores favoreciendo no necesariamente a tu proyecto sino a todo sector y esto es porque el estado no tuvo la capacidad de gestión para anticiparse a ese crecimiento y hacer estas redes por propia cuenta. Se la dejan al privado. A pesar de que no tiene que ver con las regulaciones son barreras muy grandes que tienen los proyectos y golpean el presupuesto del proyecto, en los temas de agua y desagüe, básicamente. El estado favorece mucho a las viviendas económicas; a veces las municipalidades acogen con buen ánimo este tipo de inversiones porque la propiedad del terreno es muy informal, entonces al consolidar zonas, la provincia se ordena y son más permeables a los parámetros q favorecen este tipo de proyectos. El acceso a los suministros de agua y electricidad es limitado porque las redes son accesibles en las zonas céntricas y en las aledañas no. Son grandes infraestructuras de saneamiento que tienen que conectarse con las redes antiguas de la ciudad o 
Pregunta 4:

Respuesta 4:

Pregunta 5:

Respuesta 5:

Cierre: muy lejanas y que son un golpe para los flujos de estos proyectos.

\section{¿Cree UD. que la demanda por viviendas multifamiliares ha} evolucionado en los últimos años?

Si el crecimiento demográfico, que viene de la mano con el número de hijos que incrementa cada año y con la necesidad de las familias, la demanda siempre ha crecido; pero la demanda efectiva de las personas que necesitan realmente y pueden pagar una vivienda, ahí sí habrá que echarle un poco más de lupa. Yo creo que sí ha crecido en función de la accesibilidad al crédito y a las facilidades que entregan las instituciones financieras para otorgar estos desembolsos para adquirir la casa. Los bancos ahora se han puesto más duros. Si bien ha crecido la demanda, la oferta se ha visto castigada por las barreras de financiamiento que tienen los proyectos porque las empresas inmobiliarias ya no construyen tan rápido como antes. Ahorita hay ese juego entre estas dos variables. Yo creo que el gobierno tendría que regular y dar las facilidades a los bancos para que los créditos se den con mayor rapidez.

¿Qué factores críticos considera importantes para el éxito de un proyecto inmobiliario multifamiliar?

Bueno, básicamente el precio del terreno es determinante y lo que te define el precio final del producto, porque la construcción es en cierta forma un costo commodity; te da lo mismo el edificio puesto en varios distritos como construcción, pero el costo de ese terreno sí te determina el precio final. Si encuentras un terreno a un buen precio y bien ubicado, tienes encaminado el éxito de tu proyecto. Ese es uno, el otro es, sobre todo para aquellos que emprenden por primera vez un negocio inmobiliario, con qué cara te mira el banco cuando le presentas tu proyecto como promotor. Hay muchos que no ven en el negocio inmobiliario una oportunidad. En este tipo de emprendimiento personal o de unos pocos socios, siempre tienes que tener dentro de tu esquema de proyecto a una persona que haya construido muchas viviendas y que a los ojos del banco sea quien garantice la calidad de tu producto; el producto tiene que estar sustentado en un buen proyecto, en buenos planos, con buenos profesionales, en fin. El tercero es el tema comercial. Antes lo que ponías a la venta se vendía solo, entonces la gente sin mucha promoción hacía la venta; ahora tienen que asesorarse bien con una buena firma comercial para que tu producto sea atractivo a tus clientes o tus visitas, para que tengas una tasa de conversión más alta entre la gente que te visita y la gente que finalmente termina comprando tu producto. Antes salías con tu cartelito y la gente se acercaba y compraba; ahora los clientes antes de comprar primero buscan qué hay en el mercado ya prácticamente construido para comprarlo porque saben que ahorita la oferta está muy alta. Creo que estos son los factores más determinantes para el éxito de un proyecto.

Agradecemos mucho sus respuestas y tiempo para la presente entrevista. Que tenga un buen día. 


\section{FICHA TÉCNICA DEL ENTREVISTADO}

\begin{tabular}{ll}
\hline Nombre & Paulo Cesar Moran Villanueva \\
Edad & 31 años \\
Nacionalidad & Peruana \\
Ocupación & Ejecutivo Comercial del Fondo Mi Vivienda \\
Profesión & Administrador \\
Distrito de Residencia: & Magdalena \\
Breve Reseña: & $\begin{array}{l}\text { Profesional con experiencia de siete años en el rubro de créditos } \\
\text { hipotecarios MiVivienda. }\end{array}$ \\
\hline
\end{tabular}

\section{GUIA DE ENTREVISTA}

Día:21/03/29017

Lugar:

Tema:

Introducción:

Pregunta 1:

Respuesta 1:

Pregunta 2:

Respuesta 2:

Pregunta 3:

\section{Hora: $6.54 \mathrm{pm}$}

Correo electrónico

Oportunidad del mercado inmobiliario

Le agradecemos su participación en la entrevista que desarrollaremos a continuación. Dada su trayectoria y conocimiento en el rubro estamos seguros que sus comentarios y recomendaciones enriquecerán los objetivos de nuestro estudio de mercado que estamos desarrollando para nuestro Proyecto de Investigación para la obtención del título de la maestría. Cabe señalar que la información dad en la presente entrevista es con fines únicamente académicos

En General, si tuviera que dar una opinión acerca del mercado, ¿Cuál sería?

En los últimos tres años tanto el mercado inmobiliario como hipotecario no han tenido el crecimiento esperado, la generación de oferta inmobiliaria no ha ido de la mano con el otorgamiento de créditos hipotecarios (mecanismo más utilizado para la adquisición de una vivienda), debido a que a partir del 2014 las entidades financieras fueron más rigurosas en sus políticas de otorgamientos de créditos hipotecarios, se implementó esta medida puesto que las carteras hipotecarias de estas entidades se comenzaron a deteriorar porque en su originación se utilizaron pautas crediticias demasiado flexibles.

¿Cuáles son los principales riesgos y oportunidades que se enfrentan en el crecimiento del mercado inmobiliario?

El principal riesgo para un desarrollador es no colocar las unidades de vivienda de sus proyectos o colocaciones de muy largo aliento que afecten su flujo de caja esperado. Como oportunidad, está crecer en generación de oferta social por la gran demanda que existe en los NSE bajos, y por el enfoque que tiene el gobierno actual de facilitar el acceso a una vivienda adecuada a las familias de menores recursos.

¿Existen mejoras en las regulaciones que faciliten las ventas en el rubro? 
Respuesta 3:

Pregunta 4:

Respuesta 4:

Pregunta 5:

Respuesta 5:
Desde el ámbito regulatorio pues las cosas no han cambiado mucho, sin embargo el Estado a través del Programa Techo Propio y productos del Fondo MIVIVIENDA S.A. brindan una mejor opción para que más personas puedan acceder al mercado inmobiliario, a través de subsidios como el Bono Familiar Habitacional y el Bono del Buen Pagador. Estos incentivos a la demanda hace que esta se expanda y por ende hace que más familias estén no solo dispuestas a adquirir una vivienda sino que sean clientes potenciales para el otorgamiento de créditos hipotecarios por parte del sistema financiero.

¿Qué factor sería determinante para que el mercado en general incremente las colocaciones?

Un factor determinante es el rol que cumplirá el Estado a través de políticas y un presupuesto al Ministerio de Vivienda, Construcción y Saneamiento, que promuevan tanto la generación de oferta social como la creación de programas de incentivos a las familias para que estas se formalicen y puedan acceder a créditos a través del sistema financiero.

¿Cuál sería, según su opinión el panorama del mercado inmobiliario en el Perú para los próximos cinco años?

Este gobierno a diferencia de los anteriores tiene una meta bastante retadora de facilitar a 500,000 familias el acceso a una vivienda adecuada a través de la articulación entre en Estado y el mercado inmobiliario. El 2016 y 2017, son años en los cuales se sentarán las bases para un crecimiento sostenido en los año venideros; por ello considero que el panorama es alentador, sin embargo a partir del 2018 recién estaríamos viendo los resultados.
Cierre:
Agradecemos mucho sus respuestas y tiempo para la presente entrevista. Que tenga un buen día. 
FICHA TECNICA DEL ENTREVISTADO

\begin{tabular}{ll}
\hline Nombre & Shirley Paz Garcia Altamirano \\
Edad & 33 años \\
Nacionalidad & Peruana \\
Ocupación & Gerente de Negocios Hipotecarios BCP \\
Profesión & Ingeniero Industrial \\
Distrito de Residencia: & Chorrillos \\
Breve Reseña: & Profesional con experiencia de 10 años en el rubro de créditos \\
& hipotecarios \\
\hline
\end{tabular}

\section{GUIA DE ENTREVISTA}

Día: 17/03/2017

Hora: $4.30 \mathrm{pm}$

Lugar:

Oficinas BCP San Isidro

Tema:

Oportunidad del mercado hipotecario

Le agradecemos su participación en la entrevista que desarrollaremos a continuación. Dada su trayectoria y conocimiento en el rubro estamos seguros que sus comentarios y recomendaciones enriquecerán los objetivos

Introducción: de nuestro estudio de mercado que estamos desarrollando para nuestro Proyecto de Investigación para la obtención del título de la maestría. Cabe señalar que la información dada en la presente entrevista es con fines únicamente académicos y será grabada para poder recopilar los datos posteriormente.

Pregunta 1:

En General, si tuviera que dar una opinión acerca del mercado de créditos hipotecarios, ¿Cuál sería?

Bueno, creo que el mercado se está reactivando a raíz de las elecciones del año pasado se ha visto ya un crecimiento en la

Respuesta 1: demanda cerca desde el tercer trimestre del 2016, y, por ejemplo, el ticket promedio de un crédito hipotecario ha crecido un 10\% en comparación a antes del último trimestre del 2016.

Pregunta 2: ¿Cuáles son los principales riesgos y oportunidades que se enfrentan en el sector financiero inmobiliario?

En el principal factor de riesgo hoy, yo creo que es, en el caso de MiVivienda, la eliminación de los subsidios, por ejemplo, que, si puede ser que frene la colocación de créditos

Respuesta 2: MiVivienda, y por lado de la parte inmobiliaria que no haya una claridad en la estabilidad política. En la medida que hayan problemas entre el gobierno con la oposición, puede generar que no haya tanta tranquilidad como para que sigan invirtiendo por el tema de confianza.

Pregunta 3:

¿Existen mejoras en las regulaciones que faciliten las ventas en el rubro?

$\mathrm{Si}$, podrían darse mejoras, hoy por hoy todos los bancos ofrecen el financiamiento del 90\% del valor de los inmuebles, y de hecho hay una oportunidad ahí, de poder atender a todas las Respuesta 3: personas que alquilan, muchas veces ellas alquilan y no tienen ahorros para una cuota inicial entonces poder financiar un LTV (Loan To Value) 100\% en lugar de ahorita el 90\%. Algo que estamos haciendo nosotros como Banco es tratar de llegar a un 
LTV 95\% primero lo vamos a probar en clientes de segmento alto a ver si podemos bajarlo.

Pregunta 4:

¿Cuál sería, según su opinión el panorama de los créditos hipotecarios en el Perú para los próximos cinco años?

Yo creo que va a haber, todavía, una demanda insatisfecha, o sea, yo creo que todavía, la colocación de hipotecarios va a

Respuesta 4: seguir siendo ascendente. Debería reactivarse año con año, pero igual hoy por hoy es muy susceptible a las condiciones del país. O sea, probablemente de acá, a las siguientes elecciones, nuevamente se frene todo el tema inmobiliario.

Pregunta 5: ¿O sea, se podría decir que todo depende del tema político

Respuesta 5: para poder darle un despegue o una frenada?

Cierre:

Se mueve en función de las expectativas del país

Agradecemos mucho sus respuestas y tiempo para la presente entrevista. Que tenga un buen día. 


\section{Anexo 4: Encuesta a ser aplicada vía web}

\section{PREGUNTAS FILTRO}

1. Marque con un aspa (x) en qué rango de edad se encuentra
1.a) $\square[0-24] \quad$ (TERMINAR)
1.b) $[25-30] \quad($ CONTINUAR $)$
1.c) $[31-40] \quad$ (CONTINUAR)
1.d) $\square[41-55] \quad($ CONTINUAR $)$
1.e) $\square$ [55 a más [(TERMINAR)

2. Marque con un aspa (x) su género
2.a) $\square$ Masculino
2.b) $\square$ Femenino

3. Marque con un aspa (x) su estado civil.
3.a) $\square$ CASADO / CONVIVIENTE
3.b)
SOLTERO
3.a)
VIUDO
3.b)
DIVORCIADO

4. ¿Cuál es el grado de instrucción del jefe de familia?
4.1. Primaria incompleta o completa/ Secundaria incompleta
4.2. Secundaria completa/ Superior Técnico Incompleta
4.3. Superior Técnico Completa
4.4. Superior Univ. Completa
4.5. Superior Univ. Incompleta
4.6. Post-Grado Universitario

5. ¿Cuál es el material predominante en los acabados de pisos de su vivienda?

5.1. Cemento sin pulir o pulido / Madera (entablados)/ tapizón

5.2. Laminado tipo madera, láminas asfálticas o similares

5.3. Losetas / terrazos, mayólicas, cerámicos, vinílicos, mosaico o similares

5.4. Parquet o madera pulida y similares; porcelanato, alfombra, mármol

6. ¿A qué sistema de prestaciones de salud está afiliado el jefe de hogar?

6.1. Entidad prestadora de salud (EPS)/ Seguro privado de salud

6.2. ESSALUD

6.3. No está afiliado a ningún seguro/ Seguro Integral de Salud (SIS)

6.4. Seguro Salud FFAA/ Policiales

7. ¿Cuál de los siguientes bienes o servicios tiene en su hogar que está funcionando? (Seleccione cuales tiene y cuales no tiene)

7.1. Computadora, laptop, Tablet

7.2. Lavadora

7.3. Horno microondas 
7.4. Refrigeradora/ Congeladora

7.5. Auto o camioneta solo para uso particular

7.6. Servicio doméstico en el hogar pagado

8. ¿Con que tipo de baño o servicio higiénico cuenta en su hogar:

8.1. Baño compartido fuera de la vivienda

8.2. Baño dentro de la vivienda

9. Marque con un aspa (x) si usted está en la búsqueda de una vivienda o no.
9.1
9.2 .
SI (CONTINUAR)
NO (TERMINAR)

10. Seleccione la alternativa que se cumpla para Ud. En la actualidad usted vive en:

10.1
10.2
10.3
10.4 $\square \quad \begin{aligned} & \text { Vivienda Alquilada } \\ & \text { Vivienda Propia } \\ & \text { Vivienda Familiar } \\ & \text { Otros (especificar) }\end{aligned}$

11. ¿Cuáles son los principales inconvenientes que encuentra en su vivienda actual? Seleccione su respuesta dentro de cada cuadrado. Siendo " 1 " es totalmente en desacuerdo y " 5 " totalmente de acuerdo.

\begin{tabular}{|l|l|l|l|l|l|l|}
\hline $\mathbf{N}$ & \multicolumn{1}{|c|}{ Inconvenientes } & \multicolumn{3}{|c|}{ Calificación } \\
\hline 1 & No me gusta la locación & 1 & 2 & 3 & 4 & 5 \\
\hline 2 & El tamaño de mi vivienda no se ajusta a mis necesidades actuales & 1 & 2 & 3 & 4 & 5 \\
\hline 3 & $\begin{array}{l}\text { La distribución y/o el número de habitaciones y baños no se ajusta a mis } \\
\text { necesidades actuales }\end{array}$ & 1 & 2 & 3 & 4 & 5 \\
\hline 4 & $\begin{array}{l}\text { Hay demasiado ruido externo (congestión vehicular) y/o interno (vecinos, } \\
\text { mascotas, etc.) }\end{array}$ & 1 & 2 & 3 & 4 & 5 \\
\hline
\end{tabular}

12. ¿Cuánto estaría dispuesto a pagar por un inmueble?

12.1
12.2
12.3
12.4 $\square \quad \begin{aligned} & {[S / 0.00-S / 180,000.00[} \\ & {[S / 180,001.00-S / 300,000.00[} \\ & {[S / 300,001.00-S / 390,000.00]} \\ & \end{aligned}$

13. ¿Cuánto dinero mensual estaría dispuesto a destinar al pago de la vivienda?

\begin{tabular}{|c|c|}
\hline 13.1 & menos de S/.1,600.00 \\
\hline 3.2 & De S/. 1,600.00 a 2,200.00 \\
\hline & De S/. 2,201.00 \\
\hline 13.4 & $\mathrm{De} S / .2,901.00$ \\
\hline
\end{tabular}

14. ¿Es determinante para usted el número de departamentos con los que cuenta el edificio?

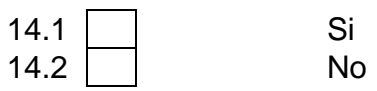

15. ¿Es determinante para usted la vivienda sea sostenible o eco amigable?

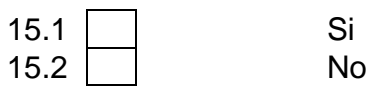


16. ¿De cuántos metros le gustaría que fuese la vivienda?

16.1
16.2
16.3
16.4
16.5 $\square \begin{aligned} & \text { Menor a } 40 \mathrm{~m}^{2} \\ & \text { entre } 40 \text { y } 55 \mathrm{~m}^{2} \\ & \text { entre } 56 \text { y } 71 \mathrm{~m}^{2} \\ & \text { entre } 72 \text { y } 87 \mathrm{~m}^{2} \\ & \text { Más de } 87 \mathrm{~m}^{2}\end{aligned}$

17. Marque con una $X$ los distritos de su preferencia para adquirir una vivienda.

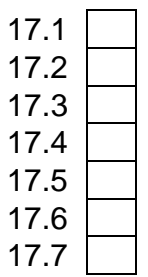
Magdalena del Mar
Jesús María
Pueblo Libre
Breña
San Miguel
Lince
Otros (especificar)

18. ¿Estaría usted interesado en adquirir la vivienda con cochera?
18.1
$\mathrm{Si}$
18.2
No 


\section{Anexo 5: Reglamento Interno de Trabajo La Inmobiliaria}

El presente Reglamento contiene las pautas principales de orden, relaciones laborales y prevención de situaciones riesgosas a las que deben atenerse los trabajadores de La Inmobiliaria en relación a su contratación, permanencia y salida de la Empresa.

\section{Capítulo I Reglamento Interno}

Art. $1^{\circ}$.

Este Reglamento Interno regimentará los requisitos de ingreso, derechos, obligaciones, prohibiciones y política general de trabajo de todo el personal que haya firmado contrato de trabajo con la Empresa, cualquiera que sea su lugar de desempeño y donde por razones de trabajo o necesidades de la Empresa, dada la naturaleza de la misma, sea necesario que preste sus servicios.

\section{Capítulo II De la contratación}

Art. $2^{\circ}$. La contratación de personal deberá realizarse a requisito de la empresa y debe ser autorizado por escrito por el área que lo solicita, y autorizado por el Administrador o Gerente General, según sea el caso.

Art. $3^{\circ}$.- Los postulantes a los cargos vacantes deberán cumplir con los requisitos mínimos que demanda su puesto y se encuentran especificados en su perfil de cargo.

Art. 4.- La comprobación posterior de que se hubiera presentado documentos falsos o adulterados para el ingreso a la empresa, será causal de terminación inmediata del contrato de trabajo.

Capítulo III Del Contrato Individual de Trabajo

Art. $5^{\circ}$.- La persona que pase el proceso de selección deberá firmar, dentro del plazo que fija la Ley, el contrato de trabajo, que será extendido en 
tres ejemplares, quedando uno en poder del trabajador y otros dos en poder de la empresa, con un cargo firmado y posterior entrega al ministerio de trabajo y también una copia de este Reglamento Interno por parte del trabajador.

Art. $6^{\circ}$.- El trabajador se obliga, con la firma de contrato, a realizar con profesionalismo el trabajo para el cual se le contrata. En el contrato de trabajo contendrá todas las disposiciones legales o reglamentarias vigentes según lo establecido por la ley general de trabajo y la empresa.

Art. $7^{\circ}$.- El trabajador está obligado de Informar, dentro de las 48 horas hábiles siguientes de producido, todo cambio que experimente en sus antecedentes personales que tengan relevancia laboral, tales como cambio de domicilio, estado civil, profesión, disminución o aumento de cargas familiares, etc., a objeto de registrarlas en sus antecedentes personales o consignarlas en su contrato de trabajo, si corresponde.

Capítulo IV De la Jornada laboral

Art. $8^{\circ}$.- La jornada semanal será de 48 horas de trabajo, distribuida, de lunes a sábado; en el horario que le corresponda a su cargo. 


\section{Anexo 6: Manual de Funciones La Inmobiliaria}

\section{Manual de Funciones La Inmobiliaria}

\begin{tabular}{|l|r|}
\hline Versión & 1 \\
\hline Fecha & \multicolumn{1}{|r}{ Mar-17 } \\
\hline Vigencia & tres años \\
\hline
\end{tabular}

\section{DESCRIPCIÓN DE CARGOS}

Nombre del Puesto: Gerente General

Departamento: Administrativo

\section{Resumen del puesto:}

$\checkmark$ Administrar y dirigir las actividades que sean necesarias para el crecimiento de la empresa.

$\checkmark$ Tomar decisiones en base al cumplimiento de los objetivos de la empresa

$\checkmark$ Evaluar el rendimiento y desempeño de La Inmobiliaria.

\section{Responsabilidades/Funciones:}

$\checkmark$ Tomar decisiones objetivas.

$\checkmark$ Evaluar la situación actual de la organización.

$\checkmark$ Gestionar las actividades para el crecimiento empresarial.

$\checkmark$ Controlar y monitorear el cumplimiento de los objetivos.

\section{Experiencia y Estudios mínimos requeridos:}

$\checkmark$ Estudios superiores en administración de empresas o Ingeniería Industrial/Civil, afines.

$\checkmark$ Conocimientos de trato con personal.

$\checkmark$ Experiencia mínima de cinco años en cargos similares.

$\checkmark$ Conocimiento en gestión inmobiliaria / construcción.

$\checkmark$ Buen análisis de reportes financieros y contables.

$\checkmark$ Conocer el sector nacional y las tendencias mundiales.

$\checkmark$ Hablar y dominar inglés.

$\checkmark$ Conocimientos avanzados de las ciencias en materiales.

Horario asignado: 8H00 AM - 17:00 PM

\begin{tabular}{|l|l|l|l|}
\hline \multirow{2}{*}{\begin{tabular}{l} 
Fecha : Marzo de \\
\cline { 2 - 4 }
\end{tabular}} & Elaborado por: & Revisado por: & Aprobado por: \\
\cline { 2 - 4 } & & & \\
\hline
\end{tabular}


Nombre del Puesto: Gerencia Administrativa

Departamento: Administrativo

Resumen del puesto: deberá dirigir las actividades de carácter financiero, contable y Administrativas de la empresa; planificando las alternativas financieras, supervisando la contabilidad y el flujo de caja. Encargado de llevar el control desde la aprobación de la orden de trabajo hasta el respectivo producto final. Encargado del recurso humano de la empresa.

Jefe inmediato: Gerente General

\section{Responsabilidades /Funciones:}

$\checkmark$ Elaborar: control de gastos diarios y mensuales de la empresa, análisis de inversiones.

$\checkmark$ Supervisar y controlar los estados financieros, contabilidad general y de costos.

$\checkmark$ Administrar los recursos financieros y el personal de la empresa.

$\checkmark$ Hacer cumplir los requerimientos exigidos por ley.

$\checkmark$ Interpretar los balances y cuentas de resultados y presentar informes al Gerente General de la empresa.

$\checkmark$ Estar informado o informada del avance de las órdenes de trabajo.

$\checkmark$ Gestionar envío y recepción de documentación.

\section{Experiencia y Estudios mínimos requeridos:}

$\checkmark$ Egresado de la carrera de Ingeniería Comercial/Industrial/Civil, Economía, Ingeniero.

$\checkmark$ Conocimientos de Contabilidad Financiera y de Costos. Experiencia mínima de cuatro años.

$\checkmark$ Liderazgo

$\checkmark$ Servicio al cliente

Horario asignado: $8 \mathrm{H} 00 \mathrm{M}-17: 00 \mathrm{PM}$

\begin{tabular}{|l|l|l|l|}
\hline \multirow{2}{*}{$\begin{array}{l}\text { Fecha : } \\
2017\end{array}$} & Marzo de & Revisado por: & Aprobado por: \\
\cline { 2 - 4 } & & & \\
\hline
\end{tabular}


Nombre del Puesto: Vendedor

Departamento: Comercial

\section{Resumen del puesto:}

Realiza la atención al cliente, se encarga de la búsqueda de nuevos clientes, la persuasión en la compra del producto por parte del cliente y las respectivas validaciones post-venta.

Jefe inmediato: Administrador General

\section{Responsabilidades/Funciones:}

$\checkmark$ Tener constante contacto con el administrador para no perder presencia ante el cliente.

$\checkmark$ Atraer nuevos clientes.

$\checkmark$ Asesorar a los clientes de manera directa acerca de las dudas del proyecto.

$\checkmark$ Comunicación constante con el administrador.

$\checkmark$ Gestionar la cartera de clientes y vender los departamentos.

\section{Experiencia y Estudios mínimos requeridos:}

$\checkmark$ Mínimo seis meses de experiencia en cargos similares.

$\checkmark$ Conocimientos de construcción y venta de departamentos.

$\checkmark$ Conocimiento de Servicio al cliente.

$\checkmark$ Estudios en carreras técnicas

Horario asignado: 8H00 AM - 17:00 PM. Horarios de Oficina y Disponibilidad de 24 horas para ventas por teléfono. 


\section{Bibliografía}

Baca, Gabriel (2013). Evaluación de proyectos. (7a ed.) México: McGraw-Hill.

Barrena M., J., López F. M., Romero F., P. (2016). Intangible Capital. Efectos de las políticas de recursos humanos socialmente responsables en el capital intelectual. España: OmniaScience

Bensassini F., M (2014), Introducción a la investigación de mercados. ( $\left.3^{\circ} \mathrm{ed}.\right)$ México: Pearson Educación.

Calleja, F.J. (2014) Contabilidad Administrativa ( $2^{\circ}$ ed.). México: Pearson Educación.

Clow, K. y Baack, D. (2011) Publicidad, promoción y comunicación integral en marketing. ( $4^{\circ}$ ed.) México: Pearson Educación.

David, F.R. (2013). Conceptos de Administración Estratégica. (14 ed.) México: Pearson Educación.

Dessler, Gary. (2015). Administración de recursos humanos. (14 ed.) México: Pearson Educación.

Horngren, C. (2012) Contabilidad de costos. Un enfoque gerencial. (14 ed.). México: Pearson Educación.

Jobber, D. y Lancaster, G. (2012) Administración de ventas ( $8^{\circ}$ ed.). México: Pearson Educación.

Jones, Gareth R. (2013). Teoría organizacional, diseño y cambio en las organizaciones. ( $7^{\circ}$ ed) México: Pearson Educación.

Kotler, P. y Armstrong, G. (2012) Marketing. (14 ed.). México: Pearson Educación.

Kotler, P. y Keller, K. (2012) Dirección de marketing. (14 ed.). México: Pearson Educación.

Ramírez, D. (2013) Contabilidad administrativa. (9ed.). México: McGraw-Hill. 
Reglamento Nacional de Edificaciones.

Robbins, Stephen P. y Judge, Timothy A. (2013). Comportamiento Organizacional. (15 edición). México: Pearson.

Ross S., A. (2012) Finanzas Corporativas. (9 Ed.) México: McGraw-Hill Interamericana 


\section{Bibliografía Electrónica}

A Donde Vivir. http://www.adondevivir.com/

América Economía, 2017. Industria de la construcción en el Perú crecerá 3,7\% en 2017 por proyectos de infraestructura. Recuperado de

http://www.americaeconomia.com/negocios-industrias/industria-de-la-construccion-en-elperu-crecera-37-en-2017-por-proyectos-de

Arellano. http://www.arellanomarketing.com/inicio/estilos-de-vida/

Asociación de desarrolladores inmobiliarios. http://www.adiperu.pe/

Bardales, E. 2015. Lima demandará 600,000 nuevas viviendas en próximos diez años, según PLAM 2035. Recuperado de http://gestion.pe

$\underline{\text { /inmobiliaria/lima-demandara-600000-nuevas-viviendas-proximos-diez-anos-segun- }}$ plam-2035-2119834

Barja, M. (2015) El misterio de cómo se construyeron las pirámides. http://www.sobrehistoria.com

Belapatiño, V. y Crispin Y. (2016). Situación Inmobiliaria 2016. Recuperado de https://www.bbvaresearch.com/?advs=1\&advsgeo=139\&advstem $=12$

Benza, P. 2017. Mercado inmobiliario en el 2017: la recuperación demorará todavía un año más. Recuperado de http://semanaeconomica.com/article/sectores-yempresas/inmobiliario/207778-la-recuperacion-demorara-todavia-un-ano-mas/?ref=ap

Crece Negocios. http://www.crecenegocios.com/el-pronostico-de-ventas/

Definición De, (2017). http://definicion.de/planeacion-financiera/

El Comercio, 2015. BIM: tendencia para construir sin pérdidas. Recuperado de http://elcomercio.pe/zona-ejecutiva/tendencias/importancia-lean-construction-gestionproyectos-noticia-1859414 
El Comercio, 2016a. Ventas de viviendas en Lima cayeron 12\% este año, dice BBVA. Recuperado de http://elcomercio.pe/economia/peru/ventas-viviendas-lima-cayeron-12-esteano-dice-bbva-noticia-1955247? ref=flujo_tags $517143 \& \mathrm{ft}=$ nota $\_$5\&e=titulo

El Comercio, 2016b. Viviendas: "El Gobierno está planteando más de lo mismo”. Recuperado de http://elcomercio.pe/economia/negocios/viviendas-gobierno-esta-planteando$\underline{\text { mas-lo-mismo-noticia-1954157?ref=flujo_tags } 517143 \& \mathrm{ft}=\text { nota } \_ \text {6\&e=titulo }}$

El Comercio, 2017. Precios de materiales de construcción subieron 3,19\% el 2016. Recuperado http://elcomercio.pe/economia/peru/precios-materiales-construccion-subieron319-2016-noticia-

1966875?ref=flujo_tags_519754\&ft=nota $3 \& \mathrm{e}=$ titulo?ref=nota_economia\&ft=mod_leatambi $\underline{\text { en\&e}=\text { titulo }}$

El economista américa, 2016. JP Morgan: la confianza del consumidor peruano alcanzó su más alto nivel. Recuperado http://www.eleconomistaamerica.pe/economia-eAmperu/noticias/7814943/09/16/JP-Morgan-la-confianza-del-consumidor-peruano-alcanzo-su$\underline{\text { mas-alto-nivel.html }}$

El Peruano, 2016. Jornal en construcción se incrementará hasta 4.78\%. Recuperado http://www.elperuano.com.pe/noticia-jornal-construccion-se-incrementara-hasta-478$\underline{44316 . a s p x}$

Galvez, V. 2017. Inmobiliarias no ven reactivación del sector en el verano. Recuperado http://elcomercio.pe/economia/negocios/inmobiliarias-no-ven-reactivacion$\underline{\text { sector-verano-noticia-1958516?ref=flujo_tags } 517143 \& \mathrm{ft}=\text { nota } 2 \& \text { e }=\text { titulo }}$

Gestión.pe, 2017a. BCR: Perú registró déficit fiscal de 2.6\% del PBI en 2016, la mayor brecha en 15 años. Recuperado http://gestion.pe/economia/bcr-peru-registro-deficitfiscal-26-pbi-2016-mayor-brecha-15-anos-2183083 
Gestión.pe, 2017b. Dólar cierra en alza por cautela de inversores extranjeros antes de discurso de Trump. Recuperado de http://gestion.pe/mercados/dolar-cierra-alza-cautela$\underline{\text { inversores-extranjeros-antes-discurso-trump-2183375 }}$

Gestión.pe, 2017c. Riesgo país de Perú subió tres puntos básicos a 1.66 puntos porcentuales. Recuperado http://gestion.pe/economia/riesgo-pais-peru-subio-tres-puntosbasico-166-puntos-porcentuales-2183106

Gestión.pe, 2017d. IGV bajará de 18\% a 17\% desde el 1 de julio. Recuperado http://gestion.pe/economia/igv-bajara-18-17-desde-1-julio-este-ano-2179122

Gestión.pe, 2017e. Cae confianza de familias limeñas en octubre por tercer mes consecutivo. Recuperado http://gestion.pe/economia/cae-confianza-familias-limenas-octubre$\underline{\text { tercer-mes-consecutivo-2173327 }}$

Hernández M., A. (2012). La prehistoria. Sophimania. http://www.sophimania.com

Holcim, 2017: ¿Qué es la construcción sostenible. Recuperado de http://www.holcim.com.ec/desarrollo-sostenible/holcim-foundation-for-sustainableconstruction/que-es-la-construccion-sostenible.html

La República, 2017. Viviendas sociales: destinan S/ 174 millones para Bono Familiar Habitacional. Recuperado http://larepublica.pe/economia/847600-viviendas-socialesdestinan-s-174-millones-para-bono-familiar-habitacional

La República. 2016a. La autoconstrucción en el Perú representa un 60\% del total dentro del sector. Recuperado http://larepublica.pe/impresa/economia/761845-la$\underline{\text { autoconstruccion-en-el-peru-representa-un-60-del-total-dentro-del-sector }}$

Lench, G. 2016. Perú: carácter inestable del crecimiento económico. Recuperado http://www.voltairenet.org/article195215.html

Miranda, O. 2016. Edificios verdes en el Perú. Recuperado http://larepublica.pe/impresa/domingo/776165-edificios-verdesen-el-peru 
Perú 21, 2017. ¿Por qué en el 2016 cayeron las importaciones que hace el Perú? Recuperado http://peru21.pe/economia/que-2016-cayeron-importaciones-que-hace-peru$\underline{2269280}$

Pineda, L.2017. Elaboración y Evaluación de Proyectos de Ingeniería Industrial. Recuperado de http://www.fsalazar.bizland.com/pdf/05tecnicas\%20de\%20proyeccion\%20de\%20mercado.pd $\mathrm{f}$

PQS, 2016. Demanda por viviendas en Lima supera las 400 mil. Recuperado http://www.pqs.pe/actualidad/demanda-por-viviendas-en-lima-supera-las-400-mil

Primera Página Perú, 2017. MEF lanza normas para facilitar inversiones y promover viviendas. Recuperado http://www.primerapaginaperu.com/politica/gobierno/mef-lanza$\underline{\text { normas-para-facilitar-inversiones-y-promover-viviendas/7816/ }}$

RPP, 2017. Modifican ley de Habilitaciones Urbanas y de Edificaciones. Recuperado http://rpp.pe/economia/economia/modifican-ley-de-habilitaciones-urbanas-y-de$\underline{\text { edificaciones-noticia-983953 }}$

Time to ast, 2014. Lineas de tiempo. https://www.timetoast.com

Trebol animation, 2013. Viviendas Cavernícolas. Trebol animation. https://www.trebolanimation.com

Solo contabilidad 2012, Factores que afectan la proyección de ventas. http://www.solocontabilidad.com/2012/10/factores-que-afectan-la-proyeccion-de.html

Victor Rivadeneira Unda http://www.eumed.net/libros-gratis/2014/1376/presupuestoventas.html 